Final Report

FHWA/IN/JTRP-2005/19

\title{
SHEAR REINFORCEMENT REQUIREMENTS FOR HIGH-STRENGTH CONCRETE BRIDGE GIRDERS
}

\author{
By \\ Julio A. Ramirez \\ Principal Investigator \\ Professor of the School of Civil Engineering \\ Purdue University \\ Gerardo Aguilar \\ Graduate Research Assistant \\ Purdue University \\ Joint Transportation Research Project \\ Project No. C-36-56III \\ File No. 7-4-60 \\ SPR 2654 \\ Prepared in Cooperation with the \\ Indiana Department of Transportation and \\ The U.S. Department of Transportation \\ Federal Highway Administration
}

The contents of this report reflect the views of the authors who are responsible for the facts and the accuracy of the data presented herein. The contents do not necessarily reflect the official views or policies of the Indiana Department of Transportation or the Federal Highway Administration at the time of publication. This report does not constitute a standard, specification, or regulation.

Purdue University

West Lafayette, Indiana 47907

July 2005 


\section{TECHNICAL Summary}

INDOT Research

Technology Transfer and Project Implementation Information

TRB Subject Code: 25-1 Bridges

Publication No.: FHWA/IN/JTRP-2005/19, SPR-2654

July 2005

Final Report

\section{Shear Reinforcement Requirements for High-Strength Concrete Bridge Girders}

\section{Introduction}

Improvement of economy, durability and strength of the built environment has been a constant quest for engineers. During recent decades, the use of high-strength has been implemented in bridge members and other structures. Typically, highstrength concrete has uniaxial compressive strengths in excess of $8000 \mathrm{psi}$, and its recognized as a more brittle material than the typical concretes with compressive strengths in the range of 4000 to 6000 psi.

The present study involved an extensive literature review to support the design of an experimental program on high-strength concrete bridge girders failing in shear. Two key concerns were kept in mind while designing the experimental program: a) the minimum amount of shear required to prevent a brittle failure at ultimate loads, and to provide adequate crack control at service loads, and b) the upper limit on the nominal shear strength to avoid failures triggered by the crushing of web concrete prior to the yielding of shear reinforcement. The program focused on bridge girders with compressive strengths in the range of 10000 to $15000 \mathrm{psi}$. The goal was to determine if the current limits for both the minimum and the maximum amount of shear reinforcement specified in the 2004 AASHTO LRFD Specifications and the ACI 318-05 Code are applicable to concrete compressive strengths up to $15000 \mathrm{psi}$.

\section{Findings}

The experimental evidence developed in this research study and findings of previous researchers indicate that the potential for overestimation of the concrete strength carried by the concrete, $V_{c}$, in beams with lower amounts of longitudinal reinforcement diminishes as the uniaxial compressive strength of concrete is increased. However, increases in the concrete compressive strength did not result in appreciable improvement on the shear strength of beams with large amounts of longitudinal reinforcement failing in shear.

The notion that the current prescribed minimum amounts of shear reinforcement in both 2004 AASHTO LRFD and ACI 318-05 provide sufficient reserve strength for beams with compressive strengths up to $15000 \mathrm{psi}$ was supported by the findings of this research project. It was observed that the increase in concrete compressive strength from 13000 to 15000 psi had minimal effect on the shear strength of reinforced concrete beams with intermediate and the ACI 318-05 Code maximum amount of shear reinforcement, and with large amounts of longitudinal reinforcement.

Although failing in shear, the specimens reinforced with the maximum amount of shear reinforcement in accordance with the ACI 31805 Code exhibited yielding of both the stirrups and the longitudinal reinforcement. The degree of underestimation of shear strength calculated using the 2004 AASHTO LRFD Specifications decreased as the amount of shear reinforcement increased.

The test results of prestressed specimens with concrete compressive strength in the range of 13500 to $16500 \mathrm{psi}$ indicated that the minimum amount of shear reinforcement prescribed in the 2004 AASHTO LRFD Specifications, both in terms of strength and maximum spacing 
requirements, is adequate to provide adequate reserve strength after initial inclined cracking and crack width control at estimated service load levels.

\section{Implementation}

Current minimum amount of shear reinforcement together with spacing limits in the 2004 AASHTO LRFD Specifications provide adequate crack width control and reserve shear strength for reinforced concrete and prestressed concrete beams with concrete compressive strengths up to 16000 psi.
Based on the results of the reinforced concrete specimens, an upper limit for the average nominal shear stress of $12 \sqrt{f_{c}^{\prime}}$ in concretes with compressive strength up to 15000 psi was shown to be adequate to prevent web crushing failures. This limit is similar to that in the ACI 318-05 Code for reinforced concrete beams.

\section{Contacts}

For more information:

Prof. Julio Ramirez

Principal Investigator

School of Civil Engineering

Purdue University

West Lafayette, IN 47907-2051

Phone: (765) 494-2716

Fax: (765) 496-1105

E-mail: ramirez@ecn.purdue.edu
Indiana Department of Transportation

Division of Research

1205 Montgomery Street

P.O. Box 2279

West Lafayette, IN 47906

Phone: (765) 463-1521

Fax: (765) 497-1665

\section{Purdue University}

Joint Transportation Research Program

School of Civil Engineering

West Lafayette, IN 47907-1284

Phone: (765) 494-9310

Fax: (765) 496-7996

E:mail: jtrp@ecn.purdue.edu

http://www.purdue.edu/jtrp 
TECHNICAL REPORT STANDARD TITLE PAGE

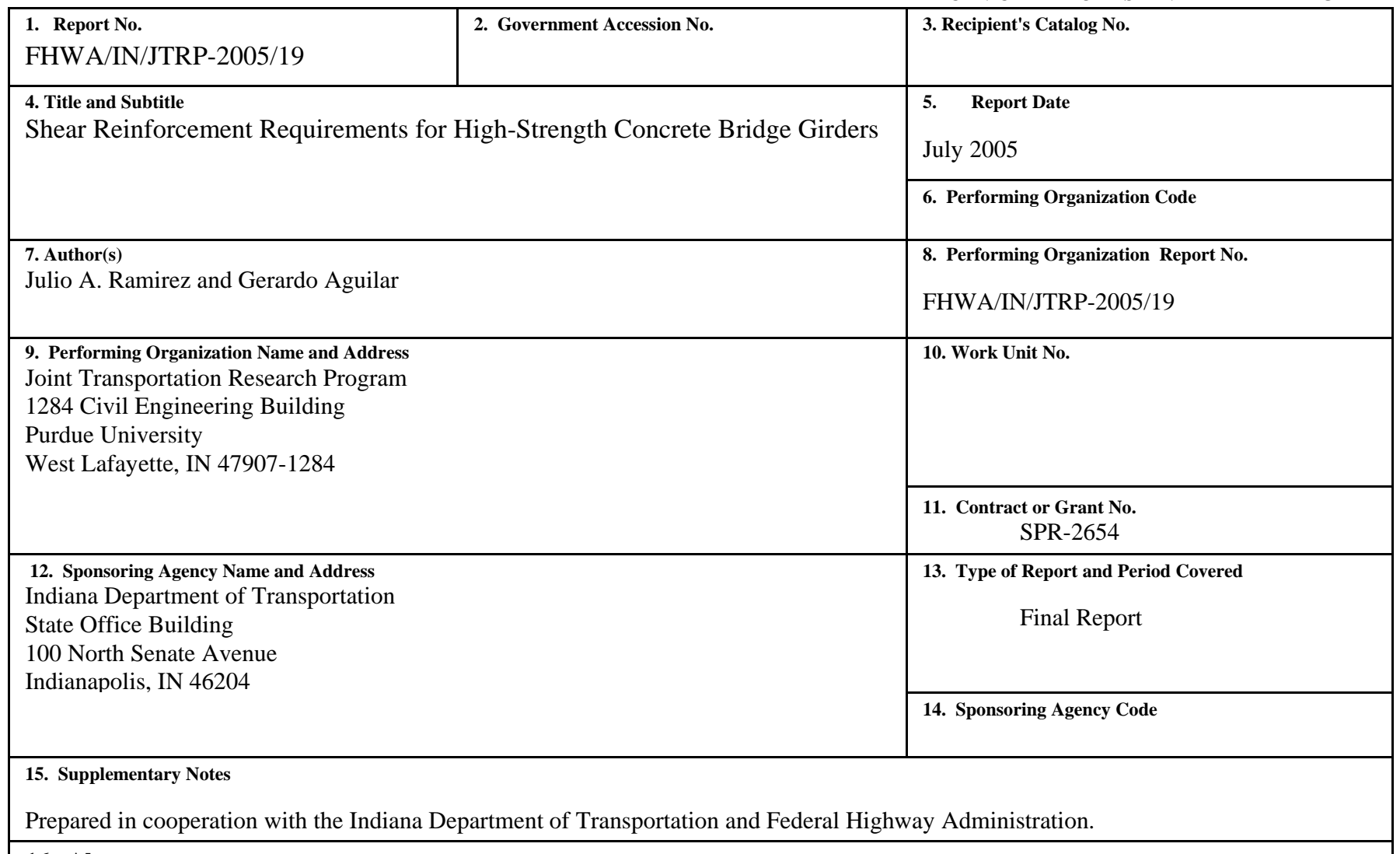

\section{Abstract}

A research program was conducted on the shear strength of high-strength concrete members. The objective was to evaluate the shear behavior and strength of concrete bridge members with compressive strengths in the range of 10000 to 15000 psi. The goal was to determine if the current minimum amount of shear reinforcement together with maximum spacing limits in the 2004 AASHTO LRFD Specifications, and the upper limit on the nominal shear strength were applicable to concrete compressive strengths up to 15000 psi.

A total of twenty I-shaped specimens were tested monotonically to failure. Sixteen specimens were reinforced concrete beams, half of them without shear reinforcement. Four AASHTO Type I prestressed concrete beams were also tested. The main variables were the compressive strength of concrete and the amount of longitudinal and transverse reinforcement. Measured concrete compressive strengths ranged from 7000 to 17000 psi. Longitudinal reinforcement ratios on the basis of web width, $\rho_{w}$, varied from 1.32 to $7.92 \%$. All specimens met the flexural requirements in Section 5.7.3.3.1 of the 2004 AASHTO LRFD Specifications. The amounts of shear reinforcement, $\rho f_{y v}$, provided were in the range of 0 to 1300 psi.

Main findings support the notion that the current prescribed minimum amounts of shear reinforcement in both the 2004 AAHTO LRFD Specifications and the ACI 318-05 Code provide sufficient reserve strength after first inclined cracking, and adequate crack width control at estimated service load levels for reinforced and prestressed concrete beams with concrete compressive strengths up to 15000 psi.

Based on the test results of reinforced concrete specimens, an upper limit for the nominal shear strength of $12 \sqrt{f^{\prime}}$ c in concretes with compressive strength up to 15000 psi was shown to be adequate to prevent web crushing failures prior to the yielding of stirrups. This limit is similar to the current upper limit on the nominal shear strength in the ACI 318-05 Code.

\section{Key Words}

beams; compressive strength; high-strength concrete; prestressed concrete; reinforced concrete; reinforcement; shear reinforcement; shear strength; web reinforcement.

\section{Distribution Statement}

No restrictions. This document is available to the public through the National Technical Information Service, Springfield, VA 22161

\begin{tabular}{|c|c|c|c|}
\hline 19. Security Classif. (of this report) & 20. Security Classif. (of this page) & 21. No. of Pages & 127 \\
Unclassified & Unclassified & Price & \\
\hline
\end{tabular}




\section{ACKNOWLEDGEMENTS}

The authors acknowledge the participation of the members of the study advisory committee. The project was funded by the Joint Transportation Research Program of Purdue University in conjunction with the Indiana Department of Transportation and the Federal Highway Administration. We acknowledge and appreciate their support and assistance. 


\section{TABLE OF CONTENTS}

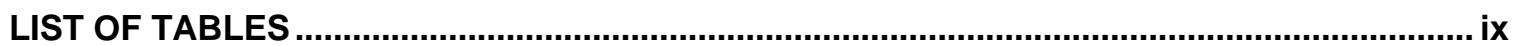

LIST OF FIGURES

\section{CHAPTER 1 INTRODUCTION}

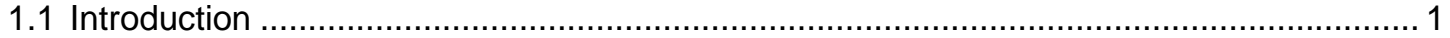

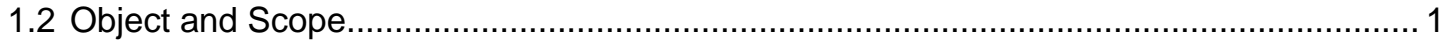

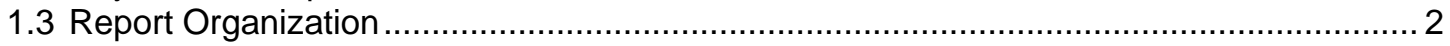

\section{CHAPTER 2 LITERATURE REVIEW}

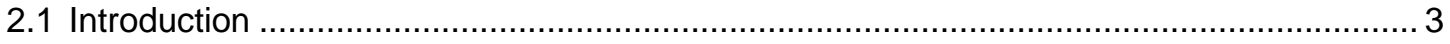

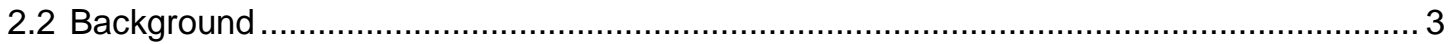

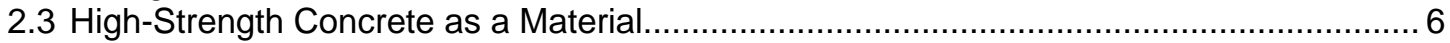

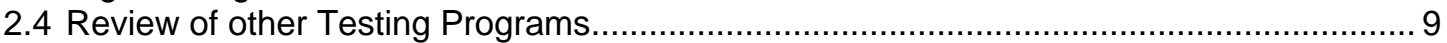

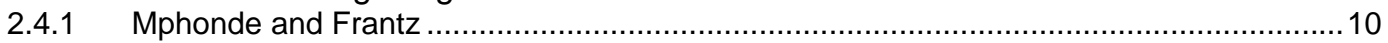

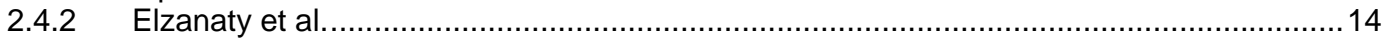

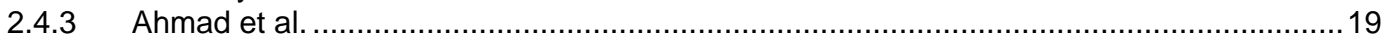

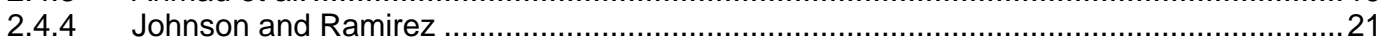

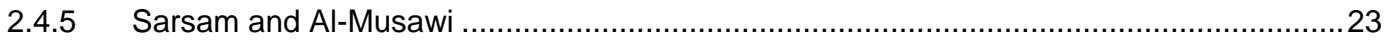

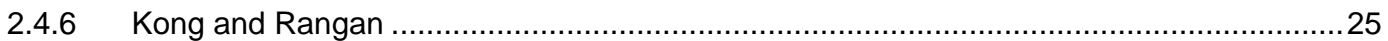

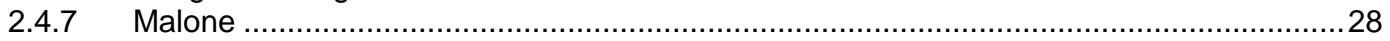

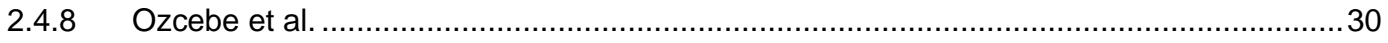

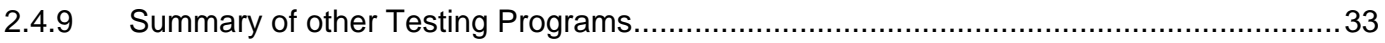

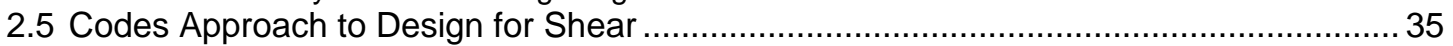

2.5.1 American Association for State Highway and Transportation Officials ...........................35

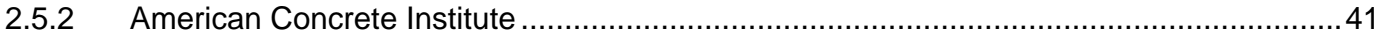

\section{CHAPTER 3 EXPERIMENTAL PROGRAM}

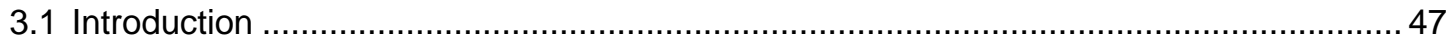

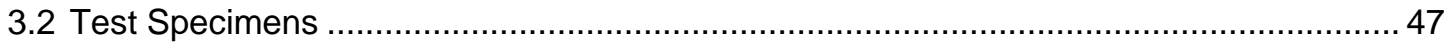

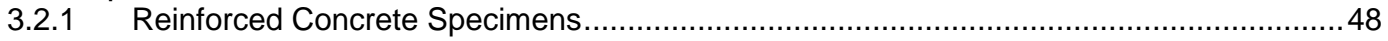

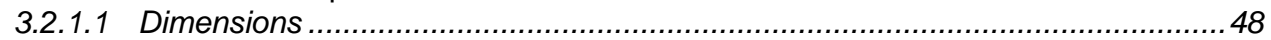

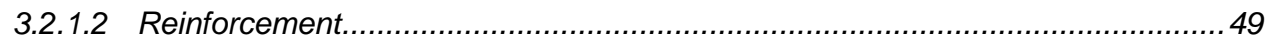

3.2.1.2.1 Beams without shear reinforcement................................................................. 49

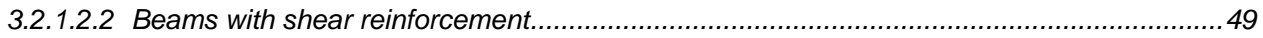

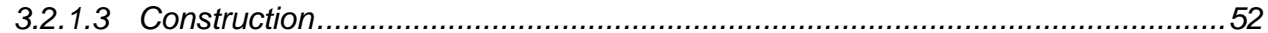

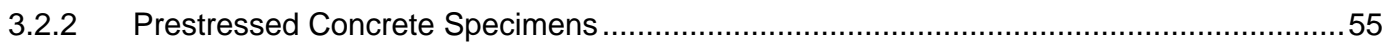

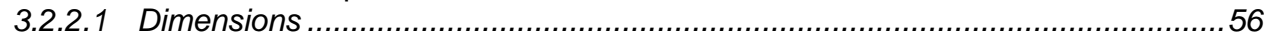

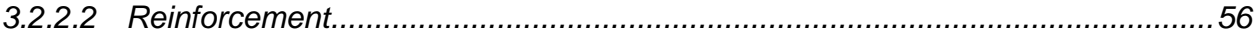

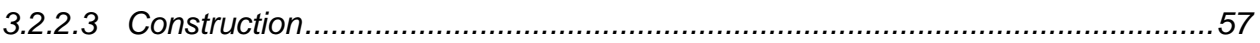

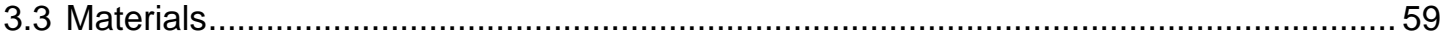

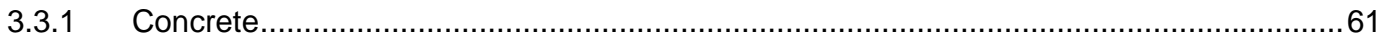

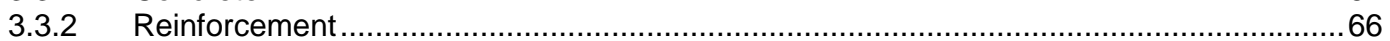

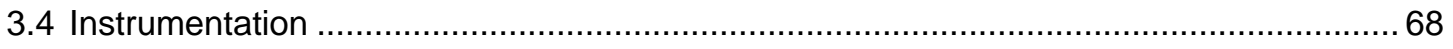

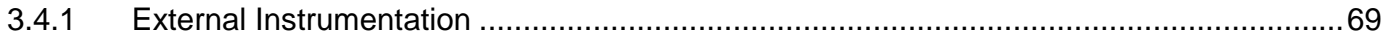

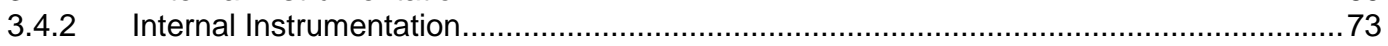




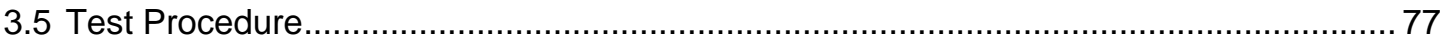

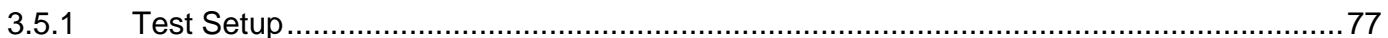

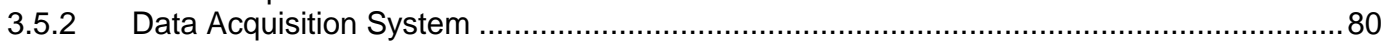

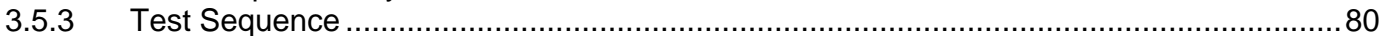

\section{CHAPTER 4 EXPERIMENTAL EVALUATION OF SHEAR BEHAVIOR}

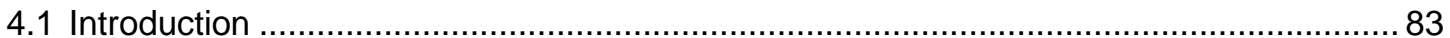

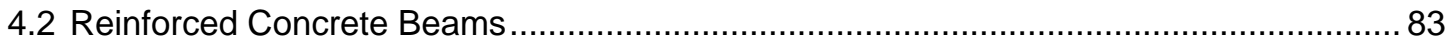

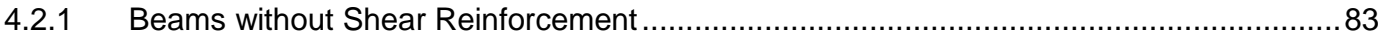

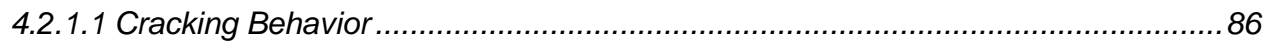

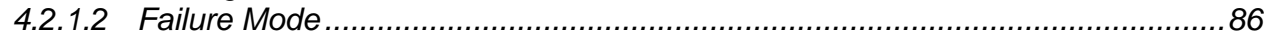

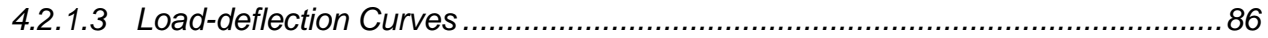

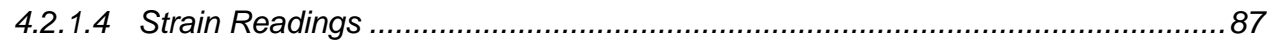

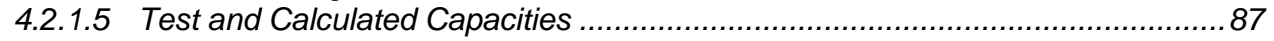

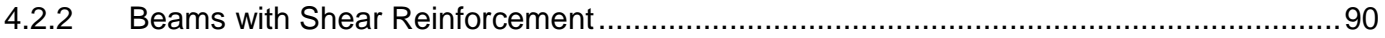

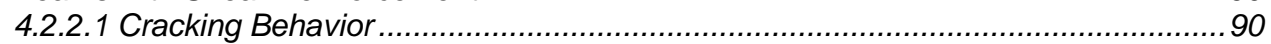

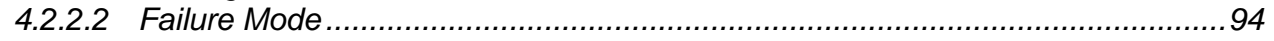

4.2.2.3 Load-deflection Curves ..................................................................... 95

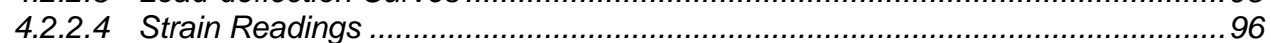

4.2.2.5 Test and Calculated Capacities ............................................................ 101

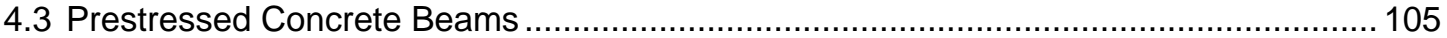

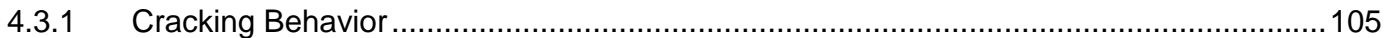

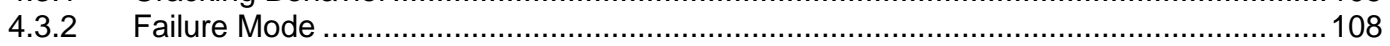

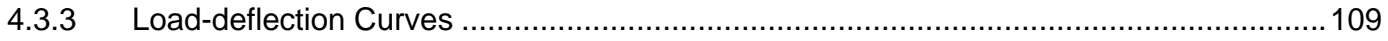

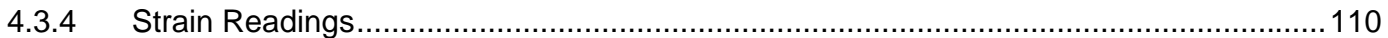

4.3.5 Test and Calculated Capacities..................................................................... 115

\section{CHAPTER 5 SUMMARY, FINDINGS AND IMPLEMENTATION}

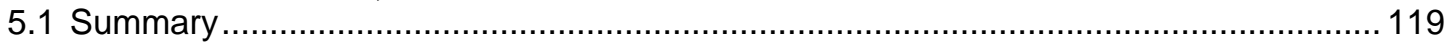

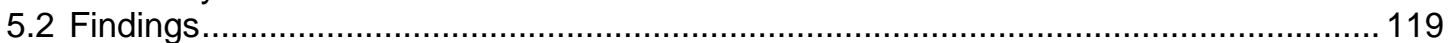

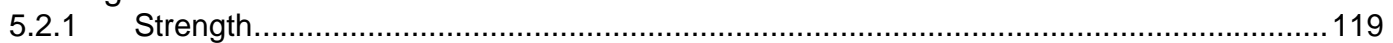

5.2.2 Average of Maximum Crack Width Measurements at Estimated Service Load Levels ...121

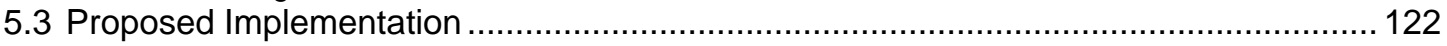

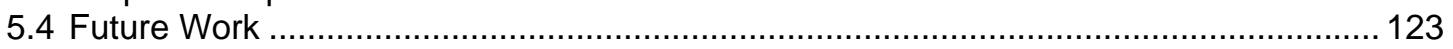

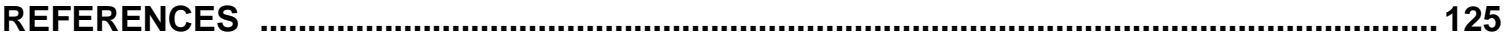




\section{LIST OF TABLES}

Table

Page

Table 2.1 Selected specimen details from Mphonde and Frantz (1984) .............................. 12

Table 2.2 Selected specimen details form Elzanaty et al. (1985) ....................................... 17

Table 2.3 Selected specimen details form Ahmad et al. (1986) ....................................... 19

Table 2.4 Selected specimen details from Johnson and Ramirez (1987) ............................. 21

Table 2.5 Selected specimen details from Sarsam and Al-Musawi (1992) ............................ 24

Table 2.6 Selected specimen details from Kong and Rangan (1997) ................................. 27

Table 2.7 Selected specimen details from Malone (1999) .............................................. 28

Table 2.8 Selected specimen details from Ozcebe et al. (1999) ....................................... 31

Table 2.9 Summary of previous research projects reviewed ............................................... 33

Table 2.10 Values of $\theta$ and $\beta$ for sections with transverse reinforcement (2004 AASHTO LRFD Table 5.8.3.4.2-1) ......................................................................... 38

Table 2.11 Values of $\theta$ and $\beta$ for sections with less than minimum transverse reinforcement (2004 AASHTO LRFD Table 5.8.3.4.2-1) .................................... 39

Table 3.1 Details of test specimens without shear reinforcement........................................... 50

Table 3.2 Details of test specimens with shear reinforcement.......................................... 51

Table $3.3 \quad$ Details of prestressed concrete specimens …................................................. 57

Table 3.4 Actual mix proportions for batches of specimens without shear reinforcement...... 62

Table 3.5 Actual mix proportions for batches of specimens with shear reinforcement

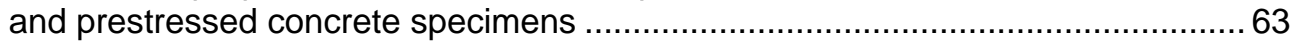

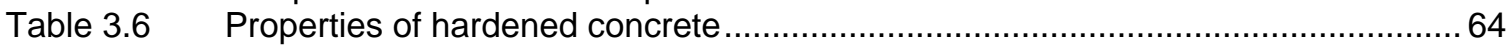

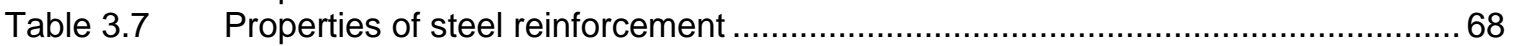

Table 4.1 Measured and calculated capacities for reinforced concrete specimens without shear reinforcement.

Table 4.2 Ratio of measured to calculated capacities for reinforced concrete specimens without shear reinforcement ................................................................................ 89

Table 4.3 Measured and calculated capacities for reinforced concrete specimens with

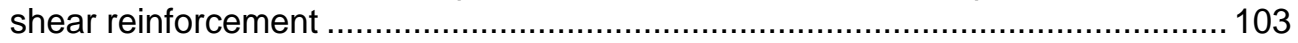

Table 4.4 Ratio of measured to calculated capacities for reinforced concrete specimens with shear reinforcement ............................................................................... 104

Table 4.5 Measured and calculated capacities for prestressed concrete specimens........... 116

Table 4.4 Ratio of measured to calculated capacities for prestressed concrete

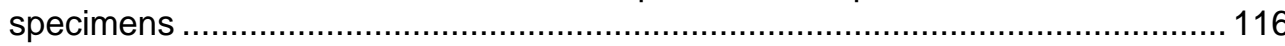




\section{LIST OF FIGURES}

Figure

Page

Figure 2.1 Internal forces after inclined cracking in a reinforced concrete beam with web reinforcement

Figure 2.2 Test setup used by Mphonde and Frantz...................................................... 11

Figure 2.3 Reinforcement details of specimens tested by Mphonde and Frantz .................... 13

Figure 2.4 Reinforcement details and load configuration for the reinforced concrete specimens tested by Elzanaty et al................................................................ 14

Figure 2.5 Reinforcement details and load configuration for the Series $\mathrm{Cl}$ of prestressed concrete specimens tested by Elzanaty et al................................................... 16

Figure 2.6 Reinforcement details and load configuration for the Series CW of prestressed concrete specimens tested by Elzanaty et al................................. 16

Figure 2.7 Reinforcement details and load configuration for selected specimens tested by Ahmad et al. ............................................................................................ 20

Figure 2.8 Reinforcement details and load configuration for selected specimens tested by Johnson and Ramirez .............................................................................. 22

Figure 2.9 Reinforcement details and load configuration for selected specimens tested by Sarsam and Al-Musawi .............................................................................. 25

Figure 2.10 Reinforcement details and load configuration for selected specimens tested by Kong and Rangan................................................................................ 26

Figure 2.11 Reinforcement details and load configuration for selected specimens tested

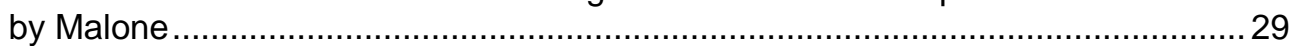

Figure 2.12 Reinforcement details and load configuration for selected specimens tested

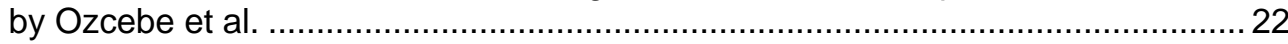

Figure 3.1 Cross section of test region in reinforced concrete specimens ........................... 48

Figure 3.2 Elevation view of the reinforced concrete specimens ...................................... 49

Figure 3.3 Reinforcement details of specimens without shear reinforcement ..........................50

Figure 3.4 Reinforcement details of specimens with minimum amount of shear reinforcement in accordance with 2004 AASHTO LRFD and ACI 318-05.............. 52

Figure 3.5 Reinforcement details of specimens with intermediate and maximum amount

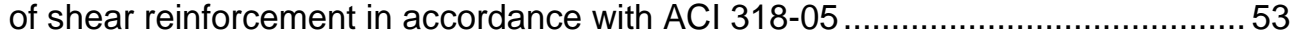

Figure 3.6 Details of construction, concrete sampling and curing of reinforced concrete

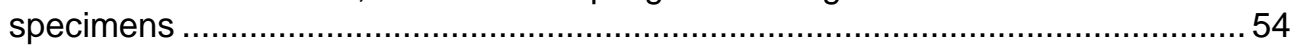

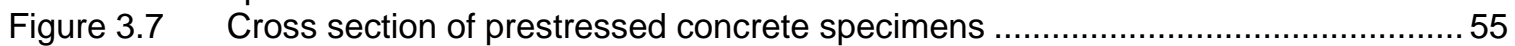

Figure 3.8 Elevation view of prestressed concrete specimens ..........................................5 56

Figure 3.9 Reinforcement details of prestressed concrete specimens ................................ 58

Figure 3.10 Details of reinforcement, construction, casting and removal operation of

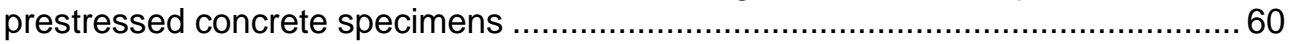

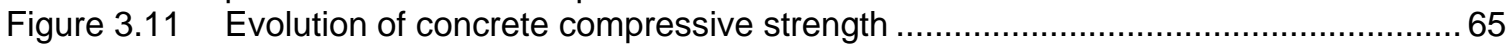

Figure 3.12 Measured stress-strain relationship for HSC and corresponding instrumented

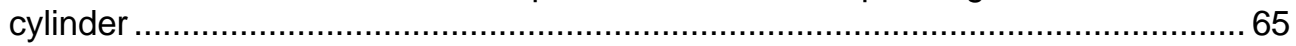

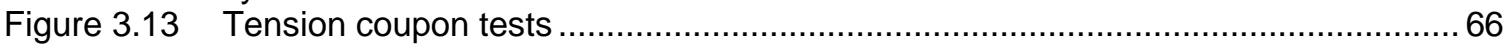


Figure 3.14 Typical stress-strain relationships for the reinforcement of the reinforced concrete specimens

Figure 3.15 Typical stress-strain relationships for the reinforcement of the prestressed

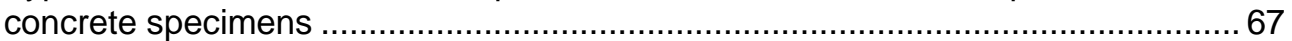

Figure 3.16 External instrumentation of the reinforced concrete specimens ...........................69

Figure 3.17 External instrumentation of the prestressed concrete specimens ........................ 70

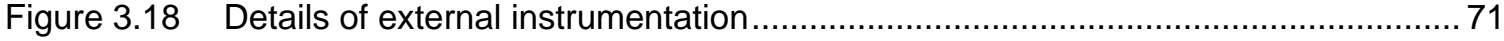

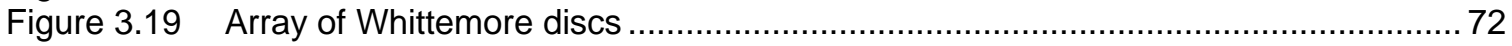

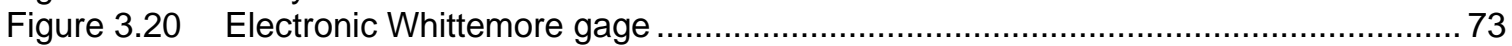

Figure 3.21 Strain gage location in the reinforced concrete specimens with shear

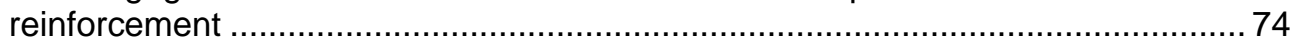

Figure 3.22 Strain gage location in the prestressed concrete specimens.............................. 75

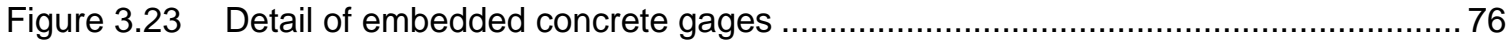

Figure 3.24 Test setup for reinforced concrete specimens ............................................ 78

Figure 3.25 Test setup for prestressed concrete specimens ............................................ 79

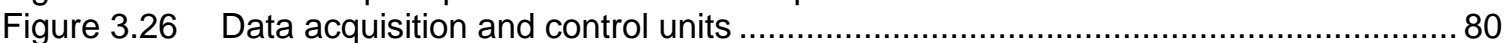

Figure 3.27 Shear force and bending moment diagrams for reinforced concrete

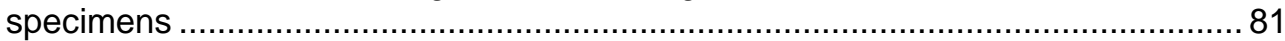

Figure 4.1 Final crack pattern of reinforced concrete specimens without shear

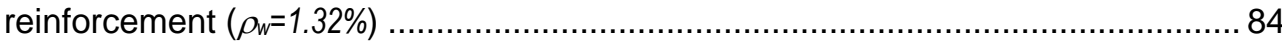

Figure 4.2 Final crack pattern of reinforced concrete specimens without shear

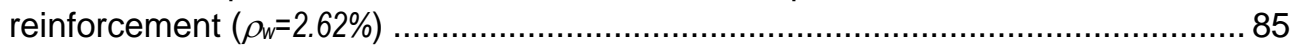

Figure 4.3 Load-deflection curves for reinforced concrete specimens without shear reinforcement

Figure 4.4 Final crack pattern of reinforced concrete specimens with minimum amount of shear reinforcement in accordance with 2004 AASHTO LRFD and ACl 318-05

Figure 4.5 Final crack pattern of reinforced concrete specimens with intermediate amount and the maximum amount of shear reinforcement in accordance with $\mathrm{ACl} 318-05$

Figure 4.3 Load-deflection curves for reinforced concrete specimens with shear

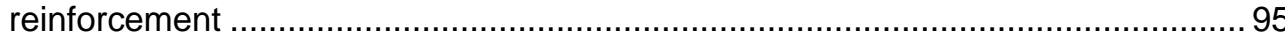

Figure 4.7 Selected load-strain curves for reinforced concrete specimens with minimum shear reinforcement in accordance with 2004 AASHTO LRFD and ACI 318$05\left(\rho f_{v v}=98 \mathrm{psi}\right)$.....

Figure 4.8 Selected load-strain curves for reinforced concrete specimens with intermediate amount and the maximum amount of shear reinforcement in accordance with $\mathrm{ACl}$ 318-05 ( $\left.\rho f_{\mathrm{y}}=902 \mathrm{psi}\right)$.....

Figure 4.9 Selected distributions of measured shear strain in specimens with shear

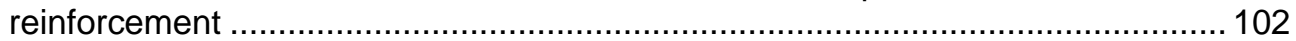

Figure 4.10 Final crack pattern of prestressed concrete specimens.................................. 106

Figure 4.11 Load-deflection curves for prestressed concrete specimens............................. 109

Figure 4.12 Selected load-strain curves for mild longitudinal and shear reinforcement of prestressed concrete specimens ................................................................. 111

Figure 4.13 Selected load-strain curves for prestressing strands of prestressed concrete

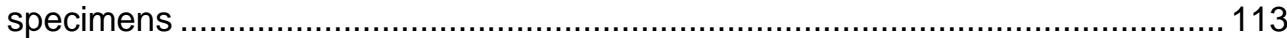

Figure 4.14 Selected distributions of measured shear strain in prestressed specimens ......... 114 


\section{CHAPTER 1 INTRODUCTION}

\section{$1.1 \quad$ Introduction}

In the quest to improve economy, durability and strength of the built environment during the past several decades, engineers have implemented the use of high-strength concrete for bridge members and other structures. High-Strength Concrete (HSC) has typically been defined as having uniaxial compressive strengths in excess of 8000 psi. HSC is a more brittle material than the typical concretes with compressive strengths in the range of 4000 to $6000 \mathrm{psi}$. Its brittle behavior has made designers cautious in extending existing empirical or phenomenological based design rules to higher strength concretes. For the purposes of this report, the label HSC is assigned to members with a compressive strength of at least $10000 \mathrm{psi}$.

Two key concerns related to the design for shear of reinforced and prestressed HSC members are the focus of this report:

a) The minimum amount of shear reinforcement to suppress the brittle, sudden failure of HSC following diagonal cracking and to provide adequate crack control at service loads, and

b) The upper limit for the maximum shear stress carried by the web concrete, to prevent failures initiated by concrete crushing prior to yielding of the shear reinforcement.

The use of HSC often results in economic savings associated with the reduction of member weight and the quantity of shear reinforcement. However, the consequences of an unsatisfactory service and ultimate load behavior due to inappropriate reductions in the amount of shear reinforcement, or the excessive amounts of the same, resulting in unconservative predictions of shear strength easily could overcome the economic benefits of the use of HSC.

\subsection{Object and Scope}

The main objective of this research project is to evaluate the shear behavior and strength of concrete bridge members with compressive strengths in the range of 10000 to $15000 \mathrm{psi}$. The goal is to determine if the current minimum amount of shear reinforcement and the upper limit for the nominal shear strength are applicable to concrete compressive strengths up to $15000 \mathrm{psi}$. The 
adequacy will be established from the standpoint of safety against ultimate loads, and crack width control.

An experimental program was put together and conducted to achieve the objectives of this research project. A total of twenty specimens were tested. Sixteen of them were reinforced concrete and four prestressed concrete series. All test specimens had an I-shaped cross section. The results of the test program were used to evaluate the relevant 2004 AASHTO LRFD Specifications for shear. The test results were also used to examine the relevant provisions in the 318-05 ACl Building Code.

\subsection{Report Organization}

This report is divided into five chapters. Chapter 1 presents the main objective of the study. An extensive review of applicable works is presented in Chapter 2. It includes a brief description of the general shear behavior of reinforced concrete members and previous relevant research

projects related to the behavior of flexural members under shear. Chapter 2 also describes the procedure for the design for shear in both the 2004 AASHTO LRFD Specifications and the $\mathrm{ACI}$ 318-05 Code. Chapter 3 describes the experimental program, with information on the materials used in the construction of the test specimens, design, geometric properties, instrumentation, and testing protocols. Chapter 4 discusses the experimental behavior of the test specimens and includes a comparison between computed specimen shear capacity and the test value. Finally, Chapter 5 presents a summary of the findings of this research project. It includes the proposed implementations and needed future research work as well. 


\section{CHAPTER 2 LITERATURE REVIEW}

\section{$2.1 \quad$ Introduction}

This chapter provides background on the shear behavior of structural concrete beams; and presents a summary of previous research projects which have studied the effect of the amount of shear reinforcement on the behavior of both reinforced and prestressed concrete members made with High-Strength Concrete (HSC). A brief review of the approach for design for shear in two US major specifications for design of concrete structures is included in this chapter as well.

\section{$2.2 \quad$ Background}

Shear in concrete structures has been studied for over one hundred years. Critical summaries of the work to date can be found elsewhere in more detail (Hognestad, 1952; ACI-ASCE Committee 326, 1962; ACI-ASCE Committee 426, 1973; ASCE-ACl Committee 445, 1998). In structural applications, shearing forces are often accompanied by one or more of the following actions: axial, flexural and torsional. It is very rare to observe a shear failure due to shearing force alone. Instead, shear failures are often due to a combination of forces on the structural member. Shear failures are associated with brittle mechanisms where reduced or no ductility is observed prior to collapse. In the case of HSC, there is additional concern since HSC is inherently brittle.

Depending on a variety of factors, reinforced concrete members without shear reinforcement subject to external forces exhibit different cracking patterns and failure mechanisms. It has been observed that one of the parameters influencing the shear failure mechanism is the moment to shear ratio:

$$
\frac{a}{d}=\frac{V a}{V d}=\frac{M}{V d}
$$

Where: $a$ is the shear span, i.e. the distance from the concentrated load to the edge of the support,

$d$ is the depth of the tension reinforcement,

$V$ is the shear force at the section, and

$M$ is the moment at the section. 
From Eq. 2.1, it is also possible to express the moment to shear ratio in terms of the ratio of shear span to effective depth of tension reinforcement $(a / d)$. This ratio is often called slenderness ratio. The relative magnitude of stresses due to moment and shear varies with the a/d ratio, which changes the structural behavior of the member. The ultimate shear behavior of reinforced concrete elements can be loosely grouped in four general categories depending on the $a / d$ ratio (Park and Paulay, 1975):

a) Members showing a diagonal tension mechanism where failure takes place at or shortly after the presence of inclined cracking $(a / d>3)$,

b) Failure of an arch mechanism due to shear compression or flexural tension (anchorage) failure after the presence of inclined cracking $(2<a / d<3)$,

c) Failure of an arch mechanism by crushing or splitting of concrete $(1<a / d<2.5)$, and

d) Direct shear $(a / d<1)$.

ACI-ASCE Committee 426 (1973) recognized as many as five components to be part of the shear transfer mechanism in the case of structural concrete beams with shear reinforcement. It is envisioned that shear forces in a reinforced/prestressed member are resisted by a combination of the following components (Figure 2.1):

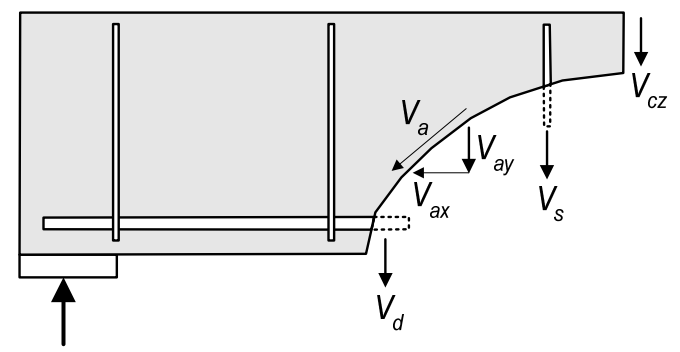

Figure 2.1

a) Shear in the uncracked concrete $\left(V_{c z}\right)$,

b) Shear along the inclined crack $\left(V_{a y}\right)$,

c) Shear due to dowel action of tension reinforcement $\left(V_{d}\right)$,

d) Shear carried by the web reinforcement $\left(V_{s}\right)$; and

e) Shear carried by the prestressing reinforcement if a tendon profile exists and it is other than a straight line $\left(V_{p}\right)$.

Considering a simple superposition of all previous components results in Eq. 2.2 to calculate the total shear resistance of a reinforced/prestressed element $\left(V_{t}\right)$.

$$
V_{t}=V_{c z}+V_{\text {ay }}+V_{d}+V_{s}+V_{p}
$$

The shear in the uncracked concrete $\left(V_{c z}\right)$ is carried by the concrete in the uncracked flexural compression zone of the beam above inclined cracks. In this region of a flexural member, the interaction of shear stresses and normal compressive stresses produces principal stresses that may lead to additional inclined cracking and crushing of concrete. 
The shear along the inclined crack $\left(V_{a y}\right)$ is developed through the scraping between the surfaces defined by the inclined cracking on a beam. Thus, it is assumed that the roughness of the surfaces plays a significant role in this transfer mechanism. The relative movement along the inclined crack interface causes the crack to open further thus introducing tensile forces in the web reinforcement and eventually reduces the transfer of shear through friction along the crack.

The shear due to dowel action of longitudinal tension reinforcement $\left(V_{d}\right)$ is developed when a crack crosses the reinforcement. The doweling forces increase the tensile stresses in the concrete neighboring the reinforcement and together with the stresses due to the wedging action of the bar deformations, may result in splitting cracks along the tension reinforcement. Once splitting cracks have formed, and prior to yielding of the longitudinal steel, the shear force that may be carried through dowel action relates to the spacing between stirrups and to the stiffness of the concrete around the longitudinal reinforcement. The development of dowel action requires particularly large displacements along the shear plane. These displacements are often too large for an acceptable structural behavior thus the contribution of dowel action to shear is not considered significant. Furthermore, in the case of prestressed members, the axial stiffness of strands is much less than that of reinforcing bars leading to an even smaller development of dowel action.

The shear carried by the web reinforcement $\left(V_{s}\right)$ has the primary role of resisting shear by providing tensile strength across inclined cracks. Once an inclined crack is formed and reaches the location of a stirrup, the tension stresses in this reinforcement will start increasing as the shear demand increases. The stirrup will carry tension until an anchorage/bond failure or its fracture occurs. The presence of web reinforcement also enhances the force carried by other shear mechanisms such as interface shear transfer, dowel action, and/or arch action.

Even though arch action may not be considered a shear mechanism, it does allow the direct transfer of stresses from a concentrated vertical load to a support reaction, thus relieving other shear transfer mechanisms from being fully utilized. Arch action has a larger influence in the shear strength of so-called deep members where the $a / d$ ratio is smaller than 2.5 . The development of arch action is largely dependent on the capacity of the tie that is formed at the base of the arch linking its two ends. The tie force is carried by the main longitudinal reinforcement which, especially in deep members, has to be properly anchored at the supports to provide for its adequate development. Also bearing stresses must be kept under acceptable limits at the ends of the arch to prevent concrete failures.

The shear carried by the prestressing reinforcement $\left(V_{p}\right)$ exists only when the tendon profile is other than a straight line. 
It is difficult to quantify individually the components previously described. Thus for purposes of design, it has been a common approach to group $V_{c z}, V_{a y}$, and $V_{d}$ into a single amount $V_{c}$, namely the shear carried by the concrete. This simplification reduces Eq. 2.2 to:

$$
V_{t}=V_{c}+V_{s}+V_{p}
$$

Even though it does not explicitly represent all the known components of the shear resistance mechanism in structural concrete members, Eq. 2.3 has been generally adopted by bridge and building design codes in North America.

The amount of transverse reinforcement plays a key role on the type of failure. For lightly reinforced members from the standpoint of shear reinforcement, the failure is precipitated shortly after the first inclined cracks are observed with little or no increase in the load carrying capacity. For members with larger amounts of shear reinforcement, a more significant redistribution of forces after first inclined cracking takes place.

\subsection{High-Strength Concrete as a Material}

Before presenting a brief summary of the properties of High-Strength Concrete (HSC) and their relation to the research conducted in this project, it is worth noting that the terms High Performance Concrete (HPC) and Ultra-High Performance Concrete (UHPC) are often used as synonyms of HSC. However, most authors now make a more definite distinction between HPC, UHPC and HSC. In Japan, for instance, HPC may be used to describe concrete designed to flow with limited or no vibration (self-compacting concrete). It is currently agreed that HSC and HPC are not interchangeable terms. HPC usually includes more attributes that just high compressive strength, and meets special performance and uniformity requirements that may not be achieved by using conventional materials and normal mixing, placing and curing practices. In this document, and in many others, it is considered that HSC is a form of HPC. The inverse is not necessarily true (Farny and Panarese, 1994).

In 1971, the Portland Cement Association (PCA) first published a report on High-Strength Concrete. In the report, it was written that a practical and economical strength limit for readymixed concrete would be about 11000 psi for normal-weight concrete. Today, that limit has been greatly exceeded and it is not uncommon to see projects where the specified compressive strength of concrete is around 20000 psi (Two Union Square in Seattle, 1988 and Pacific First Centre in Seattle, 1989).

For lower strength concretes, compressive strength of concrete is determined through a standard test (ASTM C 39-04) usually when specimens are 28 days old. In contrast, it is reasonable to specify compressive strengths of HSC at either 56 or 90 days, taking advantage of the strength 
gain that usually continues to develop after 28 days. Currently, the upper limit of compressive strength of concrete at 90 days and beyond appears to be 25000 to 30000 psi (Perenchio, 1973). However, compressive strengths of up to $106000 \mathrm{psi}$ have been obtained when very special materials and compacting techniques are used (NSF-CSTACBM, 1992).

HSC is made with the same ingredients as normal-strength concrete (NSC) namely cement, aggregates and water. However, a process of optimization is done to the cementing medium; the characteristics of the aggregates; the proportions of the paste; the paste-aggregate interaction; the mixing, consolidating and curing; and the testing procedures. The presence of atypical materials has also been explored through research but focus has been set on the abovementioned factors.

Cement paste is a very important factor in the production of HSC. Its optimization is usually done lowering the sand content and/or selecting a more finely ground cement such as Type III (high early-strength cement). However, the use of finer cements is not very common in actual practice. The coarse aggregate comprises the largest fraction of the volume of concrete. Therefore, it is one of the most influencing factors in the properties of concrete. In NSC, where the coarse aggregate usually has a greater compressive strength than the hardened cement paste, the concrete compressive strength is generally determined by the quality of the paste. In HSC, however, the strength of the cement paste may be high enough to challenge the strength of the aggregate. Not only the strength of the coarse aggregate but the adhesion to the cement paste and its absorption characteristics become more important in HSC because any of these properties may be the limiting factor in ultimate strength considerations.

It has been observed that, for a given maximum size of coarse aggregate, the gradation does not significantly affect the strength of concrete as long as it is within the limits set by the American Association of Testing and Materials (ASTM). The maximum size of coarse aggregate, however, has been found to be very influential of the ultimate compressive strength. Contrary to NSC, the larger sizes of coarse aggregate in HSC tend to reduce compressive strength. Some ready-mix producers have found that $1 / 2-i n$. maximum size coarse aggregate results in optimum strength. In the research conducted in this project (SPR 2654), two maximum sizes of coarse aggregate were used: 3/8-in. pea gravel and 1/2-in. crushed limestone.

The effect of the fine aggregate on the compressive strength of concrete is due to both its surface texture and shape which have a large influence on the water demand for a given mix. However, this variable is not very influential on the ultimate compressive strength since HSC relies on the use of water-reducing admixtures for workability purposes; thus making less relevant the initial water demand of the fine aggregate. 
HSC would not have been possible without the development of chemical admixtures. In the mid1980 's, an estimation claimed that $80 \%$ of all concrete produced in North America contained at least one type of admixture (Ramachandran, 1995). One of the most common practices for the production of HSC is the use of not only a water-reducing admixture (plasticizer), but also a highrange water-reducing admixture (superplasticizer). Even though the superplasticizer will reduce the amount of water required by about 15 to $40 \%$, the loss in slump, i.e. workability, is then overcome by the use of a plasticizer which would extend the setting time; thus allowing the placement of concrete. In general, dosages of both plasticizers and superplasticizers for HSC mixes are well over the manufacturer's recommendations, which are usually intended for NSC. Currently, a so-called third generation superplasticizers is being used to replace both plasticizers and superplasticizers with the intention of only using one chemical admixture and, therefore, reducing the risk of incompatibility between admixtures (Master Builders, 2002).

In addition to the chemical admixtures, HSC often calls for the use of mineral admixtures. These are powdered or pulverized byproduct materials that are added to concrete before or during mixing to improve its fresh or hardened properties. Mineral admixtures in HSC are usually provided in addition to the mix, rather than as a partial replacement of cement as it is often the case in NSC. Pozzolans are the mineral admixtures most commonly used in the production of HSC. Fly ash and silica fume are two of these materials, and they may be used by themselves or combined. Granulated blast-furnace slag is a pozzolanic material that is also used, especially in Canada. Silica fume was used as mineral admixture in all the mixes throughout this research project. Silica fume is a byproduct of the reduction of high-purity quartz using coal in electric arc furnaces during the manufacture of silicon and ferrosilicon alloys. The effect of adding pozzolanic materials to a HSC mix is reflected in its compressive strength. Despite the fact that pozzolans by themselves have little cementitious value, once the hydration of cement takes place, the released calcium hydroxide reacts with the pozzolans to produce a highly cementitious compound which in turn strengthens the cement paste.

Proportioning of HSC has been also a process of optimization. Generally, three main actions are performed: reduction or removal or entrained air; addition of normal-range and/or high-range water-reducing admixtures to ensure workable conditions at very low water-cementitious materials ratios; and use of pozzolans to improve the quality of the paste. The combination of these three actions results in an infinite number of possible mixes to achieve a certain compressive strength in HSC.

One of the goals while proportioning HSC is the achievement of very low water-cementitious materials ratio to ensure that the paste is as dense as possible, hence obtaining higher compressive strengths. Currently the lowest optimal water-cementitious materials ratio appears to be close to 0.22 . This ratio may be so low that, in fact, some of the cementitious materials will not 
hydrate. The water-cementitious materials ratios for the mixes in this research project varied from 0.19 to 0.35 .

It must be noted that slump is not used as a control for HSC as it is for NSC. The main reasons are that slump in HSC is usually obtained by means of chemical admixtures and that, for flowing concretes -which is often the case of HSC- the slump has little meaning. The water-cementitious materials ratio is the variable that is often limited and which maximum value should be strictly enforced as an acceptance criterion for HSC.

The control during the mixing of HSC is also very important to achieve the design characteristics of concrete. Most of the ready-mixed HSC is produced in central-mix operations. However, some ready-mix suppliers use either a central-mix or a truck-mix operation. The use of a central-mix operation where the concrete is mixed in a stationary mixer and then put on a delivery truck allows for the best control of both time and procedure while mixing HSC. Due to the cohesive nature of HSC mixes, it is frequent to have some adherence of the paste to the mixer drum. Special precautions have to be exercised to prevent this from happening. Thorough cleaning of the drum and cooling of aggregates have both been found to beneficially impact the mixing procedure.

The curing of HSC is important in the strength-gaining process. Since HSC typically has a watercementitious materials ratio in the range of 0.2 to 0.3 , there is barely enough water to start the hydration of the cementitious materials. Being the hydration process exothermic, some of the water may evaporate reducing the internal humidity up to a point where the hydration process may be stopped.

Water curing has been suggested as the preferred method for HSC curing at least during the first 24 hours. The inclusion of additional free water during this period allows the hydration process to further be completed. It must be noted, however, that water curing is rarely done in practice. Despite the low porosity associated with HSC once it has hardened, it has been observed that water curing up to as long as 28 to 90 days results in increase of compressive strength. Test specimens in this research project were water cured for 14 days.

\subsection{Review of other Testing Programs}

A brief review of eight research projects, all related to the shear strength of HSC beams, is presented. These projects are discussed in chronological order of publication. For each project, the main variables studied are discussed together with test specimens and load setup. In reviewing relevant literature, only the observations and conclusions related to test specimens with measured compressive strength of concrete in excess of $10000 \mathrm{psi}$ are presented. This section 
concludes with a summary stating how the observations of prior investigations impacted the research conducted in this project.

In Tables 2.1 through 2.9 the following notation is used:

$b_{w}$ or $b_{v}$ is the effective web width, taken as the minimum web width within the depth $d$ (in.),

$d \quad$ is the effective depth, taken as the distance from compression face to the to centroid of the nonprestressed tension reinforcement (in.),

$d_{v}$ is the effective shear depth, defined as the distance measured perpendicular to the neutral axis between the resultants of the tensile and the compressive forces due to flexure, it need not be taken to be less than the greater of $0.9 d_{\theta}$ or $0.72 h$ (in.); $d_{e}$ is the corresponding effective depth from extreme compression fiber to the centroid of the tensile force in the tensile reinforcement (in.), and $h$ is the overall thickness or depth of a member (in.),

$f_{c}$ is the compressive strength of concrete measured through testing of representative samples at test date ( $p s i)$,

$A_{s}$ is the area of nonprestressed tension reinforcement (in. ${ }^{2}$ ),

$\rho_{w}$ is the longitudinal reinforcement ratio on the basis of web width, $A_{s} / b_{w} d(\%)$,

$A_{v}$ is the area of transverse reinforcement within distance $s\left(\right.$ in. $\left.^{2}\right)$,

$\rho_{v}$ is the transverse reinforcement ratio, $A_{v} / b_{w} S(\%)$,

$\rho f_{v v}$ is a measure of the amount of shear reinforcement, in terms of the shear strength carried by the shear reinforcement (psi); computed as $A_{v} f_{y} / b_{w} s$ or $V_{s} / b_{v} d_{v} ; f_{y v}$ is the yield strength of the shear reinforcement, measured through testing of representative coupons $(k s i), V_{s}$ is the shear resistance provided by the shear reinforcement, given as $A_{v} f_{y} d_{v} / s$ (kip),

$V_{\text {exp }}$ is the maximum shear load recorded during the test, (kip), and

$v_{\text {exp }}$ is the maximum average shear stress obtained as $V_{\text {exp }} / b_{w} d_{v},(p s i)$.

\subsubsection{Mphonde and Frantz}

In 1984, the report of an extensive research project at the University of Connecticut was published (Mphonde and Frantz, 1984). The project included the testing of 39 reinforced concrete beams with and without shear reinforcement. The main variables were the shear span to depth ratio, the compressive strength of concrete, and the amount of shear reinforcement.

All the specimens had a rectangular cross section. The dimensions were $6.00 \mathrm{in}$. wide by $13.25 \mathrm{in}$. deep. The length of specimens was changed to evaluate the effect of shear span. Three clear spans were studied: $35.25 \mathrm{in}$., $58.75 \mathrm{in}$. and $84.00 \mathrm{in}$. The member lengths resulted in shear span to depth ratios of $1.5,2.5$ and 3.6 , respectively. All specimens were loaded monotonically to failure. A 
point load at midspan over a simply supported configuration was used throughout the tests (Figure 2.2).

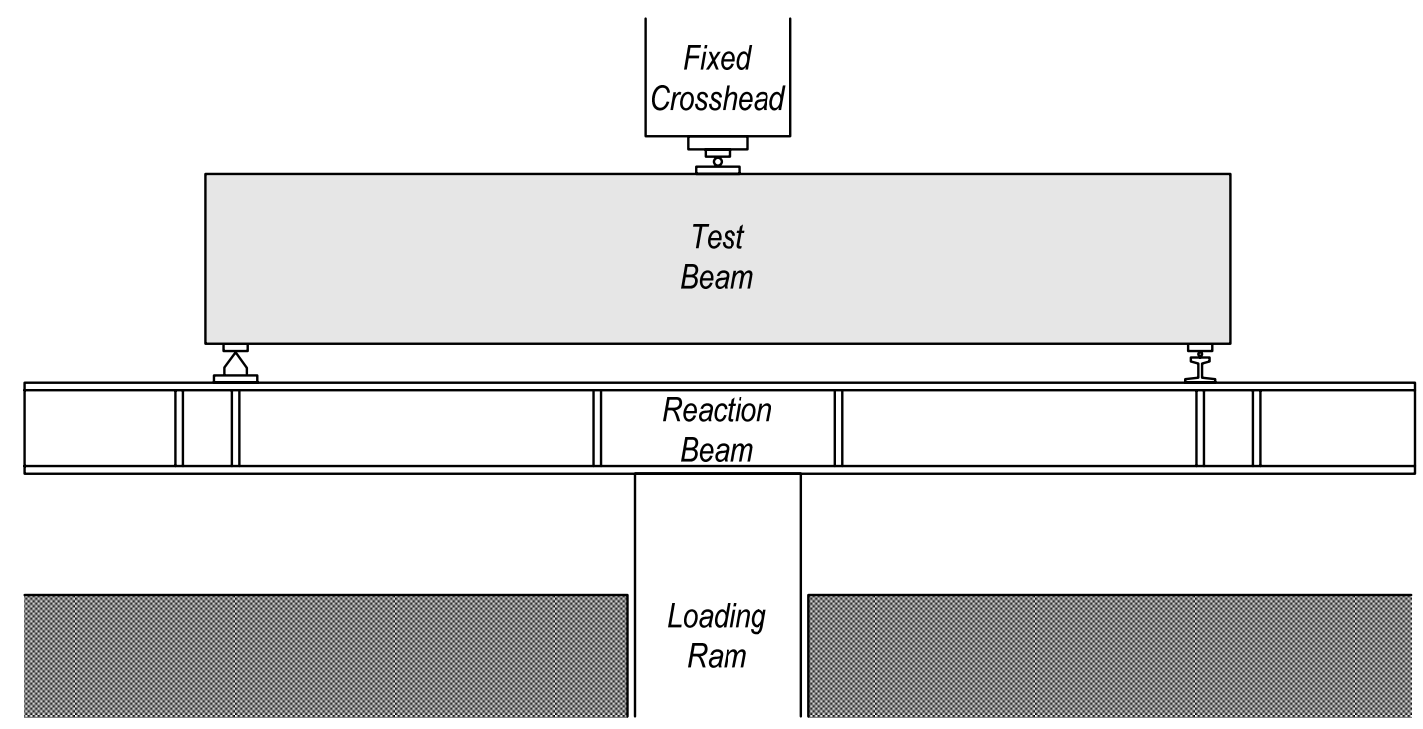

Figure 2.2 Test setup used by Mphonde and Frantz (adapted from Mphonde and Frantz, 1984)

The compressive strength of concrete in the test specimens ranged from 3000 to about $15000 \mathrm{psi}$. Nineteen of the specimens had a measured concrete compressive strength over $10000 \mathrm{psi}$, thus were considered relevant for the current research project. However, six of those specimens had a shear span to depth ratio under 3.0, and their behavior was described as that of a deep member. This summary of the Mphonde and Frantz report refers only to the thirteen HSC test specimens which had a shear span to depth ratio over 3.0. Table 2.1 presents a summary of the key parameters for the relevant specimens. Labeling of test specimens followed the scheme $X N-f_{c}-Z$, where $X$ is a letter indicating the test series, $N$ is a number indicating the shear strength attributed to shear reinforcement $\left(\rho_{v} f_{v v}\right)$, in $p s i, f_{c}$ denoted the design compressive strength of concrete in ksi, and $Z$ is an integer representing the $a / d$ ratio of the test. Table 2.1 presents the ratio of the ultimate average shear stress to the square root of the compressive strength of concrete in psi. This ratio is often used as a parameter to quantify the ability of concrete members to carry shear stresses in terms of the diagonal tensile strength of concrete.

The longitudinal reinforcement of all HSC specimens was provided by means of Gr. 60 deformed bars. However, the actual yield strength was measured to be about $65 \mathrm{ksi}$. All beams listed in Table 2.1 had 3 No. 8 bars as flexure reinforcement. Longitudinal reinforcement was located in a single layer using an inch of clear cover. The effective depth was then 11.75 in. for all HSC specimens. With the exception of one test specimen, not included in Table 2.1, the longitudinal 
reinforcement ratio on the basis of web width, $\rho_{w}$, was $3.36 \%$. The high amount of longitudinal reinforcement was used to insure a shear failure prior to flexural failure. In Series B and Series C, longitudinal reinforcement was anchored by means of welded steel plates. Specimens in Series A did not have end steel plates. Figure 2.3 shows the reinforcement details of the specimens tested by Mphonde and Frantz.

Table 2.1

Selected specimen details from Mphonde and Frantz (1984)

\begin{tabular}{|c|c|c|c|c|c|c|c|c|}
\hline Specimen & $b_{w}$, in. & $d$, in. & $d_{v}$, in. & $f_{c}, p s i$ & $A_{s}$, in. $^{2}\left(\rho_{v}, \%\right)$ & $A_{v}$, in. $^{2}\left(\rho f_{y v}, p s i\right)$ & $V_{\text {exp }}, k i p$ & $v_{\text {exp }} / \sqrt{f_{c}}$ \\
\hline$A 0-11-3 a$ & 6.00 & 11.75 & 10.58 & 10870 & $2.37(3.36)$ & $0.00(0)$ & 20.15 & 3.0 \\
\hline$A 0-11-3 b$ & 6.00 & 11.75 & 10.58 & 10830 & $2.37(3.36)$ & $0.00(0)$ & 20.10 & 3.0 \\
\hline$A 0-15-3 a$ & 6.00 & 11.75 & 10.58 & 11800 & $2.37(3.36)$ & $0.00(0)$ & 21.00 & 3.0 \\
\hline$A 0-15-3 b$ & 6.00 & 11.75 & 10.58 & 13590 & $2.37(3.36)$ & $0.00(0)$ & 22.50 & 3.0 \\
\hline$A 0-15-3 c$ & 6.00 & 11.75 & 10.58 & 13320 & $2.37(3.36)$ & $0.00(0)$ & 22.00 & 3.0 \\
\hline B50-15-3 & 6.00 & 11.75 & 10.58 & 12030 & $2.37(3.36)$ & $0.02(51)$ & 25.00 & 3.6 \\
\hline B100-15-3 & 6.00 & 11.75 & 10.58 & 11880 & $2.37(3.36)$ & 0.06 (101) & 26.00 & 3.8 \\
\hline B150-11-3 & 6.00 & 11.75 & 10.58 & 10080 & $2.37(3.36)$ & 0.08 (157) & 36.30 & 5.7 \\
\hline B150-15-3 & 6.00 & 11.75 & 10.58 & 12000 & $2.37(3.36)$ & $0.08(157)$ & 33.70 & 4.8 \\
\hline C50-11-3 & 6.00 & 11.75 & 10.58 & 10240 & $2.37(3.36)$ & $0.02(51)$ & 29.00 & 4.5 \\
\hline C50-15-3 & 6.00 & 11.75 & 10.58 & 12150 & $2.37(3.36)$ & $0.02(51)$ & 24.00 & 3.4 \\
\hline C100-11-3 & 6.00 & 11.75 & 10.58 & 10410 & 2.37 (3.36) & 0.06 (101) & 34.20 & 5.3 \\
\hline C100-15-3 & 6.00 & 11.75 & 10.58 & 12030 & $2.37(3.36)$ & $0.06(101)$ & 30.20 & 4.3 \\
\hline
\end{tabular}

Transverse reinforcement was provided by means of 1/8-in. and 3/16-in. diameter cold drawn smooth wire. The wire had an ultimate strength of $100 \mathrm{ksi}$ and no significant yield plateau but was annealed at $1100^{\circ} \mathrm{F}$ for $1-1 / 2$ hours resulting in a well defined yield plateau. The yield strengths after the annealing process were reported to be $43.9 \mathrm{ksi}$ and $38.6 \mathrm{ksi}$ for the 1/8-in. diameter and the 3/16in. diameter wire, respectively. In those test specimens where stirrups were provided, a constant spacing of $3.5 \mathrm{in}$. was used.

All test specimens listed in Table 2.1 failed in a diagonal tension mode associated with flexureshear type cracking. Short vertical cracks due to flexure were initially observed close to midspan. As applied load increased, the initial cracks curved in the direction of increasing moment. Upon further increase of load, both inclined and vertical cracks grew longer and wider. Close to failure some test specimens showed splitting cracks along the longitudinal reinforcement. The authors of the investigation reported that none of the tests specimens showed bond failures and claimed that all splitting cracks showed as secondary failures once the peak load had been reached. 
Series $A$

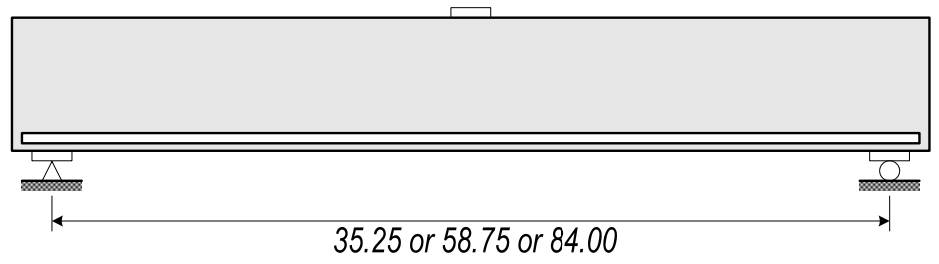

Series B
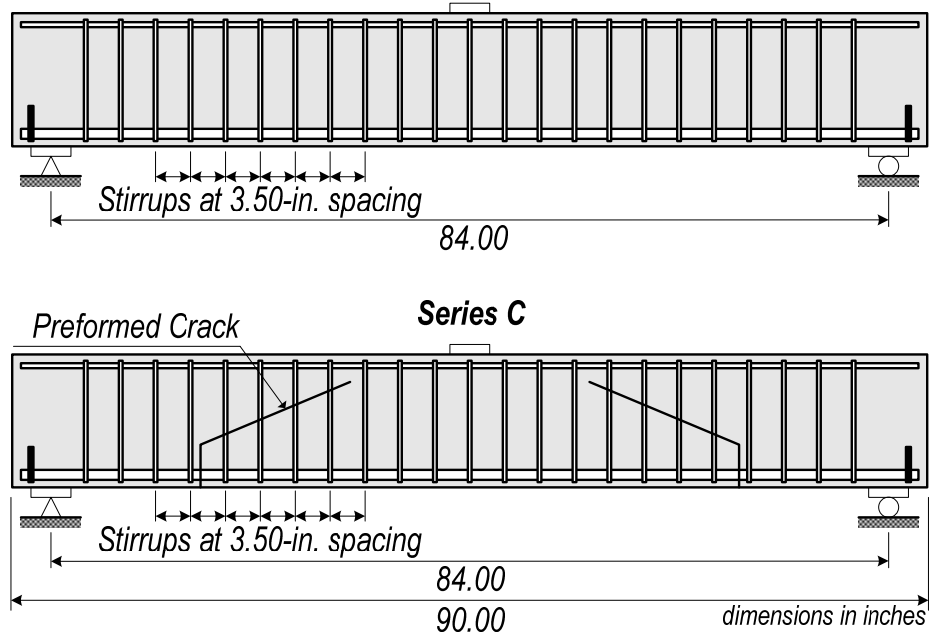

\section{Cross Section of Specimens of Series A}

Cross Section of Specimens of Series B and Series C
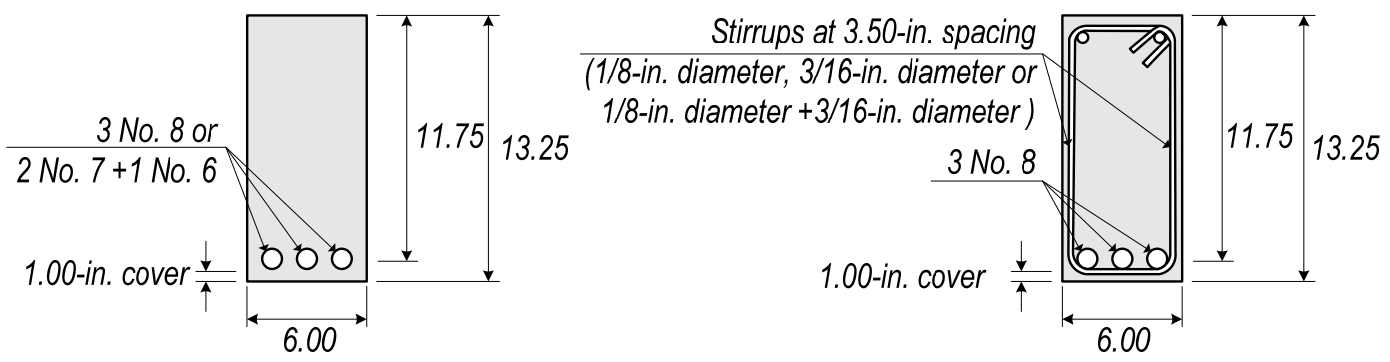

Figure 2.3 Reinforcement details of the specimens tested by Mphonde and Frantz (adapted from Mphonde and Frantz, 1984)

Mphonde and Frantz observed that both inclined and ultimate shear loads increased as the compressive strength of concrete increased. Also, they noticed that the degree of conservatism of the equations for design for shear in the 1983 Edition of the Building Code of the American Concrete Institute ( $\mathrm{ACl}$ 318-83) reduced as the compressive strength of concrete increased. However, they claimed that those equations were still conservative when designing HSC beams with shear reinforcement. The investigators also observed that the addition of stirrups did not affect the inclined cracking load but increased the ultimate capacity both in terms of strength and ductility. All shear failures were sudden and even explosive. 


\subsubsection{Elzanaty et al.}

A very extensive research project was carried out at Cornell University (Elzanaty et al., 1985; Elzanaty et al., 1986). This study included a total of 53 beams. Test specimens included nineteen rectangular reinforced concrete beams and thirty-four prestressed concrete beams. The variables considered were the compressive strength of concrete, the amounts of longitudinal and transverse reinforcement, and the shear span to depth ratio.

All test specimens in the reinforced concrete series had a rectangular section of $7 \mathrm{in}$. width, $b_{\mathrm{w}}$, and $12 \mathrm{in}$. total depth, $h$. The length of test specimens was changed to study the effect of the a/d ratio. Shear span to depth ratios of 2.0, 4.0 and 6.0 were investigated. Total lengths of test specimens, which included two 6-in. long regions past the end supports, were $75 \mathrm{in}$., $140 \mathrm{in}$., and 202 in, respectively. The compressive strength of concrete varied from 3000 to 11500 psi.

Reinforced concrete specimens were tested in a simply supported configuration using two identical loads located at the third points of the clear span. Figure 2.4 shows the details of the reinforced concrete specimens tested by Elzanaty et al.

\section{Reinforced Concrete Specimens with Shear Reinforcement}

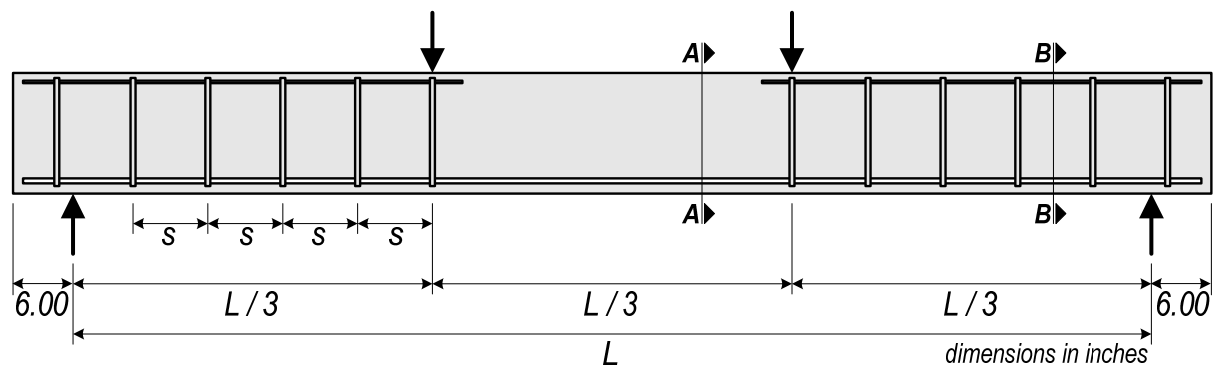

Cross Section of Specimens without Shear Reinforcement and Section A-A of Specimens with Shear Reinforcement

Section B-B of Specimens with Shear Reinforcement

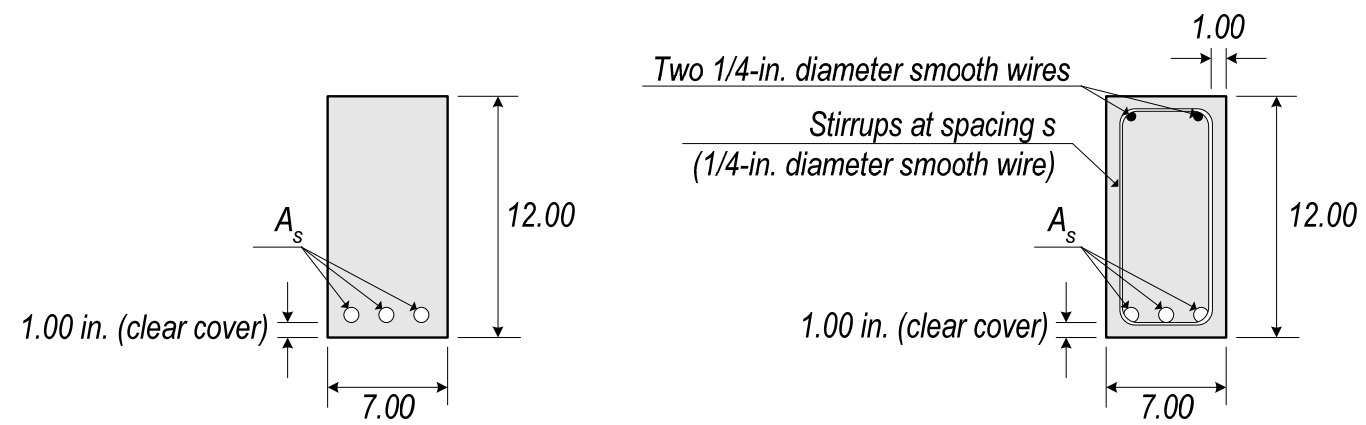

Figure 2.4 Reinforcement details and load configuration for the reinforced concrete specimens tested by Elzanaty et al. (adapted from Elzanaty et al., 1985) 
In the reinforced concrete specimens, the longitudinal reinforcement was provided by means of No. 4, No. 5, No. 6, No. 7 and/or No. 8 deformed bars of Gr. 60. Actual yield stress was 63 ksi. Two 1/4in. diameter smooth wires were provided as negative reinforcement in the test regions to facilitate the construction of the reinforced concrete specimens with shear reinforcement. Only four out of the nineteen reinforced concrete specimens had transverse reinforcement. Closed stirrups were provided in these four beams by means of 1/4-in. diameter smooth wire. The yield stress of the smooth wire was determined to be around $55 \mathrm{ksi}$.

The prestressed concrete specimens were divided into two series. Half of the thirty-four prestressed specimens had a 14-in. deep T-shaped cross section (Series $\mathrm{Cl}$ ) and the rest had an 18-in. deep I-shaped cross section (Series CW). In each of these series, eight out of the seventeen beams had transverse reinforcement. All prestressed specimens had a total length of $180 \mathrm{in}$.

For each series, specimens with shear reinforcement had the same shear span to depth ratio. Series $\mathrm{Cl}$ had a a/d ratio of 5.80 , whereas Series $\mathrm{CW}$ had a a/d ratio of 3.75 . In the case of prestressed specimens without shear reinforcement, a/d was changed. The shear span to depth radio varied from 4.0 to 8.0 in Series $\mathrm{Cl}$ and from 2.9 to 5.0 in Series CW.

The nominal compressive strength of concrete in the prestressed specimens varied from 6000 to 11000 psi. Prestressed specimens were loaded in a similar fashion to the reinforced concrete specimens. Figure 2.5 and 2.6 show the reinforcement details of specimens of Series $\mathrm{Cl}$ and specimens of Series $\mathrm{CW}$, respectively.

The longitudinal mild or nonprestressed reinforcement in the prestressed specimens consisted of 3 No. 3 or 3 No. 7 deformed bars of Gr. 60 . However, two of the specimens did not have nonprestressed longitudinal reinforcement. The longitudinal steel used in the construction of the prestressed specimens had the same mechanical properties as the one used in the reinforced concrete specimens. Transverse reinforcement of prestressed specimens was provided with single-leg stirrups made with No. 3 deformed bars. In two of the test specimens, 1/4-in. diameter smooth wire was used to fabricate the stirrups.

In order to evaluate the effect of the prestressed reinforcement ratio, $\rho_{\rho}$, two different sizes of strands were used. In some specimens four $0.5-\mathrm{in}$. diameter strands were employed. In the rest, four 0.6-in. diameter strands were provided. In all cases, low-relaxation seven-wire Gr. 270 strands were used. Within each series of prestressed specimens, both the location of strands and the effective prestressing force were kept the same.

Specimens in the reinforced concrete category were labeled by a combination of a letter and a number. The letter $F$ was used to designate specimens without shear reinforcement, whereas the 
letter $G$ was used to label specimens with shear reinforcement. The number following the letter increased sequentially to differentiate the specimens. A similar nomenclature was used for the prestressed specimens. However, the letters $F$ or $\mathrm{G}$ were replaced by $\mathrm{Cl}$ or $\mathrm{CW}$ depending of the series.

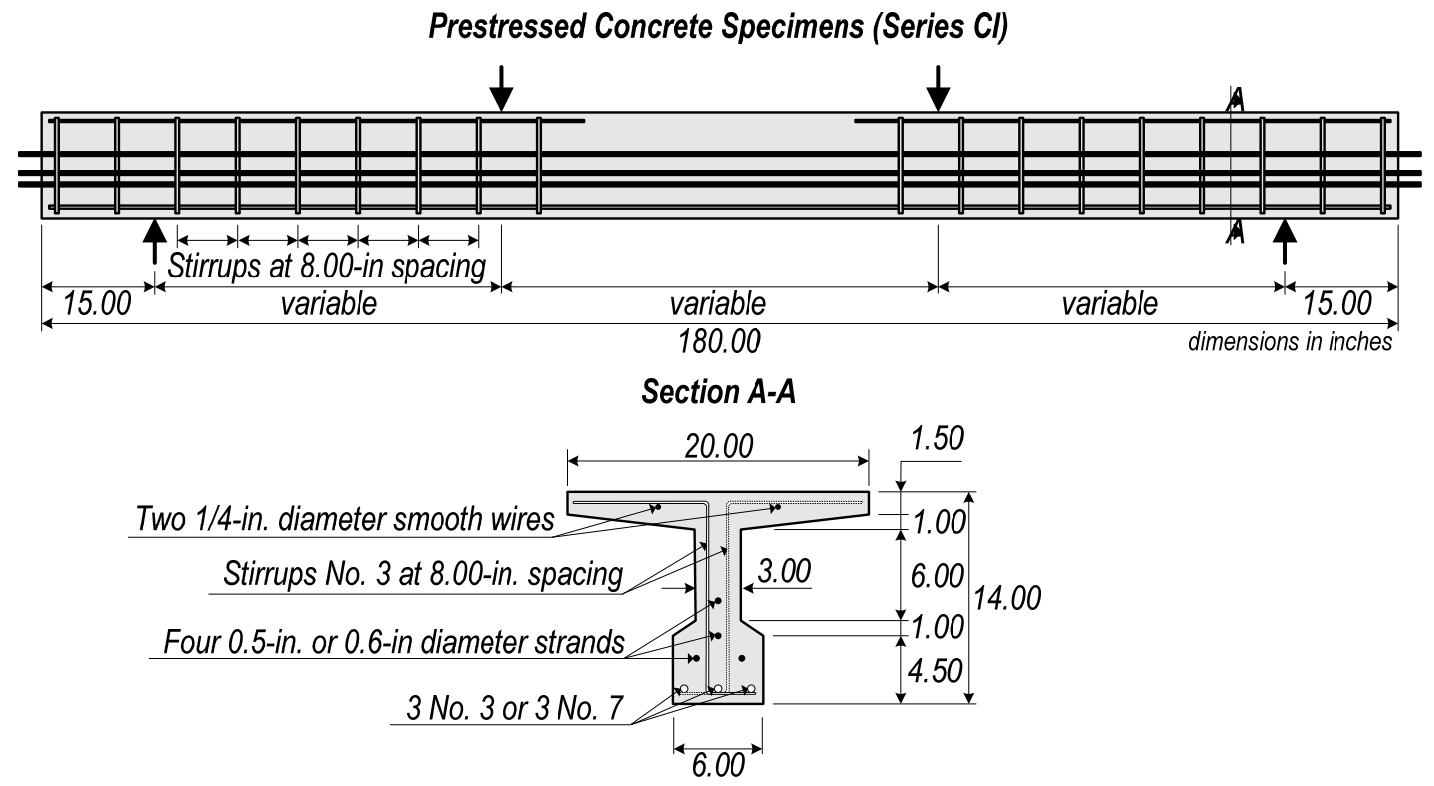

Figure 2.5 Reinforcement details and load configuration for the Series $\mathrm{Cl}$ of prestressed concrete specimens tested by Elzanaty et al. (adapted from Elzanaty et al., 1985)
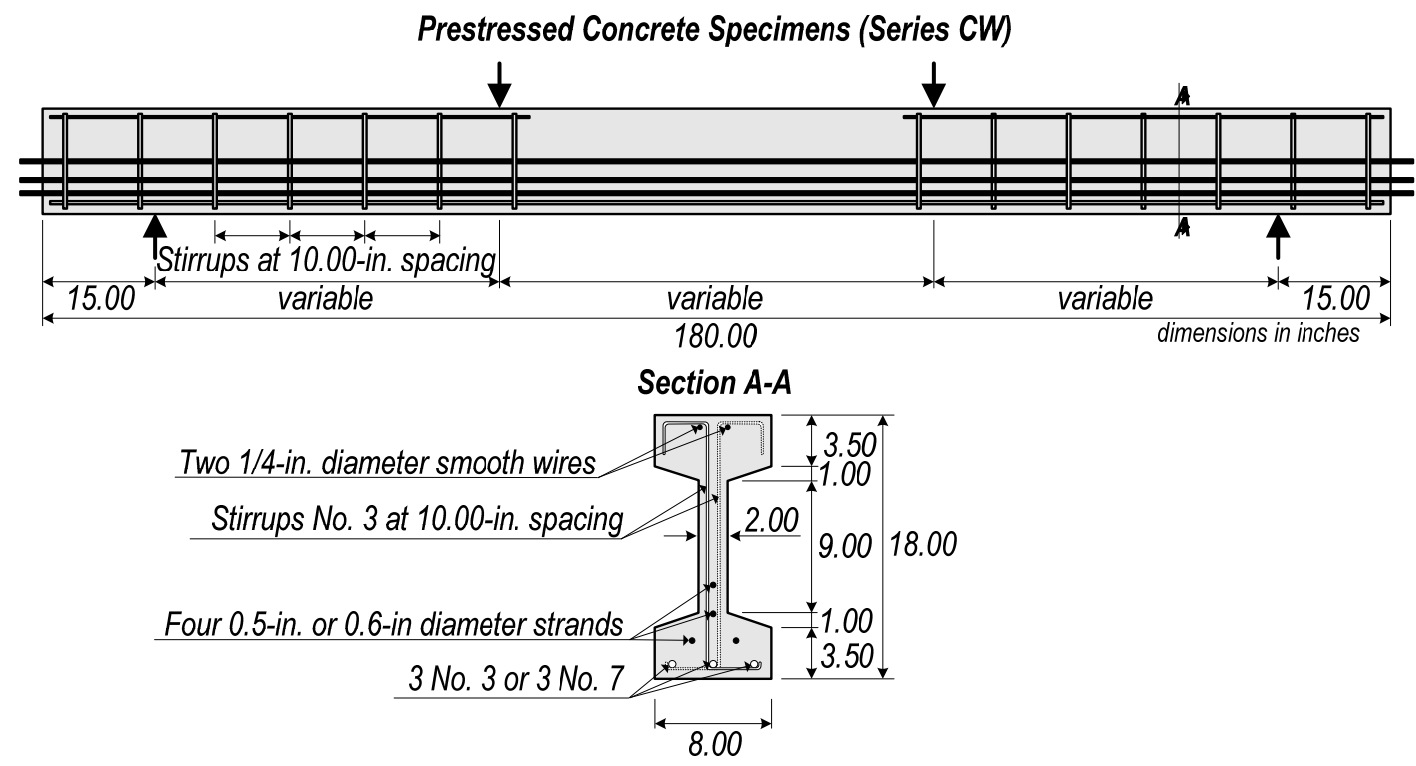

Figure 2.6 Reinforcement details and load configuration for the Series CW of prestressed concrete specimens tested by Elzanaty et al. (adapted from Elzanaty et al., 1985) 
Using the aforementioned nomenclature, Table 2.2 presents the details of the HSC specimens tested by Elzanaty et al. In Table 2.2, only test specimens with a measured compressive strength of concrete over 10000 psi and test configurations with a shear span to depth ratio over 3.0 are listed.

Table 2.2 Selected specimen details from Elzanaty et al. (1985)

\begin{tabular}{|c|c|c|c|c|c|c|c|c|}
\hline Specimen & $b_{w}$, in. & d, in. & $d_{v}$, in. & $f_{c}, p s i$ & $A_{s}, \operatorname{in}^{2}\left(\rho_{w}, \%\right)$ & $A_{v}$, in. $^{2}\left(\rho v f_{y v}, p s i\right)$ & $V_{\text {exp }}, k i p$ & $v_{\exp } / \sqrt{f_{c}}$ \\
\hline F9 & 7.00 & 10.56 & 9.51 & 11600 & $1.20(1.62)$ & $0.00(0)$ & 14.00 & 2.0 \\
\hline$F 15$ & 7.00 & 10.56 & 9.51 & 11300 & $1.80(2.43)$ & $0.00(0)$ & 14.90 & 2.1 \\
\hline Cl1 & 3.00 & 12.81 & 11.53 & 11100 & $0.33(0.86)$ & $0.00(0)$ & 17.50 & 5.5 \\
\hline $\mathrm{Cl} 2$ & 3.00 & 12.81 & 11.53 & 11100 & $0.33(0.86)$ & $0.00(0)$ & 26.00 & 8.2 \\
\hline $\mathrm{Cl} 3$ & 3.00 & 12.81 & 11.53 & 11100 & $0.33(0.86)$ & $0.00(0)$ & 27.20 & 8.5 \\
\hline $\mathrm{Cl}$ & 3.00 & 13.00 & 11.70 & 11400 & $0.00(0.00)$ & $0.00(0)$ & 24.40 & 7.6 \\
\hline $\mathrm{Cl}$ & 3.00 & 12.56 & 11.31 & 11300 & $1.80(4.78)$ & $0.00(0)$ & 26.90 & 8.4 \\
\hline $\mathrm{Cl} / 6$ & 3.00 & 12.81 & 11.53 & 11300 & $0.33(0.86)$ & $0.00(0)$ & 20.00 & 6.2 \\
\hline $\mathrm{Cl} 7$ & 3.00 & 12.81 & 11.53 & 11250 & $0.33(0.86)$ & $0.00(0)$ & 18.30 & 5.7 \\
\hline CW2 & 2.00 & 16.81 & 15.13 & 11100 & $0.33(0.86)$ & $0.00(0)$ & 28.00 & 10.3 \\
\hline CW3 & 2.00 & 16.81 & 15.13 & 11100 & $0.33(0.86)$ & $0.00(0)$ & 26.40 & 9.7 \\
\hline CW4 & 2.00 & 17.00 & 15.30 & 11400 & $0.00(0.00)$ & $0.00(0)$ & 28.60 & 10.3 \\
\hline CW5 & 2.00 & 16.56 & 14.91 & 11300 & $1.80(5.43)$ & $0.00(0)$ & 27.90 & 10.1 \\
\hline CW6 & 2.00 & 16.81 & 15.13 & 11300 & $0.33(0.98)$ & $0.00(0)$ & 25.20 & 9.1 \\
\hline CW7 & 2.00 & 16.81 & 15.13 & 11250 & $0.33(0.98)$ & $0.00(0)$ & 23.80 & 8.7 \\
\hline Cl10 & 3.00 & 12.81 & 11.53 & 10600 & $0.33(0.86)$ & $0.11(290)$ & 31.80 & 10.2 \\
\hline Cl13 & 3.00 & 12.81 & 11.53 & 10500 & $0.33(0.86)$ & $0.11(290)$ & 34.80 & 11.2 \\
\hline Cl14 & 3.00 & 12.81 & 11.53 & 10700 & $0.33(0.86)$ & $0.11(464)$ & 37.00 & 11.8 \\
\hline Cl15 & 3.00 & 12.81 & 11.53 & 10200 & $0.33(0.86)$ & $0.11(290)$ & 27.20 & 8.9 \\
\hline Cl16 & 3.00 & 12.56 & 11.31 & 10600 & $1.80(4.78)$ & $0.11(290)$ & 36.70 & 11.8 \\
\hline Cl17 & 3.00 & 12.81 & 11.53 & 10100 & $0.33(0.86)$ & $0.05(112)$ & 29.10 & 9.6 \\
\hline CW10 & 2.00 & 16.81 & 15.13 & 10600 & $0.33(0.98)$ & $0.11(348)$ & 39.00 & 14.6 \\
\hline CW13 & 2.00 & 16.81 & 15.13 & 10500 & $0.33(0.98)$ & 0.11 (348) & 41.00 & 15.4 \\
\hline CW14 & 2.00 & 16.81 & 15.13 & 10700 & $0.33(0.98)$ & $0.11(497)$ & 42.20 & 15.7 \\
\hline CW15 & 2.00 & 16.81 & 15.13 & 10200 & $0.33(0.98)$ & 0.11 (348) & 33.80 & 12.9 \\
\hline CW16 & 2.00 & 16.56 & 14.91 & 10600 & $1.80(5.43)$ & 0.11 (348) & 42.00 & 15.7 \\
\hline CW17 & 2.00 & 16.81 & 15.13 & 10100 & $0.33(0.98)$ & $0.05(135)$ & 32.00 & 12.3 \\
\hline
\end{tabular}

Elzanaty et al. recognized the complexity of the shear problem due to interdependence of all parameters affecting the shear strength such as shear span to depth ratio, compressive strength of concrete, prestressed and non-prestressed reinforcement, and amount of shear reinforcement. 
As other researches have previously pointed out, Elzanaty et al. observed that the shear strength of reinforced concrete beams with and without shear reinforcement increased as the compressive strength of concrete increased. The researchers at Cornell University compared their results with strengths computed using $\mathrm{ACl} 318-83$, and observed that the code calculated values became less conservative when increasing the compressive strength of concrete in the reinforced concrete specimens without shear reinforcement.

In the prestressed beams without shear reinforcement, Elzanaty et al. observed two distinctive cracking patterns and failure modes corresponding to Series $\mathrm{Cl}$ and Series CW. Specimens of Series $\mathrm{Cl}$ showed a flexural-shear failure mode where flexural cracks were originally observed around midspan. These cracks later appeared in the shear spans and deviated from their initially vertical orientation to become inclined and propagate towards the loading points. Failure was ultimately observed when these flexural-shear cracks and additional web-shear cracks reached the load points.

Test specimens of Series CW failed in a web-shear dominated mode where few or no flexural cracking was observed prior to diagonal cracking, which occurred suddenly. Usually, only one main crack was formed on the web of the test specimens. The extension and widening of the main inclined crack ultimately caused the failure of test specimens.

In both reinforced concrete and prestressed concrete specimens with shear reinforcement, the stirrups intersecting the main inclined crack showed signs of yielding. The strains in the stirrups at failure were observed to increase as the compressive strength of concrete increased. Increasing the number of stirrups led to a reduction in the maximum width of the main inclined crack.

The amounts of shear reinforcement provided in the prestressed specimens allowed evaluating the strength and behavior of concrete beams with significant amounts of shear reinforcement. A brittle web crushing failure may be triggered when beams have large amounts of shear reinforcement. The number of cracks in the shear span was directly related to the number of stirrups provided. As more and larger diameter stirrups were provided, more inclined cracks were observed. Specimen Cl14, which had the second largest amount of shear reinforcement (No. 3 bars at $5.0 \mathrm{in}$., and $\rho_{v} f_{y v}=464 \mathrm{psi}$ ), showed numerous cracks in the shear span. These cracks, however, had very small widths.

It was also observed that the ratio of test to predicted inclined cracking loads increased with the increase of concrete compressive strength for specimens in Series CW where web shear cracking dominated. The opposite was observed in specimens of Series $\mathrm{Cl}$ where failure was caused by flexural-shear cracking. Failures in these series became more explosive as both the concrete compressive strength and the effective prestressing force increased. 
For both series of prestressed specimens, Elzanaty et al. noticed that the shear strength increased with the increase of the amount of shear reinforcement. By comparing the test results to the prediction of $\mathrm{ACl} 318-83$, it was concluded that the code underestimated the beneficial effect of increasing the resistance associated with the shear reinforcement, $\rho f_{v}$, for values of $\rho f_{v v}$ up to around $300 \mathrm{psi}$. The $\mathrm{ACl}$ 318-83 Code overestimated this effect of $\rho_{v} f_{\mathrm{yv}}$ for values larger than $300 \mathrm{psi}$. The change in trend around the $300 \mathrm{psi}$ value seemed to be related to the fact that beams with $\rho f_{y} v$ up to about $300 \mathrm{psi}$ showed an inclined tension failure, whereas beams with larger values of $\rho_{v} f_{y v}$ exhibited a shear-compression failure with decreased stirrups effectiveness. This means that increasing $\rho f_{y v}$ would change the failure mode from diagonal tension to shear-compression. Elzanaty et al. pointed out that an upper limit exists for $\rho_{v} f_{y v}$ after which no contribution of the shear reinforcement to the shear capacity of the beam would be observed. This would be the case of the maximum shear in beams failing in web crushing.

\subsubsection{Ahmad et al.}

Thirty-six reinforced concrete beams without shear reinforcement were tested at North Carolina State University (Ahmad et al., 1986). Test specimens were divided in three groups, namely Group A, Group B and Group C. Each group had slightly different compressive strength of concrete and different amounts of longitudinal reinforcement. The shear span to depth ratio was changed within specimens of each group. The main objective of the study was to evaluate the expressions for design for shear included in $\mathrm{ACl} 318-83$ on the light of the increasing use of HSC in flexural members. Relevant to the current research project were four beams from Group B and four beams from Group C, which had measured compressive strengths over $10000 \mathrm{psi}$ and a shear span to depth ratio over 3.0. Some reinforcement details and test results for selected specimens are presented in Table 2.3.

Table 2.3 Selected specimen details from Ahmad et al. (1986)

\begin{tabular}{|c|c|c|c|c|c|c|c|c|}
\hline Specimen & $b_{w}$, in. & $d$, in. & $d_{v}$, in. & $f_{c, p s i}$ & $A_{s}$, in. $^{2}\left(\rho_{\mathrm{w}}, \%\right)$ & $A_{v}$, in. $^{2}\left(\rho f_{y v}, p s i\right)$ & $V_{\text {exp }}, k i p$ & $v_{\exp } / \sqrt{f_{c}}$ \\
\hline B1 & 5.00 & 7.94 & 7.14 & 10560 & $2.00(5.04)$ & $0.00(0)$ & 11.51 & 3.1 \\
\hline B2 & 5.00 & 7.94 & 7.14 & 10560 & $2.00(5.04)$ & $0.00(0)$ & 15.50 & 4.2 \\
\hline$B 7$ & 5.00 & 8.19 & 7.37 & 10560 & $0.93(2.27)$ & $0.00(0)$ & 10.03 & 2.6 \\
\hline B8 & 5.00 & 8.19 & 7.37 & 10560 & $0.93(2.27)$ & $0.00(0)$ & 10.50 & 2.8 \\
\hline C1 & 5.00 & 7.25 & 6.53 & 10140 & $2.40(6.62)$ & $0.00(0)$ & 12.20 & 3.7 \\
\hline $\mathrm{C2}$ & 5.00 & 7.25 & 6.53 & 10140 & $2.40(6.62)$ & $0.00(0)$ & 17.00 & 5.2 \\
\hline$C 7$ & 5.00 & 8.13 & 7.31 & 10140 & $1.32(3.25)$ & $0.00(0)$ & 10.20 & 2.8 \\
\hline C8 & 5.00 & 8.13 & 7.31 & 10140 & $1.32(3.25)$ & $0.00(0)$ & 10.00 & 2.7 \\
\hline
\end{tabular}


All specimens tested by Ahmad et al. had a rectangular section 5 -in. wide by 10 -in. deep. Longitudinal reinforcement was provided by means of Gr. 60 deformed bars, only in the positive moment region. No. 5, No. 6, No. 7, and No. 9 bars were used in the selected specimens. The longitudinal reinforcement was anchored at both ends using either 180-deg. or 90-deg. hooks. Test specimens had a 6-in. long overhanging region at both ends where a pair of stirrups was located. Specimens where loaded in a 120-kip hydraulic testing machine using a simply supported configuration using two equal and symmetrically located point loads. Figure 2.7 shows the reinforcement details and load configuration of selected test specimens.

All test specimens listed in Table 2.3 failed in shear. The observed behavior in the selected specimens was characterized by vertical cracks that initiated at midspan. On further loading, additional vertical cracks due to flexure and inclined cracks developed at sections away from midspan. In these specimens, failure was sudden, accompanied by a loud noise, and took place soon after the inclined cracking.

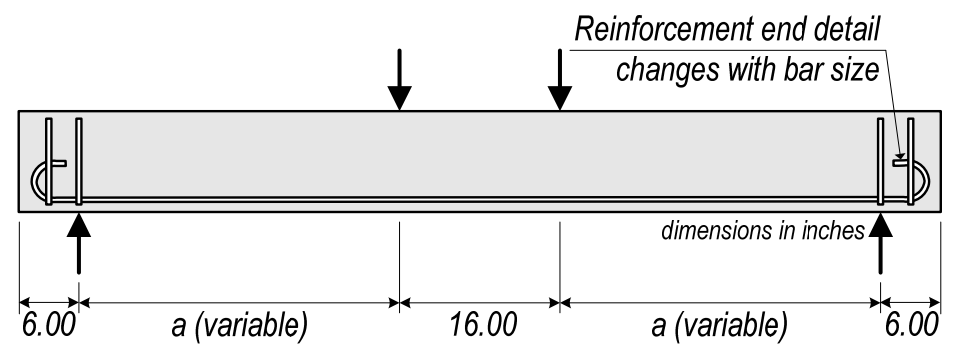

Specimens B1 to B6 (2 No. 9)
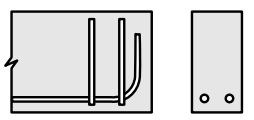

Specimens $B 7$ to $B 12$ (3 No. 5) and Specimens $\mathrm{C7}$ to $\mathrm{C} 12$ (3 No. 6)

Specimens C1 to C6 (4 No. 7)
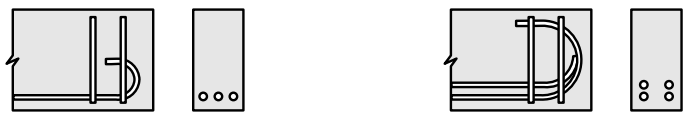

Typical Cross Section

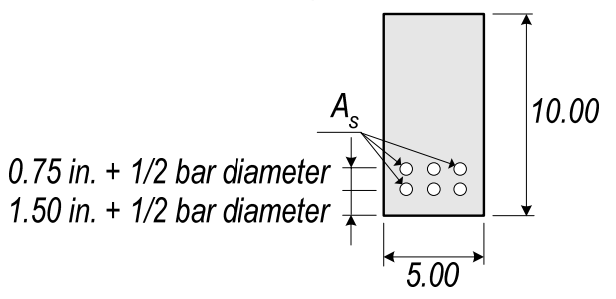

Figure 2.7 Reinforcement details and load configuration for selected specimens tested by Ahmad et al. (adapted from Ahmad et al., 1986)

Ahmad et al. proposed an equation to calculate the ultimate shear stress as a function of the concrete compressive strength, the longitudinal reinforcement ratio, the shear span to depth ratio, and a coefficient $\eta$ derived statistically from their test results. It was found that the $\mathrm{ACl} 318-83$ 
Code was conservative for low shear span to depth ratios but unconservative for beams with larger a/d ratios and relatively low longitudinal reinforcement ratios. It was also concluded that the design expressions for shear at the time overestimated the effect of concrete compressive strength and underestimated the impact of the longitudinal reinforcement ratio on the shear strength of beams without shear reinforcement.

\subsubsection{Johnson and Ramirez}

An experimental program consisting of the monotonic test to failure of eight rectangular reinforced concrete specimens was carried out at Purdue University (Johnson, 1987; Johnson and Ramirez, 1989). The research involved two main variables: the amount of shear reinforcement and the concrete compressive strength.

The amount of shear reinforcement, measured by the product $\rho f_{y v}$, varied from 0 to $100 \mathrm{psi}$. The compressive strength of concrete was in the range of 5000 to $10500 \mathrm{psi}$. All other parameters, including cross sectional dimensions, shear span to effective depth ratio, longitudinal reinforcement ratios and span length were kept identical among test specimens.

Test specimens were 186 -in. long and had 12 -in. wide by 24 -in. deep rectangular cross sections. Both effective depth (21.2 in.) and the shear span length (65.8 in.) were kept constant throughout the tests. Shear span to effective depth ratio was 3.1 for all specimens. Figure 2.8 shows a sketch of the load setup and the reinforcement details of some of the specimens tested by Johnson and Ramirez. Figure 2.8 shows only the reinforcement scheme of the specimens which had a measured compressive strength of concrete over $10000 \mathrm{psi}$. Only two of the specimens tested by Johnson and Ramirez had a compressive strength of concrete over 10000 psi. Details of these test specimens are shown in Table 2.4.

Table 2.4

Selected specimen details from Johnson and Ramirez (1987)

\begin{tabular}{|c|c|c|c|c|c|c|c|c|}
\hline Specimen & $b_{w}$, in. & d, in. & $d_{v}$, in. & $f_{c}, p s i$ & $A_{s}$, in. $^{2}\left(\rho_{v}, \%\right)$ & $A_{v}$, in. $^{2}\left(\rho f_{y v}, p s i\right)$ & $V_{\text {exp }}, k i p$ & $v_{\exp } / \sqrt{f_{c}}$ \\
\hline Beam 3 & 12.00 & 21.21 & 19.09 & 10490 & $6.35(2.49)$ & $0.10(54)$ & 59.00 & 2.5 \\
\hline Beam 4 & 12.00 & 21.21 & 19.09 & 10490 & $6.35(2.49)$ & $0.10(54)$ & 71.00 & 3.0 \\
\hline
\end{tabular}

Several concrete mixes were tried to achieve the selected compressive strengths. Type III normal cement, 3/4-in. maximum diameter size crushed limestone, C-33 natural sand, and a superplasticizer admixture were used as part of the mix design. A microsilica admixture was used in place of the superplasticizer for the construction of the beams with the highest concrete compressive strength. Measured compressive strength of concrete ranged from 5280 to $10490 \mathrm{psi}$. 


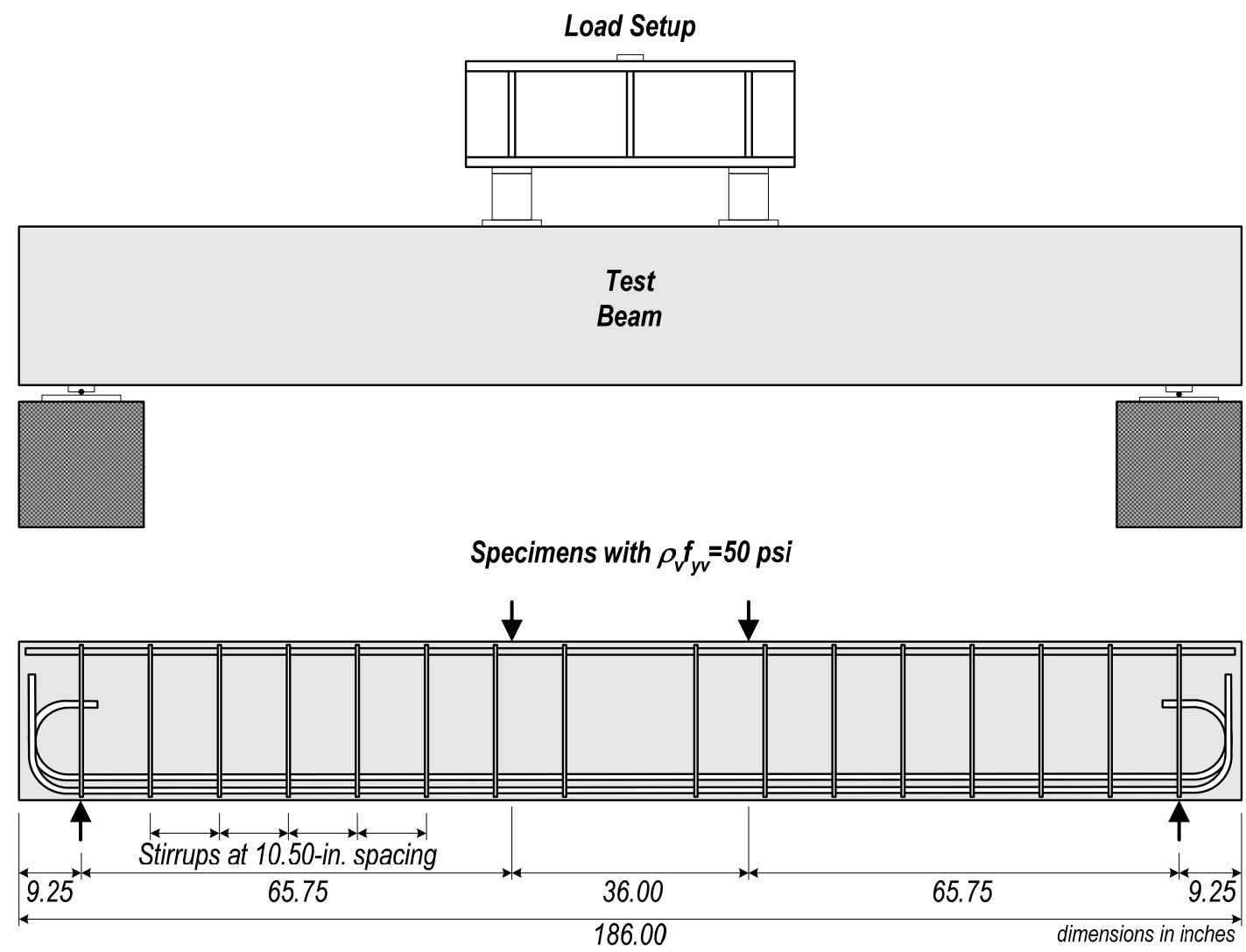

Cross Section

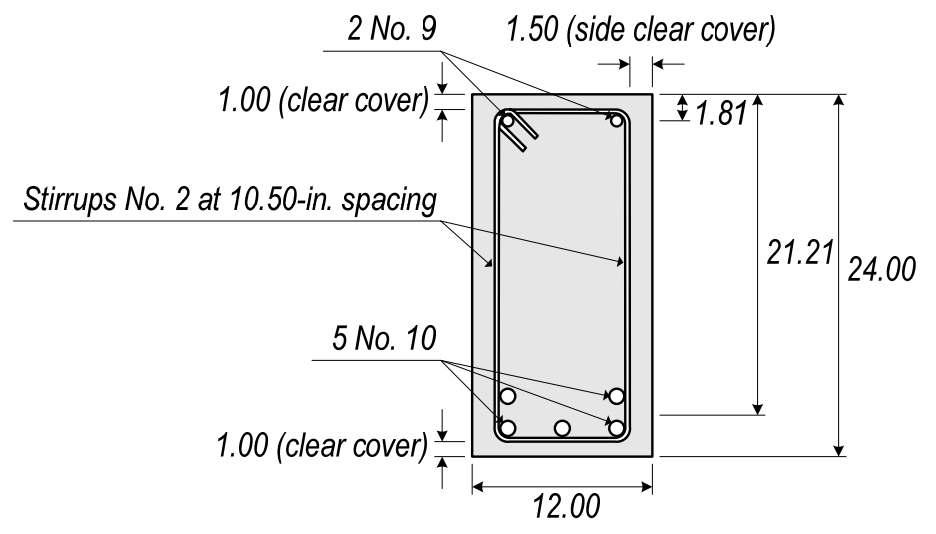

Figure 2.8 Reinforcement details and load configuration for selected specimens tested by Johnson and Ramirez (adapted from Johnson, 1987)

Positive and negative longitudinal reinforcement consisted of 2 No. 9 and 5No. 10, Gr. 60 deformed bars, respectively. While the negative longitudinal reinforcement was kept straight and located in a single layer, the positive longitudinal reinforcement was distributed in two layers and anchored by means of $90-$ and 180-deg hooks. Shear reinforcement consisted of No. 2 deformed bars with a 
nominal yield point of $70 \mathrm{ksi}$. All stirrups were closed loops and were ended with 135 -deg. hooks. Two different spacing between stirrups were evaluated: 5.25 and 10.50 in.

The tests were carried out by monotonically increasing the load applied trough a 600-kip capacity loading machine. The specimens were simply supported over two rollers spanning $167.5 \mathrm{in}$. center to center. The total load was divided into two symmetrically located sections, $18 \mathrm{in}$. away from the midspan section, by means of a steel spreader beam.

All beams failed in a shear-compression mode but one, which failed after a stirrup fractured (Beam 3). It was found that the behavior of the beams after the first flexural cracking was observed tended to be unpredictable. The extension of cracks and change in slope of the cracking pattern were different after the first flexural cracking. Cracking patterns were symmetrical and nearly alike in all cases. Only two inclined cracks were observed in the shear span of the selected specimens. These specimens had the minimum amount of shear reinforcement specified in the $\mathrm{ACl} 318-83$ Code. The width of the main inclined crack was monitored and observed to be larger as the concrete compressive strength increased. Also, the number of inclined cracks increased with increasing amount of shear reinforcement.

Johnson and Ramirez used the reserve shear strength index, defined as the ratio between the maximum shear load and the shear load at first inclined cracking, to evaluate the effect of the amount of shear reinforcement. They observed that the reserve shear strength index increased as both the concrete compressive strength and the amount of shear reinforcement increased. By increasing the shear strength associated with shear reinforcement from 50 to $100 \mathrm{psi}$, the reserve shear strength index increased around $50 \%$.

From the load-deflection curves reported by Johnson and Ramirez, it was observed that the test specimens showed a transition in behavior as the concrete compressive strength increased. Specimens with higher concrete compressive strengths were able to carry higher loads by mobilizing an improved shear transfer mechanism, mainly through a stronger concrete compression block. The amount of shear force carried by the stirrups increased as the concrete compressive strength increased. Therefore, the potential for stirrup fracture to control failure increased with increasing concrete compressive strength.

\subsubsection{Sarsam and Al-Musawi}

Sarsam and Al-Musawi (1992) tested fourteen reinforced concrete beams. All specimens had a 7.1-in. wide by 10.6-in. deep rectangular section. The dimensions and values mentioned throughout this review may seem awkward due to the fact that specimens were built using SI units. The main variables studied were shear span to depth ratio, amounts of longitudinal and transverse reinforcement, and compressive strength of concrete. 
The measured compressive strength of concrete in all test specimens ranged from 5660 to 11620 psi. However, only three specimens had a concrete compressive strength over 10000 psi at their test dates and a shear span to depth ratio over 3.0. Table 2.5 presents some details of the selected specimens. Test specimens were divided into three series depending on the amount of main longitudinal reinforcement. The first letter in each test specimen mark reflects the series to which the specimen belonged.

Table 2.5 Selected specimen details from Sarsam and Al-Musawi (1992)

\begin{tabular}{|c|c|c|c|c|c|c|c|c|}
\hline Specimen & $b_{w}$, in. & $d$, in. & $d_{v}$, in. & $f_{c}, p s i$ & $A_{s}$, in. $^{2}\left(\rho_{w}, \%\right)$ & $A_{v}$, in. $^{2}\left(\rho f_{y v}, p s i\right)$ & $V_{\text {exp, }}$ kip & $v_{\exp } / \sqrt{f_{c}}$ \\
\hline$A L 2-H$ & 7.09 & 9.25 & 8.33 & 10920 & $1.46(2.23)$ & $0.04(111)$ & 27.59 & 4.5 \\
\hline$B L 2-H$ & 7.09 & 9.15 & 8.24 & 10980 & $1.83(2.83)$ & $0.04(111)$ & 31.12 & 5.1 \\
\hline CL2-H & 7.09 & 9.15 & 8.24 & 10170 & $2.28(3.52)$ & 0.04 (111) & 33.12 & 5.6 \\
\hline
\end{tabular}

Longitudinal reinforcement of specimens of Series A was 3 No. 6 bars; for specimens in Series B was 2 No. 8 and one No. 5 bar, and for Series C specimens, it was 3 No. 8 bars. Main longitudinal reinforcement was anchored at both ends of the test specimens by means of 90-deg. hooks. To improve anchorage, 2 No. 8 bars transversally located at the ends were used to weld together all bars of the longitudinal reinforcement (Figure 2.9).

All specimens were provided with 2 No. 3 bars as negative reinforcement. Yield stress of the longitudinal reinforcement was reported to be in the range of 65.3 to $78.7 \mathrm{ksi}$. Shear reinforcement was provided by means of 0.16 -in. diameter cold-drawn smooth wire. Stirrups were closed and ended with 3.9-in. long legs bent with 135-deg. hooks. The measured yield strength of the smooth wire used to make the stirrups was $118.9 \mathrm{ksi}$. The amount of shear reinforcement provided in the specimens listed in Table 2.5 was approximately twice the minimum specified in the 1989 Edition of the American Concrete Institute Building Code ( $\mathrm{ACl} 318-89)$.

Specimens were tested in a simply supported configuration using two symmetrical point loads $15.8 \mathrm{in}$. apart. Several shear spans were evaluated in the range of 22.9 to $37.0 \mathrm{in}$. Therefore, corresponding a/d ratios were between 2.5 and 4.0. Figure 2.9 shows the test setup and reinforcement details of selected specimens listed in Table 2.5, which had a shear span to depth ratio of 4.0 .

All beams tested by Sarsam and Al-Musawi failed in shear. Initially flexural cracks appeared in the midspan region, extending outwards as load increased. Then, inclined cracks developed and extended towards the loading points. Close to failure, these cracks changed their orientation to become more horizontal towards the location of the longitudinal tension steel. Main inclined cracks had angles between 35 and $40 \mathrm{deg}$. to the longitudinal axis of the beams. 

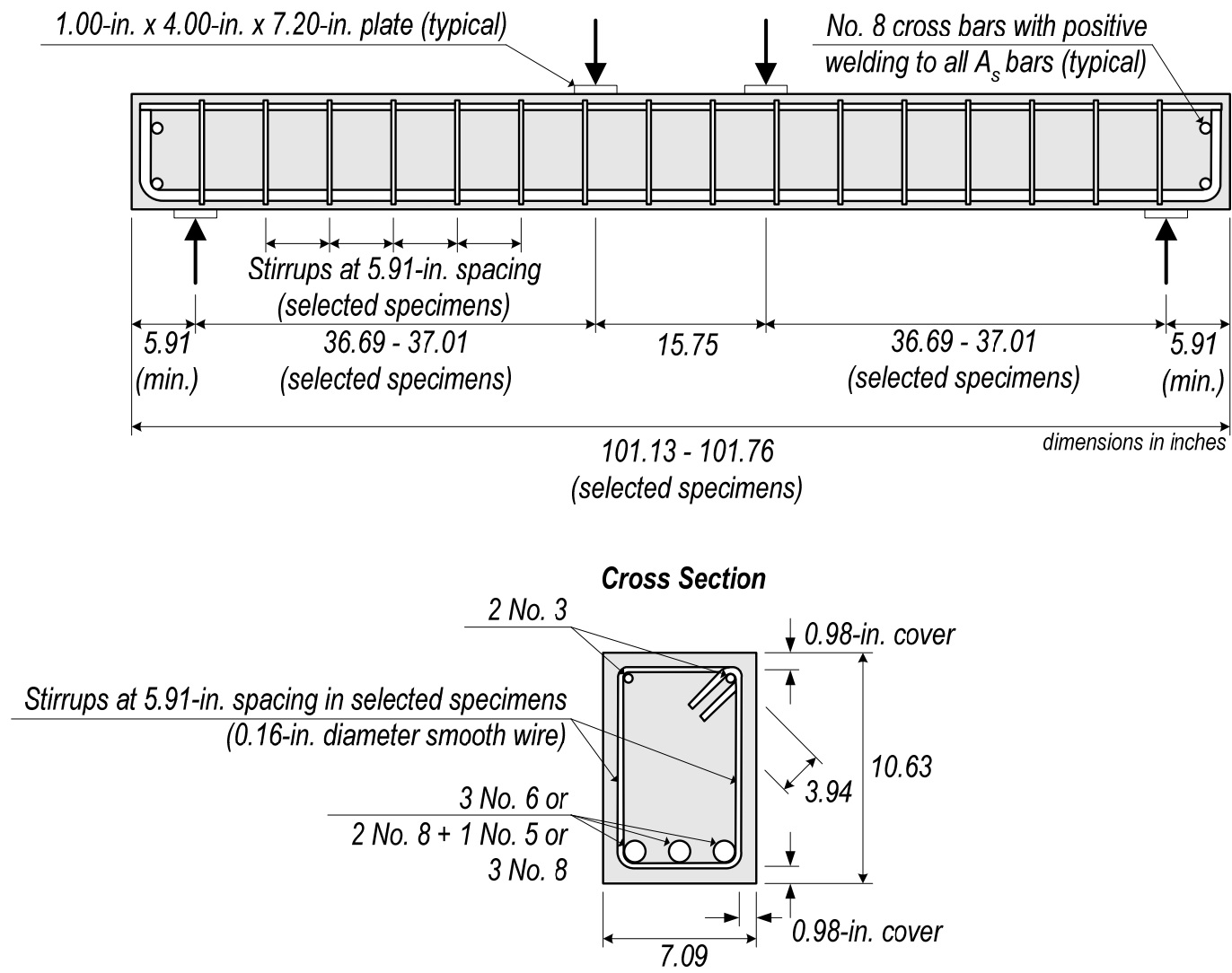

Figure 2.9 Reinforcement details and load configuration for selected specimens tested by Sarsam and Al-Musawi (adapted from Sarsam and Al-Musawi, 1992)

Observations from Sarsam and Al-Musawi allowed them to conclude that both $\mathrm{ACl}$ and Canadian building codes used at the time of publication of their research were conservative. In contrast with other researchers, Sarsam and Al-Musawi concluded that the increase in compressive strength of concrete up to 11600 psi did not reduce the degree of conservatism of the design equations in $\mathrm{ACl}$ 318-89.

\subsubsection{Kong and Rangan}

An experimental program was carried out at Curtin University of Technology, in Western Australia by Kong and Rangan (1997). The research project involved the testing of forty-eight rectangular beams. The original dimensions and material properties described by the authors of this research had SI units. The parameters under study included concrete cover to shear reinforcement, amount of both longitudinal and shear reinforcement, overall depth of members, shear span to depth ratio and compressive strength of concrete. Kong and Rangan tested eight series of six beams each using different load configurations. Out of the forty-eight specimens tested by Kong 
and Rangan, all six specimens of Series 7 were selected following the same criteria used in the review of other studies in this report.

Specimens in Series 7 were 9.8-in. wide by 13.8-in. deep. These specimens were 106.4-in. long including the two 15.0-in. long overhangs they had at both ends. Free span between supports was 76.4-in. long, with a corresponding a/d ratio of 3.4. Specimens were tested using a simply supported configuration with a point load at midspan. Figure 2.10 shows details of the specimens in Series 7 of Kong and Rangan.
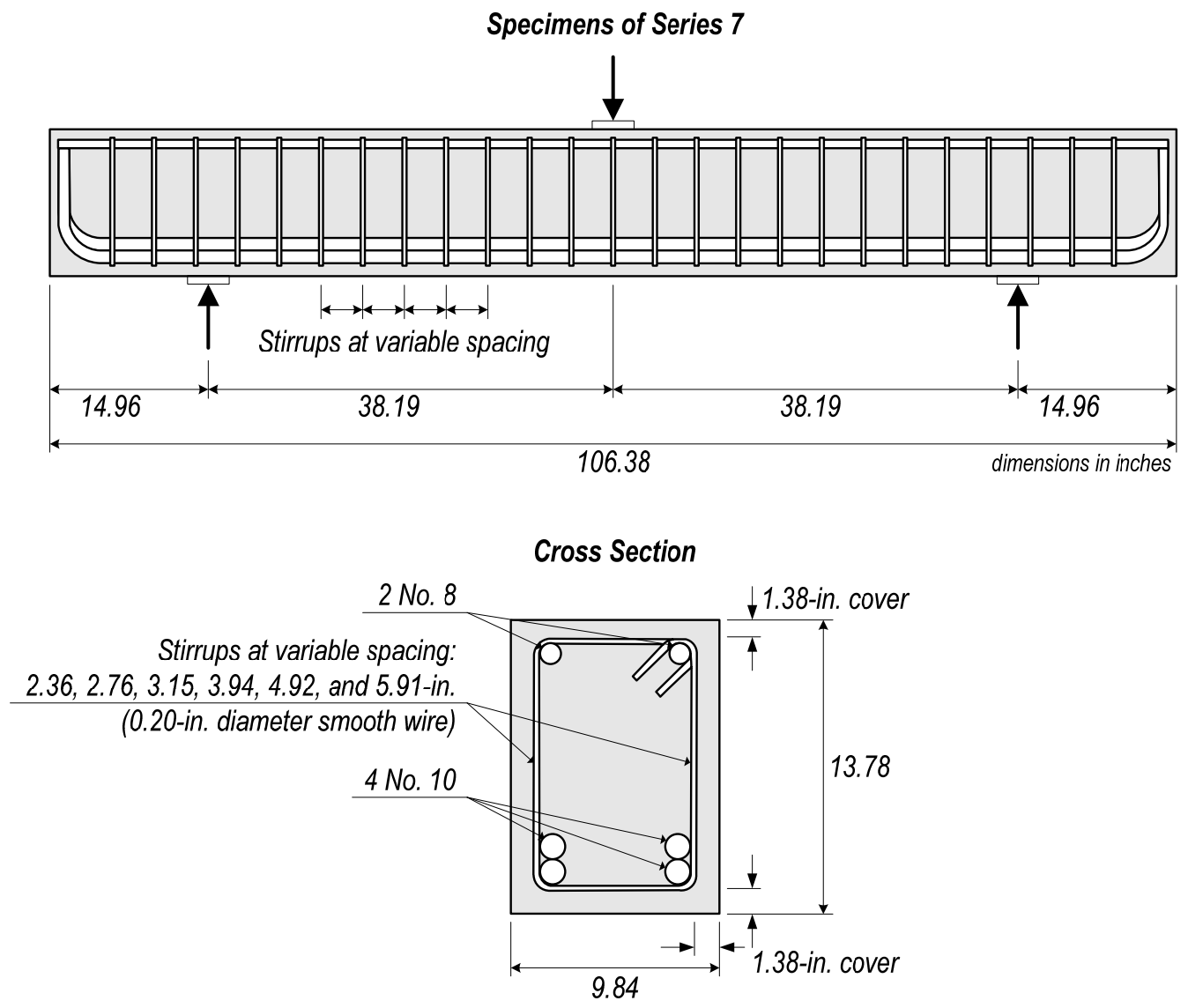

Figure 2.10 Reinforcement details and load configuration for selected specimens tested by Kong and Rangan (adapted from Kong and Rangan, 1997)

Compressive strength of concrete in Series 7 had a measured average of 10850 psi. Main longitudinal reinforcement was provided by 4 No. 10 deformed bars bundled in pairs. Longitudinal reinforcement was anchored by means of $90-\mathrm{deg}$. hooks at both overhanging ends. Additional top longitudinal reinforcement was provided with 2 No. 8 deformed bars. Measured yield strength of the longitudinal reinforcement was 64.1 and $62.8 \mathrm{ksi}$ for No. 8 and No. 10 bars, respectively. 
In Series 7, rectangular closed stirrups with 135-deg. hooks at their ends were used as shear reinforcement. Stirrups were made with 0.20 -in. diameter smooth hard-drawn high-tensile wires. Yield strength of stirrups was obtained to be $82.5 \mathrm{ksi}$. The $0.2 \%$ strain offset method was used in obtaining this figure since the wires did not show a clear yielding point. Each specimen in this series had a different stirrup spacing, which ranged from 2.4 to $5.9 \mathrm{in}$. Table 2.6 presents some details of the selected test specimens.

Table 2.6 Selected specimen details from Kong and Rangan (1997)

\begin{tabular}{|c|c|c|c|c|c|c|c|c|}
\hline Specimen & $b_{w}$, in. & d, in. & $d_{v}$, in. & $f_{c}, p s i$ & $A_{s}$, in. $^{2}\left(\rho_{w}, \%\right)$ & $A_{v}$, in. $^{2}\left(\rho f_{y v}, p s i\right)$ & $V_{\text {exp, }}$ kip & $v_{\exp } / \sqrt{f_{c}}$ \\
\hline$S 7-1$ & 9.84 & 11.96 & 10.76 & 10850 & $4.99(4.24)$ & $0.06(86)$ & 48.87 & 4.4 \\
\hline$S 7-2$ & 9.84 & 11.96 & 10.76 & 10850 & $4.99(4.24)$ & $0.06(104)$ & 46.22 & 4.2 \\
\hline$S 7-3$ & 9.84 & 11.96 & 10.76 & 10850 & 4.99 (4.24) & $0.06(130)$ & 55.46 & 5.0 \\
\hline S7-4 & 9.84 & 11.96 & 10.76 & 10850 & $4.99(4.24)$ & $0.06(162)$ & 61.56 & 5.6 \\
\hline$S 7-5$ & 9.84 & 11.96 & 10.76 & 10850 & $4.99(4.24)$ & $0.06(185)$ & 68.49 & 6.2 \\
\hline$S 7-6$ & 9.84 & 11.96 & 10.76 & 10850 & $4.99(4.24)$ & $0.06(216)$ & 69.89 & 6.3 \\
\hline
\end{tabular}

Specimens were loaded monotonically to failure using a 560-kip capacity Avery testing machine. Proper dispersion of force was achieved using 4-in. wide and 3/4-in. thick steel plates between the loading machine and the top surface of the specimens. These plates rested on rubber pads or plywood strips absorbing the irregularities associated with the finish of the top surface of the test specimens. A similar configuration, replacing the rubber pads or plywood strips by a high-strength quick-set gypsum cement grout (Hydrostone) was used throughout the present research project.

In Series 7, the trend of increasing shear strength with increase in the amount of shear reinforcement was evident. An increase in the shear strength of over $40 \%$ was observed when the amount of shear reinforcement was increased by a factor of 2.5. A slight increase in the maximum deflection was also observed as the amount of shear reinforcement increased.

The cracking pattern in all beams of Series 7 was somewhat similar. At early stages of the test, vertical cracks due to flexure were observed close to midspan; then, inclined cracks were formed at the ends of flexural cracks and extended towards the point loads. The beams with larger amounts of shear reinforcement showed more inclined cracks. Also, the width of cracks decreased as the amount of shear reinforcement increased.

In the range of 8700 to $13050 \mathrm{psi}$ and contrary to conventional wisdom, the compressive strength of concrete had little influence on the shear strength of the test specimens. Kong and Rangan suggested that the presence of bundled bars as longitudinal reinforcement might have had a positive impact in the shear strength of their test specimens. As part of their recommendations for 
further research, Kong and Rangan proposed the testing of specimens with thin webs such as Isection, and the testing of axially loaded and prestressed beams. The present research project addresses partially two of their recommendations.

\subsubsection{Malone}

Malone (1999) conducted a series of tests with the objective of studying the effect of lightweight aggregate on the shear strength of reinforced and prestressed concrete beams. However, some of the specimens tested by Malone were made with normal weight aggregate and HSC. An additional source of information on this research project was found to be Ramirez et al. (1999).

The experimental program consisted of the test to failure of twelve reinforced concrete and four prestressed concrete specimens. The variables under study were the effects of aggregate type, concrete compressive strength and amounts of both longitudinal and transverse reinforcement. Only one reinforced concrete beam and two prestressed concrete beams had compressive strengths of concrete over 10000 psi. However, only the two prestressed specimens had a shear span to depth ratio over 3.0. Attention was focused on these beams despite the fact that they were constructed using sand-lightweight aggregate (Haydite).

The prestressed specimens tested by Malone were composed of an AASHTO Type I prestressed girder and a 4-in. thick, 48-in. wide cast-in-place topping slab designed to act compositely with the beam. The two prestressed beams selected were cast simultaneously and had a measured concrete compressive strength of $10100 \mathrm{psi}$. The measured compressive strength of concrete corresponding to the cast-in-place slabs ranged from 4960 to $6050 \mathrm{psi}$.

For the two beams considered, mild longitudinal reinforcement was provided by means of 3 No. 8 deformed bars for positive moment and 2 No. 5 bars for negative moment. No. 5 bars were also used to reinforce the topping slab. All mild reinforcement was Gr. 60. Measured yield strength for the No. 8 bars was $75.4 \mathrm{ksi}$. Prestressing was done using eight 1/2-in. diameter special strands in the bottom flange. Two more strands of the same type and size were provided in the top flange. All prestressing strands were seven-wire, low-relaxation and Gr. 270. One of the selected specimens did not have shear reinforcement. The shear reinforcement in the other selected specimen was provided by open Gr. 60, No. 3 stirrups. Measured yield strength for the stirrups was $72.8 \mathrm{ksi}$. Table 2.7 presents some details of the selected specimens.

Table 2.7 Selected specimen details from Malone (1999)

\begin{tabular}{ccccccccc}
\hline Specimen & $\boldsymbol{b}_{w}$, in. & d, in. & $\boldsymbol{d}_{v}$, in. & $\boldsymbol{f}_{c}$, psi & $\boldsymbol{A}_{\boldsymbol{s}}$, in. ${ }^{2}\left(\rho_{w}, \%\right)$ & $\boldsymbol{A}_{v}$, in. ${ }^{2}\left(\rho f_{y v}\right.$, psi) & $V_{\text {exp }, \text { kip }}$ & $V_{\text {exp }} / \sqrt{f_{c}}$ \\
\hline PC10N & 6.00 & 28.75 & 23.04 & 10100 & $2.37(1.37)$ & $0.00(0)$ & 104.63 & 7.5 \\
PC10S & 6.00 & 28.75 & 23.04 & 10100 & $2.37(1.37)$ & $0.22(133)$ & 120.15 & 8.6 \\
\hline
\end{tabular}


The selected prestressed specimens were simply supported and subjected to a single point load at midspan. A 600-kip Baldwin testing machine was used to apply the load. Figure 2.11 shows some details of the reinforcement and the load configuration of the two selected specimens.
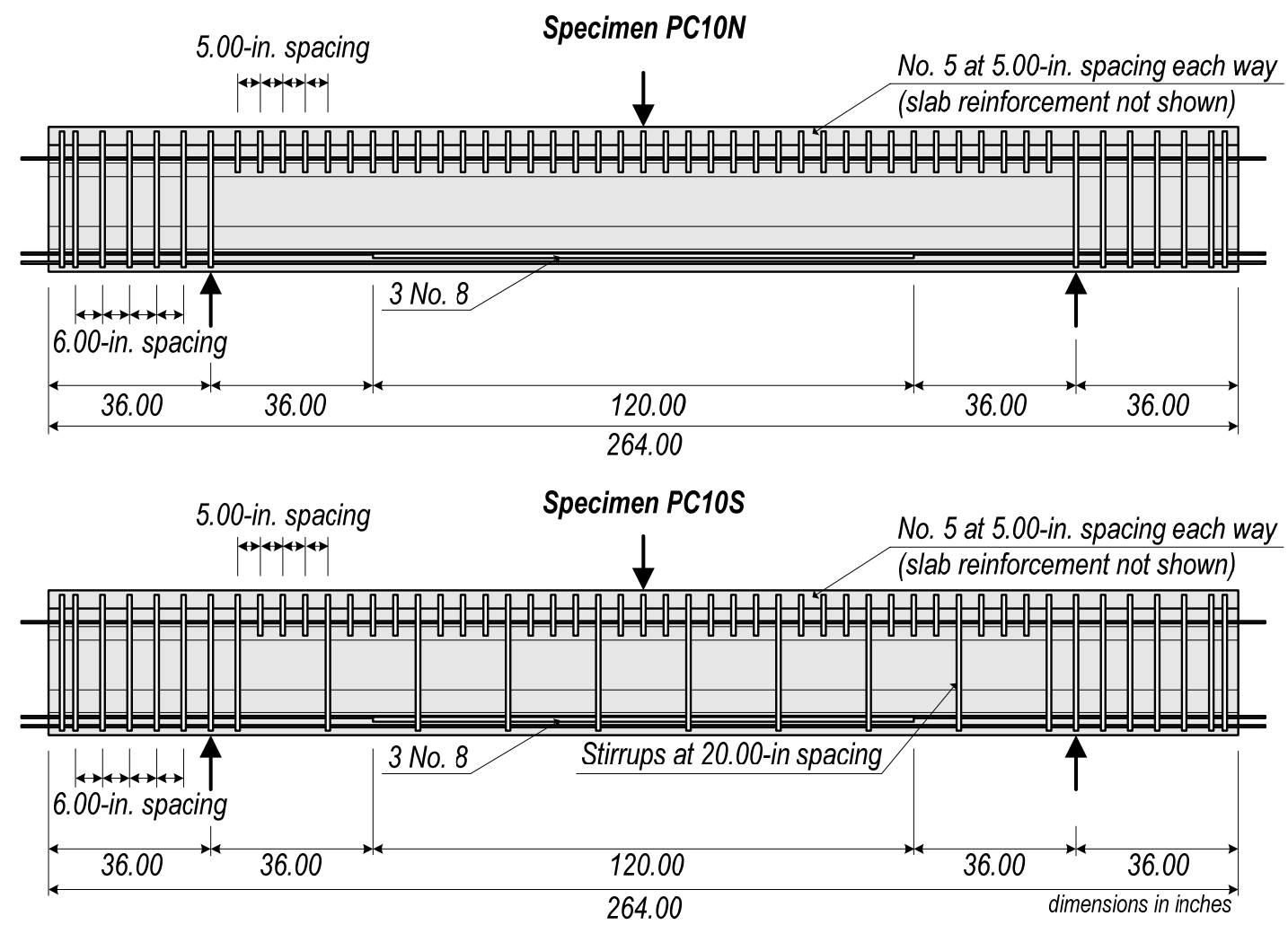

Cross Section

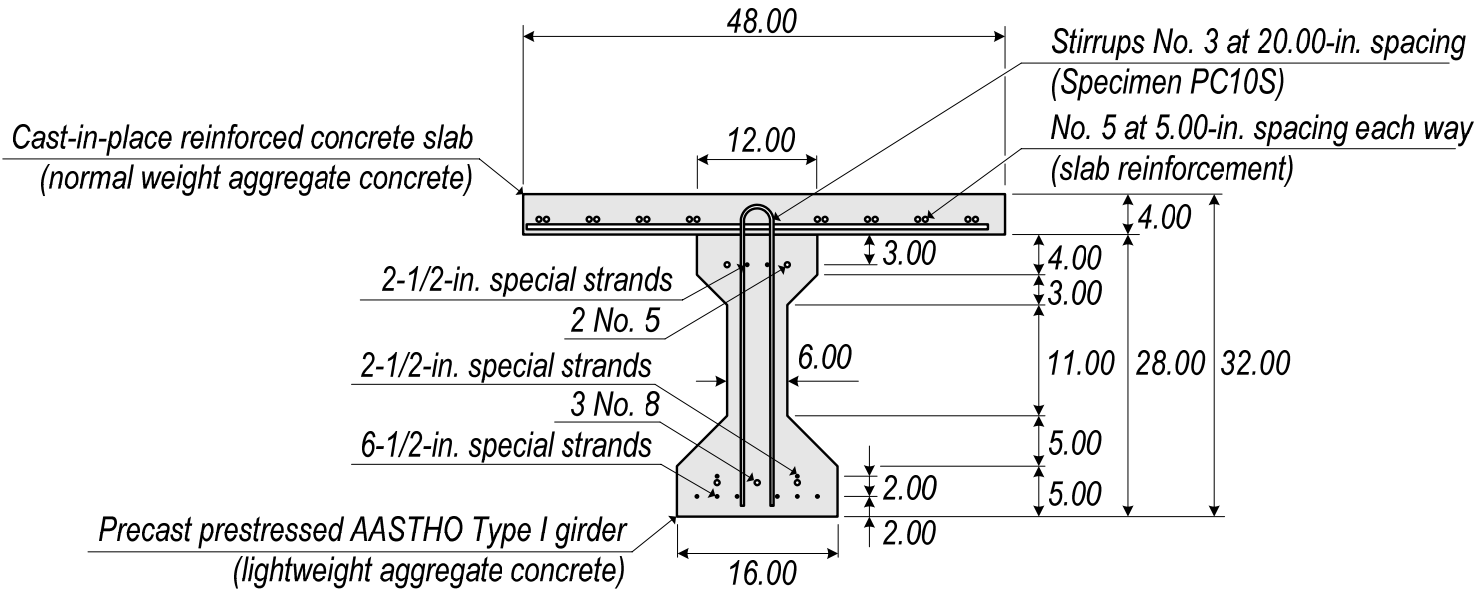

Figure 2.11 Reinforcement details and load configuration for selected specimens tested by Malone (adapted from Malone, 1999) 
Malone observed that the shear capacity of the prestressed specimens did not changed significantly when the compressive strength of concrete was changed. For all test specimens both the 1995 Edition of the American Concrete Institute Building Code (ACI 318-95) and the 1994 Edition of the LRFD Bridge Design Specifications of the American Association for State Highway and Transportation Officials (1994 AASHTO LRFD) proved to be conservative.

Malone recommended that the minimum amount of shear reinforcement specified in design codes be increased to enhance the post-cracking reserve strength. This reserve was observed to be limited in some of his test specimens. Malone considered that additional tests using the minimum amount of shear reinforcement in HSC members were necessary. The current research project included the testing to failure of HSC beams reinforced with the minimum amount of shear reinforcement.

Despite the fact that Malone's research involved the use of lightweight aggregates and that the current project does not focus on that variable, his investigation was included as a good reference where the effect of shear reinforcement in prestressed concrete beams is evaluated by comparing a specimen without shear reinforcement (PC10N) with a second with shear reinforcement (PC10S with p prfyv of 133 psi).

\subsubsection{Ozcebe et al.}

An experimental program was carried out at the Middle East Technical University (Ozcebe et al., 1999). The research included the test to failure of thirteen reinforced concrete beams. Dimensions and material properties were originally given in SI units. Main focus was to review code requirements for the minimum amount of shear reinforcement and verify that adequate reserve shear strength beyond inclined cracking was developed. The minimum shear requirements in $\mathrm{ACl} 318-83, \mathrm{ACl} 318-95$, the 1993 Turkish Code and the 1994 Canadian Code were reviewed. Main variables under study were concrete compressive strength, the amount of both longitudinal and transverse reinforcement, and the a/d ratio. Three shear span to depth ratios were evaluated: $1.9,3.0$, and 5.0.

Test specimens were organized in five series according to their nominal concrete compressive strength and the shear span to depth ratio used during the test. The mark for each specimen consisted of a sequence of letters and two numbers. The letters corresponded to the expression used for the design ( $\mathrm{ACl}$, Turkish Code or proposed equation); the first number indicated the $\mathrm{a} / \mathrm{d}$ ratio, and the second number reflected the nominal compressive strength of concrete as a tenth of its value in MPa. Details of selected specimens are presented in Table 2.8.

Test specimens were rectangular in shape with a $5.9 \mathrm{in}$. width and a $14.2 \mathrm{in}$. depth. Measured compressive strength of concrete ranged from 8410 to $11890 \mathrm{psi}$. Positive longitudinal 
reinforcement was provided by means of No. 5 and No. 6 hot rolled steel bars. Top longitudinal reinforcement was the same for all test specimens: 2 No. 3 bars. Yield strength of the longitudinal reinforcement was obtained to be in the range of 59.5 to $62.3 \mathrm{ksi}$.

Shear reinforcement was provided by stirrups made with 0.16-in. diameter bars with yield strength of $37.0 \mathrm{ksi}$. Spacing of stirrups varied from 2.4 to $4.7 \mathrm{in}$. in various specimens. Figure 2.12 shows the reinforcement details of selected specimens.

Specimens were tested under a two-point loading scheme using a simply supported configuration. A specially built test frame was used where loads were applied using a 110-kip hydraulic jack and measured by load cells.

Table 2.8 Selected specimen details from Ozcebe et al. (1999)

\begin{tabular}{|c|c|c|c|c|c|c|c|c|}
\hline Specimen & $b_{w}$, in. & d, in. & $d_{v}$, in. & $f_{c}, p s i$ & $A_{s}$, in. $^{2}\left(\rho_{w}, \%\right)$ & $A_{v}$, in. $^{2}\left(\rho f_{y v}, p s i\right)$ & $V_{\text {exp }}, k i p$ & $v_{\text {exp }} / \sqrt{f_{c}}$ \\
\hline$A C l 36$ & 5.91 & 12.20 & 10.98 & 10880 & $1.87(2.59)$ & $0.04(52)$ & 23.69 & 3.5 \\
\hline TH36 & 5.91 & 12.20 & 10.98 & 10880 & $1.87(2.59)$ & $0.04(62)$ & 31.70 & 4.7 \\
\hline TS36 & 5.91 & 12.20 & 10.98 & 10880 & $1.87(2.59)$ & $0.04(89)$ & 35.08 & 5.2 \\
\hline$A C / 39$ & 5.91 & 12.20 & 10.98 & 10590 & $2.22(3.08)$ & $0.04(52)$ & 25.16 & 3.8 \\
\hline TH39 & 5.91 & 12.20 & 10.98 & 10590 & $2.22(3.08)$ & $0.04(77)$ & 32.15 & 4.8 \\
\hline TS39 & 5.91 & 12.20 & 10.98 & 10590 & $2.22(3.08)$ & 0.04 (103) & 40.32 & 6.0 \\
\hline$A C / 59$ & 5.91 & 12.20 & 10.98 & 11890 & $3.19(4.43)$ & $0.04(52)$ & 21.71 & 3.1 \\
\hline TH59 & 5.91 & 12.20 & 10.98 & 10880 & $3.19(4.43)$ & $0.04(69)$ & 26.84 & 4.0 \\
\hline TS59 & 5.91 & 12.20 & 10.98 & 11890 & $3.19(4.43)$ & $0.04(103)$ & 28.22 & 4.0 \\
\hline
\end{tabular}

The mode of failure of beams in Series $\mathbf{5 9}$ was characterized as diagonal tension where the yield strength of the main longitudinal reinforcement was not reached before failure. Initially, flexural cracks were observed in the maximum moment region. These cracks later extended into the shear spans and gradually became inclined towards the load points.

In general, diagonal tension was the mode of failure in Series $\mathbf{3 6}$ and Series 39. However, Specimen ACl36 failed in shear-compression. Damage evolution was similar to the one described for Series 59. Final failure took place when one of the inclined cracks widened while some horizontal cracks appeared at the location of the main longitudinal reinforcement. The steel plates welded to the end of the longitudinal bars prevented the horizontal cracks from extending to the end of the beams, which could have triggered anchorage failures. In the current research project, some of the longitudinal bars had mechanical anchorages (Lenton ${ }^{\circledR}$ Terminators $^{\mathrm{TM}}$ ). 
In all series, specimens designed with the $\mathrm{ACl}$ 318-89 or the $\mathrm{ACl}$ 318-95 Codes had fewer and wider cracks than comparable specimens designed with other equations. Ozcebe et al. concluded that the minimum amount of shear reinforcement specified in ACl 318-89 or ACl 318-95 was not satisfactory when using HSC. Not only reduced reserve strength after first inclined cracking, but a much larger crack width than the permissible at serviceability conditions $(0.01 \mathrm{in}$.) was observed. Ozcebe et al. also suggested the use of reserve strength -difference between ultimate shear and shear at inclined cracking- as the most important parameter in determining the minimum shear reinforcement.

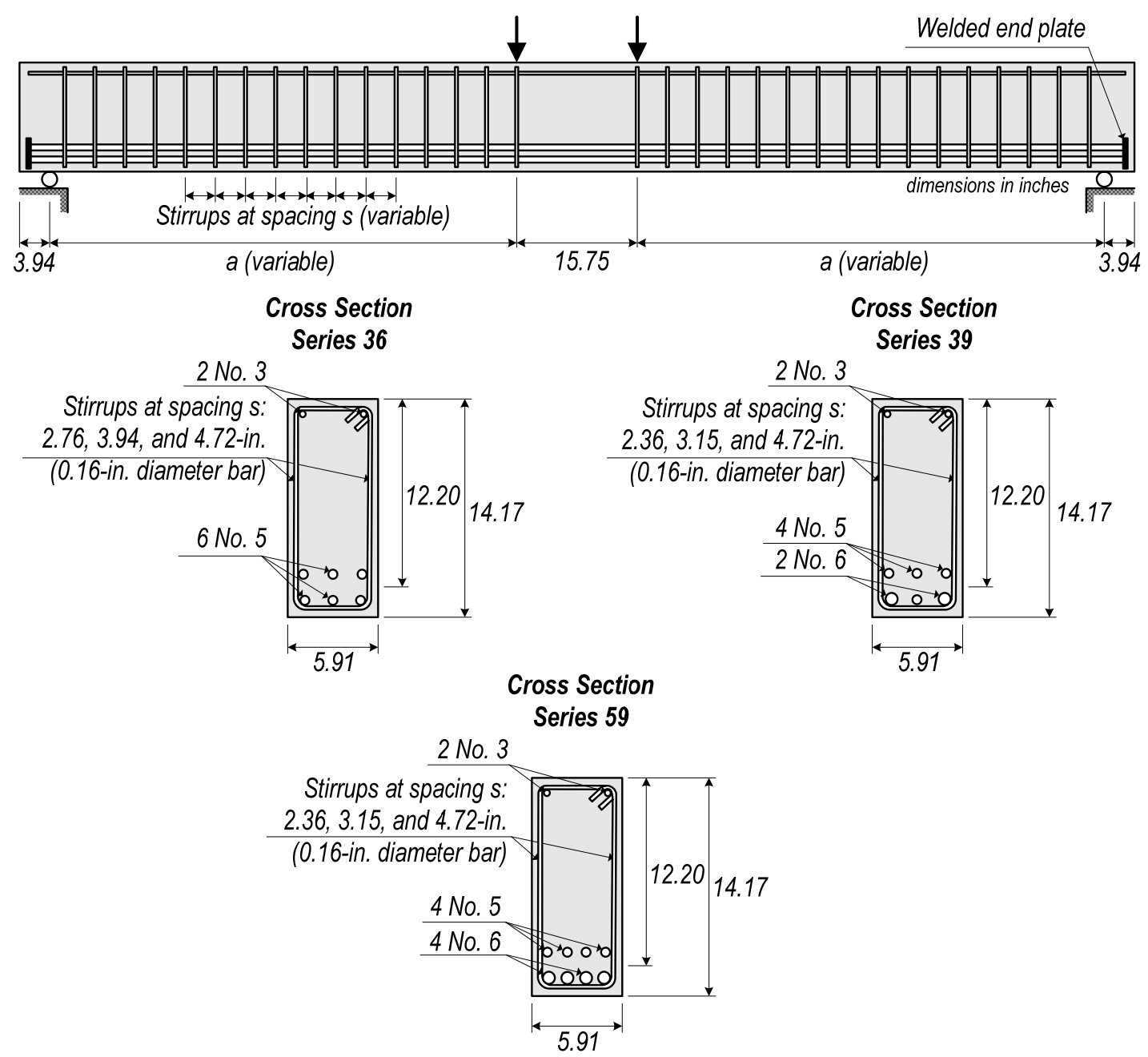

Figure 2.12

Reinforcement details and load configuration for selected specimens tested by Ozcebe et al. (adapted from Ozcebe et al., 1999) 


\subsubsection{Summary of other Testing Programs}

Brief summaries of eight experimental programs involving testing of reinforced concrete and prestressed concrete specimens were presented. The variables under study were the compressive strength of concrete, the shear span to depth ratio, and the amount of longitudinal and transverse reinforcement.

In the review of previous research, only measured concrete compressive strengths over $10000 \mathrm{psi}$ and $a / d$ ratios over 3.0 were considered. Compressive strength of concrete ranged from 10080 to $13590 \mathrm{psi}$, and a/d ratios were in the range of 3.0 to 5.0. Longitudinal (mild) reinforcement ratios varied from 0.00 to $6.62 \%$, whereas transverse reinforcement indices, $\rho f_{v}$, ranged from 0 to $497 \mathrm{psi}$.

The ratio of the failure average shear stress to the square root of the compressive strength of concrete in psi was computed for each of the selected specimens and was used as a parameter to quantify the ability of concrete members to carry shear stresses. This ratio ranged from 2.0 (Specimen F9 by Elzanaty et al.) on a reinforced concrete beam without shear reinforcement, to 15.7 (Specimen CW14 by Elzanaty et al.) on a prestressed specimen with the highest transverse reinforcement ratio. Table 2.9 presents a summary of relevant data of the research projects reviewed.

Table 2.9 Summary of previous research projects reviewed

\begin{tabular}{|c|c|c|c|c|c|c|}
\hline Researcher & Specimens Selected & $a / d$ & $f_{c}, p s i$ & $\rho w, \%$ & $\rho_{u} f_{y v}, p s i$ & $v_{\text {exp }} / \sqrt{f_{c}}$ \\
\hline Mphonde & 13 & 3.6 & $10080-13590$ & 3.36 & $0-157$ & $3.0-5.7$ \\
\hline Elzanaty & 27 & $4.0-6.0$ & $10100-11600$ & $0.00-5.43$ & $0-497$ & $2.0-15.7$ \\
\hline Ahmad & 8 & 3.0-4.0 & $10140-10560$ & $2.27-6.62$ & 0 & $2.6-5.2$ \\
\hline Johnson & 2 & 3.1 & $10490-10490$ & 2.49 & 54 & $2.5-3.0$ \\
\hline Sarsam & 3 & 4.0 & $10170-10980$ & $2.23-3.52$ & 111 & $4.5-5.6$ \\
\hline Kong & 6 & 3.4 & 10850 & 4.24 & $86-216$ & $4.2-6.3$ \\
\hline Malone & 2 & 3.0 & 10100 & 1.37 & 133 & $7.5-8.6$ \\
\hline Ozcebe & 9 & $3.0-5.0$ & $10590-11890$ & $2.59-4.43$ & $52-103$ & $3.1-6.0$ \\
\hline
\end{tabular}

From the findings, conclusions and recommendations of the projects reviewed, and from the authors' own review of their results, the following conclusions and observations were made:

- Different experimental evidence has been obtained on the effect of the compressive strength of concrete on the shear strength of concrete members. Some authors have observed an increase in shear strength with the increase of compressive strength of concrete (Mphonde and Frantz, 1984; Elzanaty et al., 1985) but others have not observed a clear influence of this variable, or even consider it to be unimportant (Kong 
and Rangan, 1997). The research projects reviewed have included specimens with concrete compressive strength up to $13590 \mathrm{psi}$. With the current production and increase use of concrete of even larger compressive strengths, this research project focused on concrete members with compressive strengths in the range of 10000 to $15000 \mathrm{psi}$.

- The minimum amount of shear reinforcement specified in American design codes was observed to limit the reserve strength of reinforced concrete specimens after the first inclined cracking and to have excessively large crack widths (Johnson and Ramirez, 1989; Ozcebe et al., 1999). The objective of the lower limit for the amount of shear reinforcement in the design of reinforced and prestressed concrete members is to provide minimum reserve strength after the first inclined cracking is observed. As noted before, some investigators have concluded that the current minimum amounts of shear reinforcement may not be adequate, especially for HSC beams where the first inclined cracking may be observed at lower shear stresses that it NSC members.

- The shear strength provided by the transverse reinforcement increased as the amount of shear reinforcement increased. However, it has been observed that the trend of such increase is not always the same (Elzanaty et al., 1985). As the amount of shear reinforcement was increased, the maximum stress in the stirrups decreased. This loss in the effectiveness of shear reinforcement was compensated with more uniform cracking patterns and reduced crack widths.

- Few research projects have addressed the web crushing problem associated with large amounts of shear reinforcement. Elzanaty et al. tested prestressed beams with measured concrete compressive strengths up to $10700 \mathrm{psi}$ and amounts of shear reinforcement with $p_{v} f_{y v}$ up to 497 psi. Only one selected specimen (CW10) showed an evident web crushing failure. In the present investigation, the behavior of reinforced concrete and prestressed concrete specimens with large shear reinforcement ratios is evaluated.

- All the eight projects reviewed tested simply supported beams under either a midspan point load or a symmetrical two-point load configuration. Few research projects have evaluated the behavior of HSC beams under the combination of high shear and moment at the same section.

- Experimental evaluations of the design equations in several codes showed that most of these expressions become less conservative in terms of the ratio test/calculated capacity as the shear span to depth ratio increases, or the amount of longitudinal reinforcement decreases. The latter particularly noted for specimens without shear reinforcement. In 
this research project, the 2004 AASHTO Specifications and the ACI 318-05 Code are evaluated in terms of the test/calculated shear capacity ratio.

The highest compressive strength of concrete measured at test date throughout this research program was $17040 \mathrm{psi}$, which is $25 \%$ larger than the highest concrete compressive strength used for the construction of test specimens among the reviewed research projects. The experimental program of this research studied the behavior of reinforced and prestressed concrete beams with the minimum amount of shear reinforcement specified in U.S. design codes. This review was done in light of the use of even higher concrete compressive strengths and from the standpoint of reserve strength and crack width control. Six test specimens were reinforced with the minimum amount of shear reinforcement as prescribed by 2004 AASHTO LRFD and ACI 318-05 in the range of 10000 to 15000 psi.

Also in this research project, the upper limit for the amount of shear reinforcement beyond which it would not be of practical or economical use was investigated. Four tests specimens were reinforced with large amounts of shear reinforcement. The effect of prestressing on the shear behavior of HSC beams was evaluated through the testing of prestressed members with measured compressive strengths of concrete up to $17040 \mathrm{psi}$ and shear reinforcement indices, prfyv, up to 1305 psi.

Since few researchers have studied the behavior of HSC beams under the combination of high shear and moment at the same section, one of the test setups devised for this research project allowed for the test of beams in both a cantilever and a simply supported configuration. Four reinforced concrete specimens were tested as cantilevers where the critical section for shear is also under high moment.

\subsection{Codes Approach to Design for Shear}

In United States, there are several design codes that may be used for the design for shear of concrete members. However, only two documents are reviewed here, as they are commonly used for the design for shear in concrete members; namely the Second Edition of the American Association of State Highway and Transportation Officials of the Load and Resistance Factor Design Bridge Design Specifications (AASHTO, 2004), and the current edition of the American Concrete Institute Building Code Requirements for Structural Concrete and Commentary ( $\mathrm{ACl}$ Committee 318, 2005). Reference to the actual equation numbering in these two codes is included in brackets. 


\subsubsection{American Association of State Highway and Transportation Officials}

The Second Edition of the Load and Resistance Factor Specifications for Bridge Design of the American Association of State Highway Officials and Transportation (2004 AASHTO LRFD) is the current reference document for bridge design. The notation used by 2004 AASHTO LRFD is used throughout this section. Each notation is defined only the first time it is used.

The 2004 AASHTO LRFD Specifications contain two different approaches for the design for shear (Section 5.8.1.1). In flexural regions where the assumptions of traditional beam theory are valid, either a sectional model or a strut-and-tie model may be used for design. In disturbed regions such as the vicinity of concentrated loads or supports, the members under design should be considered deep components and require a special design procedure. Only the sectional model is presented here.

In 2004 AASHTO LRFD, the design for shear based on the sectional approach may be carried out through two procedures. The first one, namely the Simplified Procedure (Section 5.8.3.4.1), is permitted for the design of nonprestressed members with depth less than 16 in. However, the 2004 AASHTO LRFD Specifications also include a General Procedure (Section 5.8.3.4.2) based on the Modified Compression Field Theory (MCFT) initially introduced by Collins and Mitchell (1991). A summary of the MCFT is also presented in Collins et al. (1996). In both procedures, the contributions of concrete, shear reinforcement and prestressing steel to shear resistance are additive.

Section 5.8.3.3 of 2004 AASHTO LRFD defines the nominal shear resistance, $V_{n}$, of a concrete member as:

but no more than: $\quad V_{n}=0.25 f^{\prime}{ }_{c} b_{v} d_{v}+V_{p}$

Where: $f_{c}^{\prime}$ is the specified compressive strength of concrete at 28 days, unless another age is specified (ksi),

$b_{v}$ is the effective web width, taken as the minimum web width within the depth, $d_{v}$ (in.),

$d_{v}$ is the effective shear depth (in.), and

$V_{p}$ is the component in the direction of the applied shear of the effective prestressing force, taken positive is resisting the applied shear (kip).

In Equations 2.4 and 2.5, the concrete $\left(V_{c}\right)$ and shear reinforcement $\left(V_{s}\right)$ contributions to shear resistance are given by:

$$
V_{c}=0.0316 \beta \sqrt{f^{\prime}} b_{v} d_{v}
$$




$$
V_{s}=\frac{A_{v} f_{y v} d_{v}(\cot \theta-\cot \alpha) \sin \alpha}{s}
$$

Where: $\beta$ is a factor indicating the ability of diagonally cracked concrete to transmit tension,

$A_{v}$ is area of shear reinforcement within a distance $s$ (in. ${ }^{2}$ ),

$f_{y v}$ is the specified minimum yield strength of shear reinforcement $(k s i)$,

$\theta$ is the angle of inclination of diagonal compressive stresses (deg.),

$\alpha$ is the angle of inclination of shear reinforcement to longitudinal axis (deg.), and

$s \quad$ is the spacing of stirrups (in.).

Usually, the shear reinforcement is perpendicular to the longitudinal axis of the member, thus $\alpha=90$ deg. In this document, all equations assume the latter, which reduces Eq. 2.7 to:

$$
V_{s}=\frac{A_{v} f_{y v} d_{v} \cot \theta}{s}
$$

The values of $\beta$ and $\theta$ depend on the procedure followed. In the Simplified Procedure, $\beta=2.0$ and $\theta=45$ deg. Eq. 2.6 and 2.7 are then further simplified to:

$$
\begin{gathered}
V_{c}=0.0632 \sqrt{f^{\prime}{ }_{c}} b_{v} d_{v} \\
V_{s}=\frac{A_{v} f_{y v} d_{v}}{s}
\end{gathered}
$$

If the General Procedure is followed, parameters $\beta$ and $\theta$ have to be determined. 2004 AASHTO LRFD provides Table 5.8.3.4.2-1 and Table 5.8.3.4.2-2 for this purpose. In general, $\beta$ and $\theta$ are both functions of the strain at the centroid of the main longitudinal reinforcement, $\varepsilon x$; the shear stress on the concrete, $v_{i}$; the spacing between layers of longitudinal crack control reinforcement, $s_{x} ;$ and the maximum aggregate size in the concrete, ag.

The use of one table or the other depends on the amount of shear reinforcement provided. If the minimum amount of shear reinforcement is provided, Table 5.8.3.4.2-1 (Table 2.10) must be used and $\beta$ and $\theta$ are function of $\varepsilon_{x}$ and $v_{c}$ only. Table 5.8.3.4.2-1 and Table 5.8.3.4.2-2 are reproduced here as Table 2.10 and Table 2.11, respectively.

If the minimum amount of shear reinforcement is not provided, Table 2.11 must be used. In this table, $\beta$ and $\theta$ are function of $x_{s}$ and $a_{g}$ only. The requirement for the minimum transverse reinforcement (Section 5.8.2.5) is expressed as follows:

$$
A_{v}=0.0316 \sqrt{f^{\prime}}{ }_{c} \frac{b_{v} s}{f_{y v}}
$$

Additional requirements for the amount of shear reinforcement are provided in terms of a maximum spacing of transverse reinforcement (Section 5.8.2.7). The 2004 AASHTO LRFD 
Specifications recognize the need for more closely spaced shear reinforcement to provide crack control in highly stressed sections and therefore gives two spacing limits depending on the maximum concrete shear stress, $v_{u}$. If $v_{u}<0.125 f_{c}^{\prime}$, then the maximum spacing for shear reinforcement is $0.8 d_{v}$, but not more than 24 in. If $v_{u} \geq 0.125 f_{c}^{\prime}$, the maximum spacing is reduced to half $\left(0.4 d_{v}\right.$, but not more than 12 in.).

Table 2.10 Values of $\theta$ and $\beta$ for sections with transverse reinforcement (2004 AASHTO LRFD Table 5.8.3.4.2-1)

\begin{tabular}{|c|c|c|c|c|c|c|c|c|c|}
\hline \multicolumn{10}{|c|}{ Values of $\theta$} \\
\hline \multirow{2}{*}{$\frac{v_{u}}{f_{c}^{\prime}}$} & \multicolumn{9}{|c|}{$\varepsilon_{x} \times 1000$} \\
\hline & $\leq-0.20$ & $\leq-0.10$ & $\leq-0.05$ & $\leq 0.00$ & $\leq 0.125$ & $\leq 0.25$ & $\leq 0.50$ & $\leq 0.75$ & $\leq 1.00$ \\
\hline$\leq 0.075$ & 22.3 & 20.4 & 21.0 & 21.8 & 24.3 & 26.6 & 30.5 & 33.7 & 36.4 \\
\hline$\leq 0.100$ & 18.1 & 20.4 & 21.4 & 22.5 & 24.9 & 27.1 & 30.8 & 34.0 & 36.7 \\
\hline$\leq 0.125$ & 19.9 & 21.9 & 22.8 & 23.7 & 25.9 & 27.9 & 31.4 & 34.4 & 37.0 \\
\hline$\leq 0.150$ & 21.6 & 23.3 & 24.2 & 25.0 & 26.9 & 28.8 & 32.1 & 34.9 & 37.3 \\
\hline$\leq 0.175$ & 23.2 & 24.7 & 25.5 & 26.2 & 28.0 & 29.7 & 32.7 & 35.2 & 36.8 \\
\hline$\leq 0.200$ & 24.7 & 26.1 & 26.7 & 27.4 & 29.0 & 30.6 & 32.8 & 34.5 & 36.1 \\
\hline$\leq 0.225$ & 26.1 & 27.3 & 27.9 & 28.5 & 30.0 & 30.8 & 32.3 & 34.0 & 35.7 \\
\hline$\leq 0.250$ & 27.5 & 28.6 & 29.1 & 29.7 & 30.6 & 31.3 & 32.8 & 34.3 & 35.8 \\
\hline \multicolumn{10}{|c|}{ Values of $\beta$} \\
\hline$v_{u}$ & \multicolumn{9}{|c|}{$\varepsilon \times 1000$} \\
\hline$f_{c}^{\prime}$ & $\leq-0.20$ & $\leq-0.10$ & $\leq-0.05$ & $\leq 0.00$ & $\leq 0.125$ & $\leq 0.25$ & $\leq 0.50$ & $\leq 0.75$ & $\leq 1.00$ \\
\hline$\leq 0.075$ & 6.32 & 4.75 & 4.10 & 3.75 & 3.24 & 2.94 & 2.59 & 2.38 & 2.23 \\
\hline$\leq 0.100$ & 3.79 & 3.38 & 3.24 & 3.14 & 2.91 & 2.75 & 2.50 & 2.32 & 2.18 \\
\hline$\leq 0.125$ & 3.18 & 2.99 & 2.94 & 2.87 & 2.74 & 2.62 & 2.42 & 2.26 & 2.13 \\
\hline$\leq 0.150$ & 2.88 & 2.79 & 2.78 & 2.72 & 2.60 & 2.52 & 2.36 & 2.21 & 2.08 \\
\hline$\leq 0.175$ & 2.73 & 2.66 & 2.65 & 2.60 & 2.52 & 2.44 & 2.28 & 2.14 & 1.96 \\
\hline$\leq 0.200$ & 2.63 & 2.59 & 2.52 & 2.51 & 2.43 & 2.37 & 2.14 & 1.94 & 1.79 \\
\hline$\leq 0.225$ & 2.53 & 2.45 & 2.42 & 2.40 & 2.34 & 2.14 & 1.86 & 1.73 & 1.64 \\
\hline$\leq 0.250$ & 2.39 & 2.39 & 2.33 & 2.33 & 2.12 & 1.93 & 1.70 & 1.58 & 1.50 \\
\hline
\end{tabular}

In the use of Table 2.10, the maximum concrete shear stress, $v_{u}$ shall be determined as:

$$
v_{u}=\frac{V_{u}-\phi V_{p}}{\phi b_{v} d_{v}}
$$

Where: $V_{u}$ is the factored shear force acting in the section (kip), and

$\phi \quad$ is the resistance factor for shear as specified in Section 5.5.4.2 of 2004 AASHTO LRFD. 
Table 2.11 Values of $\theta$ and $\beta$ for sections with less than minimum transverse reinforcement (2004 AASHTO LRFD Table 5.8.3.4.2-2)

\begin{tabular}{|c|c|c|c|c|c|c|c|c|c|c|c|}
\hline \multicolumn{12}{|c|}{ Values of $\theta$} \\
\hline \multirow{2}{*}{$\begin{array}{l}s_{x e} \\
\text { in. }\end{array}$} & \multicolumn{11}{|c|}{$\varepsilon_{x} \times 1000$} \\
\hline & $\leq-0.20$ & $\leq-0.10$ & $\leq-0.05$ & $\leq 0.00$ & $\leq 0.125$ & $\leq 0.25$ & $\leq 0.50$ & $\leq 0.75$ & $\leq 1.00$ & $\leq 1.50$ & $\leq 2.00$ \\
\hline$\leq 5$ & 25.4 & 25.5 & 25.9 & 26.4 & 27.7 & 28.9 & 30.9 & 32.4 & 33.7 & 35.6 & 37.2 \\
\hline$\leq 10$ & 27.6 & 27.6 & 28.3 & 29.3 & 31.6 & 33.5 & 36.3 & 38.4 & 40.1 & 42.7 & 44.7 \\
\hline$\leq 15$ & 29.5 & 29.5 & 29.7 & 31.1 & 34.1 & 36.5 & 39.9 & 42.4 & 44.4 & 47.4 & 49.7 \\
\hline$\leq 20$ & 31.2 & 31.2 & 31.2 & 31.3 & 36.0 & 38.8 & 42.7 & 45.5 & 47.6 & 50.9 & 53.4 \\
\hline$\leq 30$ & 34.1 & 34.2 & 34.1 & 34.2 & 38.9 & 42.3 & 46.9 & 50.1 & 52.6 & 56.3 & 59.0 \\
\hline$\leq 40$ & 36.6 & 36.6 & 36.6 & 36.6 & 41.2 & 45.0 & 50.2 & 53.7 & 56.3 & 60.2 & 63.0 \\
\hline$\leq 60$ & 40.8 & 40.8 & 40.8 & 40.8 & 44.5 & 49.2 & 55.1 & 58.9 & 61.8 & 65.8 & 68.6 \\
\hline$\leq 80$ & 44.3 & 44.3 & 44.3 & 44.3 & 47.1 & 52.3 & 58.7 & 62.8 & 65.7 & 69.7 & 72.4 \\
\hline \multicolumn{12}{|c|}{ Values of $\beta$} \\
\hline$s_{x e}$ & \multicolumn{11}{|c|}{$8 x \times 1000$} \\
\hline in. & $\leq-0.20$ & $\leq-0.10$ & $\leq-0.05$ & $\leq 0.00$ & $\leq 0.125$ & $\leq 0.25$ & $\leq 0.50$ & $\leq 0.75$ & $\leq 1.00$ & $\leq 1.50$ & $\leq 2.00$ \\
\hline$\leq 5$ & 6.36 & 6.06 & 5.56 & 5.15 & 4.41 & 3.90 & 3.26 & 2.86 & 2.58 & 2.21 & 1.96 \\
\hline$\leq 10$ & 5.78 & 5.78 & 5.38 & 4.89 & 4.05 & 3.52 & 2.88 & 2.50 & 2.23 & 1.88 & 1.65 \\
\hline$\leq 15$ & 5.34 & 5.34 & 5.27 & 4.73 & 3.82 & 3.27 & 2.64 & 2.27 & 2.01 & 1.68 & 1.46 \\
\hline$\leq 20$ & 4.99 & 4.99 & 4.99 & 4.61 & 3.65 & 3.09 & 2.46 & 2.09 & 1.85 & 1.52 & 1.31 \\
\hline$\leq 30$ & 4.46 & 4.46 & 4.46 & 4.43 & 3.39 & 2.82 & 2.19 & 1.84 & 1.61 & 1.30 & 1.10 \\
\hline$\leq 40$ & 4.06 & 4.06 & 4.06 & 4.06 & 3.20 & 2.62 & 2.00 & 1.66 & 1.43 & 1.14 & 0.95 \\
\hline$\leq 60$ & 3.50 & 3.50 & 3.50 & 3.50 & 2.92 & 2.32 & 1.72 & 1.40 & 1.18 & 0.92 & 0.75 \\
\hline$\leq 80$ & 3.10 & 3.10 & 3.10 & 3.10 & 2.71 & 2.11 & 1.52 & 1.21 & 1.01 & 0.76 & 0.62 \\
\hline
\end{tabular}

In the use of Table 2.11, the crack spacing parameter, sxe is determined as:

$$
s_{x e}=s_{x} \frac{1.38}{a_{g}+0.63} \leq 80 \mathrm{in}
$$

Where: $s_{x}$ is the lesser of either the $d_{v}$ or the maximum distance between layers of longitudinal crack control reinforcement, where the area of the reinforcement is not less than $0.003 b_{v} s_{x}$ (in.), and

$a_{g}$ is the maximum aggregate size (in.).

Now, in computing the longitudinal strain in the web reinforcement on the flexural tension side of the member, $\varepsilon x$, to be used to read the corresponding $\beta$ and $\theta$ values from Tables 2.10 or 2.11, two equations depending on the amount of shear reinforcement are given in lieu of a more accurate calculation. 
If the section contains at least the minimum specified by Section 5.8 .2 .5 (Eq. 2.11), then $\varepsilon_{x}$ is given by:

$$
\varepsilon_{x}=\frac{\frac{M_{u}}{d_{v}}+0.5 N_{u}+0.5\left(V_{u}-V_{p}\right) \cot \theta-A_{p s} f_{p o}}{2\left(E_{s} A_{s}+E_{p} A_{p s}\right)}
$$

Where: $M_{u}$ is the factored moment, taken as positive quantity, but not to be taken less than $V_{u} d_{v}$ (kip-in.),

$N_{u}$ is the factored axial force, taken as positive if tensile and negative if compressive (kip),

$A_{p s}$ is the area of prestressing steel on the flexural tension side of the member (in. ${ }^{2}$ ),

$f_{p o}$ is a parameter taken as modulus of elasticity of prestressing tendons multiplied by the locked in difference in strain between the prestressing tendons and the surrounding concrete; for the usual levels of prestressing, a value of $0.7 f_{p u}$ will be appropriate for both pretensioned and posttensioned members $(k s i)$; $f_{p u}$ is the specified tensile strength of prestressing steel $(k s i)$,

$E_{s}$ is the modulus of elasticity of reinforcing bars $(k s i)$,

$A_{s}$ is the area of nonprestressed tension reinforcement (in. ${ }^{2}$ ),

$E_{p}$ is the modulus of elasticity of prestressing tendons $(k s i)$, and

$A_{p s}$ is the area of prestressing steel (in.2).

The initial value of $\varepsilon_{x}$ should not be taken greater than 0.001 . If, on the contrary, the section contains less than the minimum shear reinforcement specified in Section 5.8.2.5 of the 2004 AASHTO LRFD Specifications, then $\varepsilon_{x}$ is given by:

$$
\varepsilon_{x}=\frac{\frac{M_{u}}{d_{v}}+0.5 N_{u}+0.5\left(V_{u}-V_{p}\right) \cot \theta-A_{p s} f_{p o}}{\left(E_{s} A_{s}+E_{p} A_{p s}\right)}
$$

For Eq. 2.15, the initial value of $\varepsilon_{x}$ should not be taken greater than 0.002 . If $\varepsilon_{x}$ computed using Eq. 2.14 or 2.15 is negative, then the strain shall be taken as:

$$
\varepsilon_{x}=\frac{\frac{M_{u}}{d_{v}}+0.5 N_{u}+0.5\left(V_{u}-V_{p}\right) \cot \theta-A_{p s} f_{p o}}{2\left(E_{c} A_{c}+E_{s} A_{s}+E_{p} A_{p s}\right)}
$$

Where: $E_{c}$ is the modulus of elasticity of concrete (ksi), and

$A_{c}$ is the area of concrete on the flexural tension side of the member (in. $\left.{ }^{2}\right)$.

The modulus of elasticity of concrete, $E_{c}$, is also provided in the 2004 AASHTO LRFD Specifications. For concretes with unit weights between 0.090 and $0.155 \mathrm{kip} / \mathrm{ft} .^{3}$, it is given as: 


$$
E_{c}=33000 w_{c}^{1.5} \sqrt{f^{\prime}}
$$

Where: $w_{c}$ is the unit weight of concrete $\left(k i p / f t^{3}\right)$.

For a normal weight concrete with unit weight of $0.145 \mathrm{kip} / \mathrm{ft} .^{3}$, like the ones used for the construction of the test specimens of this project, the modulus of elasticity may be obtained using:

$$
E_{c}=1820 \sqrt{f_{c}^{\prime}}
$$

Once $\beta$ and $\theta$ have been determined using the given equations, $V_{c}$ and $V_{s}$ may then be calculated using Eq. 2.6 and 2.8, respectively.

Since shear causes tension in the longitudinal reinforcement, the 2004 AASHTO LRFD Specifications include a requirement to check for the longitudinal tension due to shear, moment and axial load (Section 5.8.3.5). The tensile capacity of the longitudinal reinforcement in the flexural tension side of the member has to be greater than or equal to $T$, calculated as:

$$
T=\frac{M_{u}}{d_{v} \phi}+0.5 \frac{N_{u}}{\phi}+\left(\frac{V_{u}}{\phi}-0.5 V_{s}-V_{p}\right) \cot \theta
$$

In the use of Eq. 2.19, an upper limit for $V_{s}$ is set to be $V_{u} / \phi$. Also, in computing the tensile capacity of the longitudinal reinforcement, any lack of full development has to be considered. The latter is especially important in the vicinity of supports.

As seen, 2004 AASHTO LRFD has two procedures to calculate the shear strength of concrete sections. The Simplified Procedure which used fixed values for $\beta$ and $\theta$, and the General Procedure based on the more complicated MCFT. This procedure attempts to include most of the parameters known to influence shear strength. However, the labor involved in its application for design may discourage its use.

\subsubsection{American Concrete Institute}

The current version of the American Concrete Institute Building Code ( $\mathrm{ACl} 318-05)$ has a sectional approach for the design for shear. A series of design expressions are given, most of them based on experimental evidence. The shear capacity of a concrete member is computed as the summation of two basic sources of shear resistance: concrete, and shear reinforcement. Even though the shear problem is far more complicated to explain than the simple addition of components, these expressions have served their main purpose of designing safe structures. In some cases, the definition and/or the notation used in ACI 318-05 may be different than that of 2004 AASHTO LRFD. In this section, the notation used is defined or redefined the first time it appears on a given equation. 
Chapter 11 of $\mathrm{ACl}$ 318-05 deals with the design for shear and torsion. The design for shear of a structural member is governed by the following inequality (Article 11.1.1):

$$
\phi V_{n} \geq V_{u}
$$

Where: $V_{u}$ is the factored shear force at the sections considered (Ib), and

$V_{n}$ is the nominal shear strength.

The nominal shear strength, $V_{n}$, may be computed with the following equations, which has a similar form to Eq. 2:

$$
V_{n}=V_{c}+V_{s}
$$

Where: $V_{c}$ is the nominal shear strength provided by concrete $(I b)$, and

$V_{s}$ is the nominal shear strength provided by shear reinforcement (Ib).

The nominal shear strength provided by concrete, $V_{c}$, may be computed by the use of two different sets of equations. Section 11.3 of $\mathrm{ACl}$ 318-05 specifies how to compute $V_{c}$ for nonprestressed members and Section 11.4 does the proper for prestressed members. In each of those sections, a simplified equation is given first. Then a set of more detailed ones, slightly harder to evaluate, is permitted.

The shear strength provided by concrete for nonprestressed members is computed as follows. It must be noted, first, that $\mathrm{ACl}$ 318-05 recognizes the effect of axial load by setting different equations when this load is present. In this review, only the design for shear of nonprestressed members without axial load, such as the reinforced concrete specimens of this research project, is presented. When the member is subjected to shear and flexure only, $V_{c}$ is given as:

$$
V_{c}=2 \sqrt{f^{\prime}} b_{w} d
$$

Where: $f_{c}^{\prime}$ is the specified compressive strength of concrete (psi),

$b_{w}$ is the web width or diameter of circular section (in.), and

$d$ is the distance from extreme compression fiber to centroid of longitudinal tension reinforcement (in.).

Eq. 2.22 is very similar to Eq. 2.9. Their apparent difference is due to the fact that 2004 AASHTO LRFD defines $f_{c}^{\prime}$ in $k s i$ whereas $\mathrm{ACl}$ 318-05 defines it in psi. Additionally, 2004 AASHTO LRFD uses $d_{v}$ instead of the ACl 318-05 Code use of $d$. The effective shear depth $d_{v}$ is slightly smaller than $d$.

A more detailed computation of the nominal shear strength provided by concrete involves additional parameters that have been experimentally observed to influence $V_{c}$. Again, a distinction 
is made for members with and without axial load. For members subjected to shear and flexure only:

$$
V_{c}=\left(1.9 \sqrt{f_{c}^{\prime}}+2500 \rho_{w} \frac{V_{u} d}{M_{u}}\right) b_{w} d \leq 3.5 \sqrt{f_{c}^{\prime}} b_{w} d
$$

Where: $\rho_{w}$ is the longitudinal reinforcement ratio on the basis of web width obtained as $A_{s} / b_{w} d ; A_{s}$ is the area of nonprestressed longitudinal tension reinforcement (in.2), and $M u$ is the factored moment at section (Ib-in.).

In the second term of Eq. 2.23, a minimum value of $M_{u}=V_{u} d$ or $V_{u} d / M_{u} \leq 1$ is set to limit $V_{c}$ near points of inflection. As read in ACl 318-05 Commentary, this second term may be taken as $0.1 \sqrt{f_{c}^{\prime}}$ for most designs, which makes Eq. 2.23 identical to Eq. 2.22.

In the case of prestressed concrete, the shear strength provided by concrete, $V_{c}$, may be obtained using:

$$
V_{c}=\left(0.6 \sqrt{f_{c}^{\prime}}+700 \frac{V_{u} d_{p}}{M_{u}}\right) b_{w} d \leq 5 \sqrt{f_{c}^{\prime}} b_{w} d
$$

Where: $d_{p}$ is the distance from extreme compression fiber to centroid of prestressing steel (in.), and

$d$ is redefined when designing prestressed members for shear and shall be taken as the distance from extreme compression fiber to centroid of prestressed and nonprestressed longitudinal tension reinforcement, if any (in.); but it need not be taken less than $0.80 h ; h$ is the overall thickness or height of member (in.).

Eq. 2.24 is only permitted for members with effective prestress force not less than $40 \%$ of the tensile strength of flexural reinforcement. Eq. 2.24 is most applicable to members subjected to uniform load. Similarly to the restrictions of Eq. 2.23, in the second term of Eq. 2.24, a minimum value of $M_{u}=V_{u} d_{p}$ or $V_{u} d_{p} / M_{u} \leq 1$ is set. $A C l$ 318-05 gives a lower boundary value for $V_{c}$ in Eq. 2.24 equal to $2 \sqrt{f^{\prime}}{ }_{c} b_{w} d$, which is Eq. 2.22, applicable to nonprestressed members.

In a more detailed design, $V_{c}$ for prestressed members should be taken as the lesser of $V_{c i}$ and $V_{\text {cw: }}$ :

$$
\begin{aligned}
& V_{c i}=0.6 \sqrt{f_{c}^{\prime}} b_{w} d_{p}+V_{d}+\frac{V_{i} M_{c r e}}{M_{\max }} \\
& V_{c w}=\left(3.5 \sqrt{f_{c}^{\prime}}+0.3 f_{p c}\right) b_{w} d_{p}+V_{p}
\end{aligned}
$$

Where: $d_{p}$ is again, the distance from extreme compression fiber to centroid of prestressing steel (in.), but in Eq. 2.25 and 2.26 need not be taken less than $0.80 \mathrm{~h}$, 
$V_{d}$ is the shear force at section due to unfactored dead load (Ib),

$V_{i}$ is the factored shear force at section due to externally applied loads occurring simultaneously with $M_{\max }(I b)$,

$M_{\text {cre }}$ is the moment causing flexural cracking at section due to externally applied loads (Ibin.),

$M_{\max }$ is the maximum factored moment at section due to externally applied loads ( $I b-i n$.),

$f_{p c}$ is the compressive stress in concrete (after allowance for all prestress losses) at centroid of cross section resisting externally applied loads or at junction of web and flange when the centroid lies within the flange ( $p s i)$, and

$V_{p}$ is the vertical component of effective prestress force at section (Ib).

In Eq. 2.25, $V_{i}$ and $M_{\max }$ shall be computed from the load combination causing maximum factored moment to occur at the section. A lower limit for $V_{c i}$ is set as $1.7 \sqrt{f_{c}^{\prime}} b_{w} d . M_{c r e}$ is given as:

$$
M_{\text {cre }}=\left(\frac{1}{y_{t}}\right)\left(6 \sqrt{f_{c}^{\prime}}+f_{p e}-f_{d}\right)
$$

Where: $I$ is the moment of inertia of section about centroidal axis (in. ${ }^{4}$ ),

$y_{t}$ is the distance from centroidal axis of gross section, neglecting reinforcement, to tension face (in.),

$f_{p e}$ is the compressive strength in concrete due to effective prestress forces only (after allowance for all prestress losses) at extreme fiber of section where tensile stress is caused by externally applied loads ( $p s i)$,

$f_{d}$ is the stress due to unfactored dead load, at extreme fiber of section where tensile stress is caused by externally applied loads ( $p s i)$,

Eq. 2.25 and 2.26 address the issue of different types of observed behavior in prestressed beams without shear reinforcement. As defined in the $\mathrm{ACl} 318-05$ Code, $V_{c i}$ is the nominal shear strength provided by concrete when diagonal cracking results from combined shear and moment. $V_{c w}$ is the nominal shear strength provided by concrete when diagonal cracking results from high principal tensile stress in the web.

Eq. 2.26 is based on the assumption that there is shear cracking on the web when the applied shear results in a principal tensile stress of approximately $4 \sqrt{f^{\prime}}$ at the centroidal axis of the cross section. Therefore, an alternative to the use of Eq. 2.26 is to compute $V_{c w}$ as the shear force corresponding to dead load plus live load that results in a principal tensile stress of $4 \sqrt{f^{\prime}}$ at the centroidal axis of the member, or at the intersection of flange and web when the centroidal axis is in the flange. 
Now, for the shear strength provided by shear reinforcement $V_{s}, \mathrm{ACl} 318-05$ gives the following equation:

$$
V_{s}=\frac{A_{v} f_{y t}(\sin \alpha+\cos \alpha) d}{s} \leq 8 \sqrt{f_{c}^{\prime}} b_{w} d
$$

Where: $A_{v}$ is the area of shear reinforcement in a spacing $s\left(\right.$ in. $\left.^{2}\right)$,

$f_{y t}$ is the specified yield strength of transverse reinforcement ( $\left.p s i\right)$,

$\alpha$ is the angle between shear reinforcement and longitudinal axis of the member (deg.), and

$s$ is the center-to-center spacing of items, such as longitudinal reinforcement, transverse reinforcement, prestressing tendons, wires or anchors (in.).

In most cases, including the test specimens of this research project, shear reinforcement is placed perpendicular to the longitudinal axis of the member. Therefore, Eq. 2.28 reduces to:

$$
V_{s}=\frac{A_{v} f_{y t} d}{s} \leq 8 \sqrt{f^{\prime}{ }_{c}} b_{w} d
$$

$\mathrm{ACl}$ 318-05 requires providing a minimum area of shear reinforcement, $A_{v, \min }$, for all prestressed or nonprestressed flexural members where $V_{u}>0.5 \phi V_{c}$ (Article 11.5.6.1). Exceptions to this requirement are slabs, footings, concrete joist construction, and beams with total height not greater than the largest of $10 \mathrm{in.,} 2.5$ times the thickness of the flange or 0.5 times the web width.

The minimum area of shear reinforcement is specified in article 11.5.6.3 of $\mathrm{ACl} 318-05$ as:

$$
A_{v, \min }=0.75 \sqrt{f_{c}^{\prime}} \frac{b_{w} s}{f_{y t}} \geq 50 \frac{b_{w} s}{f_{y t}}
$$

In the case of prestressed members with an effective prestress force not less than $40 \%$ of the tensile strength of the flexural reinforcement, $A_{v, \text { min }}$ shall not be less than the smaller value of Eq. 2.30 and:

$$
A_{v, \text { min }}=\frac{A_{p s} f_{p u} s}{80 f_{y t} d} \sqrt{\frac{d}{b_{w}}}
$$

Where: $A_{p s}$ is the area of prestressing steel in flexural tension zone (in. $\left.{ }^{2}\right)$, and

$f_{p u}$ is the specified tensile strength of prestressing steel (psi).

Requirements for the spacing of shear reinforcement are given in Article 11.5.5 of ACl 318-05. These spacing limits often govern over Eq. 2.30 and 2.31, especially when providing stirrups of large diameter in thin webs. Maximum spacing of shear reinforcement placed perpendicular to the longitudinal axis of nonprestressed member is specified as the lesser of $d / 2$ or $24 \mathrm{in}$. In the case of 
prestressed members, maximum spacing or shear reinforcement shall be the lesser of $0.75 \mathrm{~h}$ or 24 in.

For nonprestressed members, the critical section for design for shear is located at a distance $d$ from the face of the support. In the case of prestressed members, the critical section is located at a distance $h / 2$. The reasoning behind this consideration is that loads applied to a beam between the face of the support or column and the point $d$ away from the face are directly transferred to the support by a compressive strut through the web of the beam above the inclined crack. However, shear reinforcement is required to be provided across the potential inclined crack and the longitudinal reinforcement must carry the tension force at the face of the support. Adequate anchorage of the longitudinal reinforcement must be provided to that effect. 


\section{CHAPTER 3 EXPERIMENTAL PROGRAM}

\subsection{Introduction}

This chapter presents a detailed description of the testing program carried out to meet the study objectives. The objectives of the program were a) to evaluate the behavior of HSC flexural members with various amounts of shear reinforcement, and b) to gain understanding on the effect of increasing compressive strength of concrete on the shear capacity of HSC beam type specimens. The properties of the materials used in the construction of the test specimens are presented together with construction details, test setup, instrumentation, and test procedure. A description of the results and the analysis of the same are covered in Chapter 4.

In the experimental program, testing to failure of HSC flexural members with and without shear reinforcement was carried out. The evaluation of the capacity and behavior of these beams was done through the testing of eight beams without shear reinforcement, eight specimens with different amounts of shear reinforcement and four prestressed beams with two different amounts of shear reinforcement. The target concrete compressive strengths were in the range of 10000 to $15000 \mathrm{psi}$. The concrete compressive strength measured at test date ranged from 7000 to 17000 psi. All test specimens had some common characteristics for the purpose of establishing needed comparisons.

The longitudinal reinforcement was provided by means of Gr.60, mild reinforcement. The prestressing strands were Gr. 270, 1/2-in. special, low relaxation strands. Shear reinforcement was

provided by Gr. 60 No 2, No. 3 and No. 4 deformed bars. Testing was conducted under a monotonic load regime.

\subsection{Test Specimens}

Geometry, reinforcement details and construction processes are presented next. These items are covered in two broad categories: a) reinforced concrete specimens, and b) prestressed concrete specimens. Specimen geometry, both in terms of cross section and length changed slightly from the reinforced concrete specimens to the prestressed specimens. 
Test specimens are identified using four symbols. The first identifier is the compressive strength of concrete measured the day of the test, in ksi. The second identifier is the longitudinal mild reinforcement ratio on the basis of the web width $\left(\rho_{w}=A_{s} / b_{w} d\right)$, as a percentage. The third identifier corresponded to the shear strength provided by the transverse reinforcement ( $\left.\rho_{v f} f_{v v}\right)$ in psi. The last item was left blank for reinforced concrete specimens and had the letter $P$ when prestressed strands were present. Following this convention, Specimen 7.0-1.3-0 represents a reinforced concrete specimen as it consists of only three identifiers, with a measured concrete compressive strength of $7000 \mathrm{psi}$, a $1.3 \%$ ratio of longitudinal mild reinforcement on the basis of web width and had no shear reinforcement.

\subsubsection{Reinforced Concrete Specimens}

Sixteen reinforced concrete specimens were designed and tested to failure. Half of them were constructed without shear reinforcement. The rest were reinforced with various amounts of shear reinforcement. The variables under study in the reinforced concrete series were the compressive strength of concrete and the amounts of both longitudinal and transverse reinforcement. Measured concrete compressive strengths at test day ranged from 7000 to $15250 \mathrm{psi}$. The shear span to depth ratio of the reinforced concrete specimens was around 3.6.

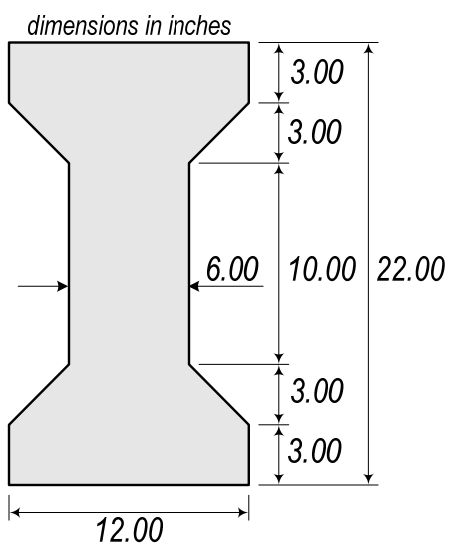

Figure 3.1
Cross section of test region in reinforced concrete specimens

\subsubsection{Dimensions}

All reinforced concrete specimens had the cross section shown in Figure 3.1. The nominal depth of the reinforced concrete specimens was $22 \mathrm{in}$. and both top and bottom flanges were 12-in. wide by 3 -in. thick. Nominal minimum web width was kept at 6 in. for all test specimens. The cross section was constant throughout the test regions.

Beams without shear reinforcement had two 72-in. long shear spans and a total length of $160 \mathrm{in}$. Total concrete volume in these specimens was $0.64 \mathrm{yd}^{3}$ and self weight was around $2580 \mathrm{lb}$. Beams with shear reinforcement were designed to yield two separate tests from each beam (Figure 3.2). This configuration allowed the study of a cantilever (Test Region B) and a simply supported beam (Test Region A) while reducing the chance of the compressive strength of concrete to be a source of variability when comparing results. Specimens with shear reinforcement had three 72-in. long shear spans and a total length of $232 \mathrm{in}$. These test specimens required a total concrete volume of $0.92 \mathrm{yd}^{3}$, and their total dead weight was around $3750 \mathrm{lb}$. Note that in these beams, a diaphragm was included at the continuous support. This diaphragm was 12-in. wide by 
22-in. deep and 16-in. long. The diaphragm prevented failures at the interior support in the simple span when loading Test Region $B$.
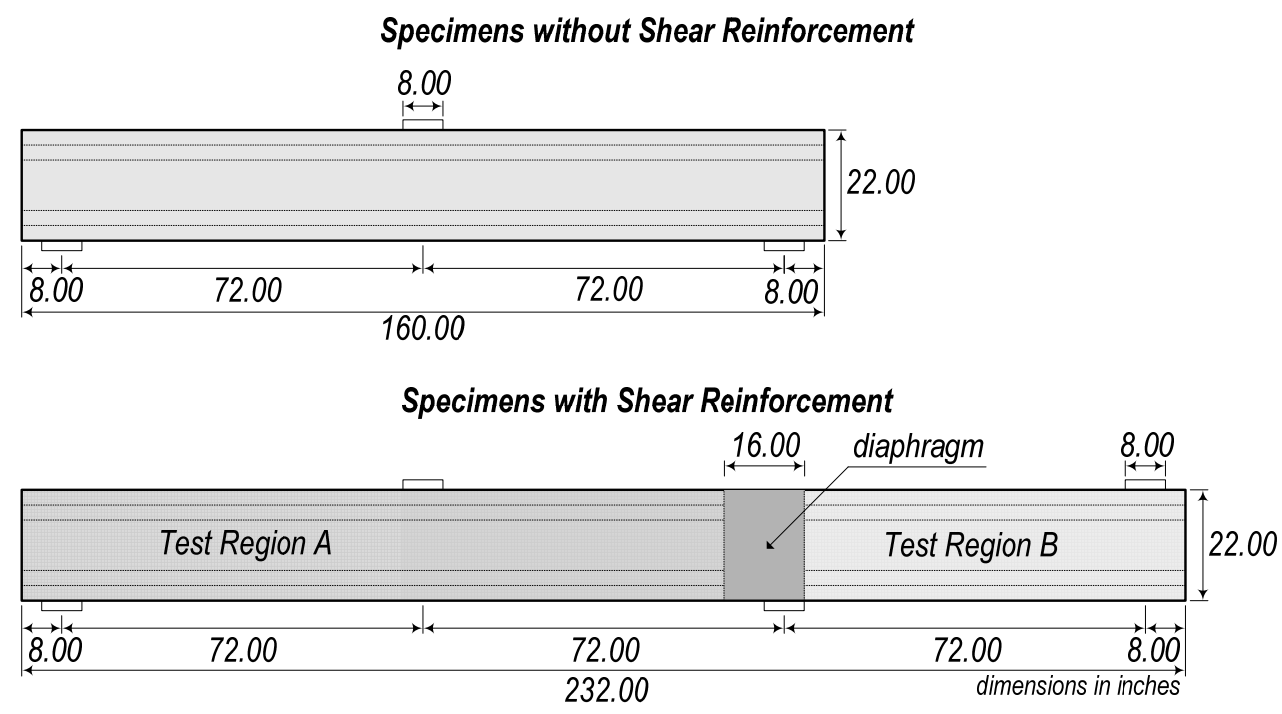

Figure 3.2 Elevation view of the reinforced concrete specimens

\subsubsection{Reinforcement}

\subsection{Beams without shear reinforcement}

All eight specimens without shear reinforcement had longitudinal tension mild reinforcement only. Two different amounts of longitudinal reinforcement were provided in these specimens. Four specimens had two No. 8 deformed bars. This reinforcement resulted in a longitudinal reinforcement ratio on the basis of web width, $p_{w}$ of $1.32 \%$. The remaining four reinforced concrete specimens without shear reinforcement had two No. 11 bars, roughly double the amount of the first four specimens (2.62\%). Longitudinal bars were continuous through the length of the beams and were not bent at their ends. Table 3.1 presents the details of the test specimens without shear reinforcement. It follows the nomenclature described in Section 3.2 for the mark of each test specimens and the notation defined in Section 2.4. Figure 3.3 shows the reinforcement details of the specimens without shear reinforcement.

\subsection{Beams with stirrups}

In the specimens with shear reinforcement, the longitudinal reinforcement was provided with No. 8 and No. 10 bars. Both top and bottom flanges of the reinforced concrete specimens had longitudinal reinforcement. The longitudinal reinforcement was distributed over the width of the flanges and, when required due to the number of bars, bundled in pairs. The longitudinal reinforcement ratios on the basis of web width varied from 2.63 to $7.92 \%$. These extraordinarily large amounts of longitudinal reinforcement were necessary to prevent a flexural failure before a 
shear failure. It must be noted that all the specimens met the criteria for tension control in both the 2004 AASHTO LRFD Specifications and the ACI 318-05 Code.

Table 3.1 Details of test specimens without shear reinforcement

\begin{tabular}{|c|c|c|c|c|c|c|c|c|}
\hline \multirow{2}{*}{ Specimen } & \multirow{2}{*}{$b_{w}$, in. } & \multirow{2}{*}{$d$, in. } & \multirow{2}{*}{$d_{v}$, in. } & \multirow{2}{*}{$f_{c, p s i}$} & \multicolumn{2}{|c|}{ Longitudinal Reinforcement } & \multicolumn{2}{|c|}{ Transverse Reinforcement } \\
\hline & & & & & Bars & $A_{s}$, in. $^{2}\left(\rho_{w}, \%\right)$ & Bars & $A_{v}$, in. $^{2}\left(\rho_{v} f_{y v}, p s i\right)$ \\
\hline $7.0-1.3-0$ & 6.00 & 20.00 & 18.00 & 7000 & 2 No. 8 & $1.58(1.32)$ & None & $0.00(0)$ \\
\hline $7.9-1.3-0$ & 6.00 & 20.00 & 18.00 & 7940 & 2 No. 8 & $1.58(1.32)$ & None & $0.00(0)$ \\
\hline $10.6-1.3-0$ & 6.00 & 20.00 & 18.00 & 10630 & 2 No. 8 & $1.58(1.32)$ & None & $0.00(0)$ \\
\hline $11.5-1.3-0$ & 6.00 & 20.00 & 18.00 & 11540 & 2 No. 8 & $1.58(1.32)$ & None & $0.00(0)$ \\
\hline $7.0-2.6-0$ & 6.00 & 19.81 & 17.83 & 7000 & 2 No. 11 & $3.12(2.62)$ & None & $0.00(0)$ \\
\hline $7.9-2.6-0$ & 6.00 & 19.81 & 17.83 & 7940 & 2 No. 11 & $3.12(2.62)$ & None & $0.00(0)$ \\
\hline $10.6-2.6-0$ & 6.00 & 19.81 & 17.83 & 10630 & 2 No. 11 & $3.12(2.62)$ & None & $0.00(0)$ \\
\hline $11.5-2.6-0$ & 6.00 & 19.81 & 17.83 & 11540 & 2 No. 11 & $3.12(2.62)$ & None & $0.00(0)$ \\
\hline
\end{tabular}
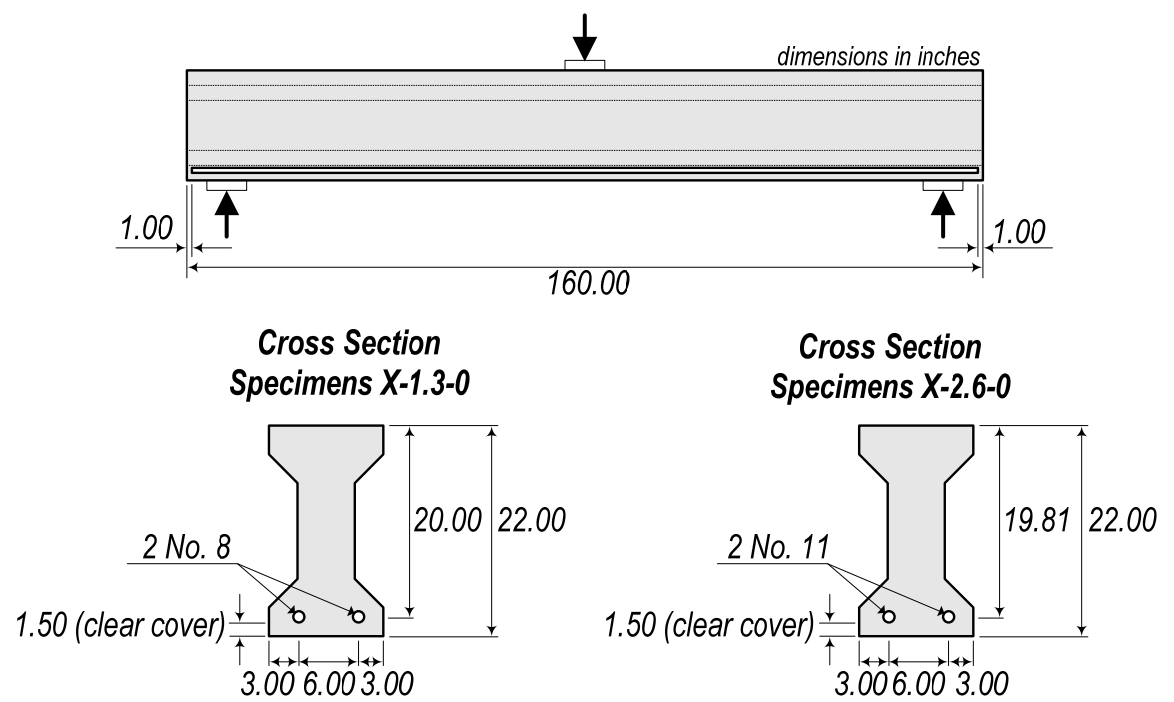

Figure 3.3 Reinforcement details of specimens without shear reinforcement

All longitudinal reinforcement was straight and continuous throughout the length of the specimens. To adequately develop the required moment capacity of the longitudinal reinforcement, two of the bars on each test specimen had mechanical anchorages at their ends. The reinforcement donated by Erico ${ }^{\circledR}$, Inc. allowed the use of Lenton ${ }^{\circledR}$ Terminators $^{\mathrm{TM}}$. No signs of anchorage deterioration were observed in any of the test specimens with Lenton ${ }^{\circledR}$ Terminators $^{\mathrm{TM}}$. The longitudinal reinforcement of all test specimens had a vertical clear cover of $1.5 \mathrm{in}$. Steel chairs across the width of the beam, 24 in. apart were used for this purpose. 
The shear reinforcement was provided with closed stirrups of No. 2 and No. 4 deformed bars. No. 2 deformed bars are no longer made in the United States. However, it was possible to obtain this type of reinforcement from Construction Technology Laboratories, Inc. which had imported it from Sweden. Stirrups free ends were anchored using 90-deg. hooks. During construction, the location of these hooks was alternated from one face of the beam to the other to avoid the formation of a plane of weakness.

The spacing of shear reinforcement was varied from 6 to $14 \mathrm{in}$. The 6 -in. stirrups spacing was used to provided the highest amount of shear reinforcement. The 14-in. spacing corresponds to the maximum allowed by the 2004 AASHTO LRFD Specifications $\left(0.8 d_{v}\right)$. Table 3.2 presents the reinforcement details of the reinforced concrete beams with shear reinforcement. Figure 3.4 shows the reinforcement details for the reinforced concrete specimens with minimum amount of shear reinforcement in accordance with both 2004 AASHTO LRFD and ACl 318-05, and Figure 3.5 shows the details of the specimens with intermediate and maximum amount of shear reinforcement in accordance to the $\mathrm{ACl}$ 318-05 Code.

Table 3.2 Details of test specimens with shear reinforcement

\begin{tabular}{|c|c|c|c|c|c|c|c|c|}
\hline \multirow{2}{*}{ Specimen } & \multirow{2}{*}{$b_{w}$, in. } & \multirow{2}{*}{$d$, in. } & \multirow{2}{*}{$d_{v}$, in. } & \multirow{2}{*}{$f_{c, p s i}$} & \multicolumn{2}{|c|}{ Longitudinal Reinforcement * } & \multicolumn{2}{|c|}{ Transverse Reinforcement } \\
\hline & & & & & Bars & $A_{s}$, in. $^{2}\left(\rho_{w}, \%\right)$ & Bars & $A_{v}$, in. $^{2}\left(\rho_{v} f_{y v}, p s i\right)$ \\
\hline $13.3-2.6-98$ & 6.00 & 20.00 & 18.00 & 13290 & 4 No. 8 & $3.16(2.63)$ & $\begin{array}{c}\text { No. } 2 \\
s=10 \mathrm{in} .\end{array}$ & $0.10(98)$ \\
\hline $14.5-2.6-98$ & 6.00 & 20.00 & 18.00 & 14540 & 4 No. 8 & 3.16 (2.63) & $\begin{array}{c}\text { No. } 2 \\
s=10 \mathrm{in} .\end{array}$ & $0.10(98)$ \\
\hline $13.3-5.4-98$ & 6.00 & 19.51 & 17.56 & 13290 & 8 No. 8 & $6.32(5.40)$ & $\begin{array}{c}\text { No. } 2 \\
s=10 \mathrm{in} .\end{array}$ & $0.10(98)$ \\
\hline $14.5-5.4-98$ & 6.00 & 19.51 & 17.56 & 14540 & 8 No. 8 & $6.32(5.40)$ & $\begin{array}{c}\text { No. } 2 \\
s=10 \text { in. }\end{array}$ & $0.10(98)$ \\
\hline $13.2-4.3-451$ & 6.00 & 19.88 & 17.89 & 13160 & 4 No. 10 & $5.08(4.26)$ & $\begin{array}{c}\text { No. } 4 \\
s=12 \text { in. }\end{array}$ & $0.40(451)$ \\
\hline $15.3-4.3-387$ & 6.00 & 19.88 & 17.89 & 15250 & 4 No. 10 & $5.08(4.26)$ & $\begin{array}{c}\text { No. } 4 \\
s=14 \text { in. }\end{array}$ & $0.40(387)$ \\
\hline 13.2-7.9-902 & 6.00 & 19.36 & 17.42 & 13160 & $\begin{array}{l}2 \text { No. } 8 \\
6 \text { No. } 10\end{array}$ & 9.20 (7.92) & $\begin{array}{l}\text { No. } 4 \\
s=6 \text { in. }\end{array}$ & 0.40 (902) \\
\hline 15.3-7.9-902 & 6.00 & 19.36 & 17.42 & 15250 & $\begin{array}{l}2 \text { No. } 8 \\
6 \text { No. } 10\end{array}$ & 9.20 (7.92) & $\begin{array}{l}\text { No. } 4 \\
s=6 \text { in. }\end{array}$ & 0.40 (902) \\
\hline
\end{tabular}


It is worth noting that, in all specimens with stirrups, reinforcement was provided to prevent the spalling of concrete around the corners of flanges. As seen in Figure 3.4 and 3.5, No. 3 bars bent to the shape of the flanges were located 12-in. apart along the beam length. Also, the diaphragms were reinforced with four closed No. 3 stirrups. Two lifting hooks made with No. 3 bar were located outside the testing region to assist in handling of the specimens. These hooks are not shown in Figure 3.4 or 3.5. All reinforcement -longitudinal, transverse, in the flanges and in the diaphragms- used in the reinforced concrete specimens was Gr. 60.

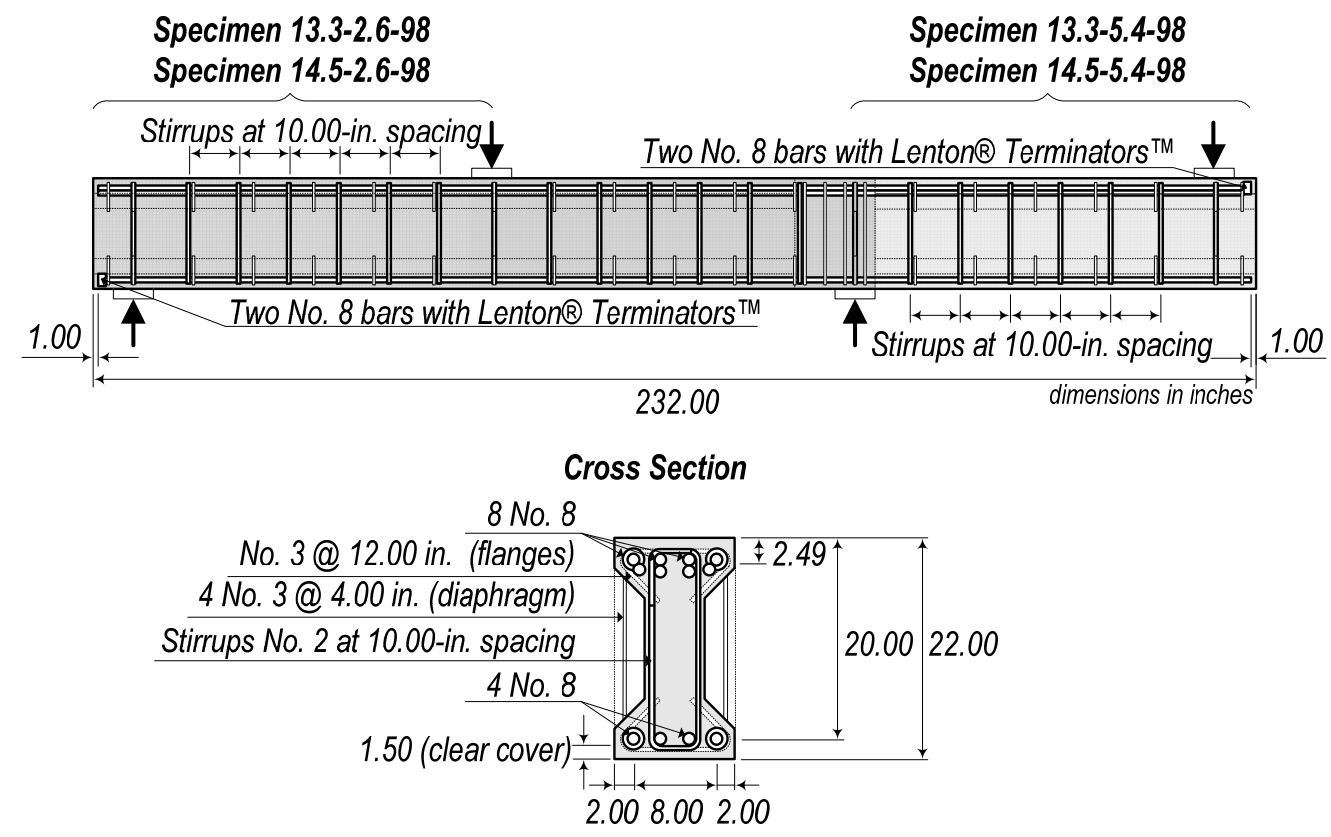

Figure 3.4 Reinforcement details of specimens with minimum amount of shear reinforcement in accordance with 2004 AASHTO LRFD and ACI 318-05

\subsubsection{Construction}

The reinforced concrete specimens were cast at the Kettelhut Structural Engineering Laboratory. Custom designed wood formwork was used to cast the specimens. Two pairs of forms were built. One pair was used to cast the beams without shear reinforcement, and the second was used to cast the specimens with stirrups. Before each cast, the forms were cleaned with a wire brush and treated with a releasing agent. Then, the reinforcing cages were introduced. Previously, the reinforcing cages had been tied using No. 16 gage steel wire.

Two beams from the same batch with identical compressive strength of concrete were cast each time. The concrete was delivered to the laboratory by a mixing truck. The distance and travel time from the ready-mix plant to the Kettelhut laboratory are $5 \mathrm{mi}$. and $15 \mathrm{~min}$., respectively. For most of 
the casts, special care -by personally attending the batching mix at the plant- was taken so that the requested mix proportion was as accurate as possible.
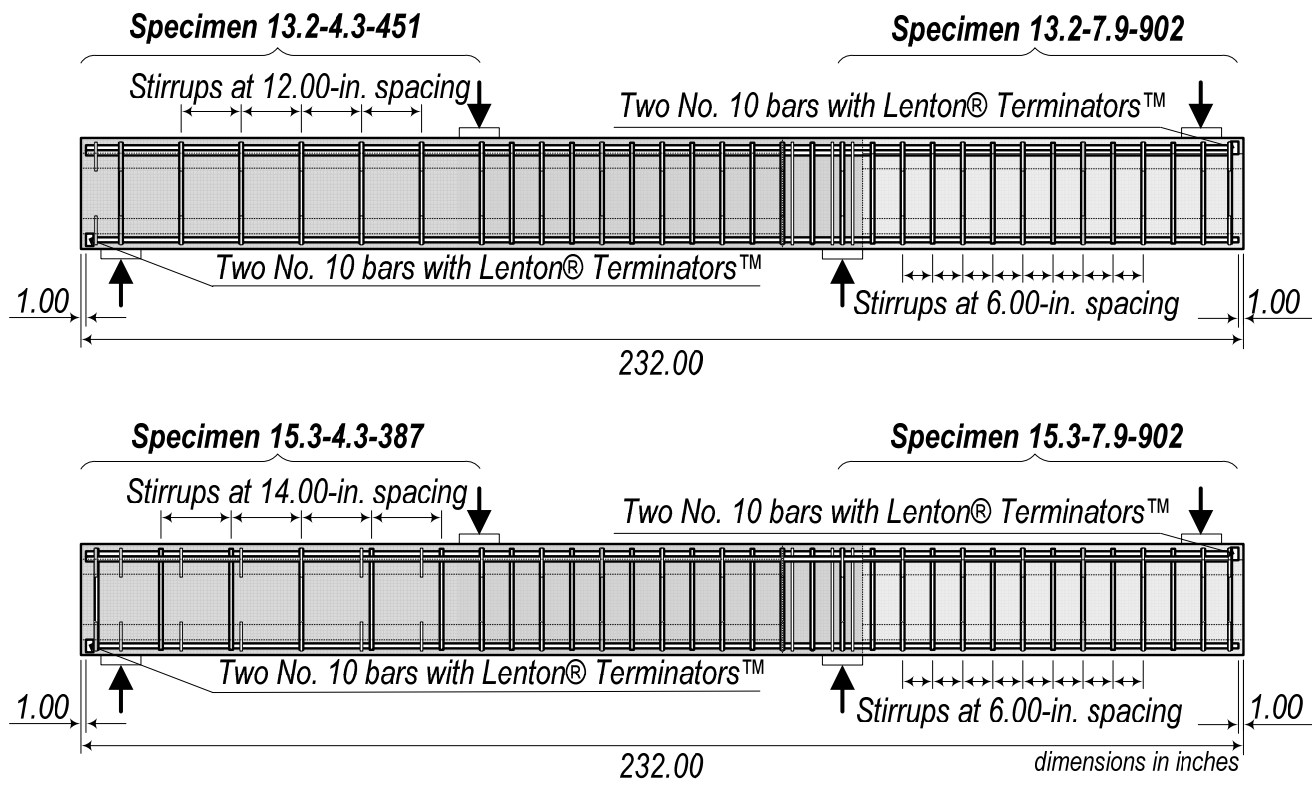

Cross Section

6 No. $10+2$ No. 8

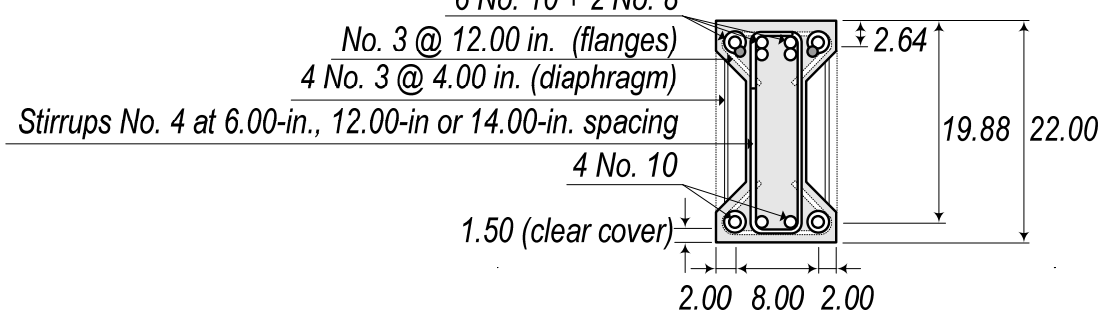

Figure 3.5 Reinforcement details of specimens with intermediate and maximum amount of shear reinforcement in accordance with $\mathrm{ACl}$ 318-05

Upon the arrival of ready-mix concrete truck to the laboratory, additional mixing was done for about 3 min. After discarding the initial load of a wheel barrel, a slump test (ASTM C 143-05) was carried out to verify the consistency of the mix. It is well known that the slump test may not be applicable to HSC; however, it was used as a reference to compare similar concrete mixes. For the reinforced concrete specimens, the air content was also measured according to ASTM C 23104. The slump, air content, evolution of compressive strength and modulus of rupture from flexural beams are all presented in section 3.3.1. For the specimens without shear reinforcement, the concrete was placed in the forms using a 0.25-yd. ${ }^{3}$ capacity bucket and a 10-ton crane. For the specimens with shear reinforcement, chutes were used to place the concrete in the forms directly from the truck. The beams were cast in two lifts of approximately half the total volume each. 


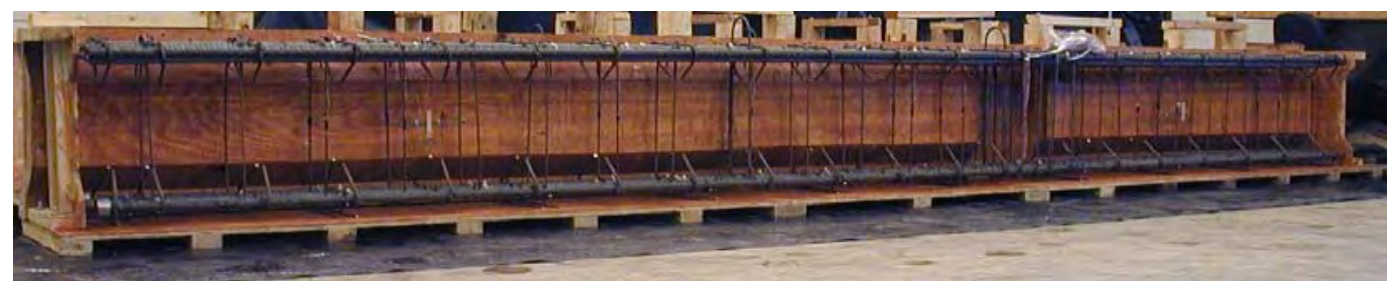

a) View of reinforcement of beam for Specimen 13.3-2.6-98 and Specimen 13.3-5.4-98 before cast

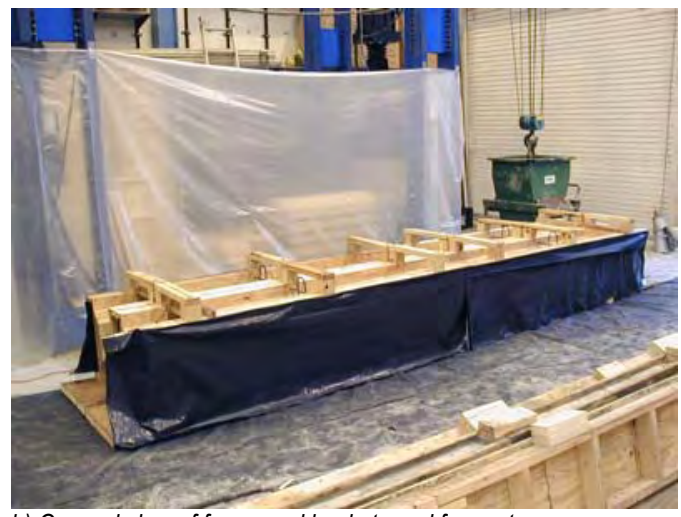

b) General view of forms and bucket used for cast

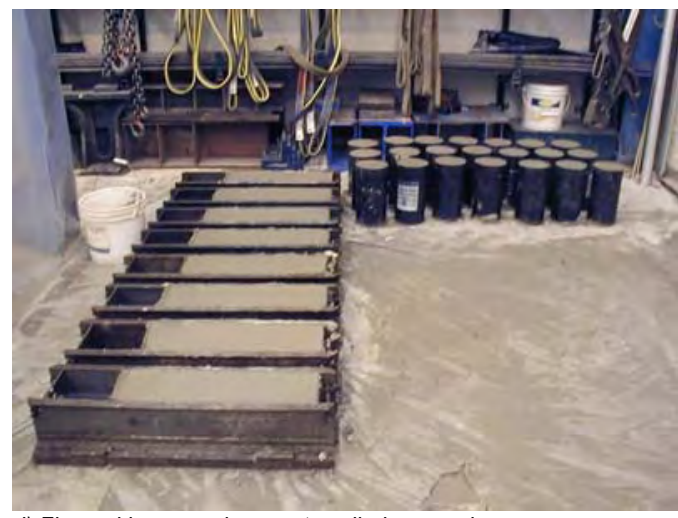

d) Flexural beam and concrete cylinder samples

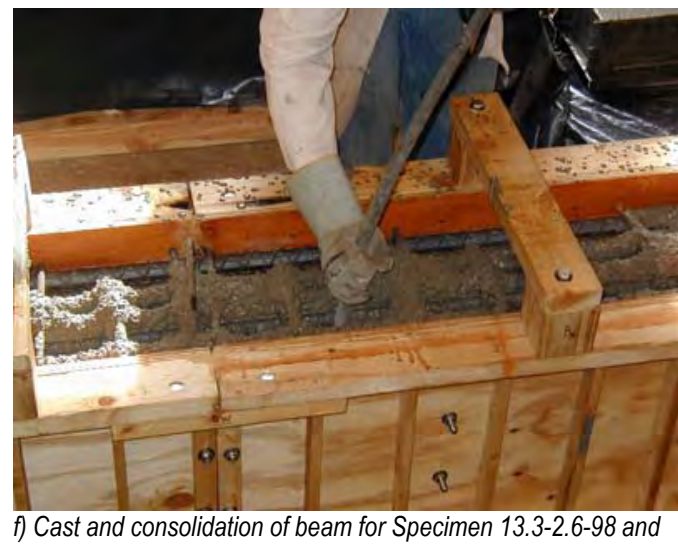

Specimen 13.3-5.4-98

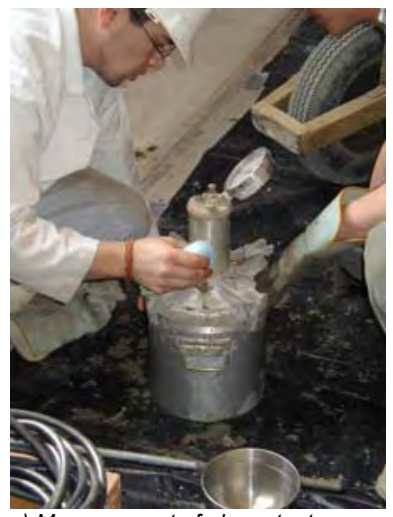

c) Measurement of air content

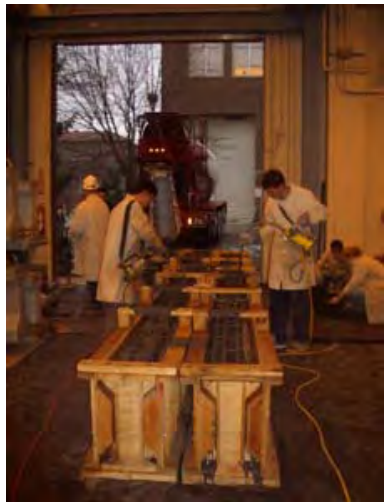

e) Consolidation of concrete

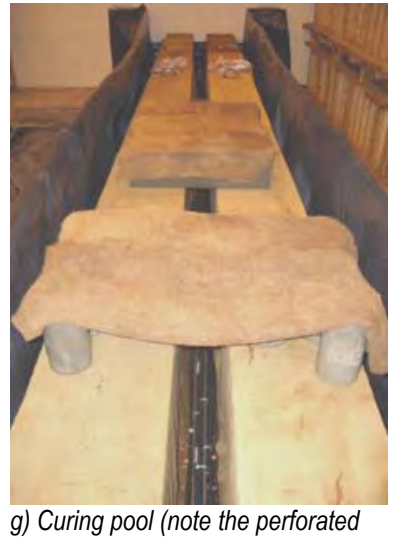
garden hoses between the beams

Figure 3.6

Details of construction, concrete sampling and curing of reinforced concrete specimens 
The concrete was consolidated with electric hand held vibrators. In all specimens, especially those with large amounts of reinforcement, 1/2-in. diameter round vibrators were necessary to adequately consolidate the concrete. The high fluidity of the HSC mixes facilitated the consolidation. The top of the beams had flat float finish.

As the test specimens were cast, some concrete samples were taken. Thirty-two 4x8-in. cylinders and up to eight $6 \times 6 \times 24$-in. flexural beams were sampled with each cast. For the cylinders, new plastic molds were used. The flexural beams were cast in steel molds. In both cases, the ASTM C 192-05 Standard was followed. All test elements were consolidated with steel rods (3/8in. diameter) and kept in the same conditions as their corresponding test beams.

After casting and once the concrete had set, the test beams, accompanying cylinders and flexural beams were covered with wet burlap and plastic for 7 to 14 days. For the test specimens with shear reinforcement, a system that provided continuous moisture to the specimens using two small fountain pumps, perforated garden hoses and a water reservoir was devised. Two or three days before the beams were tested, they were removed from the curing pool. The age of reinforced concrete specimens at the time of test ranged from 35 to 99 days. Figure 3.6 shows some details of the construction, concrete sampling and curing of the reinforced concrete specimens.

\subsubsection{Prestressed Specimens}

Four HSC prestressed beams were designed, constructed, and tested. Specimens were designed to fail in shear. They were cast at the Prestress Services Inc. plant located in Decatur, IN. Two of the beams had the minimum amount of shear reinforcement of either 2004 AASHTO LRFD or ACl 318-05, and the other two had the maximum. The concrete compressive strength was changed from one pair of beams to the other. The variables under study in the prestressed specimens were the compressive strength of concrete and the amount of shear reinforcement. Concrete compressive strengths measured at the test dates varied from 13340 to 17040 psi.

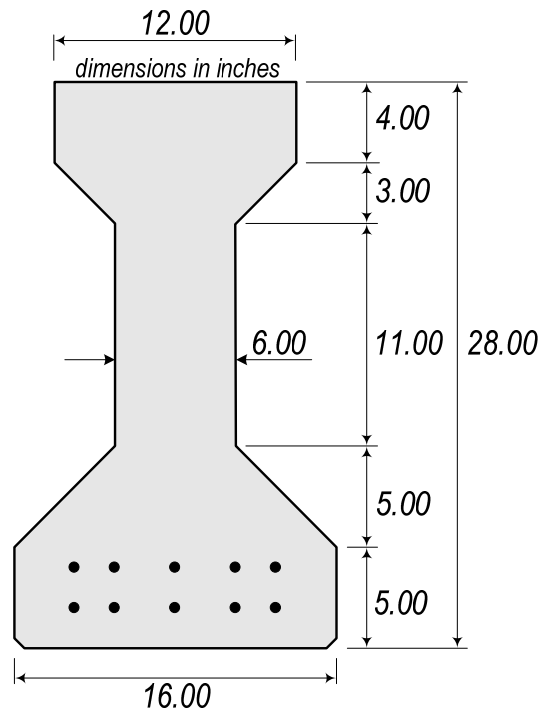

Figure 3.7
Cross section of prestressed concrete specimens 


\subsubsection{Dimensions}

All prestressed concrete specimens had an AASHTO Type I cross section. Figure 3.7 shows the typical cross section of the prestressed concrete specimens. As seen in Figure 3.7, the total depth of the specimens was $28 \mathrm{in}$. In this case, the top flange was 12-in. wide and the bottom flange was 16-in. wide. The web thickness was 6 in., the same as that of reinforced concrete specimens. Cross section was the same throughout the length of the specimens. The area of the cross section was $276 \mathrm{in}^{2}$.

The prestressed beams had two 92-in. long shear spans. The length of the shear span compared to the reinforced concrete specimens was increased to have the same a/d ratio in both reinforced concrete and prestressed concrete test specimens. Overhanging past the supports of $36 \mathrm{in}$. was provided to account for proper transfer of prestress force and to avoid shear tension failures. Total length of specimens was 256 in. The shear span to depth ratio of all prestressed specimens was 3.6. Each prestressed beam required $1.51 \mathrm{yd}^{3}$ of concrete and weighted $6130 \mathrm{lb}$, approximately. Figure 3.8 shows an elevation view of the prestressed concrete specimens.

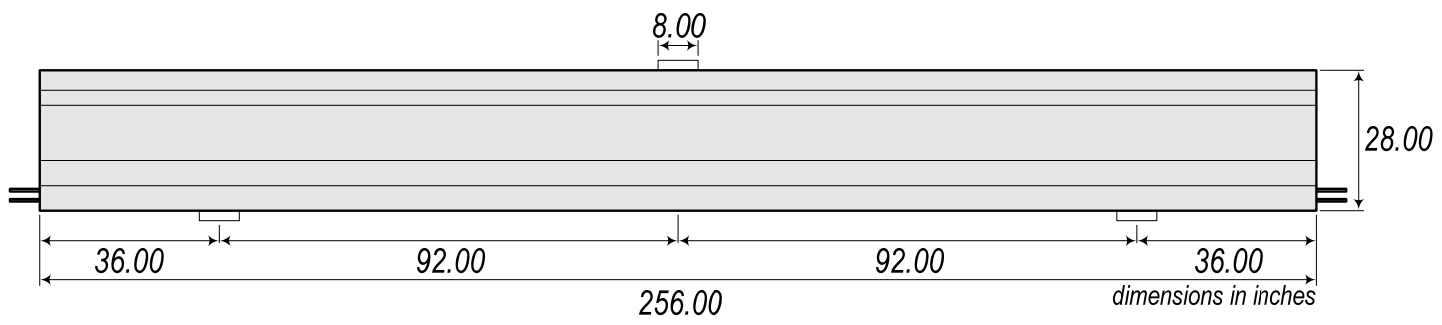

Figure 3.8 Elevation view of prestressed concrete specimens

\subsubsection{Reinforcement}

All prestressed concrete specimens had the same longitudinal reinforcement, located in both top and bottom flanges. Ten No. 8 bars were used for the tension longitudinal reinforcement. Eight of them were bundled in pairs. In the top flange, six No. 8 bars, four of them bundled in pairs were used. The longitudinal mild reinforcement ratio on the basis of web width was $5.14 \%$. For the top flange, the longitudinal mild reinforcement ratio on the basis of web width was $3.09 \%$. Large amounts of longitudinal reinforcement were necessary to prevent a flexural failure from occurring before the desired shear failure. Longitudinal bars were straight and continuous through the length of the beams. These bars were all Gr. 60 .

The prestressing steel consisted of 1/2-in. special seven-wire low-relaxation, uncoated prestressing strand. Ten strands were located in two layers of five strands each in the bottom flange of all prestressed specimens. Ultimate strength of the strands was $270 \mathrm{ksi}$. 
The shear reinforcement was provided by means of No. 4 closed stirrups. Two of the specimens had stirrups spaced at $18 \mathrm{in}$. on centers, whereas in the other two the center to center spacing was $4.5 \mathrm{in}$. The 18-in. spacing corresponds to the maximum specified in 2004 AASHTO LRFD $\left(0.8 d_{v}\right)$. Stirrups free ends were anchored by 90-deg. hooks. Stirrups were made with Gr. 60 steel.

Additional reinforcement was provided in both top and bottom flanges and at midheight of the cross section. No. 3 bars were used at the flanges. There, reinforcement had the shape of the flanges and was spaced 12 in. No. 4 bars were used as longitudinal reinforcement of the web. All reinforcement was tack welded together to form the steel cages. Four lifting hooks were provided. These hooks were formed with a section of prestressing cable inside a steel pipe bent into an inverted V-shape (Figure 3.10e). Table 3.3 presents the details for the prestressed concrete specimens. Figure 3.9 shows the reinforcement of these test specimens.

Table 3.3 Details of prestressed concrete specimens

\begin{tabular}{|c|c|c|c|c|c|c|c|c|}
\hline \multirow{2}{*}{ Specimen } & \multirow{2}{*}{$b_{w}$, in. } & \multirow{2}{*}{$D$, in. } & \multirow{2}{*}{$d_{v}$, in. } & \multirow{2}{*}{$f_{c, p s i}$} & \multicolumn{2}{|c|}{ Longitudinal Reinforcement } & \multicolumn{2}{|c|}{ Transverse Reinforcement } \\
\hline & & & & & Bars & $A_{s,}$ in. ${ }^{2}\left(\rho_{w}, \%\right)$ & Bars & $A_{v}$, in. ${ }^{2}\left(\rho f_{y v}, p s i\right)$ \\
\hline \multirow{2}{*}{$13.3-5.1-326 P$} & \multirow{2}{*}{6.00} & \multirow{2}{*}{25.60} & \multirow{2}{*}{20.16} & \multirow{2}{*}{13340} & 10 No. 8 & $7.90(5.14)$ & No. 4 & \multirow{2}{*}{$0.40(326)$} \\
\hline & & & & & 6 No. 8 & $4.74(3.09)$ & $s=18 \mathrm{in}$ & \\
\hline \multirow{2}{*}{$16.2-5.1-326 P$} & \multirow{2}{*}{6.00} & \multirow{2}{*}{25.60} & \multirow{2}{*}{20.16} & \multirow{2}{*}{16150} & 10 No. 8 & 7.90 (5.14) & No. 4 & \multirow{2}{*}{$0.40(326)$} \\
\hline & & & & & 6 No. 8 & $4.74(3.09)$ & $s=18 \mathrm{in}$ & \\
\hline \multirow{2}{*}{ 13.7-5.1-1305P } & \multirow{2}{*}{6.00} & \multirow{2}{*}{25.60} & \multirow{2}{*}{20.16} & \multirow{2}{*}{13730} & 10 No. 8 & $7.90(5.14)$ & No. 4 & \multirow{2}{*}{$0.40(1305)$} \\
\hline & & & & & 6 No. 8 & $4.74(3.09)$ & $s=4.5 \mathrm{in}$. & \\
\hline \multirow{2}{*}{$17.0-5.1-1305 P$} & \multirow{2}{*}{6.00} & \multirow{2}{*}{25.60} & \multirow{2}{*}{20.16} & \multirow{2}{*}{17040} & 10 No. 8 & $7.90(5.14)$ & No. 4 & \multirow{2}{*}{$0.40(1305)$} \\
\hline & & & & & 6 No. 8 & $4.74(3.09)$ & $s=4.5 \mathrm{in}$. & \\
\hline
\end{tabular}

* The compressive stress due to prestressing steel, $\mathrm{fpc}_{\mathrm{pc}}$ was $1225 \mathrm{psi}$.

\subsubsection{Construction}

The four prestressed concrete specimens were cast at the Prestress Services Inc. plant located in Decatur, IN. Steel forms along the prestressing beds were used. Forms were cleaned and treated with a release agent before the reinforcing cages were introduced. The reinforcement was divided into the bottom flange portion; and the web and top flange reinforcement portion. Once the reinforcing cages were put together, the electrical resistance strain gages were glued at selected locations. When all the internal instrumentation (see Section 3.4.2) was ready, the bottom flange portions of the reinforcing cages were set along one prestressing bed and the eight prestressing strands located outside the stirrups were run through all four beams. The selection of the same arrangement of prestressing strands in the cross section of all test specimens proved to be a good measure to cast all specimens in one prestressing bed. 

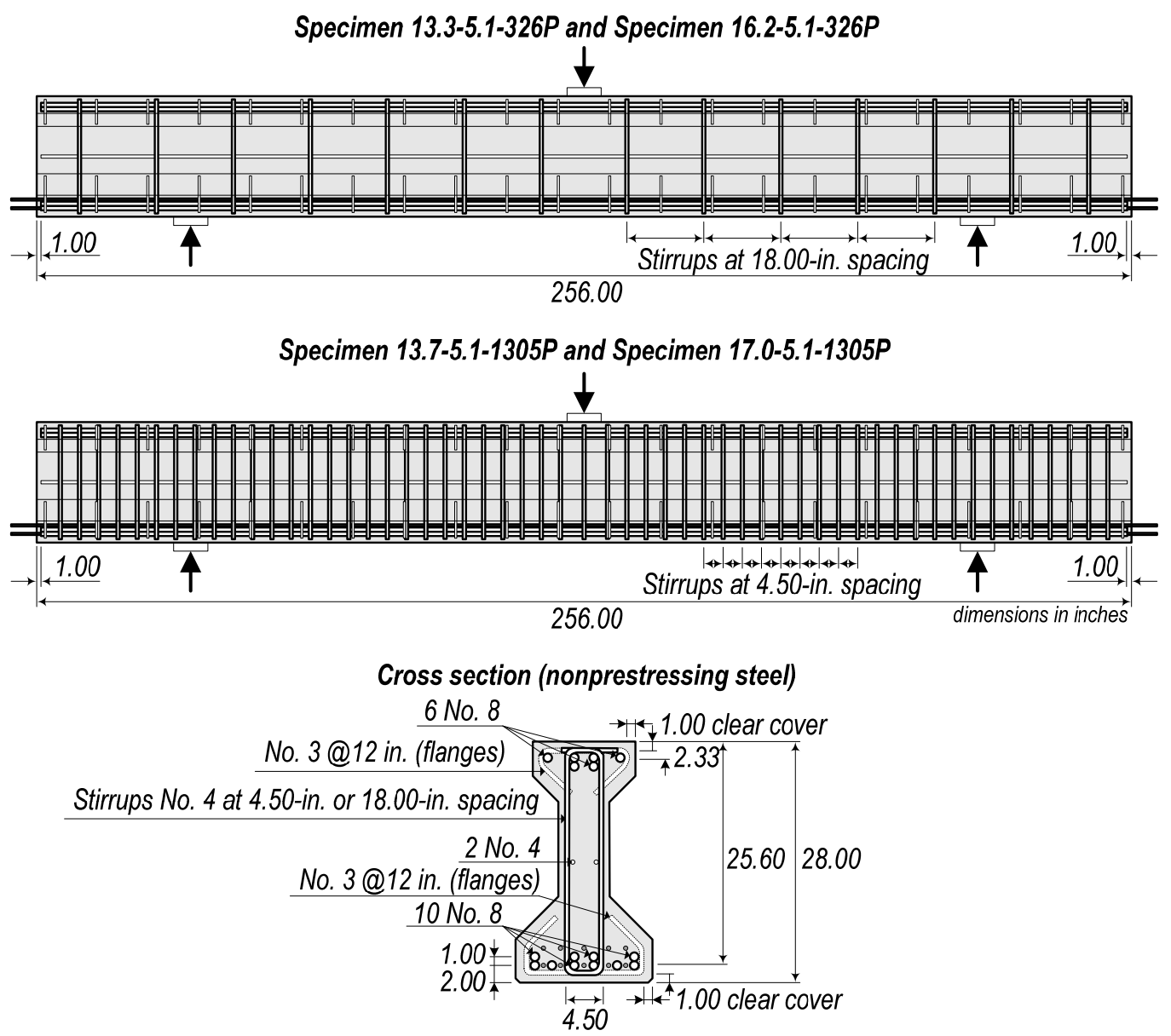

Cross section (prestressing steel)

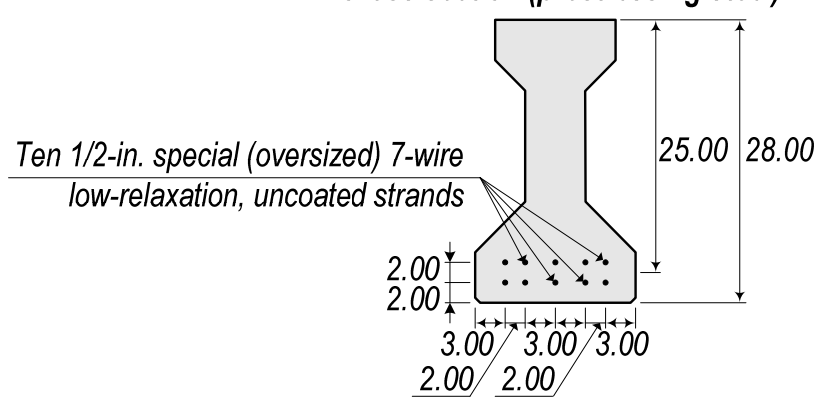

Figure $3.9 \quad$ Reinforcement details of prestressed concrete specimens

After those eight strands were inserted, a small tension force $(3000 \mathrm{lb})$ was applied to avoid tangling. Then, the two strands that were to be instrumented with electrical resistance strain gages were selected from the group of eight and tensioned to the specified force and the corresponding locations of the strain gages marked. After the locations to be instrumented were marked, these two strands were detensioned and allowed to rest on the prestressing bed. 
Once the instrumentation of strands concluded, the web and top flange portion of the reinforcing cage was brought into the forms and the two remaining strands were placed. Additional time was then required to run the wires of the electrical resistance strain gages from each instrumented location to various output ports. Then the forms were placed in their final position and all strands were tensioned to the specified force $(33818 \mathrm{lb})$. A symmetric order starting on the outside of the cross section was followed to apply the prestress force to the strands.

All four beams were cast the same day using two different batches corresponding to two different concrete strengths. Each batch had enough concrete to cast two specimens and their accompanying cylinders. Concrete was mixed at the concrete station of the prestressing plant and transported to the location of the forms in mixing trucks. The concrete was placed in the forms using a chute, directly from the mixing truck. The beams were cast in two lifts and concrete was consolidated using electric hand held vibrators of 3/4-in. diameter.

As with the reinforced concrete specimens, concrete samples were taken. Thirty-two $4 x 8-i n$. cylinders were sampled from each batch using new plastic molds. Steel rods, 3/8-in diameter, were used for the consolidation of samples, as indicated in ASTM C 192-05. Due to transportation limitations from the prestressing plant to the Kettelhut Laboratory, no flexural beams were sampled for the prestressed concrete specimens.

After casting, the prestressed beams were covered with plastic for two days. The concrete compressive strength was monitored and verified that it had reached 5000 psi. After two days, transfer of prestress was done by flame-cutting the strands with an oxyacetylene torch. Beams were removed from the prestressing bed and placed in a storage area for two days. There, the untwisted wires at the end of strands were ground $6 \mathrm{in}$. away from the end faces, and the edges of the beam cleaned with a hand held electric grinder. Four days after the cast, the beams were shipped to the Kettelhut Laboratory where they were air-cured until the respective test date. The age of specimens at the time of test ranged from 21 to 44 days. Figure 3.10 shows some photographs of the reinforcement, the cast, and the removal operation of the prestressed specimens.

\subsection{Materials}

The materials used in the construction of the test specimens were sampled and tested to determine their properties. This section summarizes the results of the testing. This section is subdivided into two subsections each corresponding to the materials used in the construction of the test specimens. 


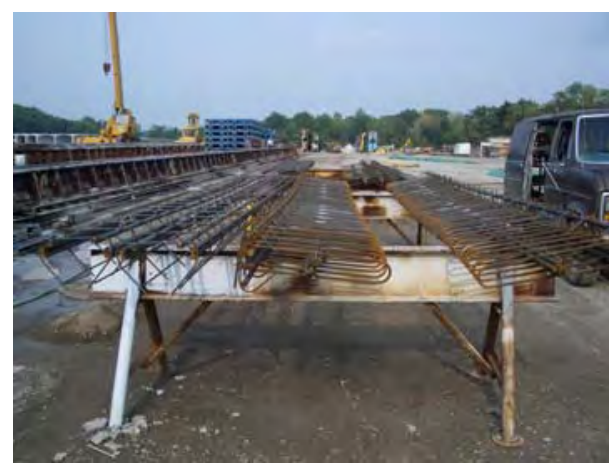

a) Bottom flange portion, and web and top flange portion of the reinforcing cages

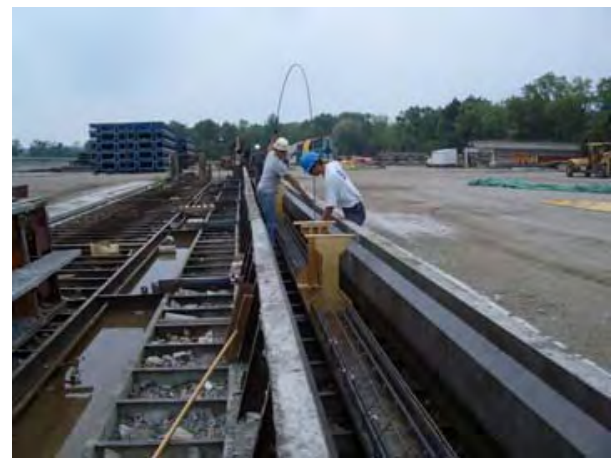

c) Run of prestressing strands

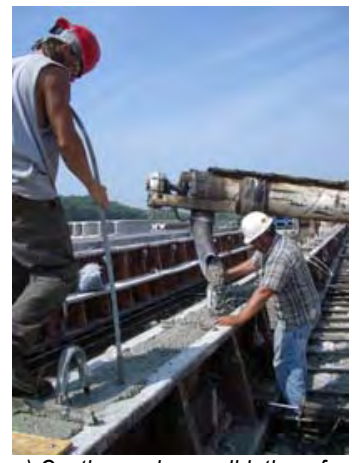

e) Casting and consolidation of concrete

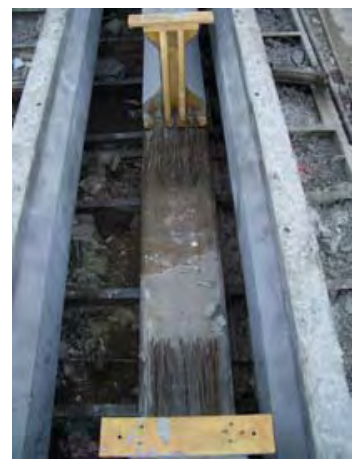

g) Strands after flame cutting

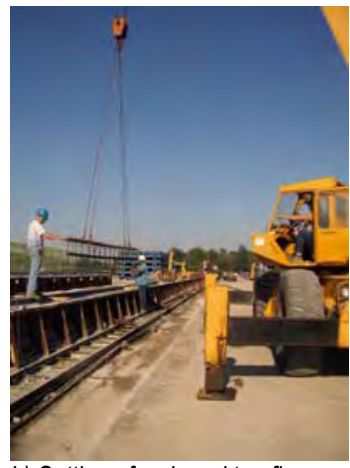

b) Setting of web and top flange portion of the reinforcing cage

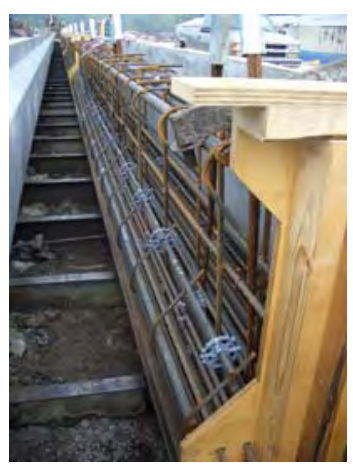

d) Final view of reinforcement before closing of forms

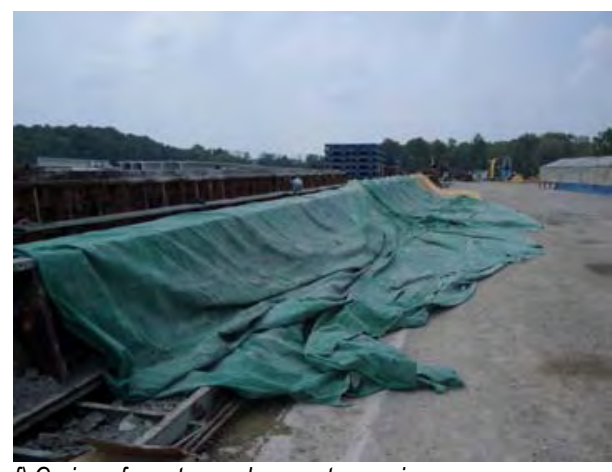

f) Curing of prestressed concrete specimens

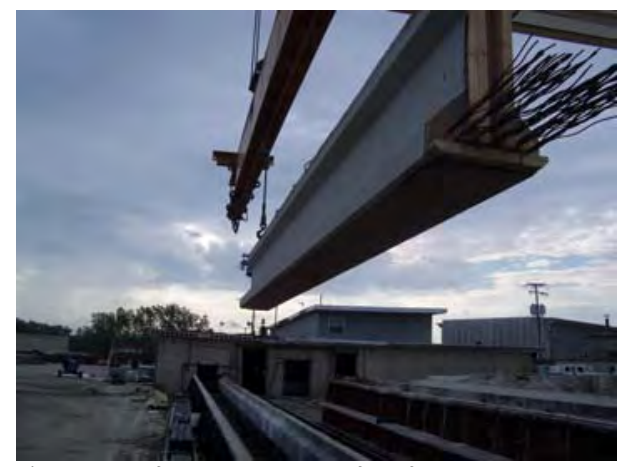

h) Removal of prestressed beam from form

Figure 3.10 prestressed concrete specimens 


\subsubsection{Concrete}

All reinforced concrete specimens were constructed at the Kettelhut Structural Engineering Laboratory of Purdue University (West Lafayette, IN). The four prestressed concrete specimens were cast at the Prestress Services Inc. plant located in Decatur, IN. Trial batches were conducted casting of the test specimens at both locations. The target concrete compressive strengths were in the range of 10000 to 15000 psi.

In the reinforced concrete specimens, the mix designs developed at Purdue University were initially used (Jonsson, 2002). Jonsson tried different mix designs in the laboratory and had obtained compressive strengths up to 14010 psi at 28 days. From Jonsson (2002), mixes LG-2, LG-4 and LG-7 were selected. These mixes had measured compressive strengths at 28 days of 10600 , 12870 and 14010 psi, respectively. Additionally, Mix 4, a 17000 psi concrete mix design from Burg and Ost (1994), which was recommended by S. Newbolds from the Study Advisory Committee of this project was used. The mix proportions were given to a local ready-mix supplier (Irving Materials, Inc.) and the mixing station at the prestressing plant and samples were taken to evaluate their strength. A total of 21 concrete cylinders were sampled for each trial batch. These cylinders were tested in groups of three at ages ranging from 1 to 91 days.

Essroc Type I cement was used in all batches for the reinforced concrete specimens. Type III cement was used in the prestressed concrete specimens. The coarse aggregates were 3/8-in. pea gravel and 1/2-in. crushed limestone. Natural sand was used as fine aggregate. Both fine and coarse aggregates at the local ready-mix supplier were provided by the Vulcan Materials Co. plant in Delphi, IN. To achieve higher compressive strengths, different amounts of silica fume were added to the mixes.

Two independent batches of $2 y d .^{3}$ of concrete each were done for each mix design for the reinforced concrete specimens. Every other batch, two test specimens without shear reinforcement were cast. It was decided that, even if the measured compressive strength of the batch would not meet the target strength, useful information would be obtained from the specimens without shear reinforcement with regards to the shear strength provided by the concrete alone.

After the first two trial batches of the reinforced concrete specimens, it became evident that the measured concrete compressive strengths were going to be difficult to achieve. Careful review of the batching and mixing process at the local plant showed that several factors affecting the target compressive strength were present. A different mix volume and a totally different control of the dosification method between the laboratory conditions and the ready-mix plant, and a different brand of admixtures were among the factors that most negatively impacted the obtained compressive strength. The inclusion of an air entraining agent, used by default by the local ready- 
mix, also affected the measured compressive strengths of concrete. After these variables were identified, slight changes to the original mix designs by Jonsson were done and the trial batches continued. Better results were obtained after these changes were implemented.

For the prestressed concrete specimens, the concrete mixes of the reinforced concrete specimens that had shown the highest compressive strength were used. These mixes were provided to the concrete mixing station and two trial batches, one for each target compressive strength, were carried out.

Table 3.4 and 3.5 show the actual mix proportions for each trial batch obtained directly from the dosification station at the local ready-mix plant or from the concrete mixing station at the prestressing plant. Table 3.4 and 3.5 also present information on other tests conducted to the fresh concrete, like slump and air content. At least one slump measurement and the air content were carried out in every batch. On occasion, multiples tests were carried out to verify the data. When more than one test was done, their results were averaged. As a reference, the measured compressive strength of concrete, $f_{c}$, at 28 days is included in Table 3.4 and 3.5. The water to cementitious materials ratio, $W / C$ is also reported in these tables.

Table 3.4 Actual mix proportions for batches of specimens without shear reinforcement

\begin{tabular}{|c|c|c|c|c|c|c|c|c|}
\hline \multirow{2}{*}{ Ingredient } & \multicolumn{8}{|c|}{ Amount per cubic yard } \\
\hline & Mix I & Mix II & Mix III & Mix IV & Mix V & Mix VI & Mix VII & Mix VIII \\
\hline Cement, Ib & 778 & 778 & 778 & 778 & 775 & 773 & 945 & 945 \\
\hline Silica fume, Ib & 38 & 38 & 40 & 38 & 38 & 38 & 150 & 150 \\
\hline Water, lb & 277 & 269 & 260 & 260 & 234 & 241 & 225 & 237 \\
\hline Fine aggregate, Ib & 1206 & 1207 & 1225 & 1215 & 1227 & 1275 & 981 & 1010 \\
\hline Coarse aggregate, Ib & 1580 & 1580 & 1592 & 1580 & 1580 & 1560 & 1780 & 1780 \\
\hline Air entraining agent, $\mathrm{oz}$ * & 16 & 17 & 12 & 12 & 10 & 9 & - & - \\
\hline$N R W R, o z$ * & 70 & 70 & 57 & 57 & 33 & 32 & 38 & 38 \\
\hline$H R W R, o z$ * & 181 & 181 & 163 & 164 & 178 & 170 & 518 & 520 \\
\hline$W / C$ & 0.34 & 0.33 & 0.32 & 0.32 & 0.29 & 0.30 & 0.21 & 0.22 \\
\hline Slump, in & 5.0 & 9.0 & 5.5 & 5.5 & 4.0 & 3.5 & 7.5 & 6.5 \\
\hline Air, $\%$ & 6.0 & 6.0 & 3.0 & 3.0 & 3.0 & 3.0 & 3.0 & 3.0 \\
\hline$f_{c}$, psi at 28 days & 8300 & 7510 & 9290 & 7950 & 10750 & 10060 & 11750 & 12540 \\
\hline \multirow{2}{*}{ Specimens } & & $7.0-1 \cdot 3-0$ & & 7.9-1.3-0 & & $10.6-1.3-0$ & & $11 \cdot 5-1.3-0$ \\
\hline & & $7.0-2.6-0$ & & $7.9-2.6-0$ & & $10.6-2.6-0$ & & $11.5-2.6-0$ \\
\hline
\end{tabular}


Table 3.5

Actual mix proportions for all batches of specimens with shear reinforcement and prestressed concrete specimens

\begin{tabular}{|c|c|c|c|c|c|c|}
\hline \multirow{2}{*}{ Ingredient } & \multicolumn{6}{|c|}{ Amount per cubic yard } \\
\hline & Mix IX & Mix X & Mix XI & Mix XII & Mix XIII & Mix XIV \\
\hline Cement, Ib & 778 & 896 & 733 & 733 & 800 & 800 \\
\hline Silica fume, Ib & 50 & 200 & 51 & 50 & 200 & 200 \\
\hline Water, Ib & 249 & 211 & 271 & 213 & 260 & 258 \\
\hline Fine aggregate, Ib & 1235 & 985 & 1098 & 1143 & 939 & 967 \\
\hline Coarse aggregate, Ib & 1612 & 1816 & 1729 & 1746 & 1610 & 1610 \\
\hline Air entraining agent, $\mathrm{oz}$ * & - & - & - & 7 & 5 & 8 \\
\hline$N R W R, \mathrm{oz}$ * & 35 & 38 & 39 & 39 & 66 & 60 \\
\hline$H R W R, o z$ * & 190 & 520 & 157 & 147 & 341 & 312 \\
\hline$W / C$ & 0.30 & 0.19 & 0.35 & 0.27 & 0.26 & 0.26 \\
\hline Slump, in & 9.5 & 10.5 & 7.5 & 8.5 & 6.5 & 9.5 \\
\hline Air, $\%$ & 3.5 & 4.7 & 3.3 & 4.7 & 4.0 & 3.2 \\
\hline$f_{c,}$ psi at 28 days & 11150 & 14030 & 14020 & 13930 & 18380 & 16450 \\
\hline \multirow{4}{*}{ Specimens } & $13.3-2.6-98$ & $14.5-2.6-98$ & & & & \\
\hline & $13.3-5.4-98$ & $14.5-5.4-98$ & & $13.3-5.1-326 P$ & & 16.2-5.1-326P \\
\hline & $13.2-4.3-451$ & 15.3-4.3-387 & & 13.7-5.1-1305P & & 17.0-5.1-1305P \\
\hline & 13.2-7.9-902 & 15.3-7.9-902 & & & & \\
\hline
\end{tabular}

Properties of hardened concrete were obtained for all concrete batches. Concrete compressive strength was determined according to ASTM C 39-04 from at least three cylinders at a given date. Concrete cylinders were capped with high-density neoprene pads as per ASTM C 1231-00. Even though the use of neoprene pads is not recommended for concrete compressive strengths over 12000 psi, it was observed that results did not differ much from cylinders capped with sulfur mortar. For their ease of use, neoprene pads were employed. Neoprene pads were discarded when indentations caused by the edges of concrete cylinders were present. Neoprene pads were used around 20 times before discarding.

The modulus of rupture of concrete was determined testing $6 \times 6 \times 24-i n$. flexural beams loaded at their third points according to ASTM C 78-02. One pair of beams was tested at a given test date and their results averaged. The tensile strength of concrete was obtained by the splitting test of 4x8-in. cylinders according to ASTM C 496-04. The average of two tests was taken as the representative value. The splitting test was not carried out for the cylinders sampled during the construction of the beams without shear reinforcement. All cylinders sampled were tested in a $600-k i p$ Forney ${ }^{\circledR}$ testing machine. Loading rate for the compressive strength tests was set at 
$2100 \mathrm{psi} / \mathrm{min}$. Loading rate for flexural beam tests and splitting tests was $150 \mathrm{psi} / \mathrm{min}$. All loading rates were within the limits prescribed in the corresponding ASTM Standards. Load was measured with a resolution of $10 \mathrm{lb}$. The testing machine was calibrated every three to five years.

Table 3.6 presents a summary of the hardened properties of concrete corresponding to each test specimen. The properties reported in Table 3.6 were measured the days of the test. In some occasions, the test of accompanying cylinders and flexural beams was done the day after the test. In Table 3.6, the modulus of rupture and the splitting tensile strength are also given in terms of $\sqrt{f_{c}}$, in $p s i$; as this parameter is often related to the tensile strength of concrete. Within the range of data collected, the average concrete tensile strength was $7.9 \sqrt{f_{c}}$ and $6.2 \sqrt{f_{c}}$ for the flexure beam and the splitting tests, respectively. Both values were under those obtained by other researchers and included in $\mathrm{ACl}$ 363-92. The differences with respect to the suggested values were 32 and $16 \%$, respectively.

Table 3.6 Properties of hardened concrete

\begin{tabular}{|c|c|c|c|}
\hline Specimen & Compressive Strength, psi & Modulus of Rupture, $p s i\left(\alpha \sqrt{f_{c}}\right)$ & Splitting Tensile Strength, psi $\left(\alpha \sqrt{f_{c}}\right)$ \\
\hline $7.0-1.3-0$ & 7000 & $670(8.0)$ & - \\
\hline $7.9-1.3-0$ & 7940 & $830(9.3)$ & - \\
\hline $10.6-1.3-0$ & 10630 & $880(8.5)$ & - \\
\hline $11.5-1.3-0$ & 11540 & $870(8.1)$ & - \\
\hline $7.0-2.6-0$ & 7000 & $670(8.0)$ & - \\
\hline $7.9-2.6-0$ & 7940 & $830(9.3)$ & - \\
\hline $10.6-2.6-0$ & 10630 & $880(8.5)$ & - \\
\hline $11.5-2.6-0$ & 11540 & $870(8.1)$ & - \\
\hline $13.3-2.6-98$ & 13290 & $880(7.6)$ & $740(6.4)$ \\
\hline $14.5-2.6-98$ & 14540 & $790(6.5)$ & $760(6.3)$ \\
\hline $13.3-5.4-98$ & 13290 & $880(7.6)$ & $740(6.4)$ \\
\hline $14.5-5.4-98$ & 14540 & $790(6.5)$ & $760(6.3)$ \\
\hline $13.2-4.3-451$ & 13160 & $940(8.2)$ & $720(6.3)$ \\
\hline $15.3-4.3-387$ & 15250 & $810(6.6)$ & $740(6.0)$ \\
\hline 13.2-7.9-902 & 13160 & $940(8.2)$ & $720(6.3)$ \\
\hline 15.3-7.9-902 & 15250 & $810(6.6)$ & $740(6.0)$ \\
\hline $13.3-5.14-326 P$ & 13340 & - & $700(6.1)$ \\
\hline $13.7-5.14-1305 P$ & 13730 & - & $730(6.2)$ \\
\hline $16.2-5.14-326 P$ & 16150 & - & $760(6.0)$ \\
\hline $17.0-5.14-1305 P$ & 17040 & - & $750(5.7)$ \\
\hline
\end{tabular}


Figure 3.11 shows the evolution of the compressive strength of concrete with time. Only the batches that were used for the construction of test specimens are presented in Figure 3.11. Just as a reference, the stress-strain relationship of HSC was determined. Two pairs of cylinders from Mix IX and Mix $X$ each were instrumented by adhering with a 2.3-in. long electrical resistance strain gage (Type FML-60-11 -120 $\Omega$ resistance- from Tokyo Sokki Kenkyujo Co., Ltd.) at their midheight. Then, the cylinders were tested monotonically to failure under a 600-kip hydraulic testing machine. The test was conducted using a load control procedure. Therefore, the descending branch of the stress-strain relationship could not be obtained. Failures were sudden and explosive. Figure 3.12 shows two representative plots of the stress-strain relationship that were obtained in the laboratory together with a close-up view of the one instrumented cylinder.
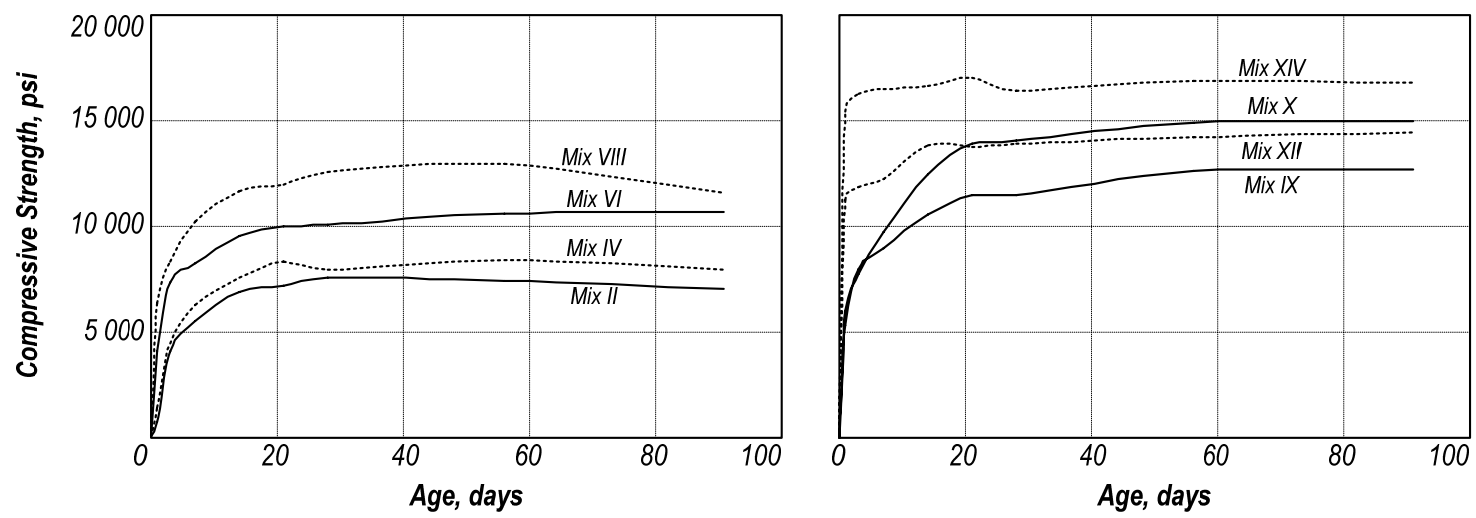

Figure 3.11 Evolution of concrete compressive strength
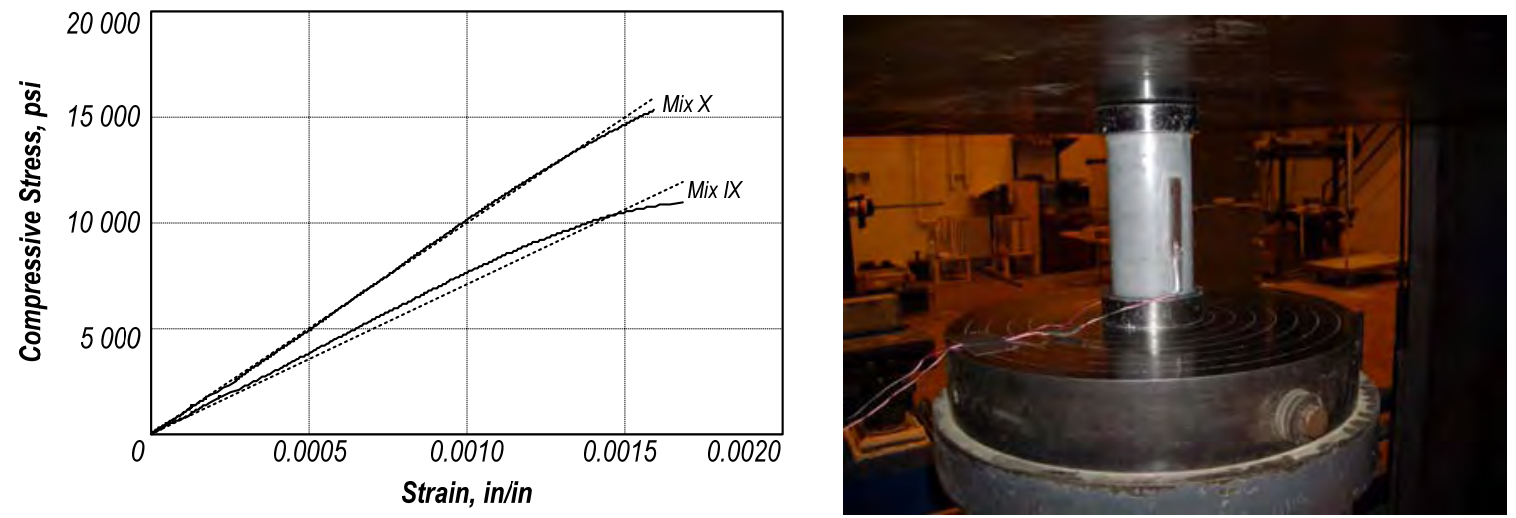

Figure 3.12

Measured stress-strain relationship for HSC and corresponding instrumented cylinder

The static modulus of elasticity, obtained as the average initial slope of the stress-strain plots, were 7080 and $9990 \mathrm{ksi}$ for Mix IX and Mix X, respectively. They are represented by the dotted lines 
in Figure 3.12. Both values measured were higher than the ones obtained using Eq. 2.18, and even higher than those obtained using $\mathrm{ACl}$ 363-92. Differences with respect to Eq. 2.18 were 15 and $29 \%$ for Mix IX and Mix X, respectively. Those differences were 27 and $40 \%$ when compared to ACl 363-92, respectively. ASTM C 469-02 was followed as a reference even though a compressometer was not used.

\subsubsection{Reinforcement}

All reinforcing mild steel used in the specimens was ASTM A 615-05. The mechanical properties of the reinforcement were determined by conducting tests of randomly sampled tension coupons. Three 36-in. long coupons of each bar size and reinforcement type used were sampled. All bars from a given size and type of reinforcement were from the same heat. Tension coupons were obtained from the same bars used in the fabrication of the specimens. ASTM A 370-05 Standard was followed throughout the test of the coupons.

To measure steel strains, each test coupon was instrumented with an electrical resistance strain gage and a 2-in. gage extensometer (MTS ${ }^{\circledR}$ Model 634.25E-54). The type of strain gage used in each tension coupon matched the one used to instrument the reinforcement of the test specimens, as described in Section 3.4.2 of this report. All tests were conducted in a 200-kip 4pole $\mathrm{MTS}^{\circledR}$ testing machine with displacement control. A single, continuous loading rate of $0.75 \mathrm{in} / \mathrm{min}$ was used throughout the tension tests. The testing machine had a precision of $10 \mathrm{lb}$ and $0.0001 \mathrm{in}$. It had not been calibrated for four years when it was used. Figure 3.13 shows the tension coupon test of a No. 8 bar.

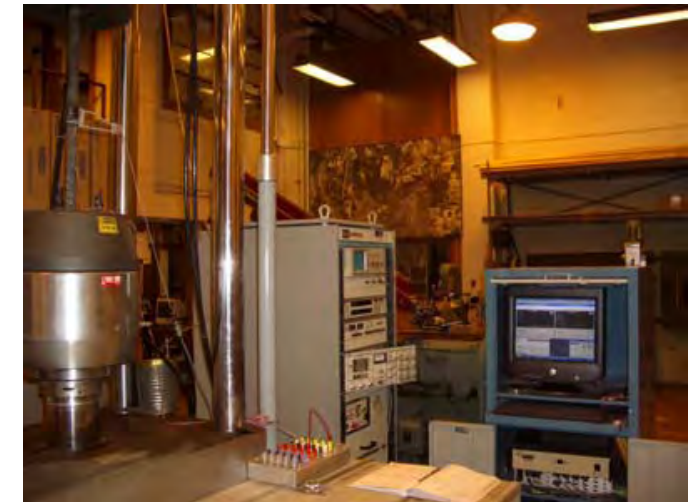

a) Four-pole MTS ${ }^{\circledR}$ testing machine, controller and data acquisition system

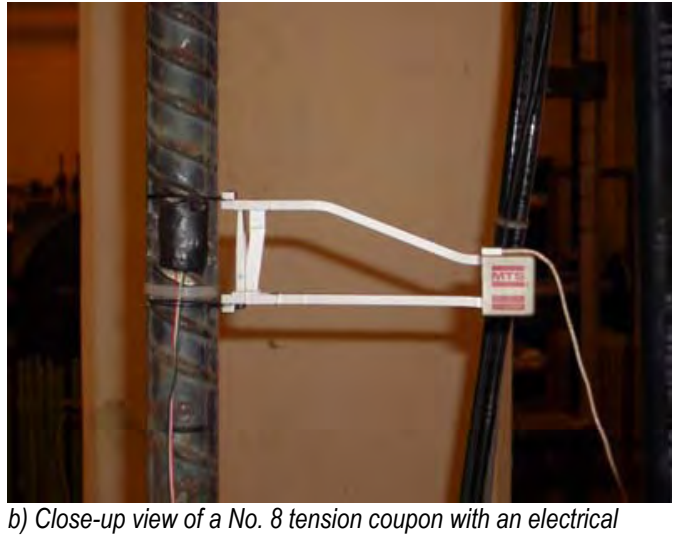

resistance strain gage and a 2-in. gage extensometer

Figure $3.13 \quad$ Tension coupon tests

The longitudinal reinforcement of the reinforced concrete specimens without stirrups consisted of No. 8 and No. 11 bars. The coupons for these bars were not instrumented with strain gages as there were none installed on the corresponding test specimens. The longitudinal reinforcement of 
the reinforced concrete specimens with shear reinforcement was provided by No. 8 and No. 10 bars. The shear reinforcement in these specimens was provided by No. 2 and No. 4 bars. No tension coupons were extracted from the No. 3 bars used for reinforcement of the flanges and the diaphragms. Figure 3.14 shows representative stress-strain relationships obtained for the different bar sizes used in the reinforced concrete specimens.

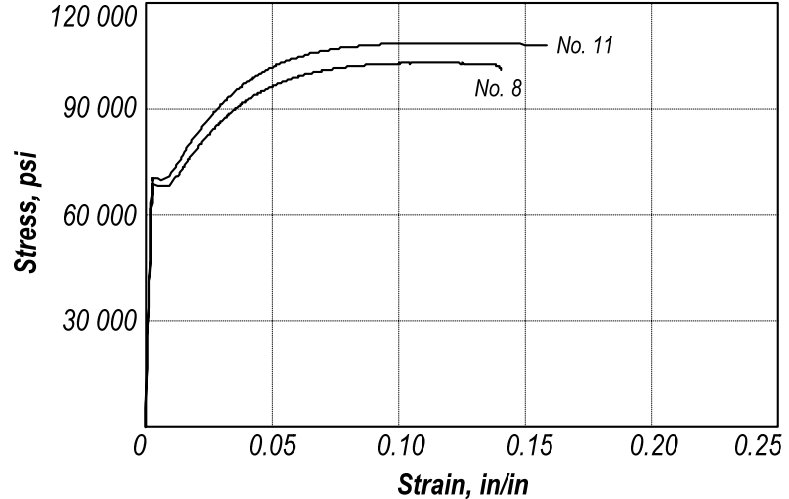

a) Specimens without shear reinforcement

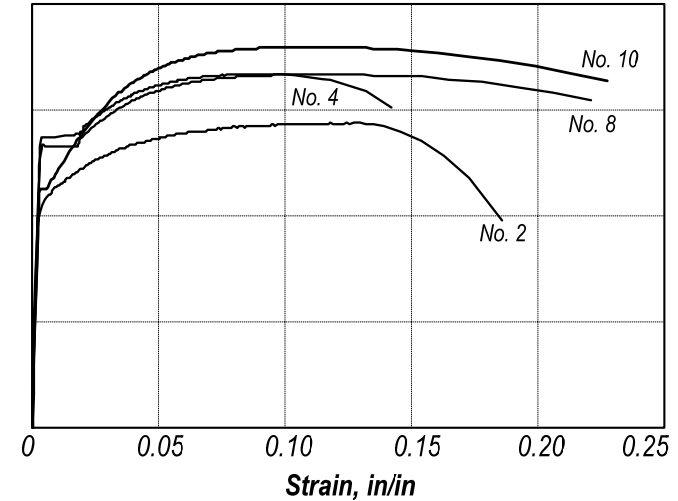

b) Specimens with shear reinforcement

Figure 3.14 Typical stress-strain relationships for the reinforcement of the reinforced concrete specimens

The longitudinal reinforcement of the prestressed concrete beams was provided with No. 8 bars. The stirrups were No. 4 bars. The prestressing strands were 1/2-in. special (oversized) seven-wire low-relaxation, uncoated strands. The corresponding representative stress-strain relationships of the reinforcement used in the prestressed beams are presented in Figure 3.15. All stress-strain relationships shown in Figure 3.14 and 3.15 were obtained with the 2-in. gage MTS $^{\circledR}$ extensometer.
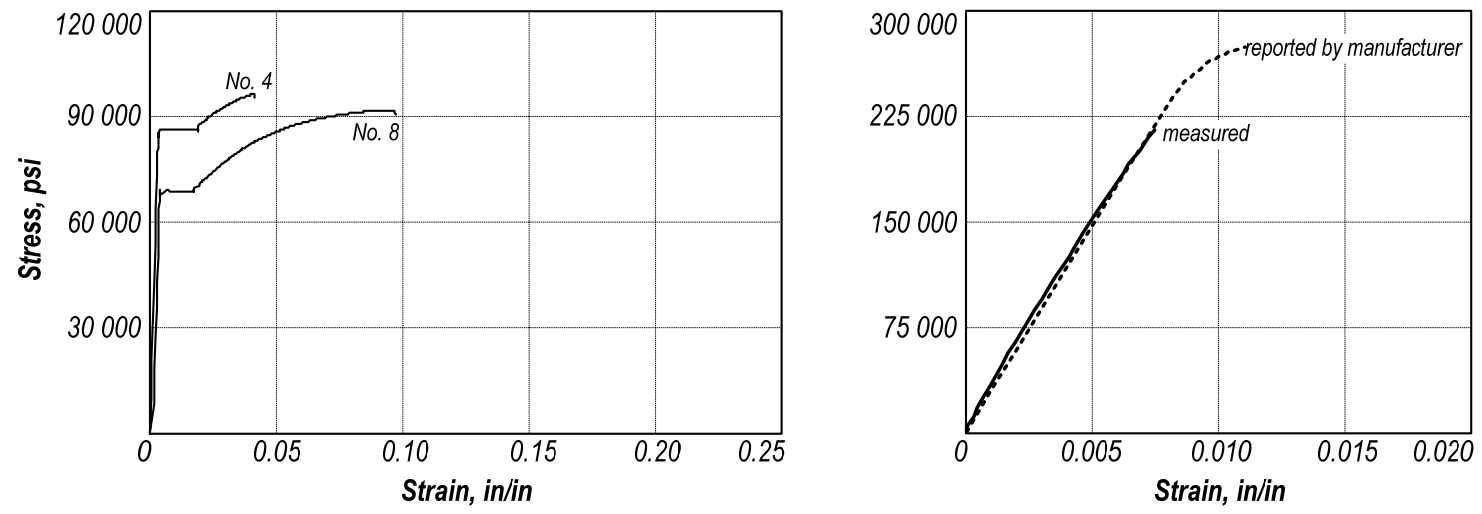

Figure 3.15 Typical stress-strain relationships for the reinforcement of the prestressed concrete specimens 
Table 3.7 summarizes relevant material properties of the reinforcement used in this research project. Data shown in Table 3.7 is the average of the three coupons tested for each type and size of reinforcement. No coupons were obtained from the No. 3 and No. 4 bars used as additional reinforcement in flanges, diaphragms or along the web in the prestressed concrete specimens as their influence in the behavior of the test specimens was considered minor. Data for the prestressing strands correspond to the reported by the manufacturer.

Table 3.7 Properties of steel reinforcement

\begin{tabular}{|c|c|c|c|c|c|}
\hline Series & Bar & $f_{y}, k s i^{*}$ & $f_{u, k s i}$ * & $\varepsilon y$, in./in. * & Elongation, \% * \\
\hline Reinforced concrete specimens & No. 8 & 68.3 & 103.6 & 0.0024 & 13.4 \\
\hline \multirow[t]{2}{*}{ without shear reinforcement } & No. 11 & 69.1 & 109.4 & 0.0024 & 12.0 \\
\hline & No. 2 & 59.0 & 82.3 & 0.0018 & 11.4 \\
\hline Reinforced concrete specimens & No. 4 & 81.2 & 99.5 & 0.0035 & 8.4 \\
\hline \multirow[t]{3}{*}{ with shear reinforcement } & No. 8 & 78.2 & 99.5 & 0.0032 & 14.4 \\
\hline & N0. 10 & 67.6 & 107.6 & 0.0029 & 11.2 \\
\hline & No. 4 & 85.0 & 95.4 & 0.0035 & 6.3 \\
\hline \multirow[t]{2}{*}{ Prestressed concrete specimens } & No. 8 & 70.9 & 94.1 & 0.0032 & 12.8 \\
\hline & 1/2-in. special strand & 243.0 & 270.0 & 0.0078 & - \\
\hline
\end{tabular}

\subsection{Instrumentation}

Depending on the location of the measuring devices and sensors, the instrumentation of the test specimens was divided in two broad categories: a) external instrumentation and, b) internal instrumentation. The type and location of instruments used in this research project were based on information obtained from previous research projects carried out at the Kettelhut Laboratory and from the references reviewed in Chapter 2.

The instrumentation was located at relevant points of the test specimens with the objective of studying their local and general behavior. Five types of devices were used: linear variable differential transformers (LVDTs), inclinometers, load cells, mechanical dial gages, and electrical resistance strain gages. The first four types were considered external instrumentation whereas the last one was part of the internal instrumentation.

The location and type of instrumentation allowed gaining complete information on the vertical displacement of the test specimens, the rotation at the supports, the applied loads, the support reactions, the slippage of the prestressing strands, and the strains in the concrete as well as in 
the nonprestressed and prestressed reinforcement. The location and the nomenclature used to describe the instrumentation were not changed significantly from one test specimen to the other to facilitate the comparison of data acquired.

\subsubsection{External Instrumentation}

The location of LVDTs, inclinometers, load cells and mechanical dial gages is shown in Figure 3.16 for the reinforced concrete specimens and in Figure 3.17 for the prestressed concrete specimens.
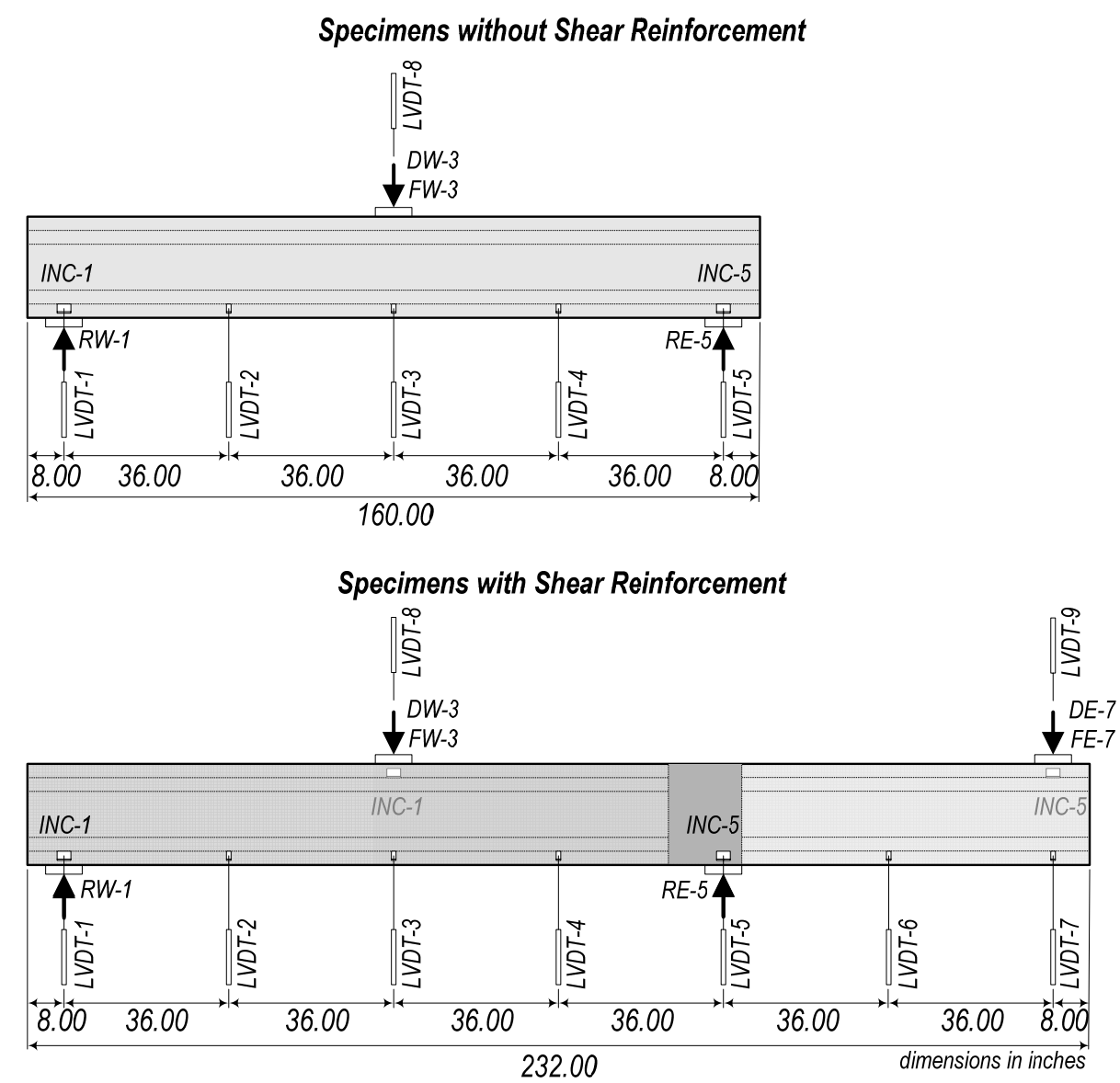

Figure 3.16 External instrumentation of the reinforced concrete specimens

Five to seven LVDTs were located along the test specimens to monitor deflections and vertical movement of supports (LVDT-1 to LVDT-7). These transformers were mounted on an aluminum frame and their cores mechanically connected to the points of measurement by means of 3/16-in. diameter threaded rods. These rods were fixed with nuts to small steel plates that were epoxy glued to the concrete surface. The aluminum frame was independent of the testing frame or the supports and was fixed to the laboratory floor by means of weights. When testing the reinforced 
concrete specimens, two more transformers (LVDT-8 and LVDT-9) were located at the loading points over the testing frame to check for its deflection during the tests, and correct other readings accordingly.

Lucas Schaevitz ${ }^{\mathrm{TM}}$ DC-operated transformers were used to measure vertical displacement of the test specimens and the beams of the loading frame. An excitation of $30 \mathrm{~V}$ was used throughout the tests. All LVDTs were Model DC-E 2000 which had a range of $\pm 2 \mathrm{in}$. The transformers used to monitor the movement of the loading frame were Model DC-EC 1000 with a range of \pm 1 in. LVDTs were calibrated before the tests using a Boeckeler micrometer with a range of $1 \mathrm{in}$. and a sensitivity of $0.00002 \mathrm{in}$. Calibration was done using the average of at least a dozen readings of the ratio of output voltage from the LVDT to the displacement in the micrometer. After the calibration, the readings in the transformers deviated as much as $0.054 \mathrm{in}$. from those in the micrometer.

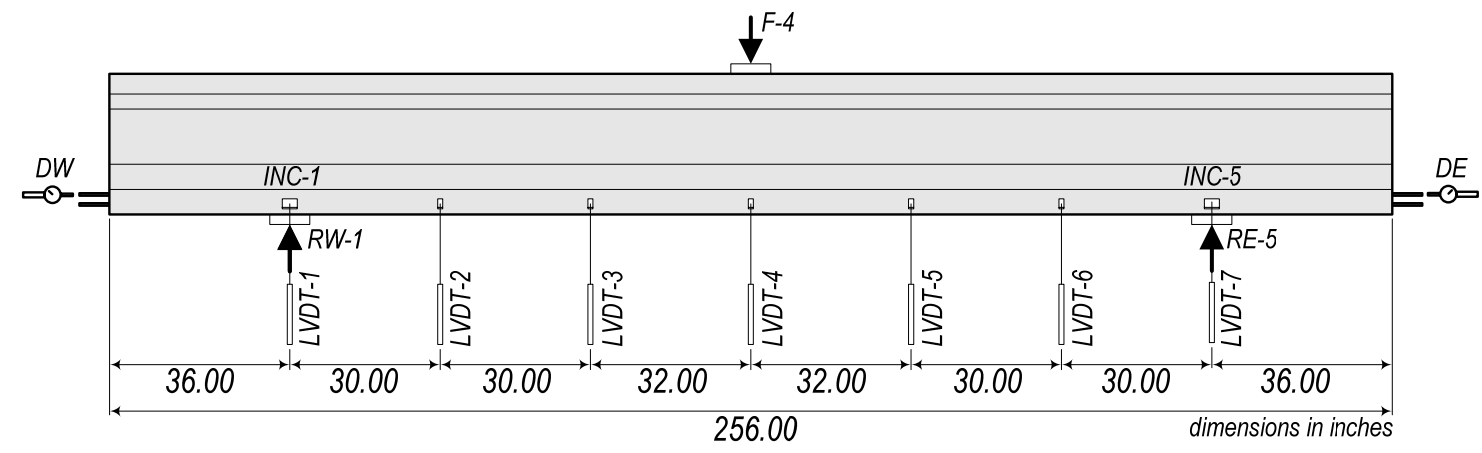

Figure 3.17 External instrumentation of the prestressed concrete specimens

Two inclinometers Model LSOC $14.5 \mathrm{Z}$ from Lucas Schaevitz ${ }^{\mathrm{TM}}$ were used at the supports to measure the rotation of the specimens at these locations (INC-1 and INC-5). Inclinometers were seated on a $2 \times 3-i n$. steel angle that was previously attached to the side of the beam by means of epoxy glue. The base of the inclinometers was $1 \mathrm{in}$. up from the bottom of the beams. When testing the cantilever region of the reinforced concrete specimens with shear reinforcement, the inclinometers were moved to the points of load application and their bases were located 2-in. down of the top of the beams. Inclinometers were excited with a direct current of $30 \mathrm{~V}$. Their manufacturer calibration was verified using the rotating table of a table saw. The rotation of the table was read directly from its rotating scale, with a precision of 0.25 -deg. The calibration from the inclinometers manufacturer was observed to be applicable and was used throughout the tests.

Two 300-kip fatigue resistant load Lebow cells (Model 3129-112 and 3129-113) were located at the supports (RW-1 and RE-5 in Figure 3.16 and 3.17). These load cells allowed the monitoring of reactions as the test evolved and were helpful in guarantying a symmetric application of the loads. These devices based their load measurement on a four strain gage, full-bridge system. 
The excitation voltage for the load cells was $10 \mathrm{~V}$. Load cells were calibrated using a 1951 600-kip Baldwin testing machine with a resolution of $100 \mathrm{lb}$. The Baldwin testing machine had not been calibrated for about ten years when it was used. However, it was used a few times only in that period. After the calibration of the load cells was done, the maximum difference in reading between the Baldwin testing machine and the load cells was $360 \mathrm{lb}$.

Finally, two Federal mechanical dial gages with 2-in. of travel distance were used to monitor the relative displacement between the end face of the prestressed beams and one prestressing strand (DW and $D E$ ). These gages had a sensitivity of $0.001 \mathrm{in}$. Figure 3.18 shows two details of the external instrumentation of the test specimens.

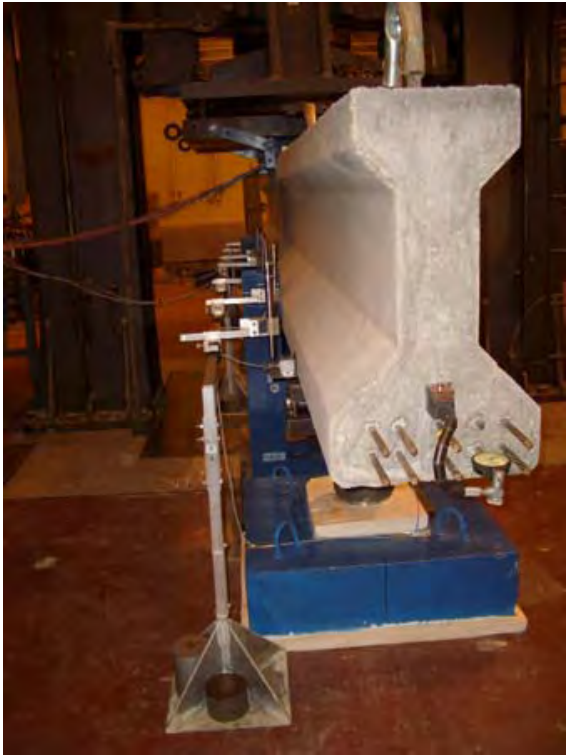

a) Detail of LVDTs, inclinometer and dial gage for relative displacement of prestressing strands

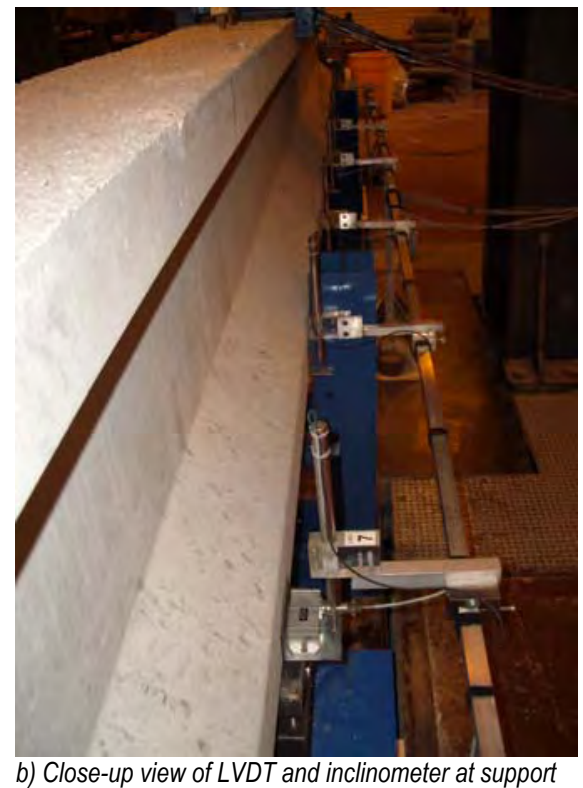

b) Close-up view of LVDT and inclinometer at support

Figure 3.18 Details of external instrumentation

Also part of the external instrumentation could be considered the displacement transducer (DW-3 and DE-7) and the force transducer (FW-3 and FE-7) installed in the 220-kip MTS ${ }^{\circledR}$ actuators used for the test of the reinforced concrete specimens. The calibration of these displacement and force transducers was carried out using one LVDT and one load cell that had been calibrated beforehand, as explained earlier in this section. Similarly, the 600-kip Baldwin testing machine that was used for the testing of the prestressed concrete specimens had been equipped with an internal LVDT which allowed the applied load to be read as an output voltage (F-4). A constant relating the output voltage with the load had been obtained previously at the Kettelhut Laboratory and was verified to be still applicable at the time the tests were carried out. 
Another set of external measurements using an electronic Whittemore gage was carried out on the reinforced concrete specimens with shear reinforcement and the prestressed concrete specimens. This device had been successfully used at Purdue University to measure deformations of the concrete surface (Malone, 1999; Pujol, 2002). The Whittemore gage consisted of an aluminum tube of 1.5-in square section in which an LVDT was mounted. The body of the transformer was fixed to the tube by means of a socket set screw. The core of the LVDT was attached to a linear crossed-roller bearing slide assembly which worked as a frictionless sliding device. Two 1/4-in. diameter drill-rod pins completed the Whittemore gage. One drill-rod was threaded to the aluminum tube near the fixing point of the LVDT, and the other was fixed to the sliding device. The moving drill-rod is maintained in its neutral position by tension springs. Both drill-rods had tapered ends which fit in the center hole of Whittemore discs. The drill-rods had to be longer $(1.5 \mathrm{in}$.) than in a usual Whittemore gage so that the gage could be used in the web of I-shaped specimens without readings being disturbed by the flanges.

\section{Reinforced Concrete Specimens with Shear Reinforcement}

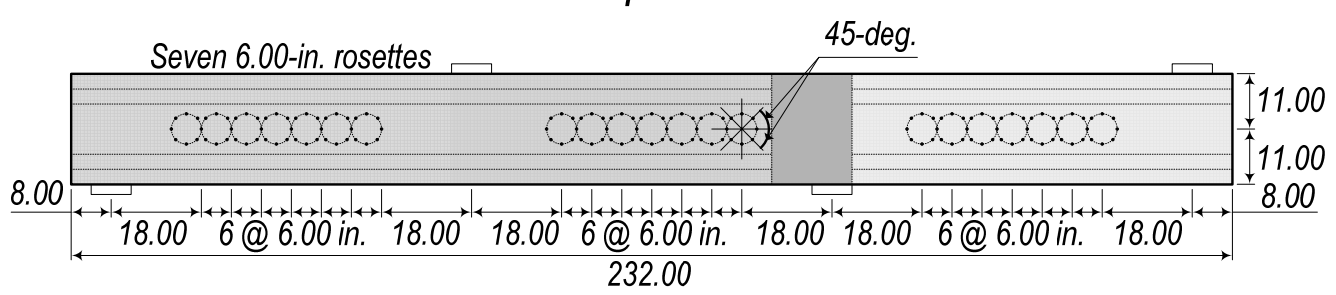

Prestressed Concrete Specimens

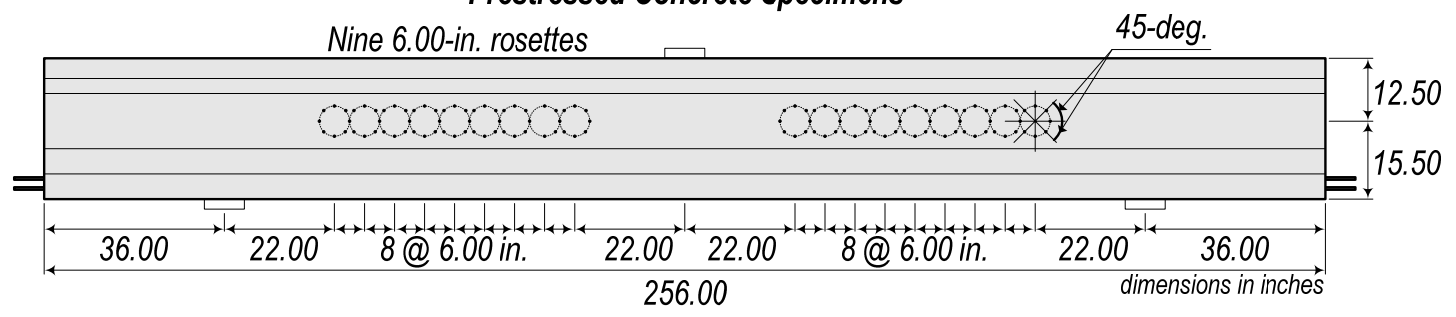

Figure $3.19 \quad$ Array of Whittemore discs

The change in distance between Whittemore discs affixed to the surface of the specimen allowed computation of the distribution of concrete deformations. A pair of discs was glued to a steel tube and used to monitor the stability of the gage during the tests. The Whittemore gages were observed to be stable within 0.02 in. during all the tests. The Whittemore discs, 3/8-in. diameter and 1/8-in. thick were made of steel and epoxy glued to the concrete surface of the test specimens at specific locations. Test specimens were tilted sideways to facilitate the adhesion of the discs. Seven 6-in. diameter rosettes with four readings each were located in each shear span of the reinforced concrete specimens with shear reinforcement (85 readings). Nine 6-in. diameter rosettes in each span were set on the prestressed concrete specimens (73 readings). Rosettes on each shear span were numbered sequentially from left to right. There were no Whittemore gage 
readings done in the reinforced concrete specimens without shear reinforcement. Figure 3.19 shows the array of Whittemore discs on the test specimens.

A single Whittemore gage with 6-in. gage length was used throughout the tests. The LVDT inside the Whittemore gage was a Lucas Schaevitz ${ }^{\text {TM }}$ Model DC-E 250 with a capacity of \pm 0.25 -in. This transformer was also calibrated using the Boeckeler micrometer referred earlier in this section. After calibration, the LVDT deviated from the micrometer reading a maximum of $0.005 \mathrm{in}$. Figure 3.20 shows a diagram and a photograph of the Whittemore gage used. The data acquired using the Whittemore gage is presented and analyzed in detail elsewhere (Aguilar, 2005). In Chapter 4 , only a summary of these measurements is presented. Crack widths were measured with plastic crack comparators provided by Construction Technology Laboratories, Inc.
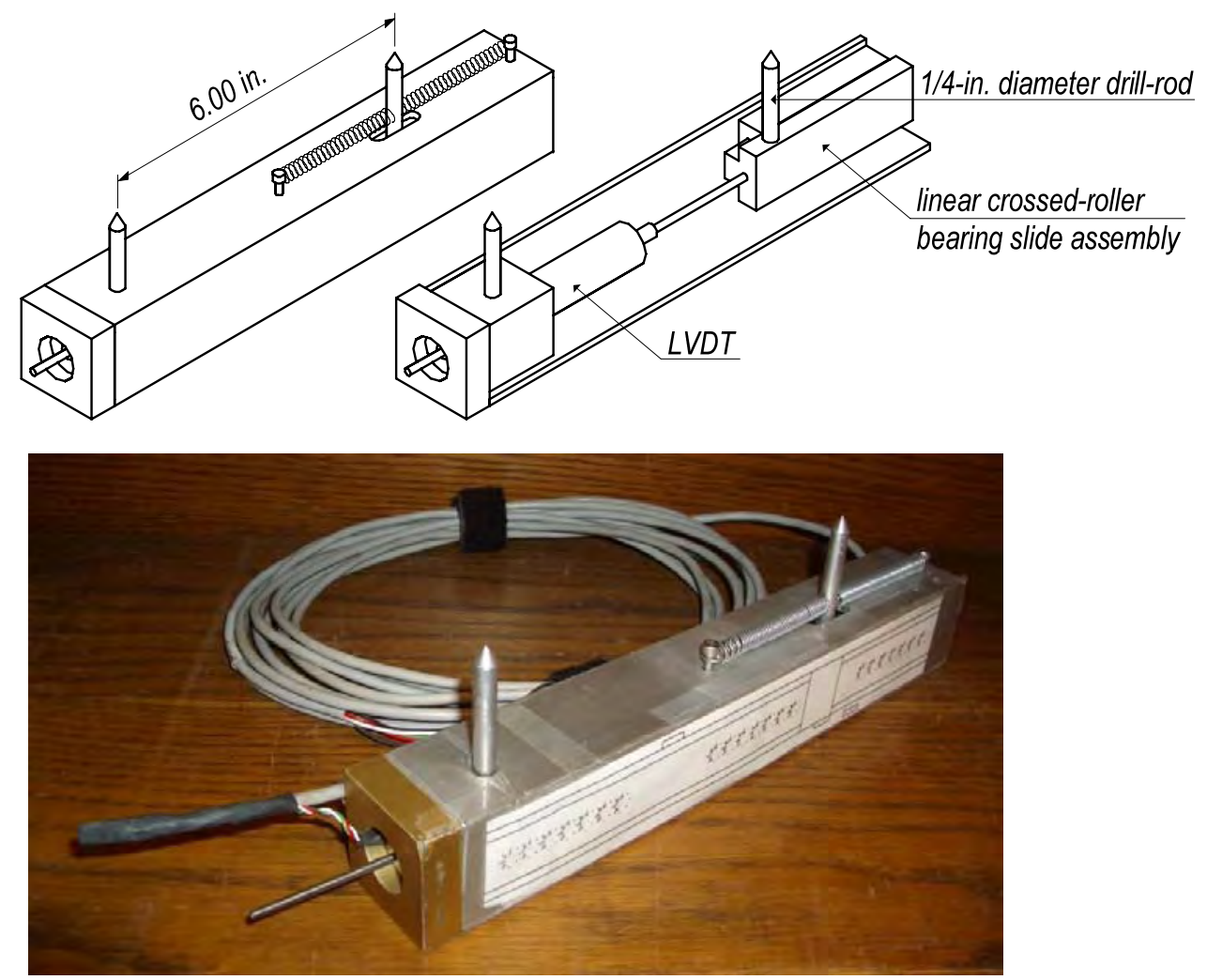

Figure $3.20 \quad$ Electronic Whittemore gage

\subsubsection{Internal Instrumentation}

The internal instrumentation of the test specimens consisted of electrical resistance strain gages. These devices were either installed on the reinforcement or embedded in the concrete at selected locations. 
The strain gage system was provided by Vishay ${ }^{\circledR}$ Micro-Measurements Group, Inc. (Raleigh, NC). The geometry of selected gages depended on the type and size of reinforcement. The gages installed on the No. 4 bars of the transverse reinforcement, and the No. 8 and No. 10 bars of the longitudinal reinforcement were type CEA-06-250UN-120 and CEA-06-250UN-350 foil gages. Type EA-06-125BT-120 foil gages were used to instrument No. 2 stirrups and prestressing strands.

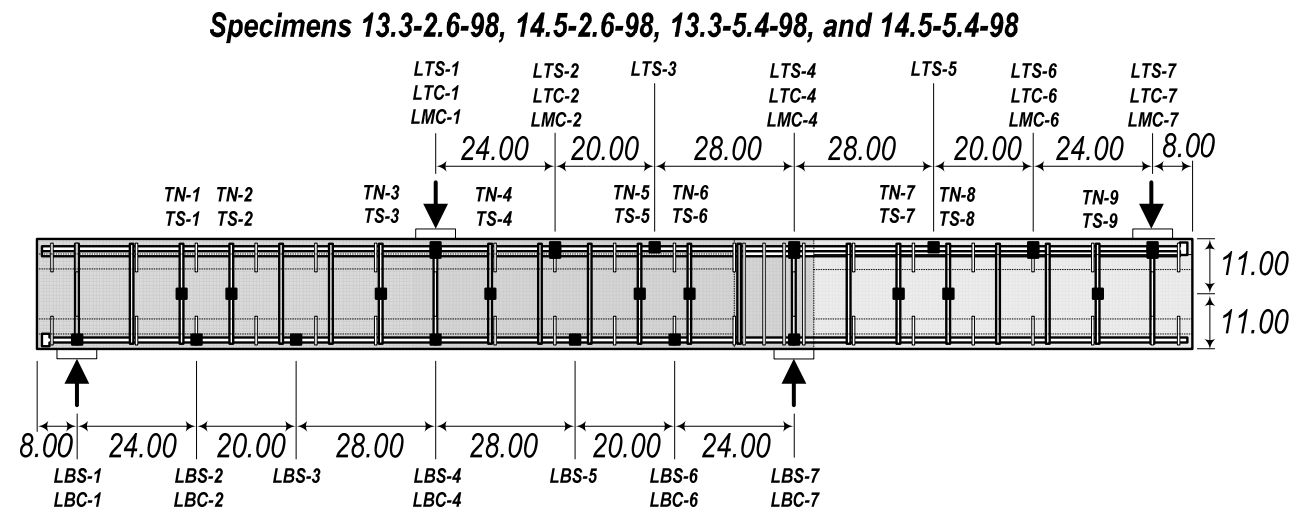

Specimens 13.2-4.3-451, 15.3-4.3-387, 13.2-7.9-902, and 15.3-7.9-902

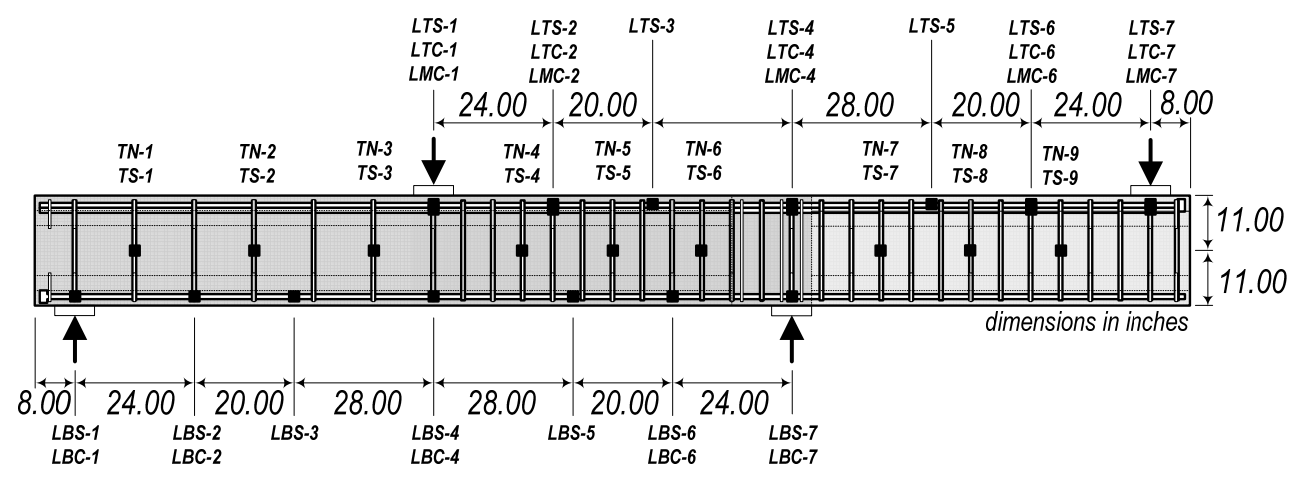

Cross Section

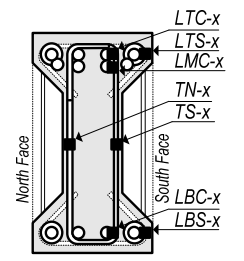

Identification Scheme:

LTS: Longitudinal Top bar (South face)

LTC: Longitudinal Top bar (Center of cross section)

LMC: Longitudinal Middle bar (Center of cross section)

LBS: Longitudinal Bottom bar (South face)

LBC: Longitudinal Bottom bar (Center of cross section)

TN: Transverse North leg of stirup

TS: Transverse South leg of stirup

Figure 3.21

Strain gage location in the reinforced concrete specimens with shear reinforcement

Strain gages were installed after grinding the deformations of the bars. Pujol (2002) had observed that grinding of the longitudinal deformation of the bar resulted in a change in the cross section area large enough to change the overall mechanical properties of the bar. Care was taken not to grind the longitudinal deformation of the bar when installing the strain gages. Only transverse 
deformations were ground and continuous visual inspection to prevent excessive reduction of the cross section of the bar was conducted. The number of deformations ground was kept to a minimum. In the case of prestressing strands, no grinding was necessary.

After grinding the required transverse deformations of the bars, the area was dry-abraded with 220- and 320-grit silicon carbide paper. Then it was wet-abraded with M-Prep Conditioner A and 400-grit silicon carbide paper. Final cleaning before installation of the gages was done with $\mathrm{M}$ Prep Neutralizer 5A. A cyanoacrylate-based adhesive, M-Bond 200, was used to attach the gages.
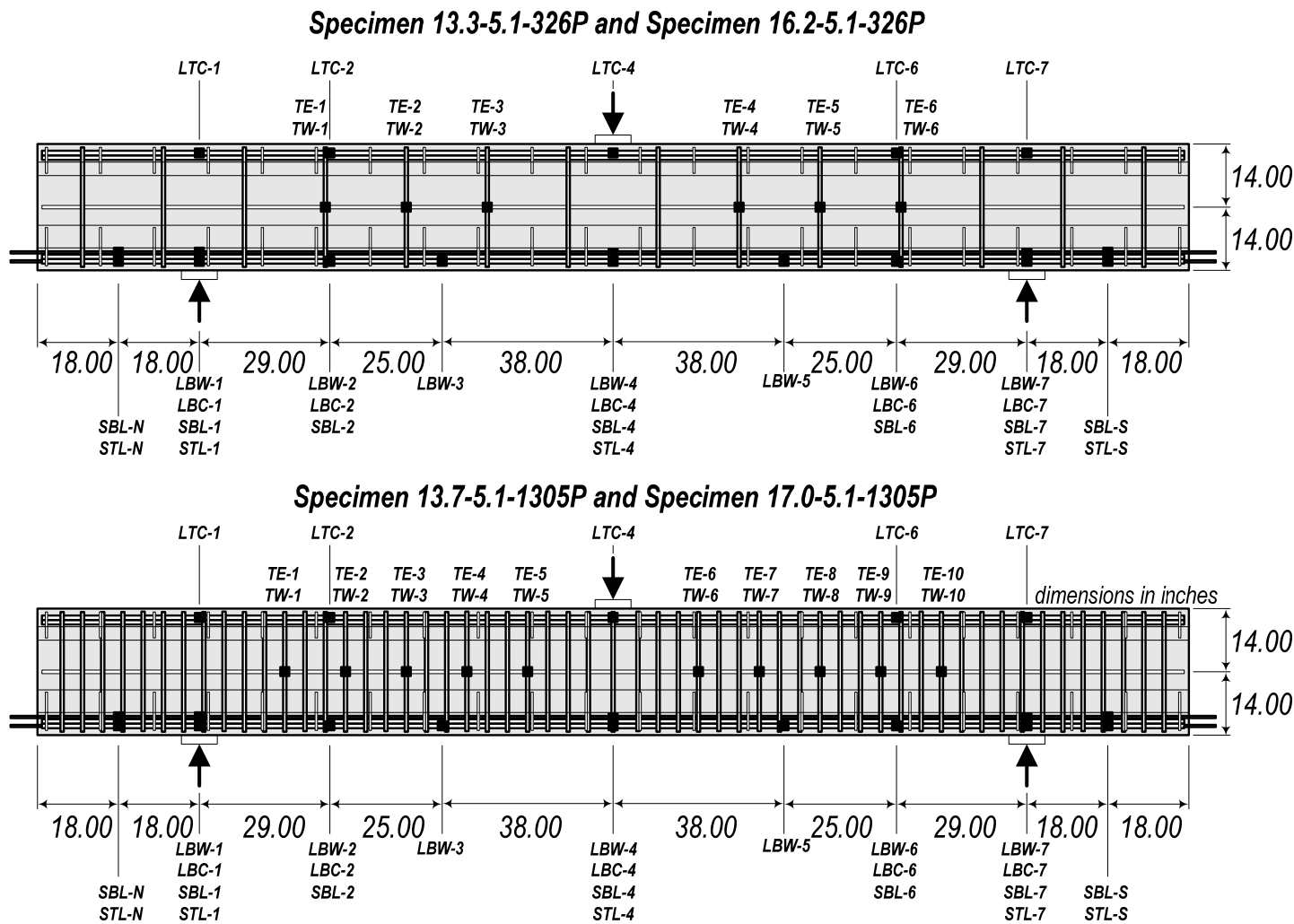

Cross Section

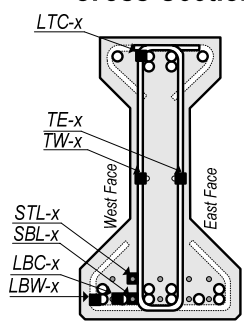

Identification Scheme:

LTC: Longitudinal Top bar (Center of cross section)

LBC: Longitudinal Bottom bar (Center of cross section) LBW: Longitudinal Bottom bar (West face)

SBL: Strand Bottom Layer

STL: Strand Top Layer

TE: Transverse East leg of stirrup

TW: Transverse West leg of stirrup

Figure 3.22 Strain gage location in the prestressed concrete specimens

Each strain gage was connected to the data acquisition system with 26 gage 3-wire cable (Model 326-DFV). Cables were guided along the reinforcement to various output ports using plastic ties. 
Different lengths of cable were used depending on the location of each gage. It was intended that each cable had around $72 \mathrm{in}$. from the output points in the specimen to the data acquisition system. After the electric connection between gages and their cables was done, the strain gages were coated with solvent-thinned polyurethane (M-Coat $A$ ). Mechanical protection and moisture barrier for the gages was finally provided by means of a butyl rubber sealant (M-Coat FB). In all cases, the installation procedure and recommendations of Vishay ${ }^{\circledR}$ Micro-Measurements Group, Inc. were followed.

The location of strain gages on the reinforced concrete specimens with shear reinforcement is shown in Fig. 3.21. In these specimens, nine closed stirrups -three per shear span- were instrumented. Strain gages were located at midheight of both vertical legs. Also, five bars of the longitudinal reinforcement were instrumented in various sections along the beam. Five to seven strain gages were installed on each instrumented longitudinal bar.

In the prestressed beams, either three or five stirrups per shear span were instrumented with strain gages located at their midheight. Both vertical legs of the stirrups were instrumented. Also, three longitudinal bars were instrumented with five to seven gages. Two prestressing strands had strain gages installed. A prestressing strand of the bottom layer had seven strain gages, and the prestressing strand of the top layer had five gages on it. The location of strain gages in the prestressed concrete specimens is shown in Fig. 3.22.

The strain gages embedded in the concrete were provided by Kyowa Electronic Instruments, Co., Ltd., and Tokyo Sokki Kenkyujo Co., Ltd. Type KM-120-H1 (2.36-in. gage length) from Kyowa was used in gages placed in the longitudinal direction of the specimens and type PML-30 from Tokyo Sokki (1.18-in. gage length) were used in the transverse (vertical) direction.

A pair of embedded gages, one perpendicular to the other, was located

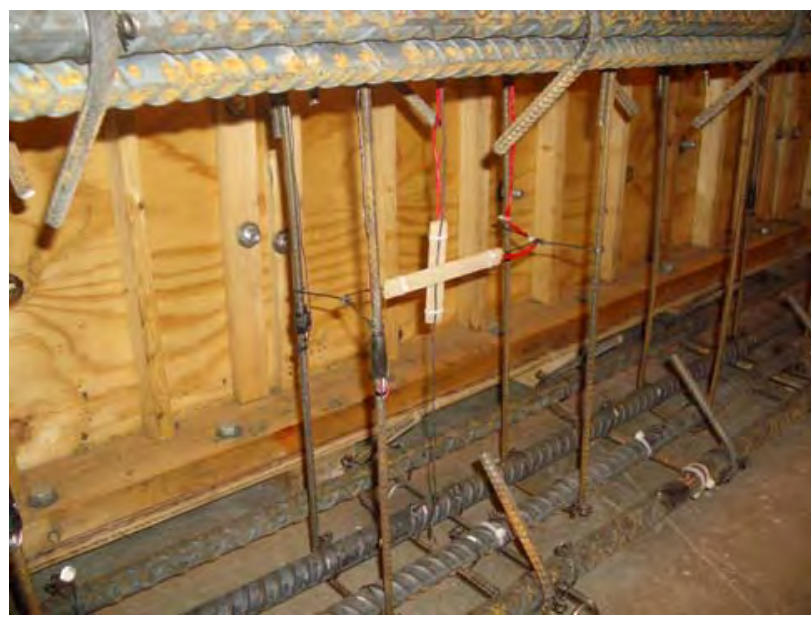

Figure 3.23 Detail of embedded concrete gages at midheight of the beam at the center of the test shear spans. Steel wire was used to position the gages in the middle of the web thickness. Only the reinforced concrete specimens with shear reinforcement had embedded gages. Figure 3.23 shows a detail of the embedded strain gages. 


\subsection{Test Procedure}

The test specimens were subjected to monotonically increasing loads up to failure. To apply the loads, two test configurations were used. In this section, test setups, data acquisition system used and test procedure followed are described.

\subsubsection{Test Setup}

The reinforced concrete specimens were tested under two identical steel frames. The design criteria for each test frame were: a) to carry loads high enough to cause failure in HSC beams, b) to maintain the load without sudden and/or large changes, c) to have adequate rigidity to avoid excessive deformations, and d) to not impose restrictions for the development and propagation of cracking in the test specimens.

The test setup included two steel frames independently anchored to the reaction floor of the laboratory by means of 1.75 -in. diameter high strength steel threaded rods and specially designed and manufactured 3.5-in. diameter plug inserts. Each frame consisted of two 180-in. long columns made with two C10x25 steel shapes positioned 15-in. apart. An 82-in. long W14x132 shape served as a reaction beam between the columns. Under each frame, a 220-kip MTS ${ }^{\circledR}$ actuator (Model 244.51) was located. These actuators had a displacement and a force transducer (Model $661.31 \mathrm{E}-01$ ). The range of displacement of the $\mathrm{MTS}^{\circledR}$ actuators was \pm 5 in. Both ends of the actuators had swivel heads (Model 249.51). The upper swivel was locked in its neutral equilibrium position by means of the attached Superbolt ${ }^{\circledR}$ Torquenut (Model ST-175-12). Lower swivel was left free to rotate. The $3000-p s i$ hydraulic pressure required to drive the actuators was provided by a $70 \mathrm{gpm} \mathrm{MTS}^{\circledR}$ pump (Model 506.61D).

These actuators were independently controlled using an $\mathrm{MTS}^{\circledR}$ 458.20 MicroConsole equipped with two 458.11 DC and two 458.13 AC modules for load and displacement control, respectively. The 458.91 MicroProfiler included in the MicroConsole was not used. The reinforced concrete specimens without shear reinforcement were tested using a load controlled scheme. The tests of reinforced concrete specimens with stirrups were displacement-controlled. In all instances, the controller was manually operated.

The test setup was checked for strength and stability before the tests were carried out. The full 220-kip capacity of the actuators was reached without problems being noticed during the two load tests carried out for each frame. In the case of the reinforced concrete specimens without shear reinforcement, which had two shear spans, only one actuator was used. When the three-shear span reinforced concrete specimens with shear reinforcement were tested, both actuators were employed. Before each test, both actuators were checked to assure their verticality. Figure 3.24 shows a photograph and a sketch of the test setup used for the reinforced concrete specimens. 


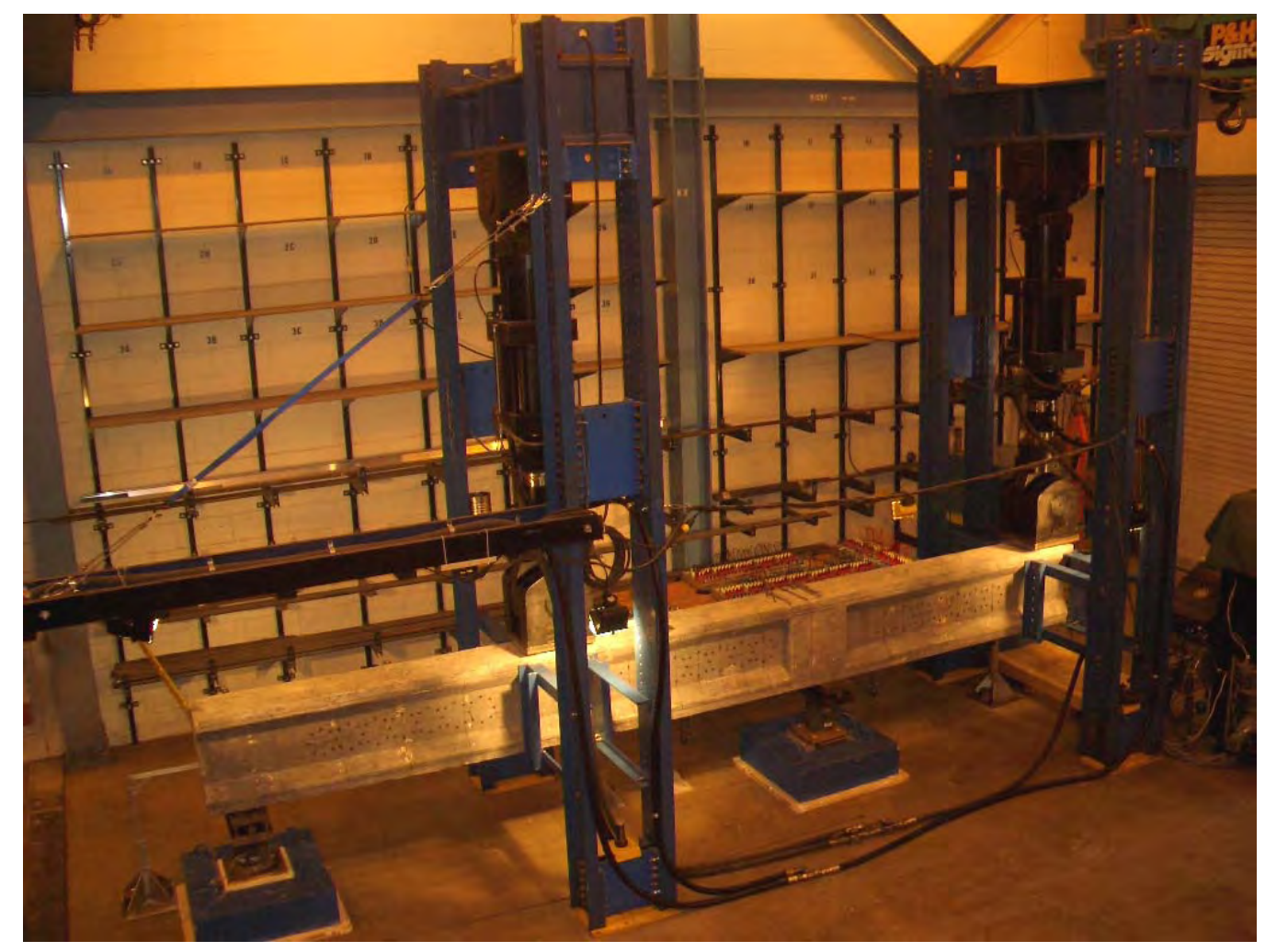

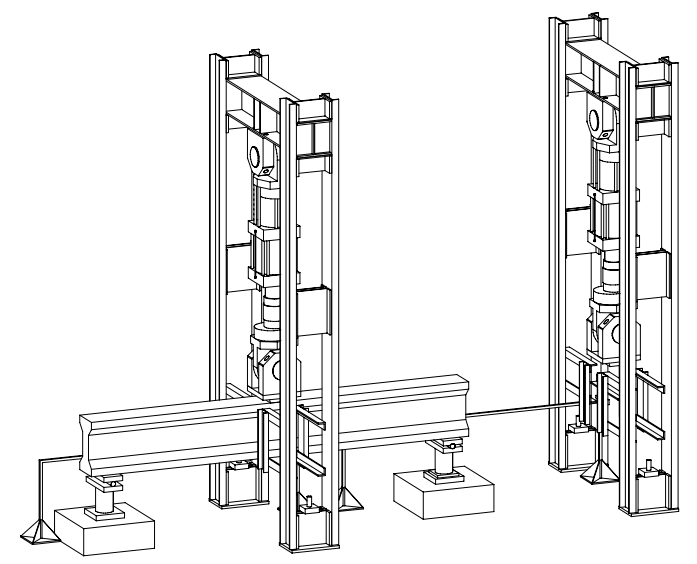

Test setup for specimens without shear reinforcement

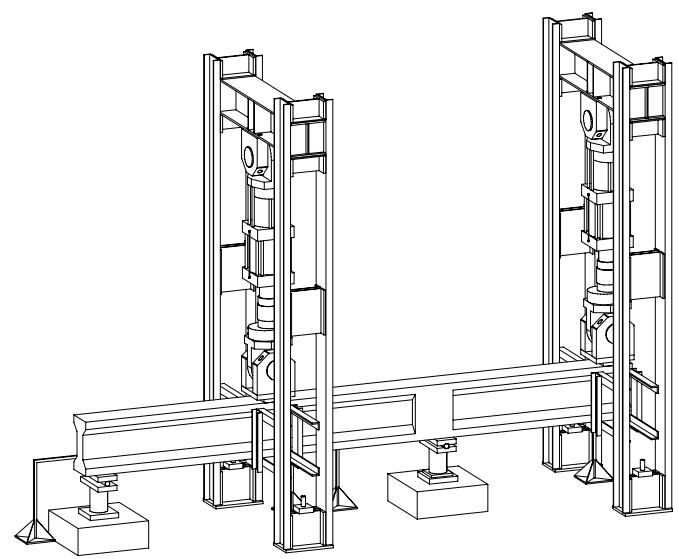

Test setup for specimens with shear reinforcement

\section{Figure 3.24 Test setup for reinforced concrete specimens}

Due to the increase in depth from the reinforced concrete to the prestressed concrete specimens, it was not possible to use the MTS ${ }^{\circledR}$ actuators to apply the estimated failure loads. Therefore, the prestressed specimens were placed under a 600-kip Baldwin testing machine. This machine is equipped with a ram with $36 \mathrm{in}$. of displacement. Only loads can be controlled with the Baldwin testing machine. The test setup used for the prestressed concrete specimens is shown in Figure 3.25. 


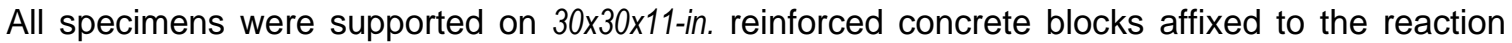

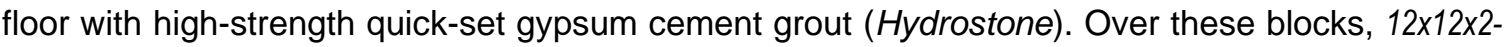
in. steel plates were leveled and fixed with the same type of cement grout. Then, the 300-kip Lebow load cells were placed over the assembly of plates. The top end of the load cells had an $8 \times 18 \times 2-i n$. steel plate bolted, which in turn supported a 2-in. diameter steel roller. These plates were machined with a concave groove to adequately hold the rollers. Over the rollers, $8 \times 18 \times 2-i n$. steel plates were placed. One of the top plates had a concave groove and was placed in one of the supports to work as a pin. The other plate was placed in the second support and rested flat on the roller. Specimens were positioned directly in contact with these plates.

As seen in Figure 3.24 and 3.25, lateral restrains were provided to avoid out of plane movement of the specimens. Each face of the reinforced concrete specimens was restrained with two 24-in. long C6x13 steel channels connected to the test frames by means of $L 3 \times 3 \times 1 / 2$ steel angles. The prestressed specimens were restrained with two W6x20 steel shapes anchored to the floor of the Baldwin testing machine by means of bolted C6x13 steel channels. No signs of out of plane displacement were observed throughout the tests.
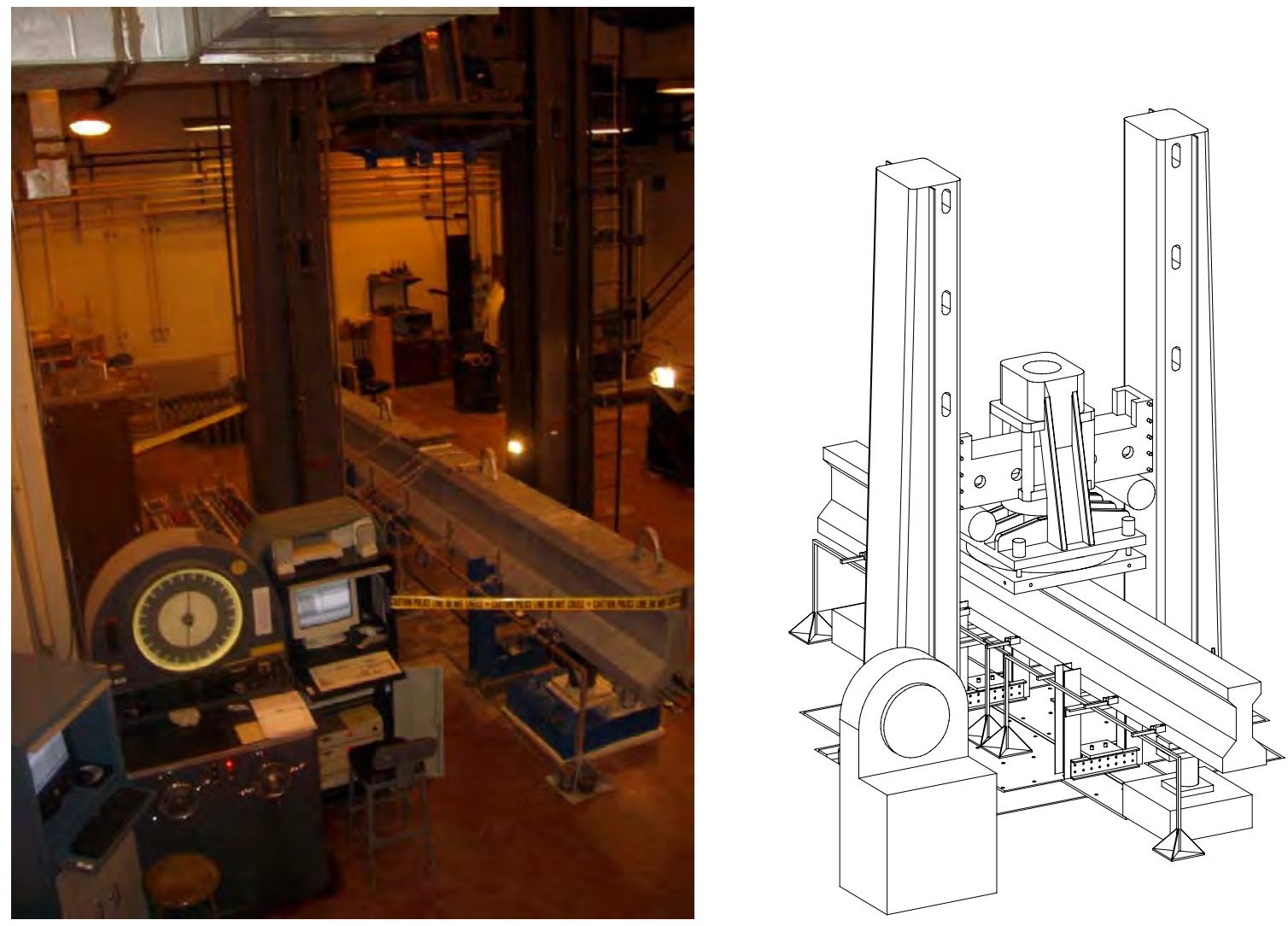

Figure 3.25

Test setup for prestressed concrete specimens 
To uniformly transmit the load from the actuators swivel or the head of the Baldwin machine to the top faces of the specimens, 2-in. thick tapered steel plates were used. These plates were leveled and fixed to the concrete surface using Hydrostone. Plates had the same 12-in. width as the test specimens.

\subsubsection{Data Acquisition System}

Outputs from all the instrumentation were conditioned and acquired using four Vishay ${ }^{\circledR}$ MicroMeasurements Group scanners (Model 5100), and a personal computer running StrainSmart, the proprietary software provided by Micro-Measurements. Each scanner monitored up to 20 channels. The reinforced concrete specimens were monitored in 12 to 68 locations, whereas the prestressed concrete specimens had 53 to 61 channels. In most of the tests, a second scannerpersonal computer set was used to record data from the Whittemore gage (Section 3.4.1). Figure 3.26 shows details of the data acquisition system and controllers used.

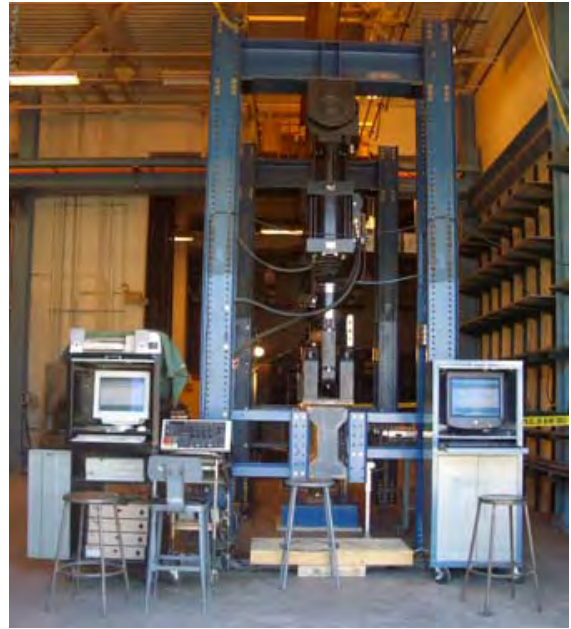

a) Reinforced concrete specimens with shear reinforcement

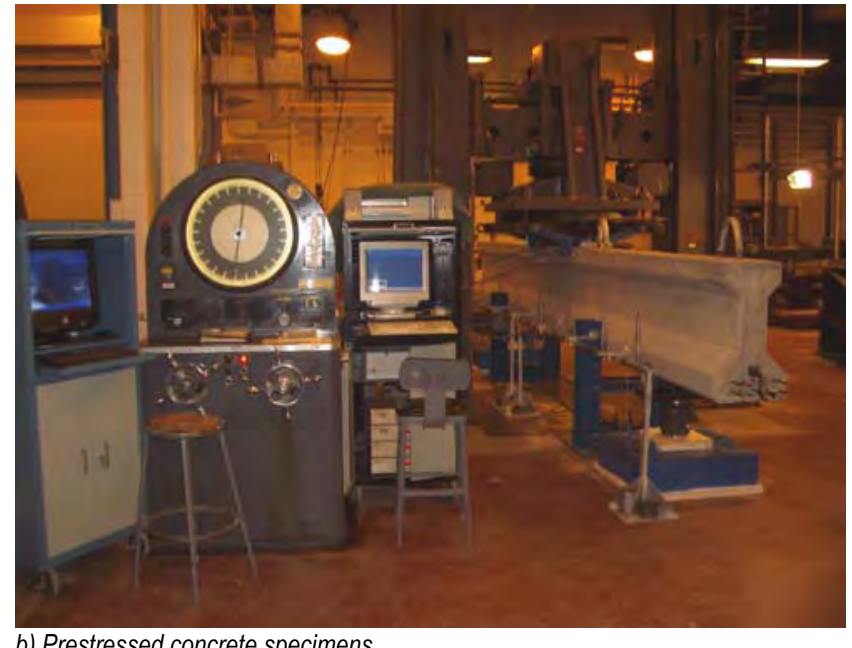

b) Prestressed concrete specimens

Figure 3.26

Data acquisition and control units

\subsubsection{Test Sequence}

Before each test, the following steps were taken: a) zero all sensors, and b) where appropriate, take at least two sets of initial readings with the Whittemore gage, if used. In the prestressed specimens, a manual reading of the strains in the prestressing strands was done before the test using a portable strain indicator (Micro-Measurements Group Model P-3500). This was done to record the strains and strain changes from fabrication to just prior to testing on the prestressing strands.

During each test, small increments of load or displacement were manually applied and kept as constant as possible while all sensors were scanned and their data acquired. Load increments 
roughly corresponded to $2000 \mathrm{lb}$. Every $5000 \mathrm{lb}$, the loading was stopped and the specimens were checked for new cracks. The cracks were then traced with permanent marker, and the widths of selected cracks measured. At these load steps, dial gage measurements were also recorded and photographs taken. Whittemore gage readings were obtained at selected load steps. These readings were taken until possible due to either the instrument going out of range or the Whittemore discs being lost due to disintegration of the concrete surface. Tests required from one up to seven hours to be concluded.

The reinforced concrete beams with shear reinforcement had two test specimens per member, as described in Section 3.2.1.1. In this case, the cantilever (Test Region B) was tested first and a simply supported beam (Test Region A) was tested afterwards. For each of the two specimens in a reinforced concrete beam with stirrups, the steps mentioned above were followed. To test Region $B$, identical loads were applied to both actuators. Care was taken not to apply any load in the second test specimen by monitoring the load readouts from the Lebow load cells located at the supports (locations RW-1 and RE-5 in Figure 3.16).
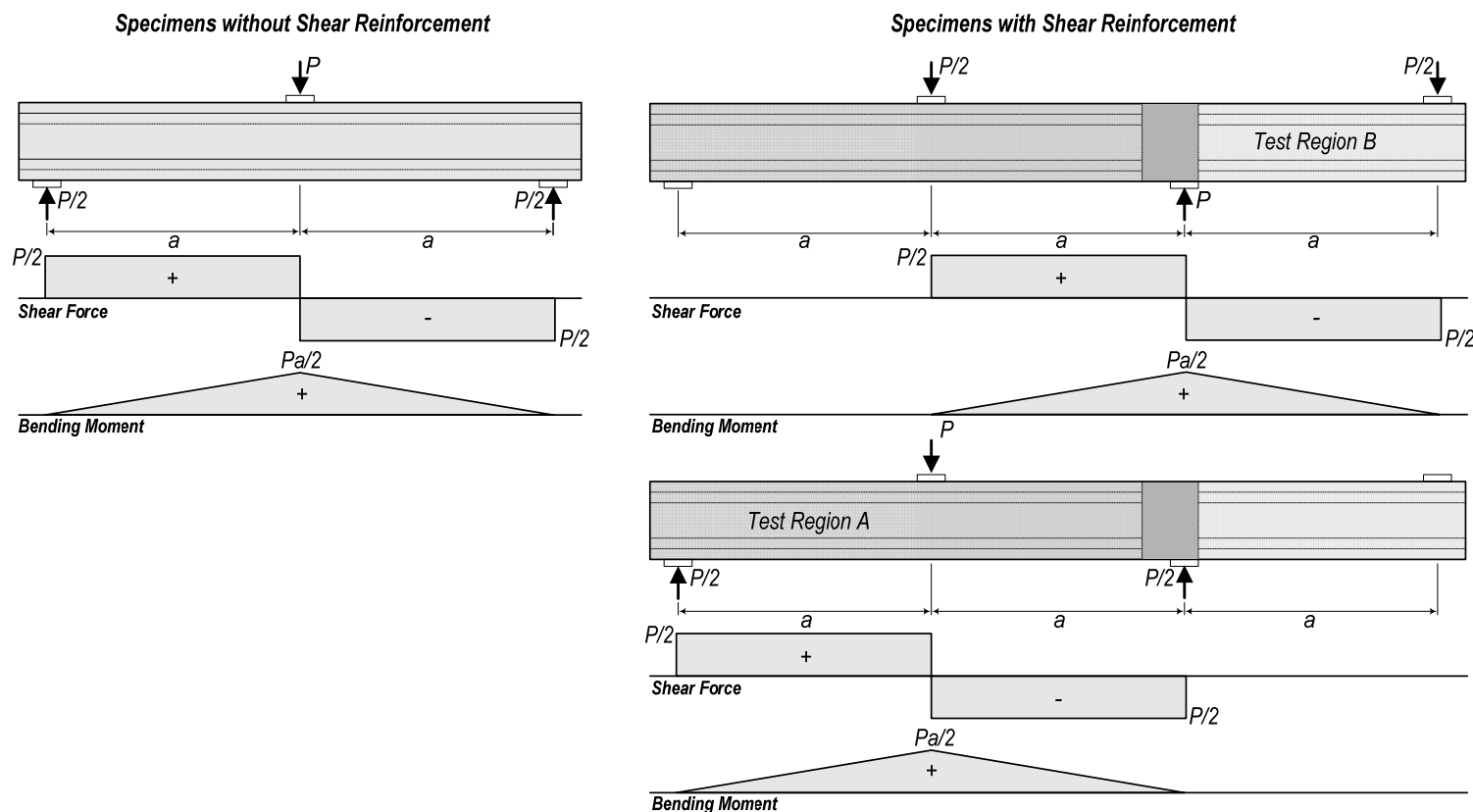

Figure 3.27 Shear force and bending moment diagrams for reinforced concrete specimens

After failure of the overhanging region took place, load in both actuators was brought back to zero and preparations for the test of Region A commenced. Testing of Region A involved the use of the actuator located between the supports only. The ram of the second actuator was fully retracted to avoid interfering with the displacement of the failed overhanging region. Figure 3.27 shows the shear force and moment diagrams for the reinforced concrete specimens. The diagrams for shear force and bending moment of the prestressed specimens are identical to those of the reinforced 
concrete specimens without shear reinforcement. In Figure 3.27, and throughout this report, the self weight of the beams has been ignored. 


\section{CHAPTER 4 EXPERIMENTAL EVALUATION OF SHEAR BEHAVIOR}

\subsection{Introduction}

In this chapter, the results of the experimental program are used to evaluate the shear behavior of the specimens described in Chapter 3. The test results are presented in terms of: a) cracking behavior, b) failure mode, c) load-deflection curves, d) strain measurements in the concrete surface, e) strain readings in the longitudinal and transverse reinforcement, and f) test to calculated shear capacity ratio obtained in accordance with the relevant provisions in the $\mathrm{ACl}$ 318-05 Code and the 2004 AASHTO LRFD Specifications. Findings are reported with regard to the adequacy of the current limits on shear reinforcement for beams with concrete strengths between 10000 and 15000 psi in both specifications.

\subsection{Reinforced Concrete Beams}

The test results of the sixteen reinforced concrete beams, eight without and eight with shear reinforcement are discussed in this section. The specimens without shear reinforcement were not part of the original research plan. However, during the design of the concrete mix the research team decided to take advantage of the concrete being produced, and cast eight specimens reinforced with longitudinal steel only and having the same cross section as the reinforced and prestressed concrete specimens with stirrups. The objective of these tests without stirrups was to obtain a baseline on the concrete contribution to the shear strength with higher strength concrete.

\subsubsection{Beams without Shear Reinforcement}

Eight I-shaped reinforced concrete beams without stirrups were tested. The amount of longitudinal reinforcement and the compressive strength of concrete were the variables under evaluation in this series. Only longitudinal tension reinforcement was provided. Two longitudinal reinforcement ratios on the basis of web width -1.32 and $2.62 \%$ - were evaluated for four different measured concrete compressive strengths in the range of 7000 to $11500 \mathrm{psi}$. Throughout this report, reference to the longitudinal reinforcement ratio, $\rho_{w}$, is always done on the basis of the web width $\left(\rho_{w}=A_{s} / b_{w} d\right)$. The details of these specimens are summarized in Table 3.1, and depicted in Figure 3.3. 


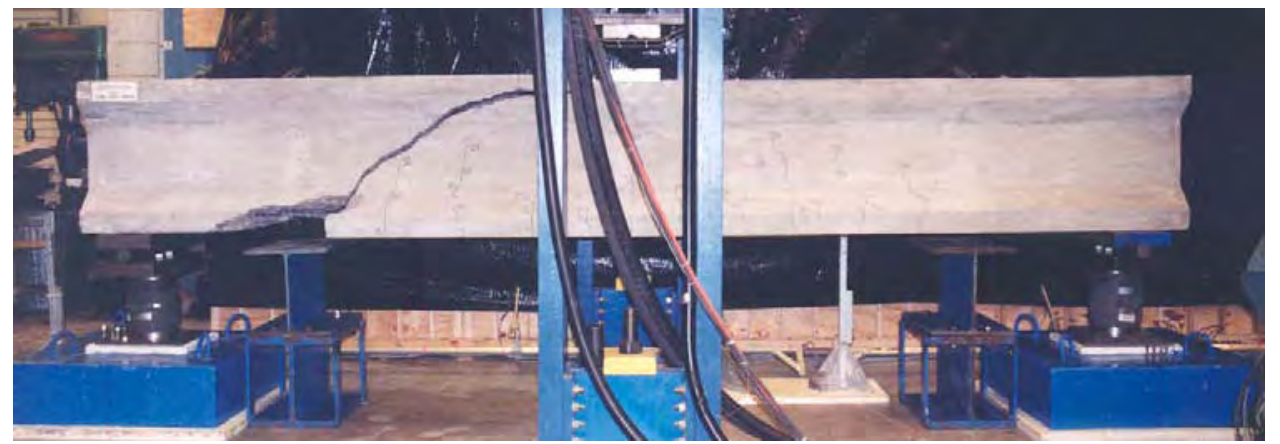

a) Specimen 7.0-1.3-0

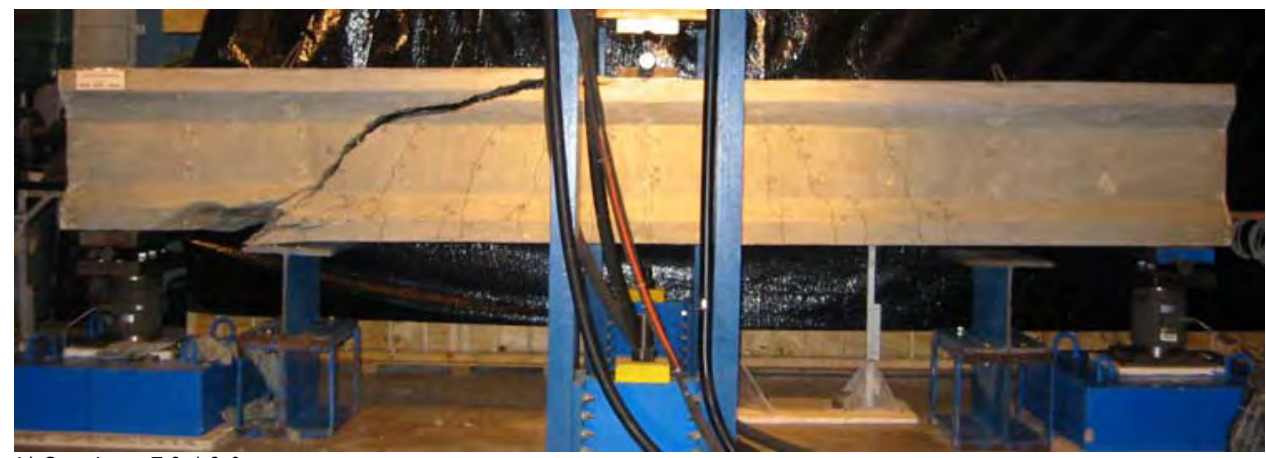

b) Specimen 7.9-1.3-0

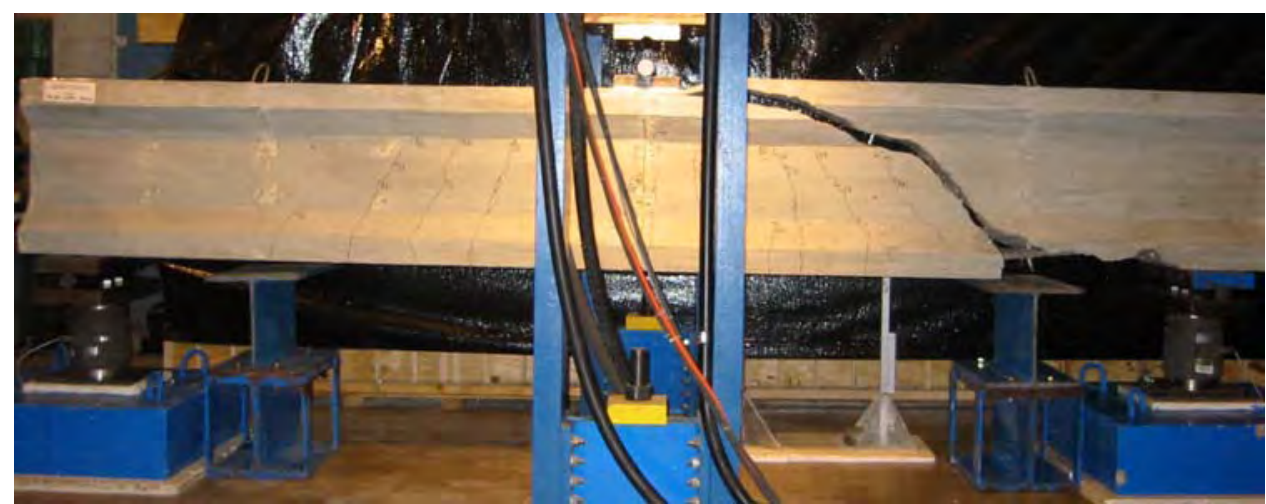

c) Specimen 10.6-1.3-0

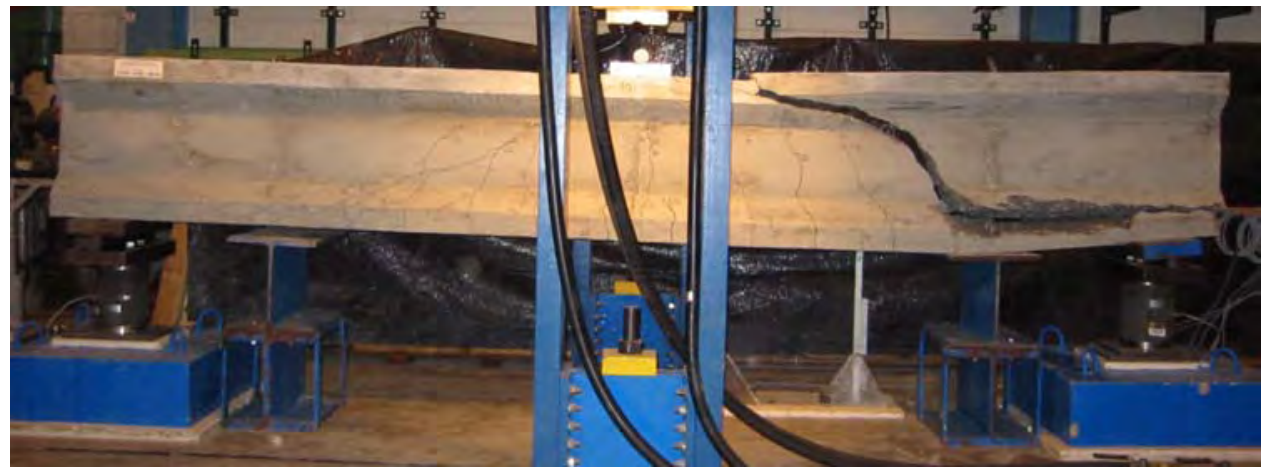

d) Specimen 11.5-1.3-0

Figure 4.1 Final crack patterns of reinforced concrete specimens without shear reinforcement $\left(\rho_{w}=1.32 \%\right)$ 


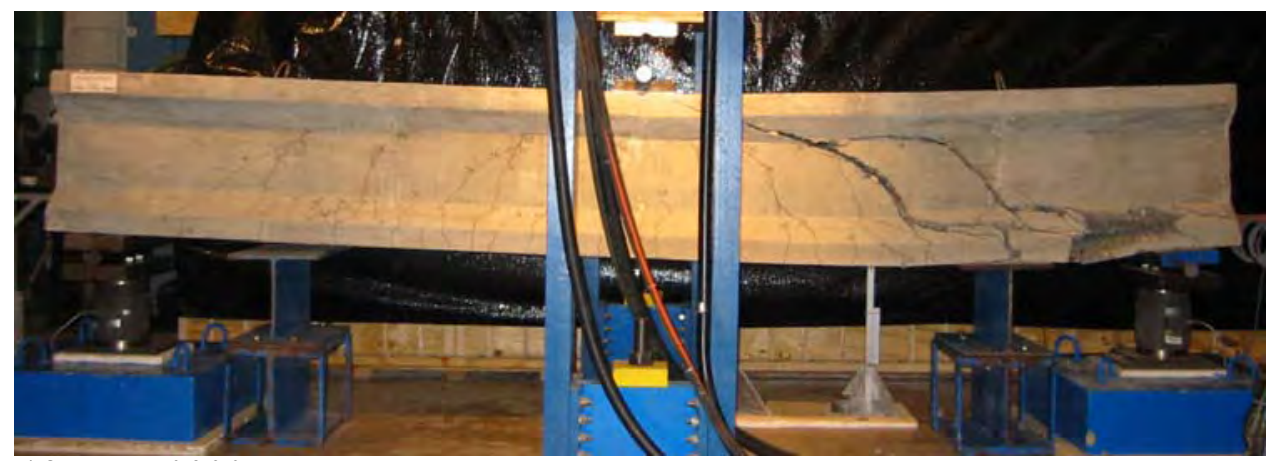

a) Specimen 7.0-2.6-0

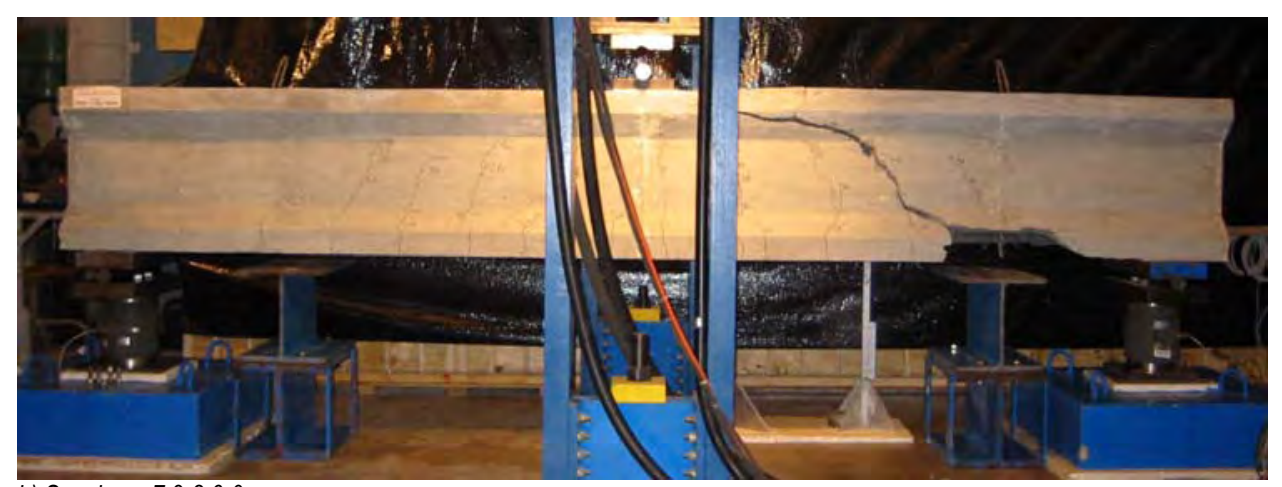

b) Specimen 7.9-2.6-0

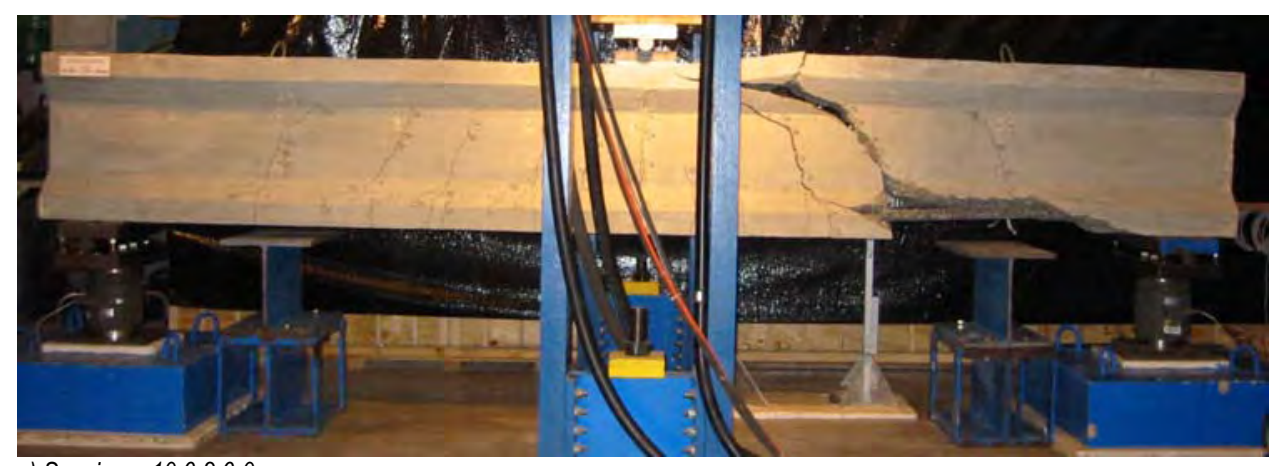

c) Specimen 10.6-2.6-0

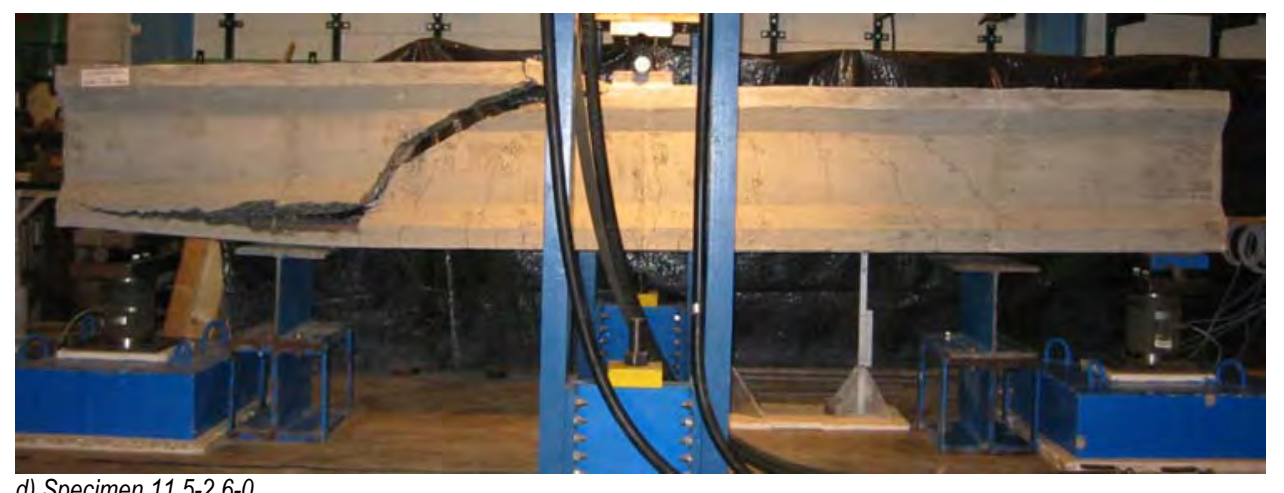

d) Specimen 11.5-2.6-0

Figure 4.2 Final crack patterns of reinforced concrete specimens without shear reinforcement $\left(\rho_{w}=2.62 \%\right)$ 


\subsubsection{Cracking Behavior}

The final crack pattern of all beams in this series is shown in Figure 4.1 and 4.2. Test specimens reinforced with 2 No. 8 longitudinal bars $\left(\rho_{w}=1.32 \%\right)$ are shown in Figure 4.1. Specimens reinforced with 2 No. $11\left(\rho_{w}=2.62 \%\right)$ are presented in Figure 4.2.

All eight crack patterns were similar. The cracking first started as vertical flexural cracks in the midspan region. As the load increased, more flexural cracks appeared away form the point load. These cracks soon started to change their orientation from vertical to inclined pointing towards the loading point. When the applied load was close to the maximum, the shear deformation concentrated causing one of the inclined cracks to widen. At failure, the main inclined crack suddenly opened and extended to both top and bottom faces. Once the main inclined crack crossed the plane of longitudinal reinforcement, the crack traveled along the reinforcement showing splitting behavior. In most of the beams, the concrete cover under the layer of longitudinal reinforcement at the support region was lost.

In five beams, the splitting cracks arrested before entering the confined support region. In Specimen 7.0-2.6-0, 11.5-2.6-0, and 11.5-1.3-0, the splitting portion of main failure crack went beyond the support. Visual record of the evolution of damage indicated that the main inclined crack reached the top compression region shortly before the horizontal splitting cracks developed along the longitudinal reinforcement. In all specimens no more than five inclined cracks per shear span were observed. The inclination of the main inclined crack with respect to the longitudinal axis of the beams ranged from 50 to $60 \mathrm{deg}$. Crack widths in this series of specimens were not monitored.

\subsubsection{Failure Mode}

All eight specimens without shear reinforcement failed in shear. Failure was sudden, loud, and characterized by one or two main inclined cracks running between the top compression zone and the bottom layer of longitudinal reinforcement, as seen in Figure 4.1 and 4.2. All longitudinal bars in the reinforced concrete specimens without shear reinforcement were straight. Note that all the final cracking patterns of specimens in this series showed signs of splitting at the ends of the longitudinal tension reinforcement. In all cases, there was spalling of the concrete cover under the layer of longitudinal reinforcement. Careful evaluation of the propagation of the main inclined crack in these specimens indicated that it first reached the top flange of the beams and, almost immediately, extended towards the supports as splitting cracks.

\subsubsection{Load-deflection Curves}

The load-deflection curves were constructed from the data recorded during the test. Figure 4.3 shows the graph of the deflection at midspan versus the applied shear force. Deflections at midspan (LVDT-3 and DW-3 in Figure 3.16) were corrected by subtracting the vertical displacements of the supports (LVDT-1 and LVDT-5) and the deformation of the test frame (LVDT-8). 
The shear force was obtained as the average of the reactions at supports (RW-1 and RE-5), and half of the load measured by the force transducer in the MTS actuator (FW-3).

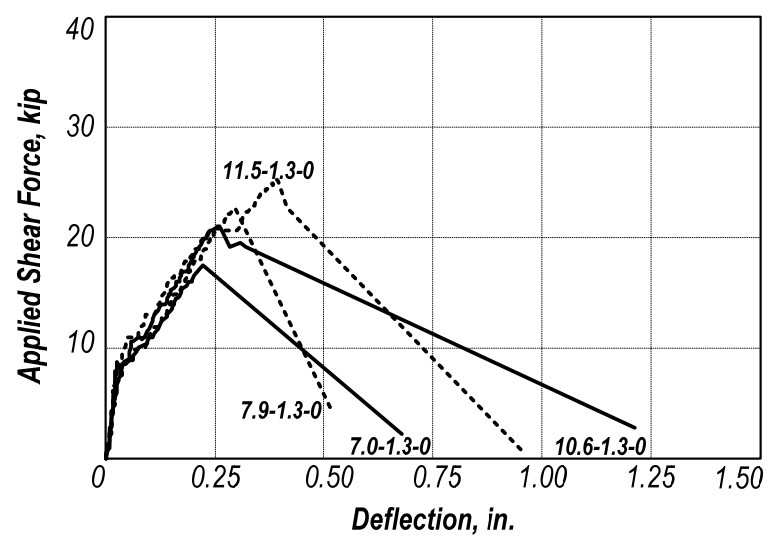

a) Specimens with longitudinal reinforcement ratio of $1.32 \%$

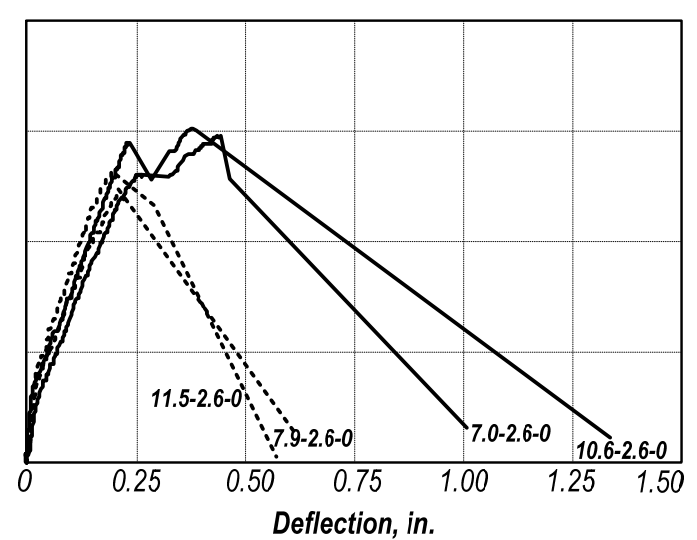

b) Specimens with longitudinal reinforcement ratio of $2.62 \%$

Figure 4.3 Load-deflection curves for reinforced concrete specimens without shear reinforcement

All load-deflection curves show similar trends. Initially, and up to the flexural cracking of the section, a linear elastic behavior was exhibited. The flexural cracking caused a decrease in the stiffness of the members observed as the change in slope of the plots in Figure 4.3. The loaddeflection relationship was roughly linear from the flexural cracking to failure. In the loaddeflection curves of Specimen 7.0-2.6-0, 10.6-2.6-0 and 11.5-1.3-0, a small trend disruption was observed. This phenomenon was related to the formation of a second main inclined crack after the first one, which allowed a slight increase in the load capacity of the specimens. Two main inclined cracks in those specimens were noticed in their final crack patterns (Figure 4.1 and 4.2).

The descending linear branches of the plots in Figure 4.3 are due to the fact that the tests were load-controlled. At failure, the loss of load carrying capacity was nearly total.

\subsubsection{Strain Readings}

No strain gages were attached to the longitudinal reinforcement. No concrete gages were embedded in the concrete either. Whittemore gage readings to measure the deformations of the concrete surface were not taken for the specimens without shear reinforcement.

\subsubsection{Test and Calculated Capacities}

The experimental shear capacity, $V_{\text {test, }}$ was recorded as the peak load carried by each specimen. The calculated shear capacities were computed using the General Procedure (Section 5.8.3.4.2) of the 2004 AASHTO LRFD Specifications and the detailed computation (Eq. 2.23) in Section 11.3 of the $\mathrm{ACl} 318-05$ Code. The actual properties of the materials, such as the compressive strength of concrete and the yield strength of the reinforcement were used in both calculations. 
Load factors and strength reduction factors were taken as the unity. For the computation of the shear strength in accordance to 2004 AASHTO LRFD, an ad-hoc electronic spreadsheet was developed, which allowed for the linear interpolation of $\beta$ and $\theta$ given in Table 2.10 and 2.11. In all cases, the initial value for iteration was $\varepsilon_{x}=0.001$. Table 4.1 summarizes the test and calculated capacities.

The components of the nominal shear strength, $V_{n}$; specified in Eq. 2.4 and 2.21 of this report with $V_{s}$ and $V_{p}$ equal to zero are presented in Table 4.1. This table also includes the shear force recorded when the first inclined cracking was observed, $V_{\text {cracking, }}$ and the peak deflection measured during test, $\delta_{\max }$. Also in Table 4.1 , the shear strength associated with the maximum calculated moment capacity, $V_{\text {flexure }}$, is presented. $V_{\text {flexure }}$ was computed as:

$$
V_{\text {flexure }}=\frac{M_{n}}{a-\frac{I_{\text {plate }}}{2}}
$$

Where: $M_{n}$ is the flexural capacity of the section (kip-in.), obtained through the construction of a moment-curvature diagram of a layered section where the concrete model was based on the Hognestad parabola (Hognestad, 1951) and the steel model was considered elastoplastic, corrected for development length,

$a$ is the shear span (72 in.), and

Iplate is the width of the support plate ( $8 \mathrm{in}$. ).

Table 4.1 Measured and calculated capacities for reinforced concrete specimens without shear reinforcement

\begin{tabular}{|c|c|c|c|c|c|c|c|c|c|c|}
\hline \multirow{3}{*}{ Specimen } & \multirow{3}{*}{$\begin{array}{c}V_{\text {cracking }} \\
\text { kip }\end{array}$} & \multirow{3}{*}{$\begin{array}{c}V_{\text {test }} \\
\text { kip }\end{array}$} & \multirow{3}{*}{$\begin{array}{c}\delta_{\max } \\
\text { in. }\end{array}$} & \multicolumn{7}{|c|}{ Calculated Capacities } \\
\hline & & & & \multirow{2}{*}{$\begin{array}{c}V_{\text {flexure }} \\
\text { kip }\end{array}$} & \multicolumn{3}{|c|}{2004 AASHTO LRFD } & \multicolumn{3}{|c|}{$A C l 318-05$} \\
\hline & & & & & $V_{c, k i p}$ & $V_{s, \text { kip }}$ & $V_{n}$, kip & $V_{c, \text { kip }}$ & $V_{s, k i p}$ & $V_{n, k i p}$ \\
\hline $7.0-1.3-0$ & 12.0 & 17.5 & 0.68 & 30.6 & 14.2 & 0.0 & 14.2 & 20.2 & 0.0 & 20.2 \\
\hline $7.9-1.3-0$ & 13.0 & 22.6 & 0.51 & 30.8 & 14.9 & 0.0 & 14.9 & 21.5 & 0.0 & 21.5 \\
\hline $10.6-1.3-0$ & 11.0 & 20.9 & 1.21 & 31.0 & 16.5 & 0.0 & 16.5 & 24.7 & 0.0 & 24.7 \\
\hline $11.5-1.3-0$ & 13.0 & 25.3 & 0.96 & 31.1 & 17.0 & 0.0 & 17.0 & 25.7 & 0.0 & 25.7 \\
\hline $7.0-2.6-0$ & 15.0 & 29.5 & 1.01 & 45.3 & 17.2 & 0.0 & 17.2 & 21.2 & 0.0 & 21.2 \\
\hline $7.9-2.6-0$ & 13.0 & 24.8 & 0.61 & 48.7 & 18.2 & 0.0 & 18.2 & 22.4 & 0.0 & 22.4 \\
\hline $10.6-2.6-0$ & 15.0 & 30.2 & 1.33 & 57.2 & 20.4 & 0.0 & 20.4 & 25.6 & 0.0 & 25.6 \\
\hline $11.5-2.6-0$ & 15.0 & 26.5 & 0.57 & 60.1 & 20.6 & 0.0 & 20.6 & 26.5 & 0.0 & 26.5 \\
\hline
\end{tabular}

For the specimens with $1.32 \%$ of longitudinal reinforcement ratio on the basis of web width, the increase in ultimate shear capacity was $45 \%$ when the concrete compressive strength changed from 7000 to 11500 psi. Kong and Rangan (1997) have observed that the effect of increasing the 
uniaxial compressive strength of concrete was somewhat unimportant on the shear capacity of flexural members. In contrast, Mphonde and Frantz (1984), and Elzanaty et al. (1985) observed an increase in the shear strength of reinforced concrete beams without stirrups as the compressive strength of concrete increased. However, Elzanaty et al. (1985) also recorded slight reductions of the shear strength of comparable test specimens as their concrete compressive strength increased. The results of the eight specimens without stirrups tested in the study reported herein indicate that the increase in concrete strength improved the shear strength of the specimens with lower amount of longitudinal reinforcement (1.32\%) more than it did the specimens with higher amount of longitudinal reinforcement (2.62\%).

Table 4.2 presents test specimen information in terms of the square root of the compressive strength of concrete, in psi. This is a commonly used approach to report shear strength of reinforced concrete flexural members. Additionally, Table 4.2 includes the comparison between measured and calculated capacities in terms of the ratios $V_{\text {tes }} / V_{n}$. In all cases, the ratio $V_{\text {test }} / V_{n}$ for 2004 AASHTO LRFD was higher than for ACl 318-05. As seen in Table 4.2, the average concrete shear stress at failure was $1.9 \sqrt{f_{c}}$ for the specimens with $1.32 \%$ longitudinal reinforcement ratio, and $2.5 \sqrt{f_{c}}$ for those with $2.62 \%$ longitudinal reinforcement ratio. This is a $32 \%$ increase in the maximum average concrete stress when doubling the amount of longitudinal reinforcement. The positive effect of larger amounts of longitudinal tension reinforcement on the shear strength is included in both the 2004 AASHTO LRFD Specifications and the ACI 318-05 Code.

Table 4.2 Ratio of measured to calculated capacities for reinforced concrete specimens without shear reinforcement

\begin{tabular}{|c|c|c|c|c|c|}
\hline Specimen & $\frac{V_{\text {test }}}{\sqrt{f_{c}} b_{w} d_{v}}$ & $\frac{V_{n, \text { AASHTO }}}{\sqrt{f_{c}} b_{w} d_{v}}$ & $\frac{V_{n, A C l}}{\sqrt{f_{c}} b_{w} d_{v}}$ & $\frac{V_{\text {test }}}{V_{n, \text { AASHTO }}}$ & $\frac{V_{\text {test }}}{V_{n, A C l}}$ \\
\hline $7.0-1.3-0$ & 1.7 & 1.4 & 2.0 & 1.2 & 0.9 \\
\hline $7.9-1.3-0$ & 2.1 & 1.4 & 2.0 & 1.5 & 1.1 \\
\hline $10.6-1.3-0$ & 1.7 & 1.3 & 2.0 & 1.3 & 0.8 \\
\hline $11.5-1.3-0$ & 2.0 & 1.3 & 2.0 & 1.5 & 1.0 \\
\hline Average & 1.9 & 1.4 & 2.0 & 1.4 & 0.9 \\
\hline $7.0-2.6-0$ & 3.0 & 1.7 & 2.1 & 1.7 & 1.4 \\
\hline $7.9-2.6-0$ & 2.3 & 1.7 & 2.1 & 1.4 & 1.1 \\
\hline $10.6-2.6-0$ & 2.5 & 1.7 & 2.1 & 1.5 & 1.2 \\
\hline $11.5-2.6-0$ & 2.1 & 1.6 & 2.1 & 1.3 & 1.0 \\
\hline Average & 2.5 & 1.7 & 2.1 & 1.5 & 1.2 \\
\hline
\end{tabular}


The average $V_{\text {tes }} / V_{n}$ ratio for 2004 AASHTO LRFD was 1.4 and 1.5 for the specimens with 1.32 and $2.62 \%$ of longitudinal reinforcement ratio, respectively. The same ratios for $\mathrm{ACl} 318-05$ were 0.9 and 1.2, respectively. As seen in Table 4.2, both design codes become more conservative as the amount of longitudinal reinforcement increases. The potential for overestimation of $V_{c}$ in beams with small longitudinal reinforcement ratios had been long recognized. When the longitudinal reinforcement ratio on the basis of web width is increased, flexural cracks do not extend as high into the beam and do not open as wide as in beams containing small longitudinal reinforcement ratios (MacGregor, 1997).

\subsubsection{Beams with Shear Reinforcement}

The results of the tests on beams without shear reinforcement confirm the improved shear performance of beams with higher longitudinal reinforcement ratios. These tests also indicated that increases in the concrete compressive strength improved the shear strength of beams with lower amounts of longitudinal steel, but resulted in little or no improvement in the case of specimens with higher amounts of longitudinal steel. Eight additional specimens with various amounts of shear reinforcement were next tested to failure. The key parameter under study in this set of specimens was the amount of shear reinforcement. The measured compressive strength of concrete was in the range of 13000 to $15000 \mathrm{psi}$. The longitudinal reinforcement ratio on the basis of web width varied from 2.36 to $7.92 \%$, and the strength in terms of stress associated with the provided shear reinforcement ( $\left.\rho f_{y v}\right)$ ranged from 98 to 902 psi.

Four beams had the minimum amount of shear reinforcement in accordance with both 2004 AASHTO LRFD and $\mathrm{ACl}$ 318-05. Two specimens had an intermediate amount of shear reinforcement, and two more beams had the maximum amount of shear reinforcement in accordance to $\mathrm{ACl}$ 318-05. All specimens had top and bottom longitudinal reinforcement and were designed to fail in shear. Specimen 13.3-5.4-98 and 14.5-5.4-98, tested as cantilevers, had a longitudinal reinforcement ratio on the basis of web width of negative moment steel of $5.40 \%$, and were provided with a compression (bottom) reinforcement ratio of $2.70 \%$. Negative reinforcement ratio on the basis of web width for Specimen 13.2-7.9-902 and 15.3-7.9-902, also tested as cantilevers, was $7.92 \%$, with $4.37 \%$ of compression steel. The amount of longitudinal steel had to be

increased in these specimens to preclude flexural failure prior to shear failure. Furthermore two of the longitudinal tension bars were anchored at the ends using mechanical anchorage devices (Lenton $^{\circledR}$ Terminators $^{\mathrm{TM}}$ ) in an attempt to preclude anchorage failures. Table 3.2 presents the details of all the reinforced concrete beams with shear reinforcement tested. Figure 3.4 and 3.5 show sketches of these test specimens.

\subsubsection{Cracking Behavior}

Figure 4.4 illustrates the final crack patterns of four specimens with the minimum amount of reinforcement ( $\rho_{v} f_{y v}=98 \mathrm{psi}$ ). Figure 4.5 shows close-up photographs of the final crack pattern of the 
specimens with intermediate ( $\rho_{v} f_{y v}=387 p s i$ and $\rho_{v} f_{v v}=451 p s i$ ) and maximum amount of shear reinforcement $\left(\rho r f_{y=}=902 p s i \approx 8 \sqrt{f_{c}^{\prime}}\right.$ ) in accordance with $\mathrm{ACl}$ 318-05. As seen in these figures, the crack patterns in the reinforced concrete specimens with shear reinforcement changed as the amount of shear reinforcement was increased.

The pattern in all four specimens with minimum amount of shear reinforcement was characterized by few inclined cracks of significant width. At early stages of the test, flexural cracks appeared in the maximum bending moment region. As the test progressed, more flexural cracks appeared more or less symmetrically on both shear spans. Upon further load increments, these cracks turned into inclined shear cracks that widened and extended towards the section under maximum moment. There were two or three inclined cracks in each shear span. When one of the inclined cracks reached both top and bottom faces of the specimen, failure was triggered. In all beams with the minimum amount of shear reinforcement, the fracture of the vertical legs of one or two stirrups occurred at failure. The inclination of the main inclined crack was similar in all four specimens with the minimum amount of shear reinforcement, and ranged between 30 to $45 \mathrm{deg}$. with respect to the longitudinal axis of the beam. The inclination of the main inclined crack in the specimens with the minimum amount of shear reinforcement was around half of that in the specimens without stirups (flatter crack). The presence of shear reinforcement positively changed the behavior of the specimens, allowing for redistribution of stresses resulting in an increase in the maximum shear carried by the section. However, the increase in concrete strength had a minimal effect on the shear strength of these specimens as an increase in concrete compressive strength from 13000 to 15000 psi for a given amount of shear reinforcement resulted in no or almost negligible change in strength.

The width of the main inclined cracks was monitored throughout the tests using a crack comparator. At first cracking, the maximum width of the main inclined crack in all specimens with minimum amount of shear reinforcement was $0.01 \mathrm{in}$. At the estimated representative service load level, the maximum width of that crack had roughly doubled its initial value, i.e. $\sim 0.02 \mathrm{in}$. This width is slightly above the upper limit of the often accepted range of 0.013 to $0.016 \mathrm{in}$. for flexural cracks. Service loads were computed assuming that the totality of the load applied with the MTS $^{\circledR}$ actuators was live load; therefore using a load factor of 1.6. The only source of dead load was considered to be the self weight of the beams; for which a load factor of 1.2 was used. Maximum crack widths of up to $0.16 \mathrm{in}$. were measured in the main inclined cracks shortly before failure of these specimens.

In contrast with the crack pattern of the specimens with the minimum amount of shear reinforcement, the test specimens with intermediate and maximum amount of shear reinforcement showed more uniformly distributed cracking throughout the shear span. 


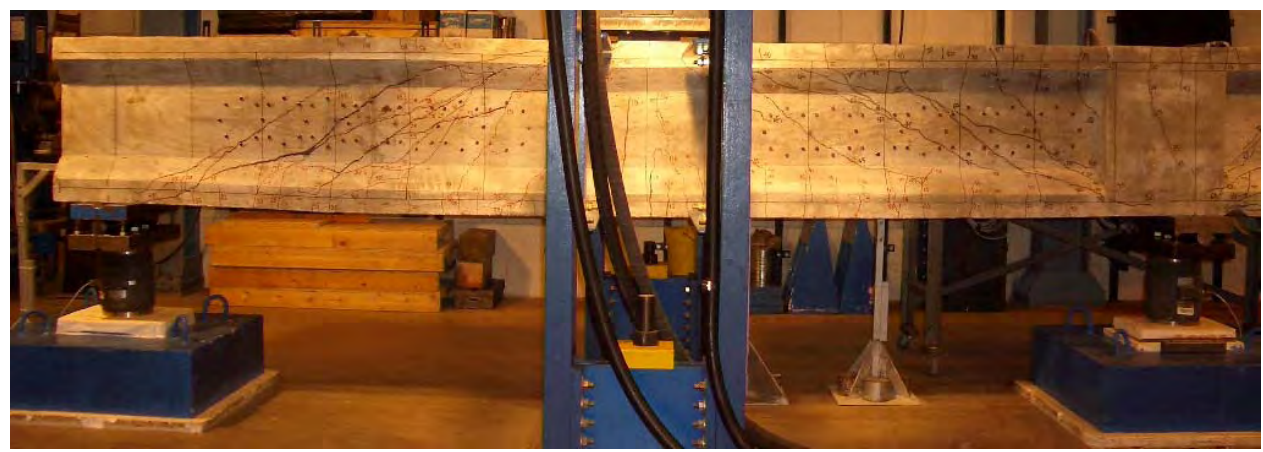

a) Specimen 13.3-2.6-98

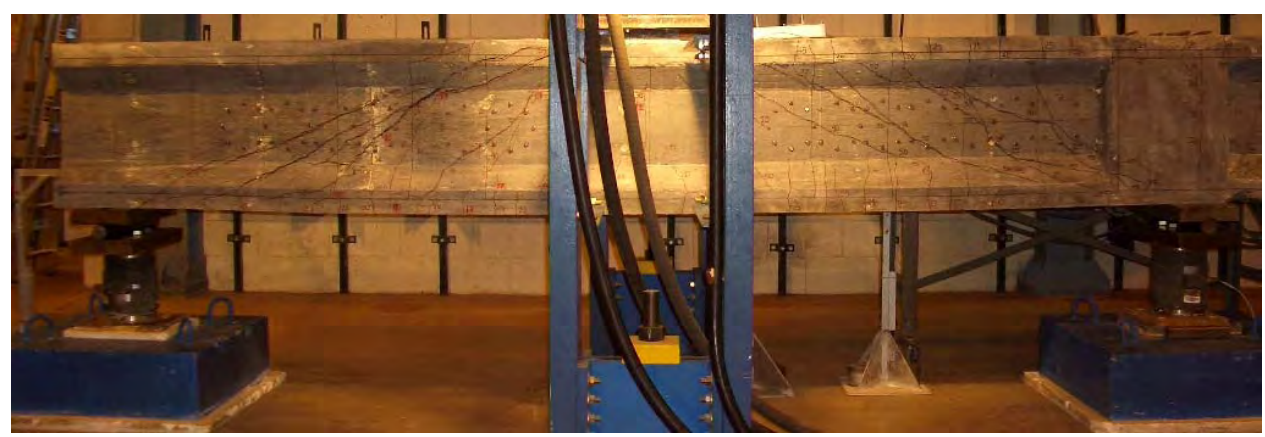

b) Specimen 14.5-2.6-98

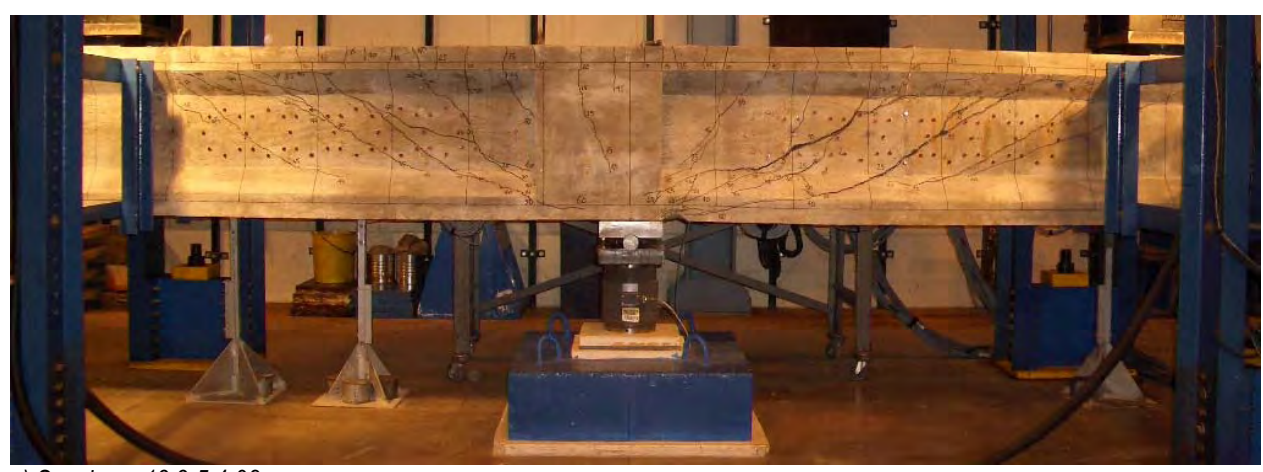

c) Specimen 13.3-5.4-98

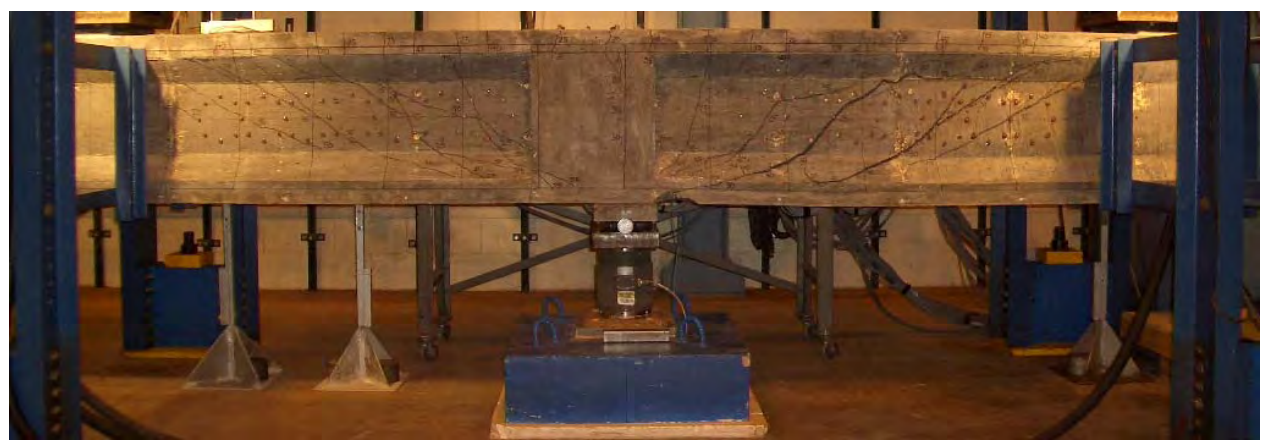

d) Specimen 14.5-5.4-98

Figure 4.4 Final crack pattern of reinforced concrete specimens with minimum amount of shear reinforcement in accordance with 2004 AASHTO LRFD and $A C l$ 318-05 


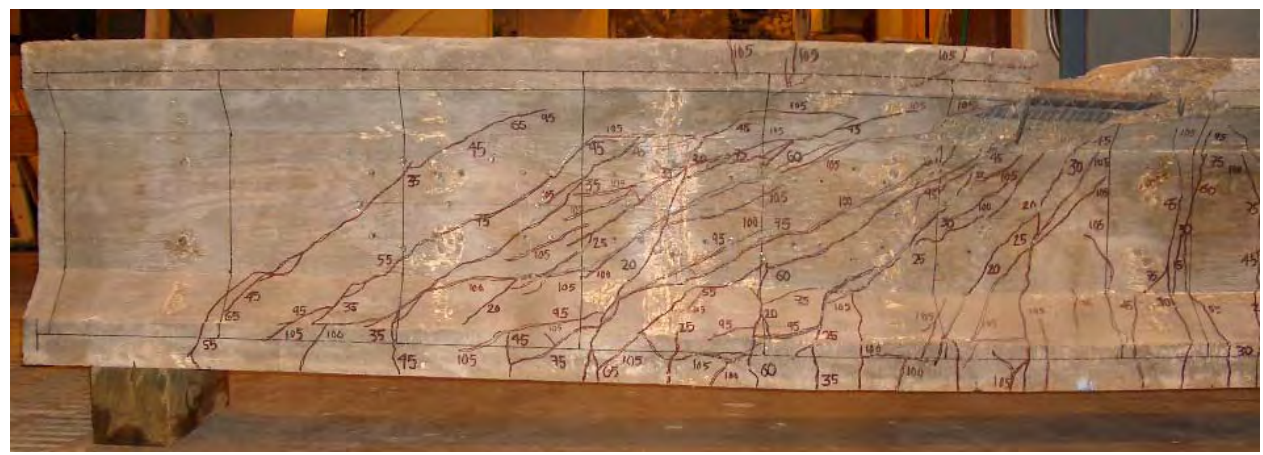

a) Specimen 13.2-4.3-451

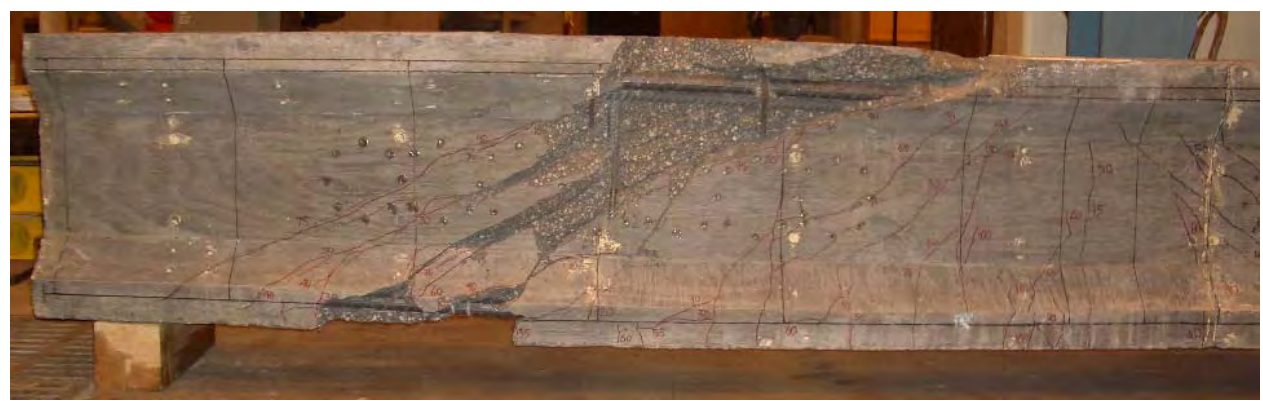

b) Specimen 15.3-4.3-387

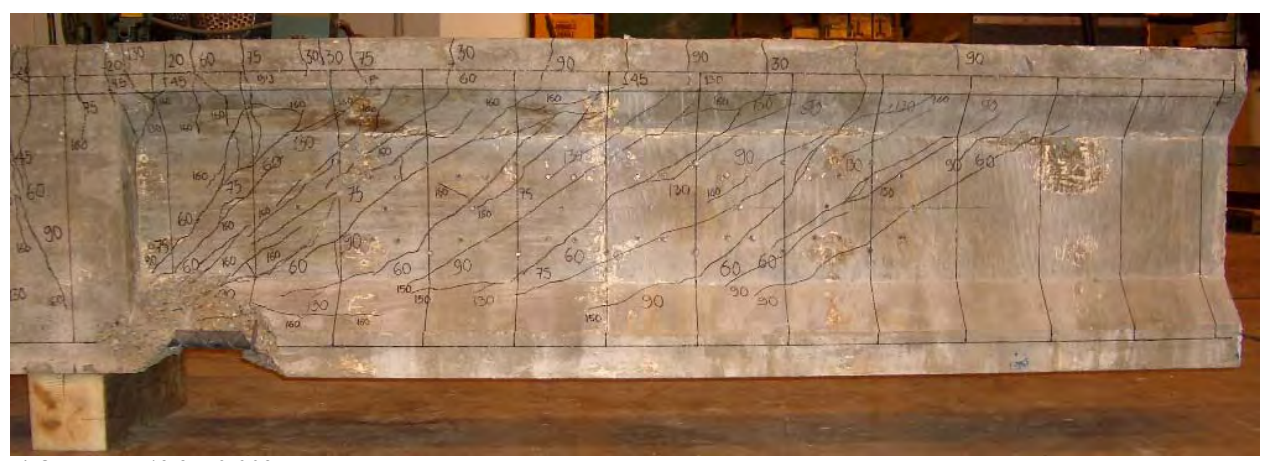

c) Specimen 13.2-7.9-902

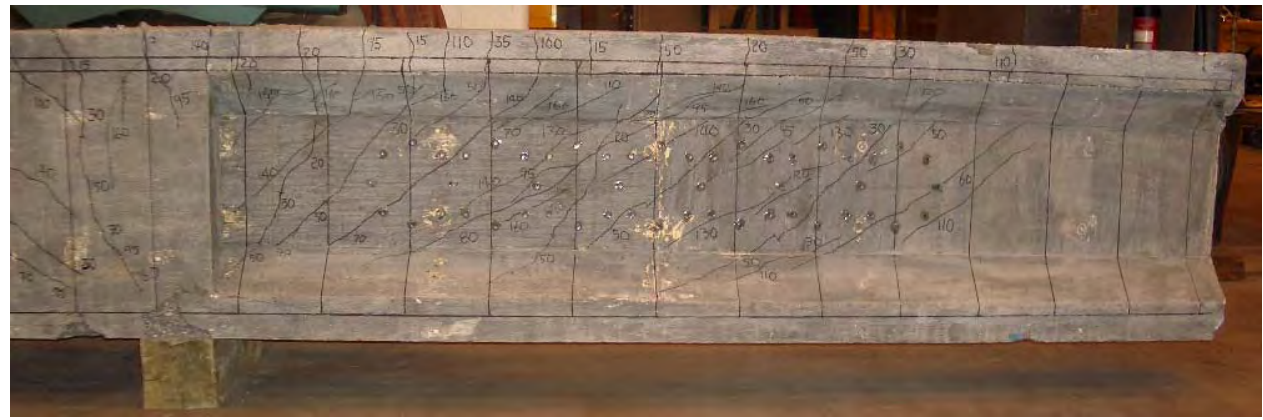

d) Specimen 15.3-7.9-902

Figure 4.5 Final crack patterns of reinforced concrete specimens with intermediate amount and the maximum amount of shear reinforcement in accordance with ACI 318-05 
Also, the width of the cracks at failure was less compared to the specimens with minimum amount of shear reinforcement. For the specimens with intermediate amounts and the maximum amount of shear reinforcement in accordance to $\mathrm{ACl} 318-05$, the failure could not be associated with a single inclined crack. Instead, failure occurred following crushing of concrete as numerous inclined cracks penetrated the compression flange.

The evolution of damage in the beams with intermediate and maximum amount of shear reinforcement was as follows. Initially, short flexural cracks appeared in the maximum bending moment region; then, they extended vertically towards the flexural compression zone. Simultaneously, additional cracks due to flexure were observed in the shear spans, away from the section under maximum moment and towards the supports (Specimen 13.2-4.3-451 and 15.3-4.3387) or towards the load-application points (Specimen 13.2-7.9-902 and 15.3-7.9-902). After the formation of numerous flexural cracks, some of the tips of the crack turned inclined towards the section of maximum bending moment under the point load.

In all of these beams, the inclined cracks were as numerous as the flexural cracks. The inclination of inclined cracks with respect to the longitudinal axis of the beam was around $35 \mathrm{deg}$. for all specimens with intermediate and maximum amount of shear reinforcement. This inclination is 10 to $15 \mathrm{deg}$. less than that of the beams with minimum amount of shear reinforcement. The only fracture of a vertical leg of a stirrup was observed in Specimen 15.3-4.3-387. This observation indicates that there is room for redistribution but it is limited even with very large amounts of shear reinforcement. After the first inclined cracking, the maximum crack widths in this subgroup of specimens were $0.01 \mathrm{in}$. Shortly before failure, maximum crack width was $0.03 \mathrm{in}$. These crack widths are around $20 \%$ of the maximum crack width observed in the specimens with minimum amount of shear reinforcement.

\subsubsection{Failure Mode}

The failure mode of all the specimens with the minimum amount of stirrups can be considered as shear. Inclined cracks extended and widened up to failure. The mode of failure of the two specimens reinforced with intermediate amounts of shear reinforcement was shear-compression, characterized by the presence of multiple inclined cracks racing towards the compression flange. In Specimen 15.3-4.3-387, the crushing of concrete was not limited to the compression flange, but it extended to the vicinity of the main inclined crack that triggered the failure. This type of web crushing has been observed in tests of both reinforced and prestressed concrete members with large amounts of shear reinforcement. Although the amount of shear reinforcement provided in Specimen 15.3-4.3-387 was not considerably large, web crushing was observed. Specimen 13.2-7.9902 and 15.3-7.9-902, both reinforced with the maximum amount of shear reinforcement in accordance to $\mathrm{ACl} 318-05$, showed shear-flexure modes of failure where the yielding of both longitudinal and transverse reinforcement took place before failure. In general, the shear 
reinforcement reached yielding strains before the longitudinal reinforcement did. This is addressed in more detail in Section 4.2.2.4 of this report.

\subsubsection{Load-deflection Curves}

The load-deflection curves for the reinforced concrete specimens with shear reinforcement were determined using the same procedure followed with the specimens without shear reinforcement (Section 4.2.1.3 of this report). The cantilever deflection (LVDT-7 and DE-7 in Figure 3.16) of Specimen 13.3-5.4-98, 14.5-5.4-98, 13.2-7.9-902, and 15.3-7.9-902, was corrected by subtracting any measured settlement of the supports (LVDT-1 and LVDT-5), and the deflection of the testing frame (LVDT-9). The shear force applied was obtained as the average of the loads in the two MTS ${ }^{\circledR}$ actuators (FW-3 and FE-7), and half of the corresponding reaction at the support (RE-5). In Specimen 13.3-2.6-98, 14.5-2.6-98, 13.2-4.3-451, and 15.3-4.3-387, the procedure outlined in Section 4.2.1.3 of this report was followed as well. Figure 4.6 presents the load-deflection curves of the reinforced concrete specimens with shear reinforcement.

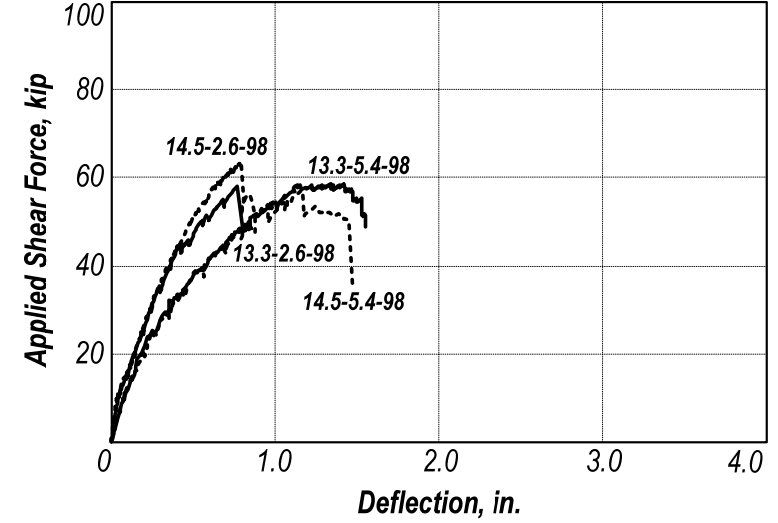

a) Specimens with minimum amount of shear reinforcement

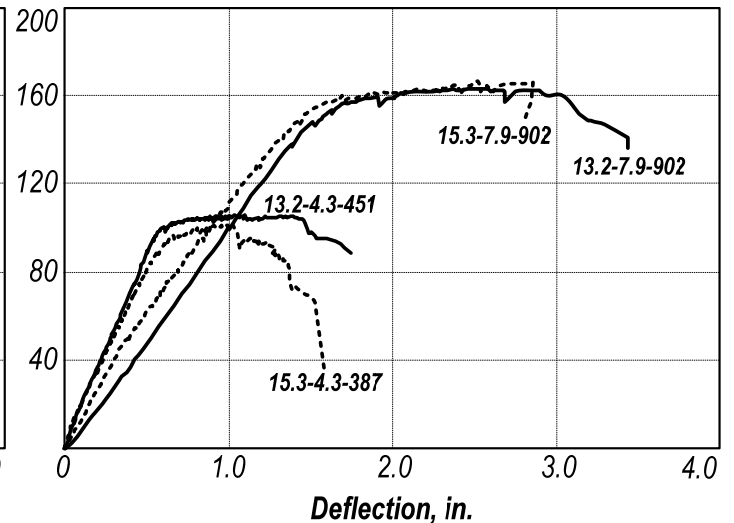

b) Specimens with intermediate and maximum amount of shear reinforcement

Figure 4.6 Load-deflection curves for reinforced concrete specimens with shear reinforcement

As seen in Figure 4.6, the general shape of the load-deflection curves was similar among specimens with similar amounts of shear reinforcement. Two pairs of similar curves may be recognized in Figure 4.6a. Each pair corresponds to specimens where the main difference was the concrete compressive strength. Specimen 13.3-2.6-98 and 14.5-2.6-98 had almost identical loaddeflection relationships up to $75 \%$ of their ultimate shear capacity. The same observation can be made in the case of Specimen 13.3-5.4-98 and 14.5-5.4-98 practically all the way up to failure. In Figure $4.6 \mathrm{~b}$, similar load-deflection relationships were observed up to $70 \%$ of the ultimate loads for Specimen 13.2-4.3-451 and 15.3-4.3-387, both with intermediate amounts of shear reinforcement. In the case of Specimen 13.2-7.9-902 and 15.3-7.9-902 provided with the maximum amount of shear reinforcement in accordance with $\mathrm{ACl} 318-05$, their load-deflection curves showed similar trends, 
as well. The load-deflection graph for each of these last two specimens shows the effect of yielding of longitudinal tension reinforcement.

The load-deflection curves of the reinforced concrete specimens with minimum amount of shear reinforcement may be roughly described by a bilinear relationship. The first part starts at the origin and keeps the same slope up to the occurrence of the first flexural cracking. Then, a second linear region at a reduced slope extends from that point and practically all the way to failure, which occurred in a sudden and brittle manner. Note that specimens with a longitudinal reinforcement ratio, $\rho_{w}$ of $2.63 \%$ exhibited a higher stiffness than specimens with a ratio of $5.4 \%$. Initial stiffness of Specimen 13.3-2.6-98 and 14.5-2.6-98 was 40\% higher than that of Specimen 13.35.4-98 and 14.5-5.4-98. A higher stiffness is manifested by a stepper slope of the load-deflection curve. However, the difference in stiffness can be attributed to the fact that specimens with $\rho_{w}=2.63 \%$ were tested in a simply supported scheme, whereas specimens with $\rho_{w}=5.40 \%$ were tested as cantilevers.

For specimens with intermediate and maximum amount of shear reinforcement as per $\mathrm{ACl} 318$ 05, the load-deflection relationship may also be considered bilinear. In this case, however, the first inclined cracking did not affect the load-deflection relationship near as much as it did in the case of specimens with smaller amounts of shear reinforcement, and the initial linear part extends from the origin to the yielding of longitudinal reinforcement. In all four specimens with intermediate and maximum amount of shear reinforcement, both longitudinal and transverse reinforcement exhibited signs of yielding. After yielding of longitudinal and/or transverse reinforcement, the load-deflection curves were characterized by a plateau to failure. The mode of failure in these specimens was shear-compression, a combination of shear and flexure.

There were two distinct stiffnesses observed in the specimens with intermediate and maximum amount of shear reinforcement. Specimen 13.2-4.3-451 and 15.3-4.3-387, tested in a simply supported configuration, exhibited higher stiffnesses than Specimen 13.2-7.9-902 and 15.3-7.9-902, which had $84 \%$ more longitudinal reinforcement ratio and were tested as cantilevers. Stiffness of specimens with $4.26 \%$ of longitudinal reinforcement ratio was $60 \%$ higher than those of specimens with a longitudinal reinforcement ratio of $7.92 \%$. Again, the difference in stiffness can be associated with the testing scheme. Specimens with $\rho_{w}=4.26 \%$ were tested in a simply supported scheme, whereas specimens with $\rho_{w}=7.92 \%$ were tested as cantilevers.

\subsubsection{Strain Readings}

Electrical resistance strain gages were installed at numerous locations in the specimens with shear reinforcement. Both longitudinal and transverse reinforcement were densely instrumented. Additionally, four strain gages were embedded in the concrete of each beam and Whittemore discs were glued to the concrete surface. 

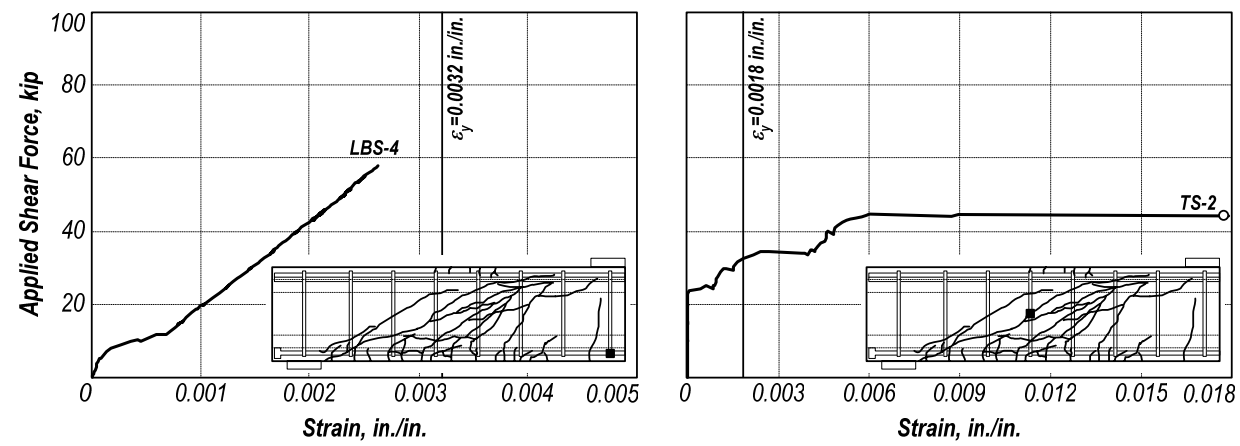

a) Specimen 13.3-2.6-98
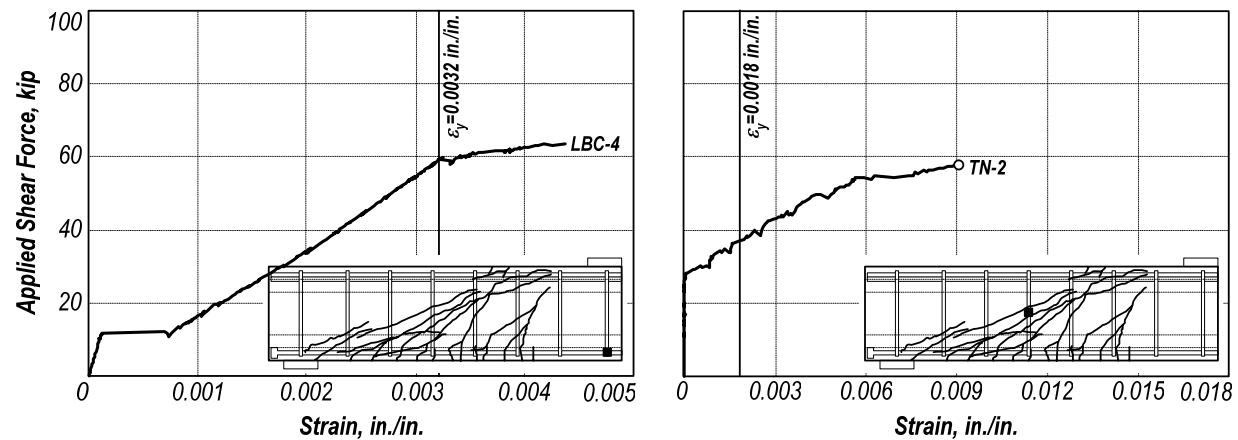

b) Specimen 14.5-2.6-98
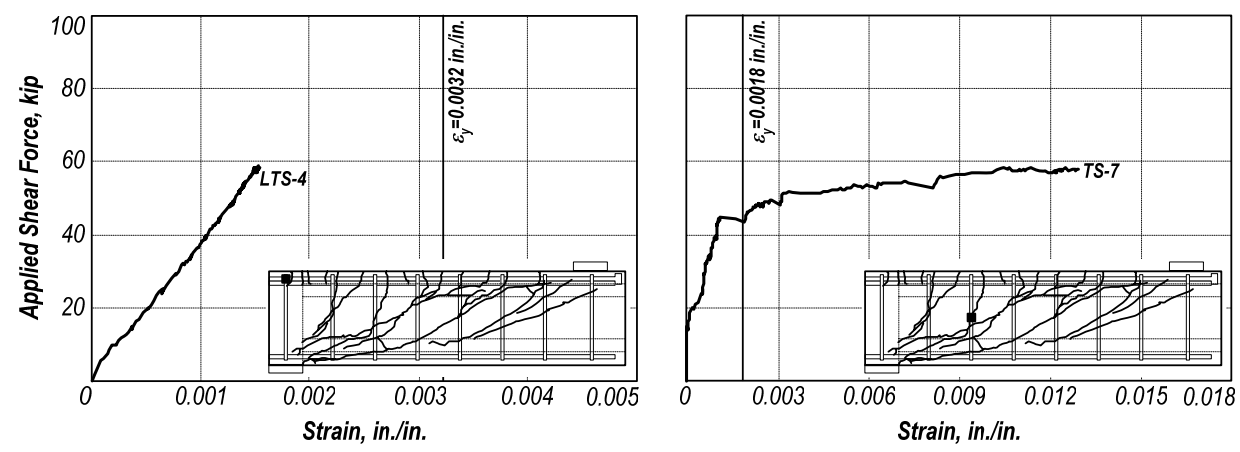

c) Specimen 13.3-5.4-98
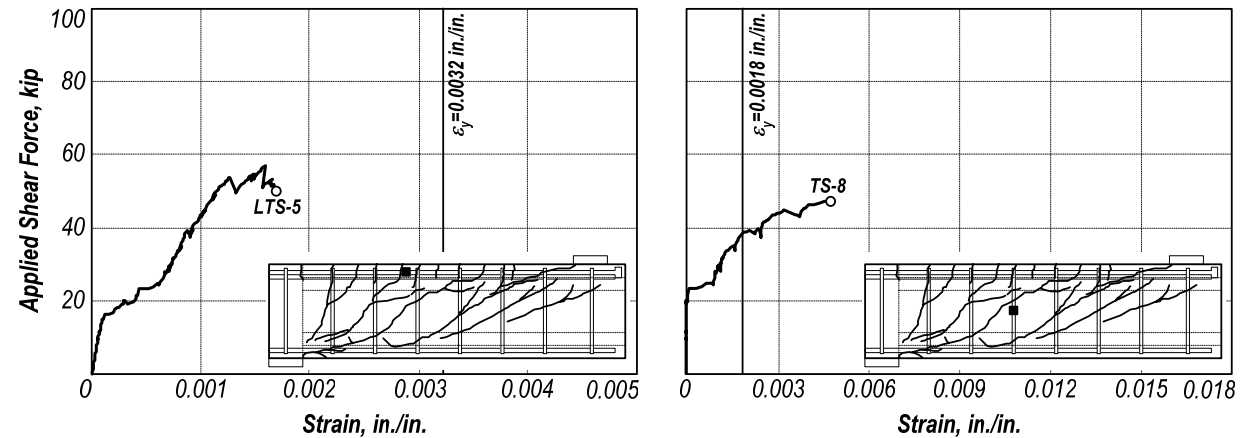

d) Specimen 14.5-5.4-98

\section{Figure 4.7}


The location and identification of Whittemore discs and all strain gages installed in this series of specimens are presented in Figure 3.19 and 3.21, respectively. Figure 4.7 presents load-strain plots for selected locations, shown as black squares on the reinforcement, in specimens with the minimum amount of shear reinforcement (Specimen 13.3-2.6-98, 14.5-2.6-98, 13.3-5.4-98, and 14.5-5.498).

Figure 4.8 presents similar plots for the reinforced concrete specimens with intermediate amount and the maximum amount of shear reinforcement in accordance with $\mathrm{ACl}$ 318-05 (Specimen 13.24.3-451, 15.3-4.3-387, 13.2-7.9-902, and 15.3-7.9-902). In Figure 4.7 and 4.8, only those locations exhibiting the largest strains in the longitudinal and transverse reinforcement are presented. To facilitate comparison and analysis, all plots for a given set of specimens have the same scale, and are accompanied by a partial view of the corresponding reinforcement arrangement and final pattern of cracks. If the strain gage showed signs of debonding from the reinforcement prior to failure of the specimen, a circular mark is set in the plots of Figure 4.7 and 4.8. A more thorough study of the strain gage readings, including the embedded ones, is presented elsewhere (Aguilar, 2005).

It is perhaps discernable in the plots on the left side of Figure 4.7 that the longitudinal reinforcement reached yielding in only one of the specimens reinforced with the minimum amount of shear reinforcement in accordance to 2004 AASHTO LRFD and ACI 318-05, i.e. Specimen 14.5-2.6-98. The strains associated with yielding, $\varepsilon_{y}$, which were presented in Table 3.7, had been determined from three coupon tension tests for each type and size of reinforcement, as described in Section 3.3.2 of this report. The strain gage installed at the midspan cross section (LBC-4 in Figure 3.21) on the No. 8 bars provided as main longitudinal tension reinforcement of Specimen 14.5-2.6-98 showed readings in excess of the corresponding yielding strain ( $\varepsilon y=0.0032 \mathrm{in}$./in.). Despite this fact, the test behavior and mode of failure of Specimen 14.5-2.6-98 were governed by shear. All other strain gages installed on the longitudinal reinforcement of this specimen did not record yielding strains.

In the case of the longitudinal reinforcement, the trend in the load-strain graphs can be described by a tri-linear relationship. The initial segment in this relationship could be associated with the flexural cracking of the specimens. Then, the load-strain curves showed a small plateau which later turned into a third increasingly linear region. In most cases, this third region extended up to failure.

In contrast, the majority of strain gages installed on the No. 2 deformed bars used as stirrups in the specimens with the minimum amount of shear reinforcement exceeded the strain associated with yielding $\left(\varepsilon_{y}=0.0018 \mathrm{in} . / \mathrm{in}\right.$.). 

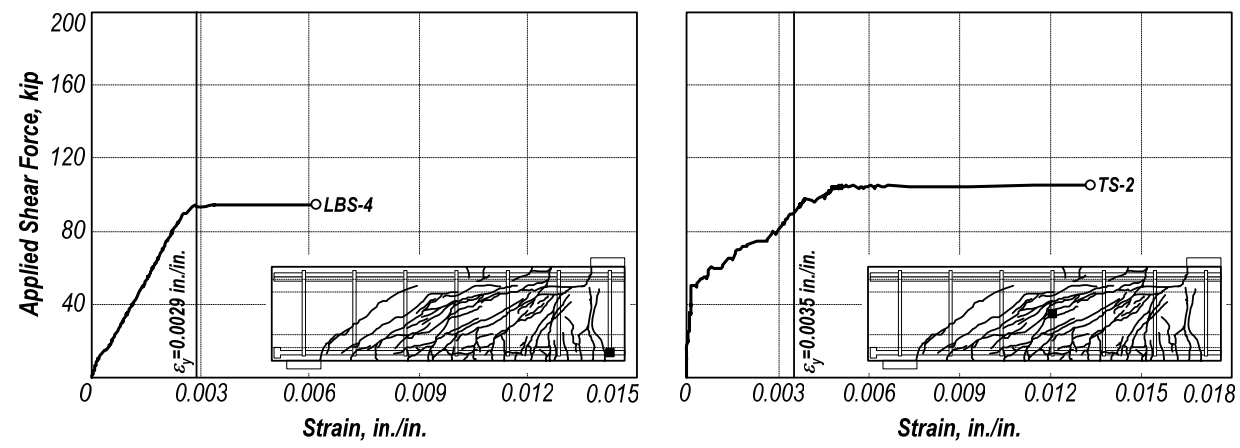

a) Specimen 13.2-4.3-451
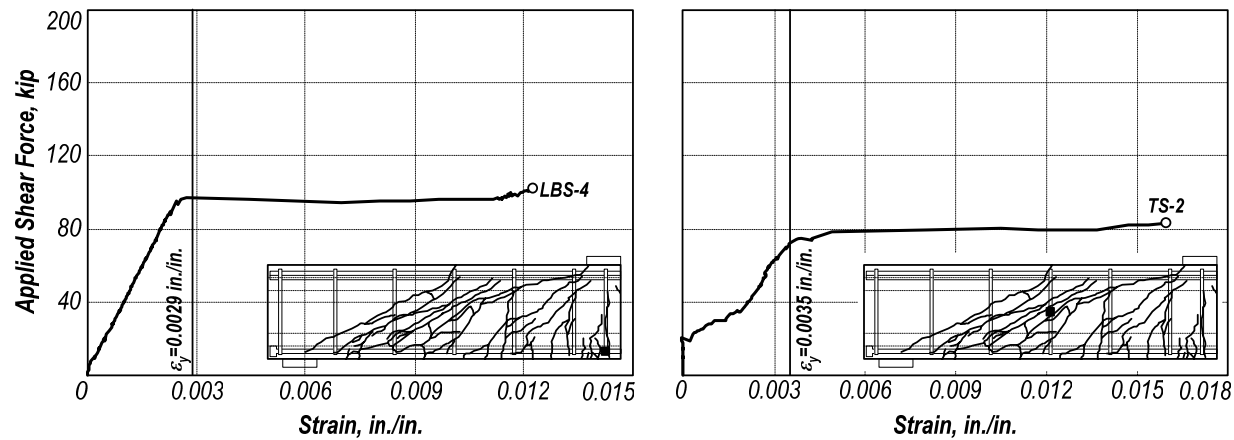

b) Specimen 15.3-4.3-387
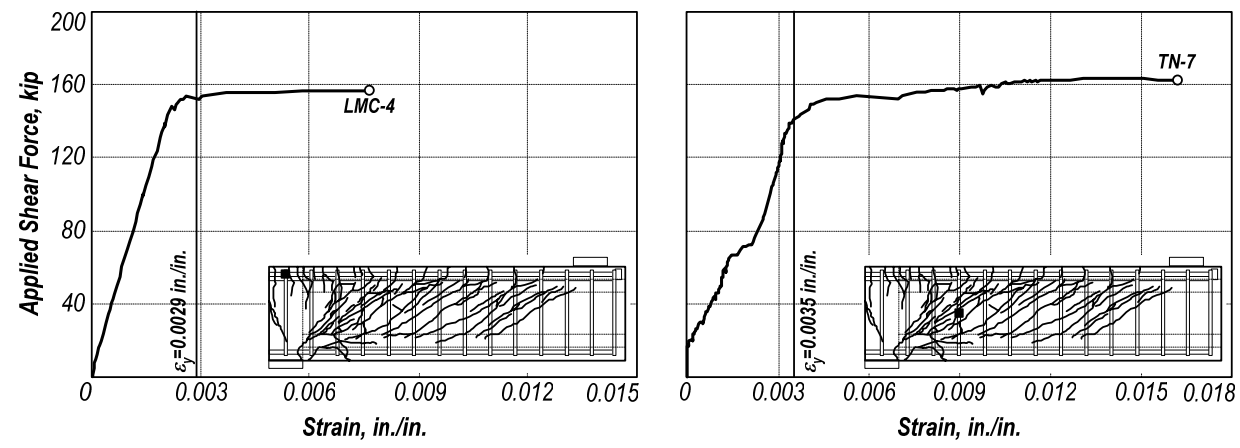

c) Specimen 13.2-7.9-902
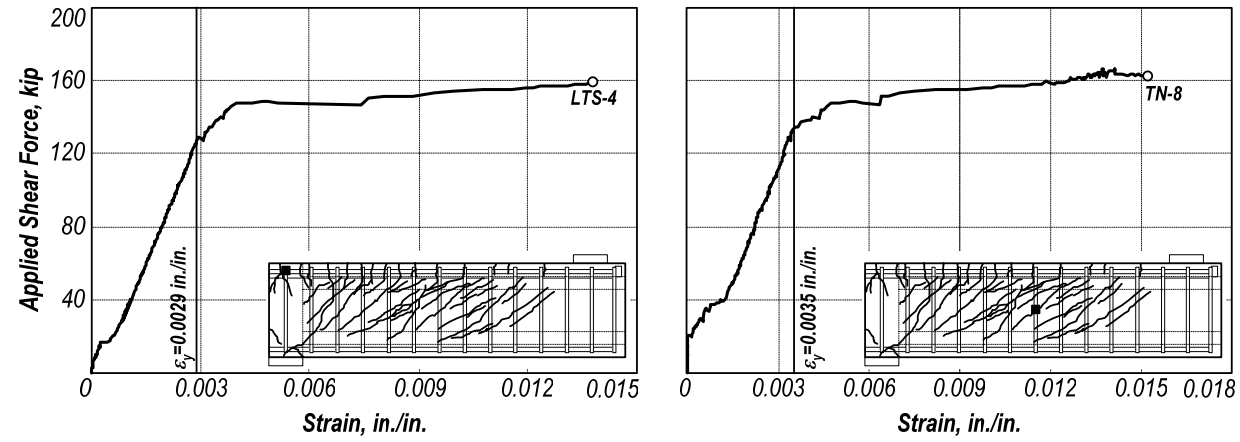

d) Specimen 15.3-7.9-902

Figure 4.8

Selected load-strain curves for reinforced concrete specimens with intermediate amount and the maximum amount of shear reinforcement in accordance with $\mathrm{ACl}$ 318-05 ( $\rho f_{\mathrm{yv}}=902 \mathrm{psi}$ ) 
It must be noted that the No. 2 coupon tests did not show a clear yield plateau and the offset method specified in ASTM A 370-05 was used to determine their yield strength. An offset of $1.8 \%$ was used since it is the deformation at which the relationship between stress and strain was no longer linear. Deformations as high as $0.018 \mathrm{in}$./in. were recorded on the vertical legs of selected stirrups prior to failure. The fracture of one or even both vertical legs of at least one stirrup in the shear span triggered failure in all specimens (13.3-2.6-98, 14.5-2.6-98, 13.3-5.4-98, and 14.5-5.4-98).

A tri-linear trend is also recognized in the load-strain curves corresponding to the strain gages installed on the vertical legs of the stirrups. In this case, however, the first breakpoint in the loadstrain plots is marked by the main inclined cracking. Note that the initial linear region is practically vertical indicating that the stirrups did not contribute to the shear strength until an inclined crack developed. The load-strain relationships corresponding to strain gages installed on the shear reinforcement, shown on the right side of Figure 4.7, were observed to be highly dependent of the cracking pattern. Only if an inclined crack crossed the stirrup in the vicinity of the location of the sensor, the recorded deformations were noticeable. Note that all strain gage readings plotted on the right side of Figure 4.7 correspond to locations close to an inclined crack, as it is indicated by the black squares placed on the reinforcement in the sketches of the final cracking pattern included with each graph.

All the load-strain curves of selected strain gages installed in the longitudinal and transverse reinforcement of the specimens with intermediate and maximum amount of shear reinforcement, presented in Figure 4.8, showed signs of yielding. This trend was observed in many other locations of strain gages, also. Similarly to the plots in Figure 4.7, a tri-linear behavior was recognized. In the case of strain gages installed on the longitudinal reinforcement, shown on the left column of Figure 4.8, the first linear region was limited by the development of the first flexural cracking. From that point and up to the yielding strain, $\varepsilon_{y}$, a second linear region could be recognized. The third region in these plots corresponds to a yielding plateau that extended up to the debonding of the gage from the reinforcement, often prior to failure. Deformations as high as $0.014 \mathrm{in}$./in. were observed in the longitudinal reinforcement, at the section of maximum moment.

A similar tri-linear trend is recognized in the plots of the right column in Figure 4.8, which correspond to strain gages installed on the vertical legs of No. 4 stirrups. The first slope change in these plots corresponds to the first inclined cracking. The second change was around $0.0035 \mathrm{in}$./in., which corresponds to the yielding strain determined on the basis of coupon tests for the bars used as stirrups. In all cases, there was a good agreement between the yielding deformation determined through the test of tension coupons and the onset of the yielding plateau in the loadstrain plots. Note that the selected strain gages in Specimen 13.2-4.3-451 and 15.3-4.3-307 reached their yielding strain at a lower shear force than Specimen 13.2-7.9-902 and 15.3-7.9-902, which were reinforced with the maximum amount of shear reinforcement in accordance to $\mathrm{ACl} 318-03$. The 
reduction of spacing between stirrups from 12 and 14 in. in specimens with intermediate amount of shear reinforcement to $6 \mathrm{in}$. in the specimens with maximum amount of shear reinforcement resulted in a higher shear capacity. The yield plateau in the load-strain curves of the right column of Figure 4.8 extended up to failure of the specimen or to the debonding of the gage from the stirrups. There was no evidence of stirrup fracture in Specimen 13.2-4.3-451, 15.3-4.3-387, 13.2-7.9902, or 15.3-7.9-902.

The Whittemore readings taken throughout the tests allowed the computation of shear strains along the test shear spans. The details of the computation are presented in Aguilar (2005). Figure 4.9 gives selected calculated shear strain distributions along the shear spans. For each test specimen, only a set of readings is shown. This set corresponds to the readings taken nearest to failure. The corresponding shear force is indicated on each plot. A single scale is used in all plots to facilitate comparison among specimens.

It is evident from the plots in Figure 4.9 that the surface shear strain decreased as the amount of shear reinforcement increased. The distortion of the web and the crack widths were reduced as larger bars and smaller spacing were used to provide the shear reinforcement.

As seen in Figure 4.9, the largest concentration of surface shear strains occurs almost at the location where the widest cracks were recorded. Note that, close to failure, the measured surface shear strains for specimens with intermediate and maximum amounts of shear reinforcement were around $0.005 \mathrm{in}$./in., whereas the shear strains determined for the specimens with the minimum amount of shear reinforcement were well above that figure; even reaching values of around $0.022 \mathrm{in}$./in. Also note a single large peak in the plot corresponding to Specimen 15.3-4.3-387, corresponding to a shear deformation of $0.02 \mathrm{in}$./in. This was exceptional for the series of specimens with amounts of shear reinforcement greater than the minimum, and was related to the observation of crushing of concrete in the web of Specimen 15.3-4.3-387. This particular set of readings was taken at $98 \%$ of the ultimate load of the specimen.

\subsubsection{Test and Calculated Capacities}

Table 4.3 summarizes the measured and calculated capacities for the reinforced concrete specimens containing shear reinforcement. The values in Table 4.3 were obtained following the same criteria stated in Section 4.2.1.5 of this report.

In Table 4.3, however, two values for the shear strength were computed in accordance with the 2004 AASHTO LRFD Specifications for the specimens with minimum amount of shear reinforcement. One set of values in Table 4.3 was developed considering that the minimum amount of shear reinforcement per Eq. 2.11 was satisfied, thus using Table 2.10 to determine $\beta$ and $\theta$. 


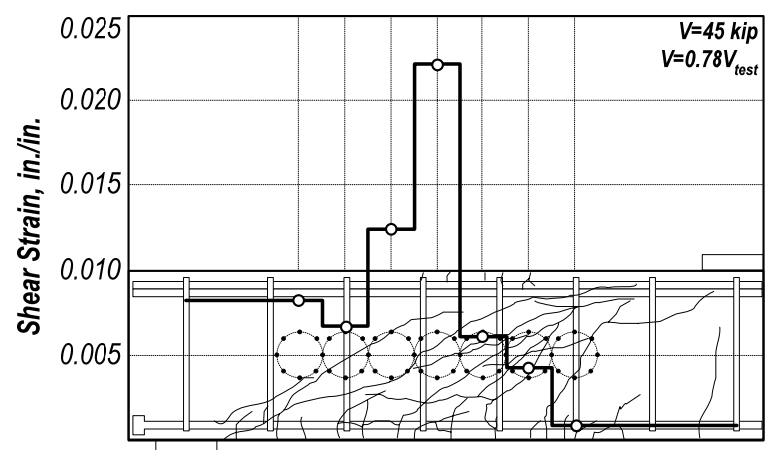

a) Specimen 13.3-2.6-98

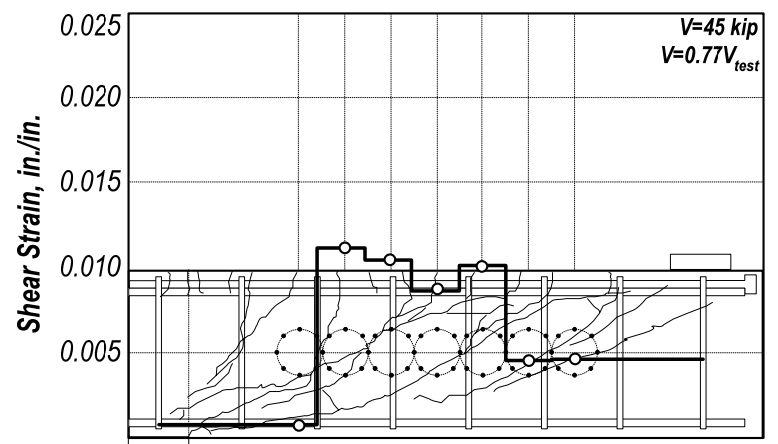

c) Specimen 13.3-5.4-98

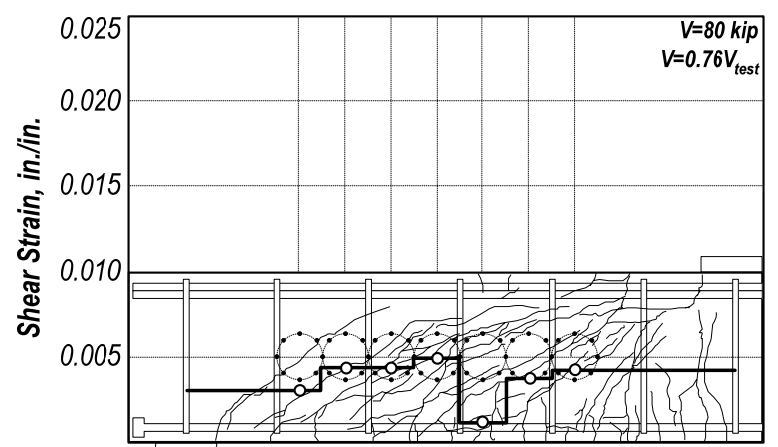

e) Specimen 13.2-4.3-451

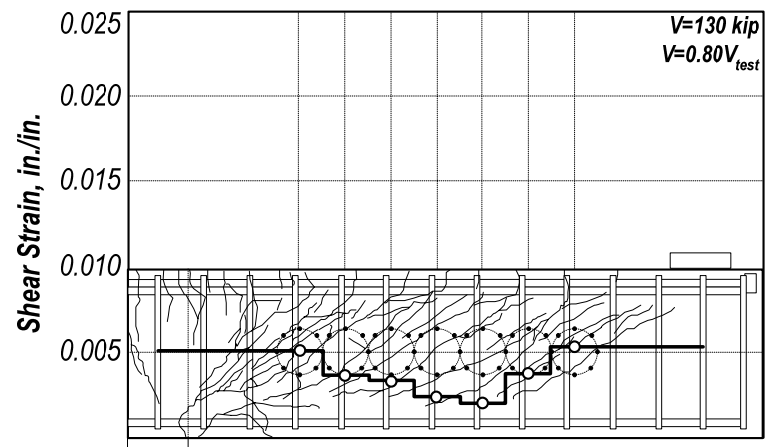

g) Specimen 13.2-7.9-902

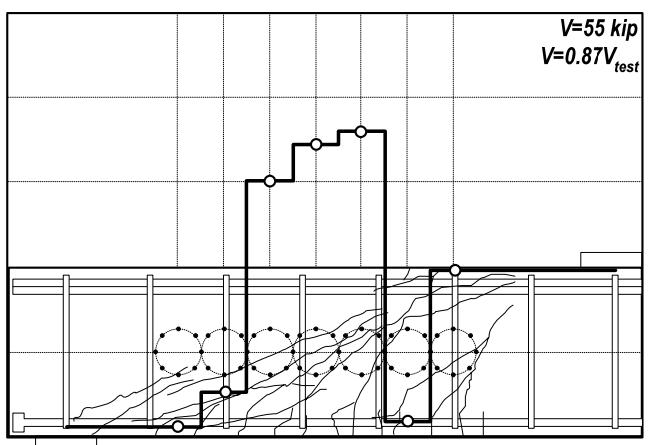

b) Specimen 14.5-2.6-98

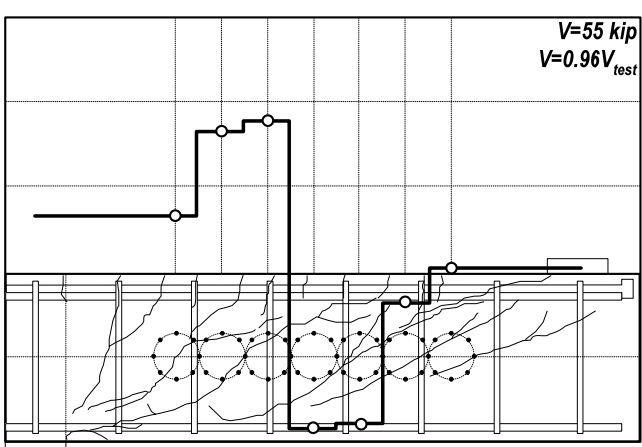

d) Specimen 14.5-5.4-98

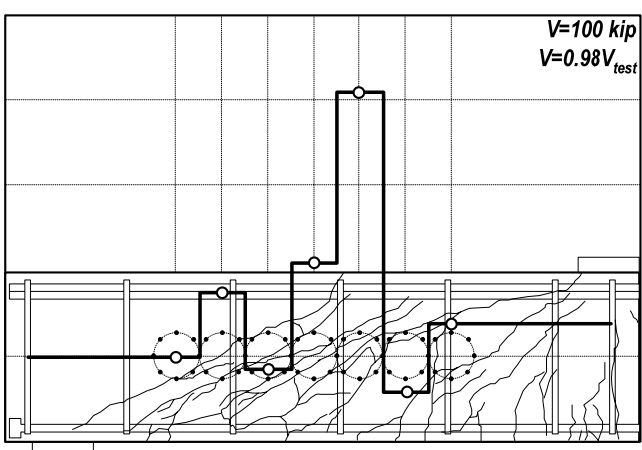

f) Specimen 15.3-4.3-387

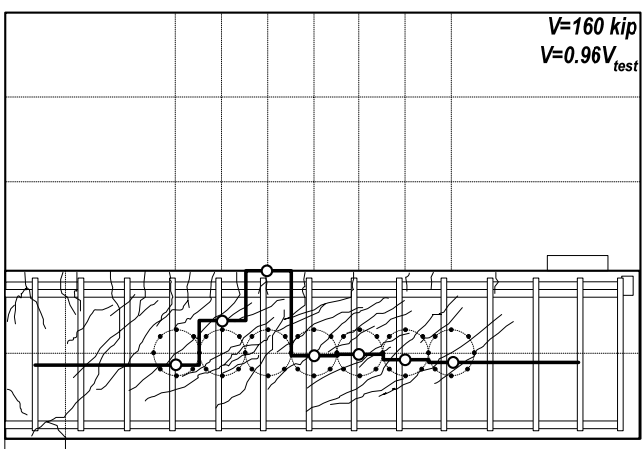

h) Specimen 15.3-7.9-902

Figure 4.9 Selected distributions of measured shear strain in specimens with shear reinforcement 
Accompanying values in parentheses for the same specimens were obtained considering that the amount of shear reinforcement provided did not satisfy Eq. 2.11, and that the use of Table 2.11 was necessary to determine $\beta$ and $\theta$. This was done to evaluate not only the contribution of the minimum amount of transverse reinforcement to the shear strength of the beams, but also to study its role of providing reserve shear strength.

\section{Table 4.3 Measured and calculated capacities for reinforced concrete specimens with shear} reinforcement

\begin{tabular}{|c|c|c|c|c|c|c|c|c|c|c|}
\hline \multirow{3}{*}{ Specimen } & \multirow{3}{*}{$\begin{array}{c}V_{\text {cracking }} \\
\text { kip }\end{array}$} & \multirow{3}{*}{$\begin{array}{c}V_{\text {test, }} \\
\text { kip }\end{array}$} & \multirow{3}{*}{$\begin{array}{c}\delta_{\max } \\
\text { in. }\end{array}$} & \multicolumn{7}{|c|}{ Calculated Capacities } \\
\hline & & & & \multirow{2}{*}{$\begin{array}{c}V_{\text {flexure }} \\
\text { kip }\end{array}$} & \multicolumn{3}{|c|}{2004 AASHTO LRFD } & \multicolumn{3}{|c|}{$\mathrm{ACl} 318-05$} \\
\hline & & & & & $V_{c, k i p}$ & $V_{s, k i p}$ & $V_{n, k i p}$ & $V_{c, k i p}$ & $V_{s, k i p}$ & $V_{n}, k i p$ \\
\hline $13.3-2.6-98$ & 20.0 & 57.9 & 0.92 & 70.8 & $29.6(19.7)$ & 15.4 (8.2) & $44.9(27.9)$ & 28.6 & 11.8 & 40.4 \\
\hline $14.5-2.6-98$ & 18.0 & 63.5 & 0.88 & 71.3 & $30.9(20.4)$ & 15.4 (8.2) & $46.3(28.6)$ & 29.8 & 11.8 & 41.6 \\
\hline $13.3-5.4-98$ & 25.0 & 58.8 & 1.55 & 131.3 & $32.0(23.8)$ & $17.6(9.2)$ & $49.6(33.0)$ & 30.2 & 11.5 & 41.7 \\
\hline $14.5-5.4-98$ & 25.0 & 57.1 & 1.53 & 131.8 & $33.5(24.7)$ & $17.5(9.2)$ & $51.0(33.9)$ & 31.4 & 11.5 & 42.9 \\
\hline $13.2-4.3-451$ & 20.0 & 105.9 & 1.75 & 109.6 & 29.1 & 69.6 & 98.7 & 29.7 & 53.8 & 83.5 \\
\hline $15.3-4.3-387$ & 20.0 & 101.7 & 1.58 & 110.7 & 31.2 & 59.5 & 90.7 & 31.7 & 46.1 & 77.8 \\
\hline 13.2-7.9-902 & 20.0 & 163.1 & 3.45 & 186.0 & 26.9 & 130.4 & 157.4 & 31.9 & 104.8 & 136.7 \\
\hline 15.3-7.9-902 & 25.0 & 166.6 & 2.86 & 187.1 & 29.9 & 133.1 & 163.0 & 33.8 & 104.8 & 138.6 \\
\hline
\end{tabular}

For the specimens with minimum amount of shear reinforcement and $2.6 \%$ of longitudinal reinforcement ratio, there was a $10 \%$ increase in shear capacity when the compressive strength of concrete was increased $9 \%$. The positive effect of increasing the uniaxial concrete compressive strength on the shear capacity as calculated using the 2004 AASHTO LRFD Specifications and the $\mathrm{ACl}$ 318-05 Code was not observed in the specimens with minimum amount of shear reinforcement and longitudinal reinforcement ratio, $\rho_{w}$ of 5.40\%. In fact, comparing Specimen 13.35.4-98 and 14.5-5.4-98, there was a 3\% reduction in the shear capacity as the compressive strength was increased by $9 \%$. This variation can be attributed to the scatter usually associated with shear tests. However, there is a significant benefit in terms of shear strength and reserve capacity above that corresponding to diagonal cracking obtained even with just the minimum amount of shear reinforcement in accordance with the 2004 AASHTO LRFD Specifications or the ACI 31805 Code throughout the range of concrete strengths considered in this project.

The same trend was observed for the specimens with intermediate amount of shear reinforcement. An increase of $16 \%$ in the concrete compressive strength resulted in a $4 \%$ reduction on the shear capacity of the beam. However, in this case, there was also a $14 \%$ reduction in the amount of shear reinforcement from Specimen 13.2-4.3-451 to 15.3-4.3-387, which may have had more impact on the shear strength than an increase in concrete compressive strength. In the case of Specimen 13.2-7.9-902 and 15.3-7.9-902, the 16\% percent increase in the compressive 
strength of concrete translated into a modest $2 \%$ increase in shear capacity. These observations have to be taken with caution since the mode of failure of these specimens was a combination of shear and flexure.

Table 4.4 presents the shear capacity in terms of the square root of the measured compressive strength of concrete. In contrast with the observations for the specimens without shear reinforcement, the ratio $V_{\text {test }} / V_{n}$ for 2004 AASHTO LRFD was less than for ACl 318-05 in all eight specimens with shear reinforcement. The average concrete shear stress at failure was $4.2 \sqrt{f_{c}}$ for specimens with minimum amount of shear reinforcement, $7.3 \sqrt{f_{c}}$ for specimens with intermediate amount of shear reinforcement, and $11.9 \sqrt{f_{c}}$ for specimens with maximum amount of shear reinforcement in accordance to the $\mathrm{ACl} 318-05$ Code.

The effect of both the compressive strength of concrete and the amount of longitudinal reinforcement on the shear capacity was seen to reduce as the amount of transverse reinforcement increased. There was over $70 \%$ increase in the ultimate average concrete shear stress when the amount of shear reinforcement was increased from 98 to 387 psi in the case of Specimen 14.5-5.4-98 and 15.3-4.3-387 and to 451 psi in Specimen 13.2-4.3-451.

Table 4.4

\section{Ratio of measured to calculated capacities for reinforced concrete specimens with} shear reinforcement

\begin{tabular}{|c|c|c|c|c|c|}
\hline Specimen & $\frac{V_{\text {test }}}{\sqrt{f_{c}} b_{w} d_{v}}$ & $\frac{V_{n, \text { AASHTO }}}{\sqrt{f_{c}} b_{w} d_{v}}$ & $\frac{V_{n, A C l}}{\sqrt{f_{c}} b_{w} d_{v}}$ & $\frac{V_{\text {test }}}{V_{n, \text { AASHTO }}}$ & $\frac{V_{\text {test }}}{V_{n, A C l}}$ \\
\hline $13.3-2.6-98$ & 4.2 & 3.2 & 2.9 & 1.3 & 1.4 \\
\hline $14.5-2.6-98$ & 4.4 & 3.2 & 2.9 & 1.4 & 1.5 \\
\hline $13.3-5.4-98$ & 4.4 & 3.7 & 3.1 & 1.2 & 1.4 \\
\hline $14.5-5.4-98$ & 4.0 & 3.6 & 3.0 & 1.1 & 1.3 \\
\hline Average & 4.2 & 3.4 & 3.0 & 1.2 & 1.4 \\
\hline $13.2-4.3-451$ & 7.7 & 7.2 & 6.1 & 1.1 & 1.3 \\
\hline $15.3-4.3-387$ & 6.9 & 6.2 & 5.3 & 1.1 & 1.3 \\
\hline Average & 7.3 & 6.7 & 5.7 & 1.1 & 1.3 \\
\hline 13.2-7.9-902 & 12.2 & 11.8 & 10.3 & 1.0 & 1.2 \\
\hline 15.3-7.9-902 & 11.6 & 11.4 & 9.7 & 1.0 & 1.2 \\
\hline Average & 11.9 & 11.6 & 10.0 & 1.0 & 1.2 \\
\hline
\end{tabular}

If $V_{c}$ increases as the concrete compressive strength increases, as per Eq. 2.22 or 2.23, then the increase in the amount of shear reinforcement from an intermediate to the maximum amount in accordance to $\mathrm{ACl}$ 318-05 resulted in significant increases in the shear capacity of the test specimens. An increase of over $50 \%$ was observed in the shear capacity as the amount of shear 
reinforcement doubled from 451 to $902 \mathrm{psi}$, and from 387 to $902 \mathrm{psi}$. The maximum amount of shear reinforcement in accordance with $\mathrm{ACl} 318$ as set by Eq. 2.28, proved to be a reasonable upper limit to prevent failures associated with the crushing of the web. Its worth noting that the design of specimens with maximum amount of shear reinforcement in accordance with 2004 AASHTO LRFD, as given in Eq. 2.5, led to impractical spacings between stirrups and could not be experimentally evaluated. In fact, Specimen 15.3-7.9-902 would have required No. 4 closed stirrups at a 1.9-in. spacing in such case.

The average $V_{\text {test }} V_{n}$ ratio for the 2004 AASHTO LRFD Specifications was 1.2, 1.1 and 1.0 for specimens with minimum, intermediate and maximum amounts of shear reinforcement, respectively. The same ratios for the $\mathrm{ACl} 318-05$ Code were 1.4, 1.3 and 1.2, respectively. Note that the degree of conservatism of both 2004 AASHTO LRFD and ACI 318-05 decreased as the amount of shear reinforcement increased. Indeed, the ratio of test to calculated values obtained for both design codes became closer to 1.0 as the amount of shear reinforcement increased. Additionally, it was observed that the degree of conservatism of 2004 AASHTO LRFD was slightly reduced as the compressive strength of concrete increased. Use of Eq. 2.23, (Eq. 11-5 on ACl 318-05 Code) resulted in the largest $V_{\text {test }} V_{n}$ ratio in the higher concrete compressive strength range.

\subsection{Prestressed Concrete Beams}

Four AASHTO Type I beams were tested to failure. The main focus of this phase of the study was to evaluate the effect of prestressing as the compressive strength of concrete and the amount of shear reinforcement varied. Concrete compressive strength ranged from 13300 to $17000 \mathrm{psi}$. Spacing of the No. 4 stirrups used as shear reinforcement was set at 18.0 and $4.5 \mathrm{in}$. These spacings resulted in amounts of shear reinforcement corresponding to $A_{v} f_{y} / b_{w} s$ of 326 and $1305 p s i$, respectively.

Two specimens were built with the minimum amount of shear reinforcement in accordance with 2004 AASHTO LRFD, as controlled by the maximum spacing specified in its Section 5.2.8.7 (Specimen 13.3-5.1-326P and 16.2-5.1-326P). The other two specimens had the maximum amount of shear reinforcement in accordance with $\mathrm{ACl}$ 318-05 (Specimen 13.7-5.1-1305P and 17.0-5.1-1305P). Flexural reinforcement and prestressing force was the same for all four prestressed specimens. General reinforcement details of the prestressed concrete specimens are presented in Table 3.3 and in Figure 3.9.

\subsubsection{Cracking Behavior}

The final cracking pattern for all four prestressed beams after hand removal of loose concrete parts is shown in Figure 4.10. 

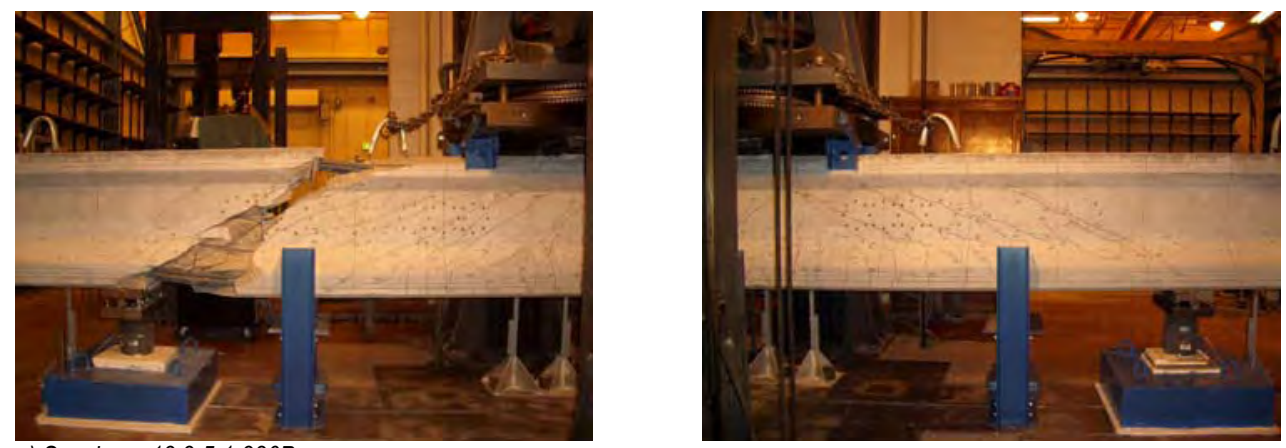

a) Specimen 13.3-5.1-326P
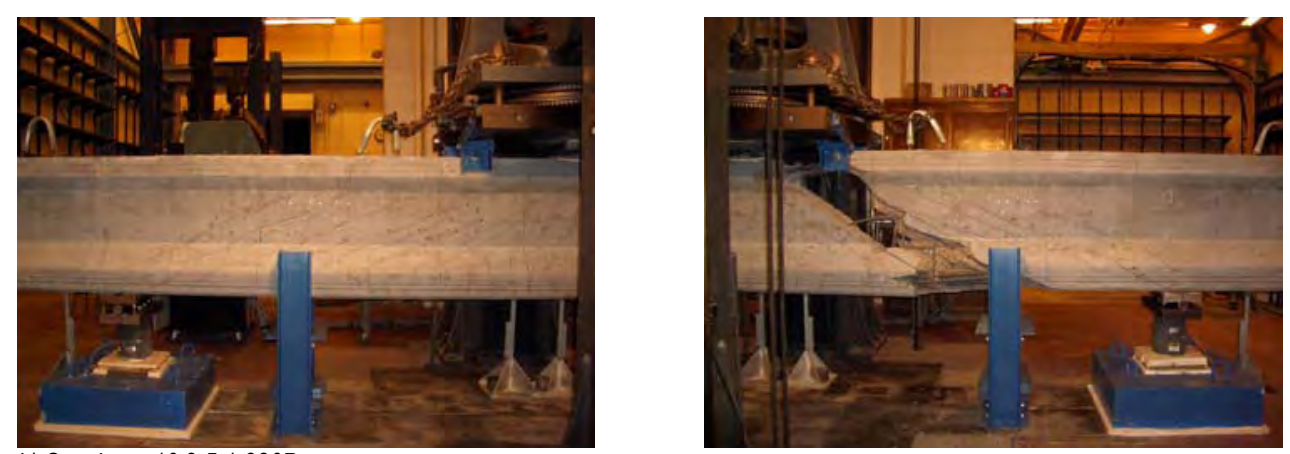

b) Specimen 16.2-5.1-326P
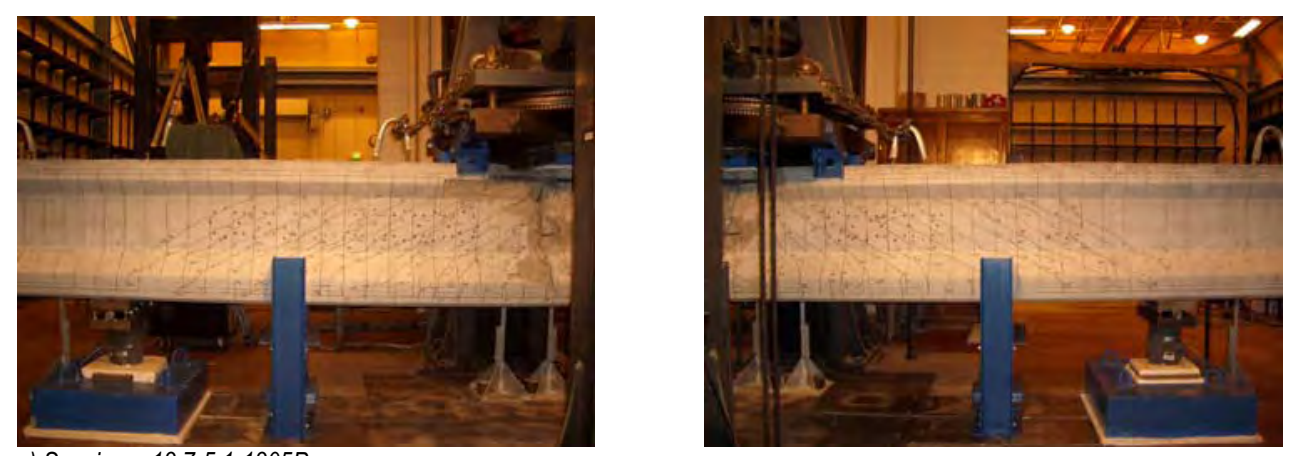

c) Specimen 13.7-5.1-1305P
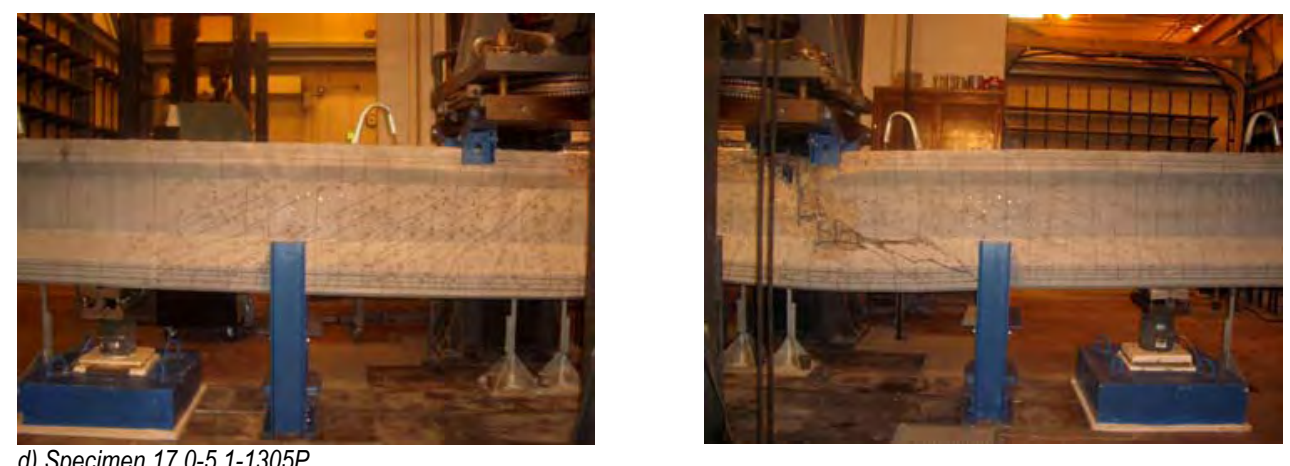

Figure 4.10 Final crack pattern of prestressed concrete specimens 
The cracking patterns were similar between pairs of companion specimens. For the specimens with the minimum amount of shear reinforcement fewer and wider cracks were observed than for specimens with the maximum amount of shear reinforcement, where numerous cracks of smaller width developed as the test progressed.

The sequence of damage in Specimen 13.3-5.1-326P and 16.2-5.1-326P, reinforced with the minimum amount of shear reinforcement, was similar. In both specimens, damage started with the simultaneous emergence of four to five inclined cracks in the shear span. Initially, these cracks were located in the web and did not penetrate the flanges. This was followed by the development of some vertical flexural cracks in the midspan region. With increasing load, the inclined cracks continue to extend towards the flexural compression zone and increased in width. Additional new inclined cracks appeared as well. Upon further load increases, more flexural cracks appeared away from the midspan cross section, along the shear span.

A single inclined crack extending from top to bottom flange led to failure of the specimens with minimum amount of shear reinforcement. The angle of inclination of the main inclined crack was 35 and $30 \mathrm{deg}$. for Specimen 13.3-5.1-326P and 16.2-5.1-326P, respectively. The concrete in the vicinity of the main inclined crack crushed and spalled at failure. Both vertical legs of the stirrup crossing the main inclined crack ruptured at midheight. This behavior was similar to that observed in the reinforced concrete specimens. However, the appearance of inclined cracking was significantly delayed by the presence of prestressing and the initial inclination of the diagonal cracks was slightly less.

The evolution of damage in both Specimen 13.7-5.1-1305P and 17.0-5.1-1305P was similar. In contrast with the behavior of the prestressed concrete specimens with minimum amount of shear reinforcement, the first cracks in the specimens reinforced with the maximum amount of shear reinforcement in accordance to $\mathrm{ACl} 318-05$ were due to flexure. At early test stages, some vertical flexural cracks appeared in the midspan region. After further increasing the load, several inclined cracks simultaneously appeared in the web of the specimens. Around five cracks were observed to form initially. As the midspan load was increased, more flexural and inclined cracks developed away from the midspan region. The cracking pattern of Specimen 13.7-5.1-1305P and 17.0-5.1-1305P showed a more uniform distribution than that of Specimen 13.3-5.1-326P and 16.2-5.1326P. The number of cracks increased and their width reduced in comparison with the cracking observed in the prestressed concrete specimens with minimum amount of shear reinforcement. Prior to failure, the main inclined crack in Specimen 13.7-5.1-1305P and 17.0-5.1-1305P was 0.020 and 0.034-in. wide, respectively. The width of the main inclined crack prior to failure of Specimen 13.35.1-326P and 16.2-5.1-326P was 0.040 and 0.016 in., respectively. 
At service load levels, the width of the main inclined crack of Specimen 13.7-5.1-1305P and 17.0-5.11305P, both with maximum amount of shear reinforcement, was 0.007 and 0.009 in., respectively. The widths at service load levels for Specimen 13.3-5.1-326P and 16.2-5.1-326P were 0.020 and $0.010 \mathrm{in}$., respectively. As can be seen, the width of the crack decreased for the same amount of shear reinforcement as the concrete compressive strength was increased. Service loads were computed assuming that the totality of the load applied was live load; therefore using a load factor of 1.6. The only source of dead load was considered to be the self weight of the beams; for which a load factor of 1.2 was used.

\subsubsection{Failure Mode}

The failure mode of Specimen 13.3-5.1-326P and 16.2-5.1-326P, reinforced with the minimum amount of shear reinforcement in accordance to 2004 AASHTO LRFD was shear. Failure in these specimens was characterized by a single inclined crack extending between top and bottom flanges. Crushing of concrete along the main inclined crack was observed in these specimens. Large portions of concrete disintegrated as the specimens reached their peak load. Failure was sudden, loud and explosive.

Failure mode of Specimen 13.7-5.1-1305P, reinforced with the maximum amount of shear reinforcement in accordance to $\mathrm{ACl}$ 318-05 was flexural compression. A portion of concrete in the side of the top flange was lost as the specimen reached its peak load. As described in Section 4.3.4 of this report, signs of yielding in the flexural reinforcement had been observed prior to failure. The failure of Specimen 13.7-5.1-1305P was sudden and loud. Right after failure, there was an abrupt loss of adherence in the prestressing strands along the most damaged region of the specimen.

Even though it may not be relevant to the objectives of the present study, its worth noting that the said loss of adherence resulted in an unsymmetrical effect of the prestressing force that caused the beam to slightly rotate around its longitudinal axis. The steel shapes that were provided as out-of-plane restrains to the prestressed specimens proved to be a good safety measure. Figure 3.25 in Section 3.5.1 of this report show details of the lateral restrains.

Specimen 17.0-5.1-1305P failed in a flexural-compression mode. Crushing of concrete in the web and in the top flange around the midspan point load was observed. Failure was characterized by the disintegration of concrete along an inclined trajectory in both faces of the web. Crushing of concrete extended throughout the height of the web. Damage was concentrated in the region neighboring the midspan load. Failure was loud and explosive. Some fragments of concrete were thrown away from the beam as far as $50 \mathrm{in}$. Both longitudinal and transverse reinforcement exhibited strains in excess of their yield strain, $\varepsilon y$, experimentally determined from coupon tests. 


\subsubsection{Load-deflection Curves}

The load-deflection relationship for all prestressed specimens was obtained as described in Section 4.2.1.3 of this report. The deflection at midspan (LVDT-4 in Figure 3.17) was corrected by subtracting the vertical displacement measured at the supports (LVDT-1 and LVDT-7). The applied shear force was obtained as the average of the load reaction at the supports (RW-1 and RE-5), and half of the load applied by the Baldwin testing machine (F-4). Figure 4.11 shows the loaddeflection curves for the prestressed concrete specimens.

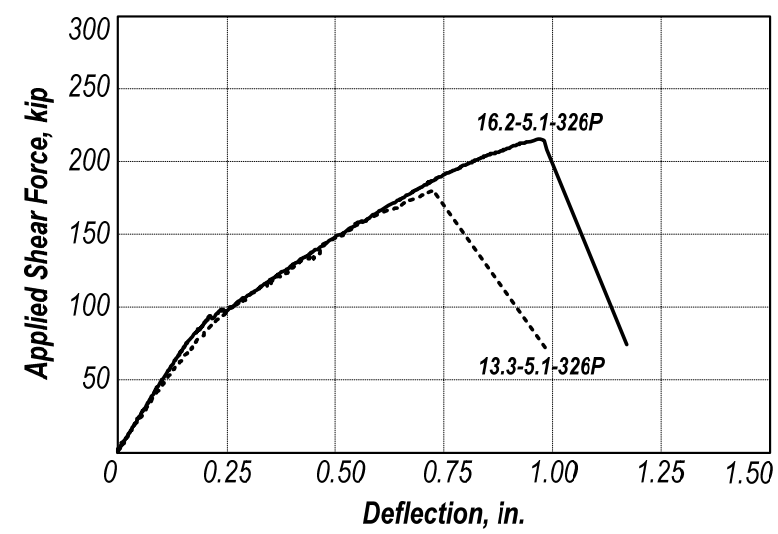

a) Specimens with minimum amount of shear reinforcement

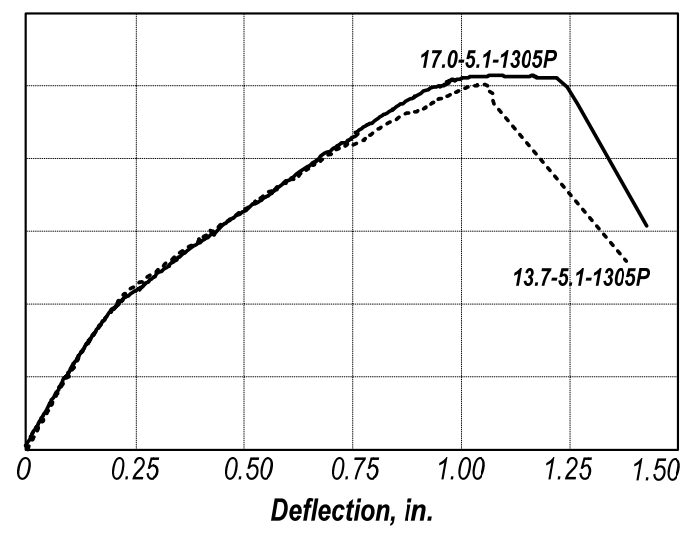

b) Specimens with maximum amount of shear reinforcement as per ACl 318-05

\section{Figure 4.11 Load-deflection curves for prestressed concrete specimens}

The trend for all four load-deflection curves shown in Figure 4.11 is similar despite the differences in both concrete compressive strength and amount of shear reinforcement. Two linear regions may be recognized in these plots. The first one starts at the origin and is limited by the appearance of inclined cracking. Then the second region commences and extends to the peak load. The initial stiffness of all four prestressed specimens was similar, as seen by the starting slope of the load-deflection curves. However, the residual stiffness (stiffness after inclined cracking) of specimens with the maximum amount of shear reinforcement was $15 \%$ greater than that of specimens with the minimum amount of shear reinforcement. The increase in stiffness after inclined cracking could be associated to the presence of more closely spaced stirrups, which prevented the propagation and widening of inclined cracks.

Note the small plateau that the load-deflection curve for Specimen 17.0-5.1-1305P showed prior to failure. This observation is usually associated with the yielding of flexural reinforcement. In fact, both longitudinal and transverse reinforcement exceeded measured yield strains from coupon tests. The abrupt descending branches of the plots in Figure 4.11 are due to the load-controlled scheme followed for the tests. The loss of load carrying capacity after failure was sudden and nearly total. Figure $4.11 \mathrm{~b}$ also indicates that increases in concrete strength benefit more beams with lower amounts of shear reinforcement. Caution most be exercised in extrapolating this 
finding since flexure appeared to be the controlling failure mode. This is further discussed in the section corresponding to strain readings in the reinforcement.

\subsubsection{Strain Readings}

Similarly to the reinforced concrete specimens with shear reinforcement, the prestressed concrete specimens were densely instrumented by means of electrical resistance strain gages. Sensors were installed on numerous locations along the longitudinal mild reinforcement, the prestressing strands and at midheight of both vertical legs of selected stirrups. Figure 3.22 shows the location and identification of the strain gages installed on the reinforcement of the prestressed specimens. Additionally, Whittemore readings to determine the shear strain on the surface of the beams were taken at selected shear loads during the tests. Figure 3.19 shows the array of steel discs used to take the Whittemore readings. Figure 4.12 presents the load-strain curves for selected sensors in the prestressed concrete specimens.

The left column of Figure 4.12 presents plots of strain gages installed on the longitudinal mild reinforcement, whereas on the right column the load-strain curves of gages located on the shear reinforcement are shown. Only those locations exhibiting the largest strains are presented in Figure 4.12. Each plot in Figure 4.12 includes a sketch of the reinforcement details and the final crack pattern of the specimen. The location of the plotted sensor is marked in the sketch with a black square. If debonding of the gage was observed, a circular mark is located at the last reliable reading of the load-strain curve. Additionally, the yielding strain determined from the test of three tension coupons for the corresponding type and size of reinforcement is marked on the graphs in Figure 4.12.

The graphs on the left column of Figure 4.12, corresponding to strain gages installed on the No. 8 bars used as longitudinal reinforcement, have two distinctive trends. For Specimen 13.3-5.1-326P and 16.2-5.1-326P with the minimum amount of shear reinforcement, the plots did not or hardly reached yielding strains.

The trend for the load-strain graphs corresponding to the longitudinal reinforcement of prestressed beams with the minimum amount of shear reinforcement could be described by a bilinear relationship. The first linear region started at the origin and was limited by the appearance of inclined cracking. Then, the second region commenced with a reduced slope and extended up to failure. In contrast, mild longitudinal bars in Specimen 13.7-5.1-1305P and 17.0-5.1-1305P, both with maximum amount of shear reinforcement, reached and exceeded their yield strain determined from tension coupons. Yielding of longitudinal reinforcement was observed not only at the maximum moment section, but also in the neighboring sensor locations, $38 \mathrm{in}$. away from midspan. 

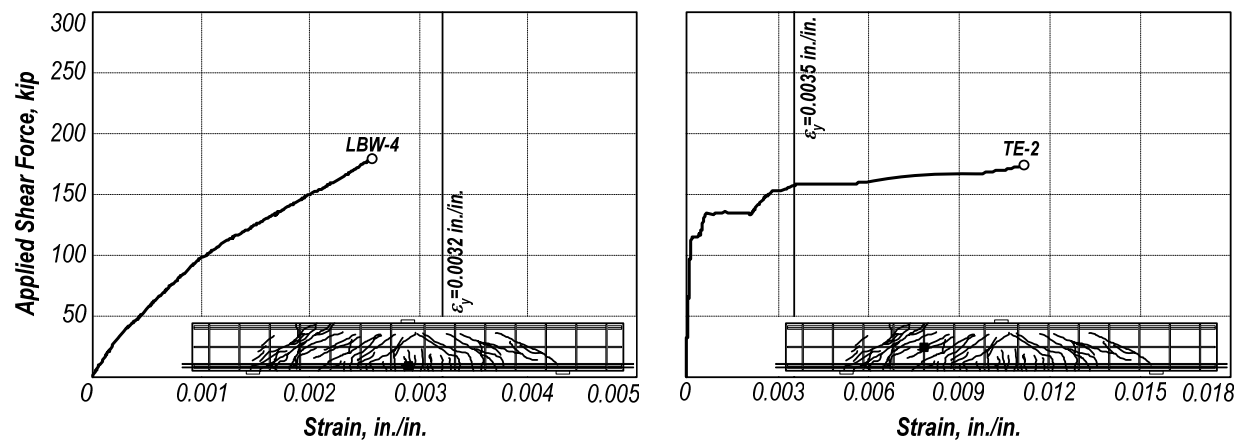

a) Specimen 13.3-5.1-326P
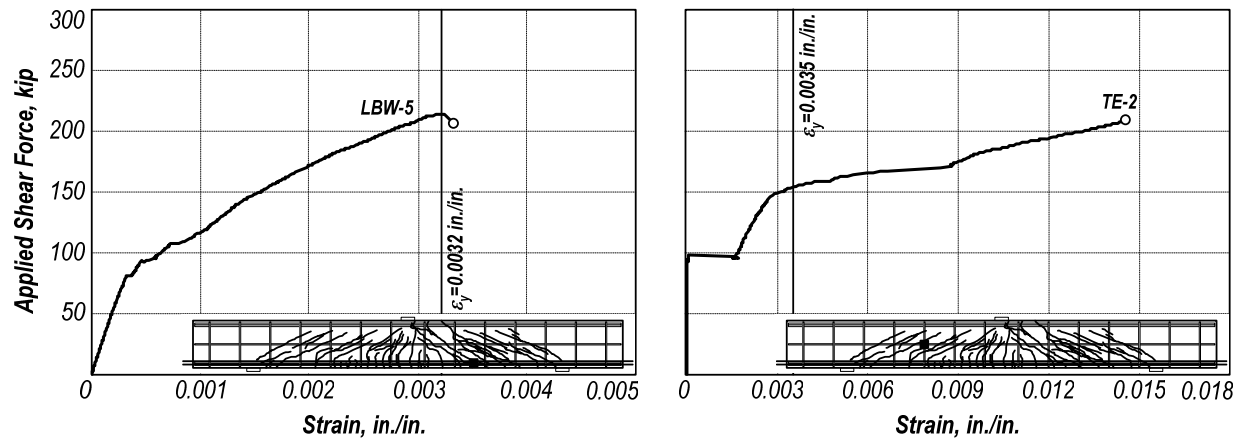

b) Specimen 16.2-5.1-326P
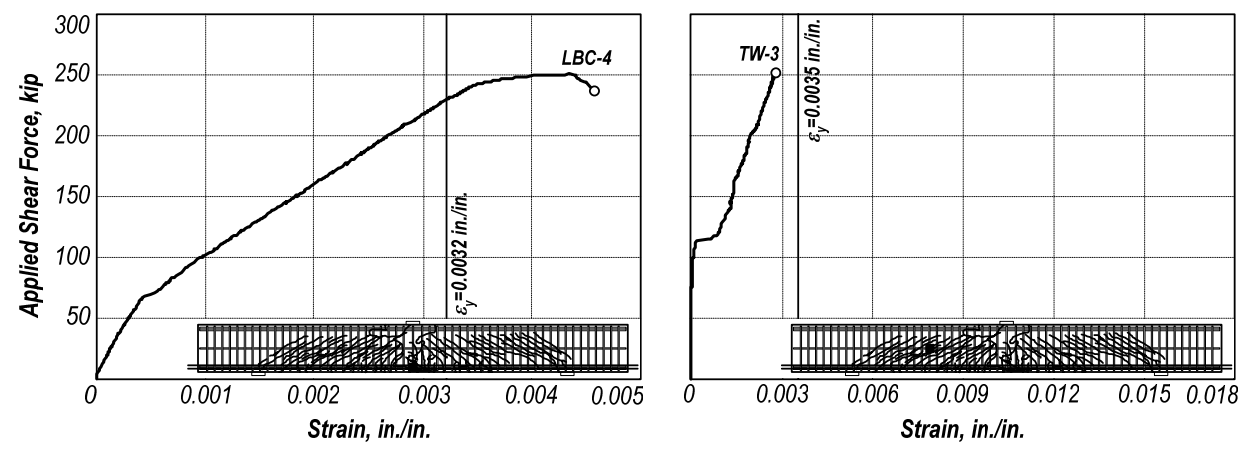

c) Specimen 13.7-5.1-1305P
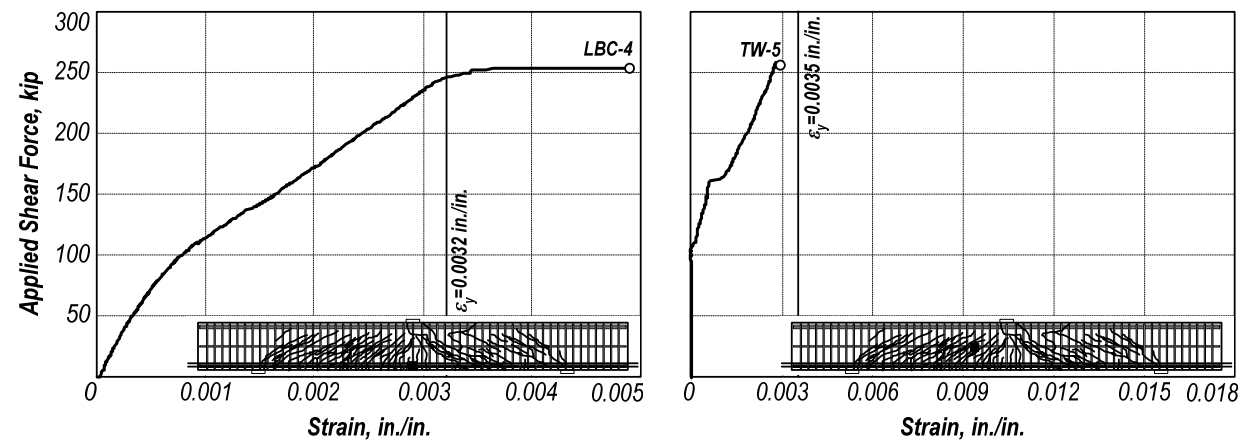

d) Specimen 17.0-5.1-1305P

Figure 4.12 Selected load-strain curves for mild longitudinal and shear reinforcement of prestressed concrete specimens 
The trend of these graphs could be approximated by a tri-linear relationship. The first two regions are similar to the ones described for the prestressed specimens with minimum amount of shear reinforcement, only separated by the occurrence of inclined cracking. However, in the case of prestressed specimens with maximum amount of shear reinforcement, a third linear region with the characteristics of a yielding plateau could be observed. The onset of this plateau showed a good agreement with the reinforcement reaching $\varepsilon_{y}$, the yield strain determined from coupon testing.

The plots on the right side of Figure 4.12 correspond to strain gages installed in the vertical legs of the No. 4 stirrups used as shear reinforcement for the prestressed concrete specimens. Again, a contrasting behavior between specimens with minimum and maximum amount of shear reinforcement may be recognized. In Specimen 13.3-5.1-326P and 16.2-5.1-326P with the minimum amount of shear reinforcement, the plots reached and well exceeded yielding strains. In Specimen 13.7-5.1-1305P and 17.0-5.1-1305P, both with maximum amount of shear reinforcement, the maximum deformations measured on the vertical legs of stirrups were around $85 \%$ of the yielding strain. This finding appears to support the failure mode being flexure in these specimens with large amounts of shear reinforcement.

In all specimens, the trend of the load-strain plots for strain gages installed on the shear reinforcement could be described by a tri-linear relationship. The first part of said relationship is defined by a line starting at the origin and extending along the vertical axis up to the emergence of the first inclined cracking. This behavior indicates that, initially, the stirrups did not contribute to the shear strength of the beams. After inclined cracking, the second region of the load-strain relationship started and extended up to the yielding strain of stirrups $\left(\varepsilon_{y}=0.0035 \mathrm{in}\right.$./in.). At the beginning of this second region a small plateau related to the sudden opening of an inclined crack could be observed in some sensors. This plateau was around $0.0005 \mathrm{in}$./in. for strain gages installed on stirrups of specimens with the maximum amount of shear reinforcement, and about three times that figure for specimens with minimum amount of shear reinforcement. The presence of more closely spaced stirrups in the beams with maximum amount of shear reinforcement reduced the deformations recorded on their vertical legs as a given inclined crack was crossed by a larger number of stirrups. The third region in the load-strain plots could be observed only in the strain gages installed on stirrups of the prestressed specimens with minimum amount of shear reinforcement, and corresponds to a yielding plateau that extended up to failure of the specimen or the debonding of the gage. In Specimen 13.3-5.1-326P and 16.2-5.1-326P, both vertical legs of the stirrup crossing the main inclined crack ruptured at midheight.

Figure 4.13 shows selected load-strain graphs corresponding to strain gages installed on the prestressing strands. Plots in this figure correspond to sensors located at midspan, the section under maximum bending moment. In the construction of these plots, the strain measured prior to 
the test, corresponding to the effective prestressing force after losses had taken place, has been added to the readings recorded during the test. When the reading taken prior to the test was considered unreliable, the design value $\left(\varepsilon_{p s}=0.0057 \mathrm{in}\right.$./in.) was used instead. Since the stress-strain curves obtained from tension coupons of the prestressing strands did not exhibit a clear yielding point, the average strain corresponding to the start of the nonlinear behavior of the stress-strain plots was used as yield strain, $\varepsilon_{y}$, as marked in the graphs of Figure 4.13. Note that the horizontal axis of the graphs in Figure 4.13 has been interrupted between 0 and $0.006 \mathrm{in}$./in. to show the loadstrain curves in more detail.
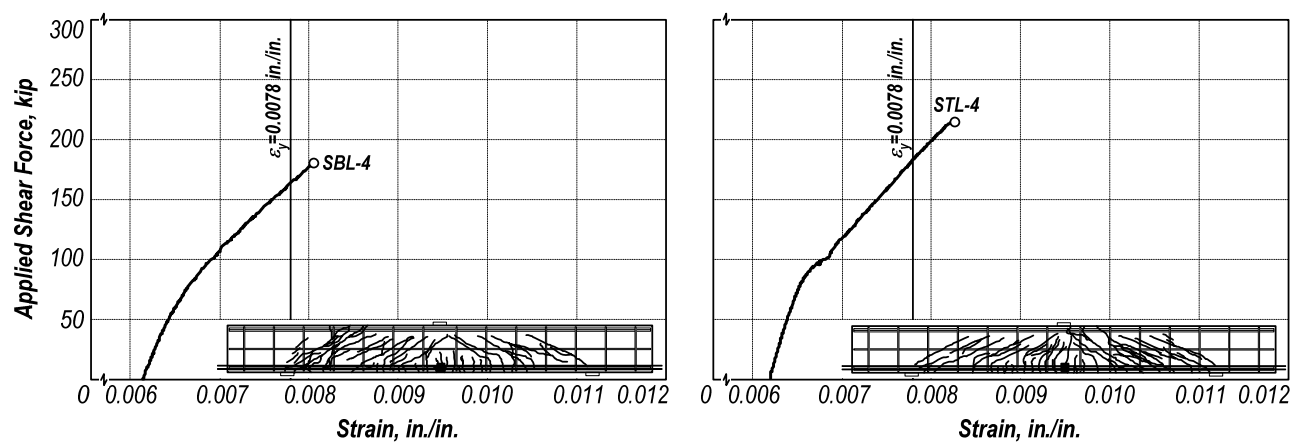

a) Specimen 13.3-5.1-326P

b) Specimen 16.2-5.1-326P
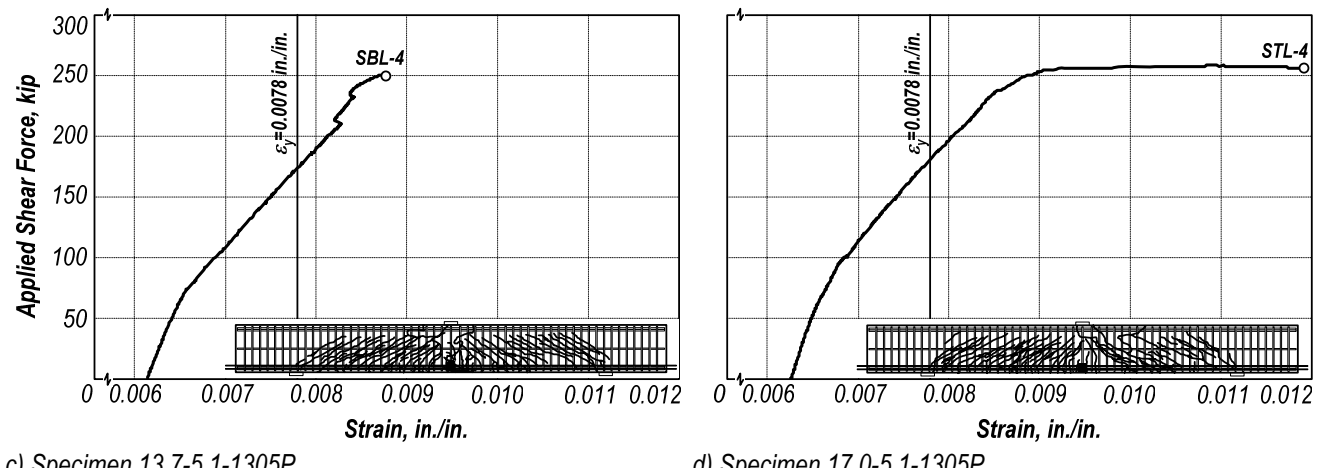

c) Specimen 13.7-5.1-1305P

d) Specimen 17.0-5.1-1305P

Figure 4.13 Selected load-strain curves for prestressing strands of prestressed concrete specimens

As seen from the plots in Figure 4.13, the prestressing strands reached the strain associated with the onset of the nonlinear relation between stress and strain, $\varepsilon_{y}$. In the specimens with minimum amount of shear reinforcement, the strains at failure were slightly smaller than those in the specimens with maximum amount of shear reinforcement. Except for some strain gages installed on the strands of Specimen 17.0-5.1-1305P, the behavior of the load-strain graphs could be described by a bilinear relationship. In all cases, the transition between these linear regions was smooth and concurrent with the development of inclined cracking. In the plot selected for Specimen 17.0-5.1-1305P, a long plateau associated with the yielding of prestressing strands at the maximum moment section was observed. 


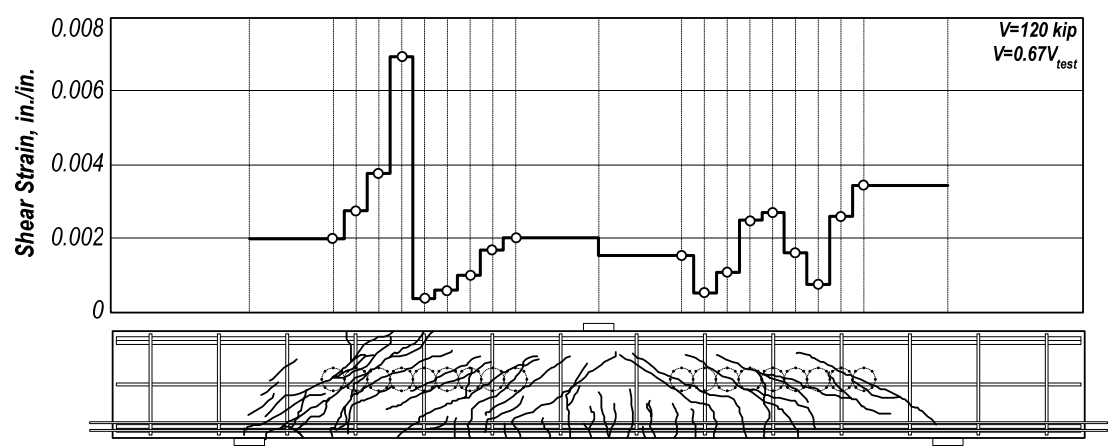

a) Specimen 13.3-5.1-326P
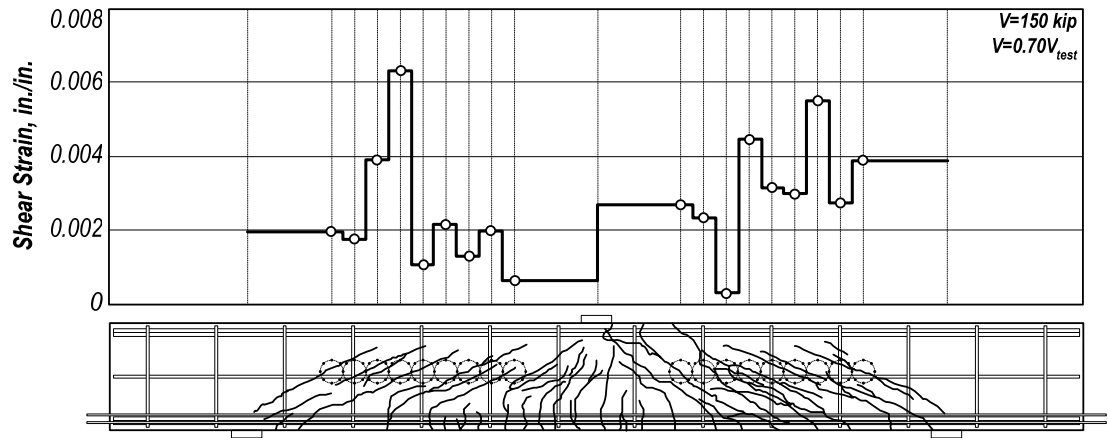

b) Specimen 16.2-5.1-326P
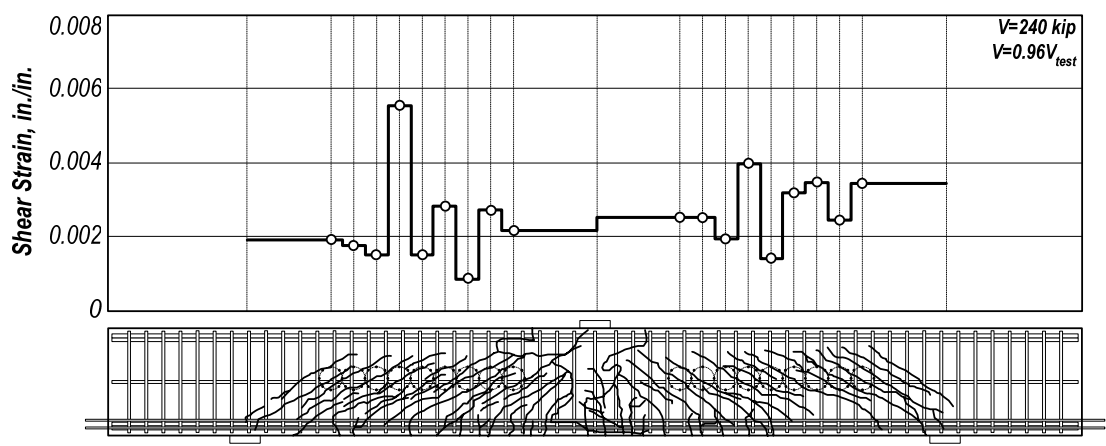

c) Specimen 13.7-5.1-1305P
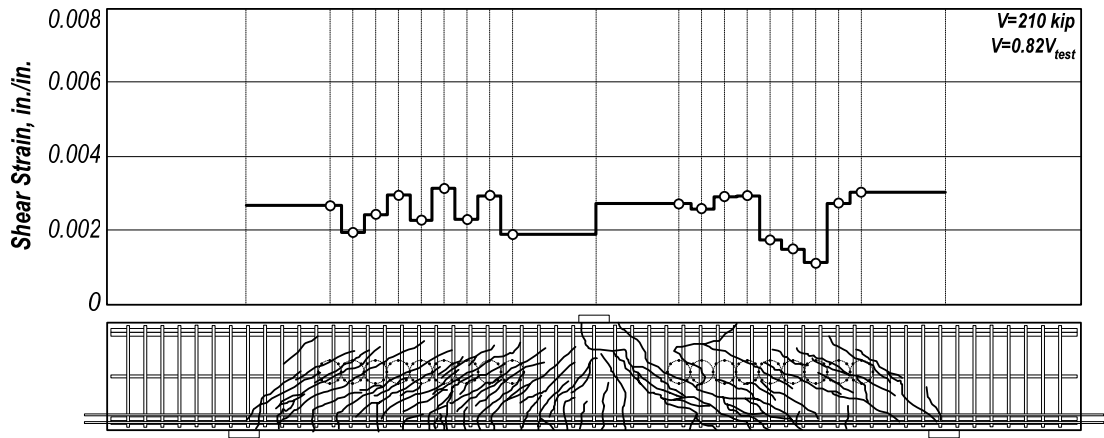

d) Specimen 17.0-5.1-1305P

Figure 4.14 Selected distributions of measured shear strain in prestressed specimens 
Figure 4.14 shows surface shear strain distributions calculated on the basis of the Whittemore readings taken during the tests. Only the last set of readings taken prior to failure is presented. Note that the corresponding shear force is marked, and that a sketch of the final cracking pattern is included. For purposes of comparison, the same scale is used in all plots of Figure 4.14.

The surface shear strains in the prestressed specimens decreased as the amount of shear reinforcement increased from the minimum to the maximum in accordance to $\mathrm{ACl} 318-05$. Due to the presence of prestressing, the concrete shear strains were lower than in the reinforced concrete specimens. This was true even for the specimens with minimum amount of shear reinforcement. The largest surface strains measured prior to the failure of the prestressed concrete specimens were about a third of those observed for the reinforced concrete beams.

Worth noting is also the more uniform distribution of surface shear strains along the shear span in the prestressed specimens. However, some isolated peaks are observed in the plots for Specimen 13.3-5.1-326P, 16.2-5.1-326P and 13.7-5.1-1305P at the points where the widest cracks were measured. The surface shear deformations were under $0.005 \mathrm{in}$./in. for all prestressed specimens up until near failure. Approaching failure, more and wider cracks appeared and the surface shear strains exceeded $0.005 \mathrm{in}$./in.

\subsubsection{Test and Calculated Capacities}

The measured and calculated capacities of the prestressed concrete beams are presented in Table 4.5. Figures in this table were obtained following the criteria stated in Section 4.2.1.5 of this report, i.e. using the actual properties of materials, and load and strength reduction factors equal to one. Similarly to the reinforced concrete specimens with minimum amount of shear reinforcement, two sets of shear capacities were calculated for the specimens with minimum amount of shear reinforcement. One set of values corresponds to the condition where the minimum amount of shear reinforcement is satisfied and the other, in parentheses, where the reinforcement is not considered in design. The first set of values is computed interpolating linearly in Table 2.10 to obtain the values of $\beta$ and $\theta$, whereas the second estimate is calculated using Table 4.5. In Table 2.11, Eq. 11-9 of the ACI 318-05 Code (Eq. 2.24 in this report) was used to estimate $V_{c}$.

In the prestressed concrete specimens containing a minimum amount of shear reinforcement (13.3-5.1-326P and 16.2-5.1-326P), a 19\% increase in the shear capacity was noted as the concrete compressive strength was increased $21 \%$. With the exception of the uniaxial compressive strength of concrete, all other design variables were similar in these two specimens. 
Table 4.5 Measured and calculated capacities for prestressed concrete specimens

\begin{tabular}{|c|c|c|c|c|c|c|c|c|c|c|}
\hline \multirow{4}{*}{ Specimen } & \multirow{4}{*}{$\begin{array}{c}V_{\text {cracking, }} \\
\text { kip }\end{array}$} & \multirow{4}{*}{$\begin{array}{l}V_{\text {test, }} \\
\text { kip }\end{array}$} & \multirow{4}{*}{$\begin{array}{c}\delta_{\max } \\
\text { in. }\end{array}$} & \multicolumn{7}{|c|}{ Calculated Capacities } \\
\hline & & & & \multirow{3}{*}{$\begin{array}{c}V_{\text {flexure }} \\
\text { kip }\end{array}$} & \multicolumn{3}{|c|}{2004 AASHTO LRFD } & \multicolumn{3}{|c|}{$A C I 318-05$} \\
\hline & & & & & $V_{c}$ & $V_{s}$ & $V_{n}$, & $V_{c}$ & $V_{s}$ & $V_{n}$ \\
\hline & & & & & kip & kip & kip & kip & kip & kip \\
\hline $13.3-5.1-326 P$ & 80.0 & 179.9 & 0.99 & 260.7 & $41.9(42.4)$ & $75.1(45.7)$ & $117.0(88.1)$ & 88.7 & 48.5 & 137.2 \\
\hline $16.2-5.1-326 \mathrm{P}$ & 85.0 & 214.9 & 1.17 & 263.5 & $45.5(45.3)$ & $74.1(44.8)$ & $119.6(90.2)$ & 97.6 & 48.5 & 146.1 \\
\hline 13.7-5.1-1305P & 113.0 & 250.7 & 1.38 & 261.1 & 33.4 & 226.5 & 259.9 & 90.0 & 193.9 & 283.9 \\
\hline $17.0-5.1-1305 P$ & 110.0 & 257.3 & 1.43 & 264.2 & 38.1 & 228.9 & 266.9 & 100.3 & 193.9 & 294.2 \\
\hline
\end{tabular}

As stated in Section 4.3.3 on load-deflection behavior, caution in extrapolating the findings in the case of Specimen 13.7-5.1-1305P and 17.0-5.1-1305P must be exercised because their failure mode was flexure-compression.

Table 4.6 presents the experimentally recorded and calculated shear capacities in terms of the square root of the measured compressive strength of concrete. As observed in the reinforced concrete specimens without shear reinforcement, the ratio $V_{\text {test }} / V_{n}$ for the 2004 AASHTO LRFD Specifications was larger than for the ACI 318-05 Code for Specimen 13.3-5.1-326P and 16.2-5.1326P. The average concrete stress at failure was $10.6 \sqrt{f_{c}^{\prime}}$ in prestressed specimens with minimum amount of shear reinforcement and $13.4 \sqrt{f_{c}^{\prime}}$ in prestressed specimens with maximum amount of shear reinforcement.

Table 4.6 Ratio of measured to calculated capacities for prestressed concrete specimens

\begin{tabular}{ccccccc}
\hline \multirow{2}{*}{ Specimen } & \multicolumn{1}{c}{$V_{\text {test }}$} & $V_{n, \text { AASHTO }}$ & $\frac{V_{n, A C l}}{\sqrt{f_{c}} b_{w} d_{v}}$ & $\frac{V_{\text {test }}}{\sqrt{f_{c}} b_{w} d_{v}}$ & $\frac{V_{\text {test }}}{\sqrt{f_{c}} b_{w} d_{v}}$ & $\frac{V_{n, \text { AASHTO }}}{V_{n, A C l}}$ \\
\hline 13.3-5.1-326P & 10.1 & 6.6 & 7.7 & 1.5 & 1.3 \\
16.2-5.1-326P & 11.0 & 6.1 & 7.5 & 1.8 & 1.5 \\
Average & 10.6 & 6.4 & 7.6 & 1.7 & 1.4 \\
\hline 13.7-5.1-1305P * & 13.9 & 14.4 & 15.8 & - & - \\
17.0-5.1-1305P * & 12.8 & 13.3 & 14.7 & - & - \\
Average & 13.4 & 13.9 & 15.3 & - & - \\
\hline * Flexure failure & & & & &
\end{tabular}

The average for the 2004 AAHSTO LRFD Specifications and the ACl 318-05 Code was 1.7 and 1.4 for the prestressed specimens with minimum amount of shear reinforcement, respectively. For these specimens, the conservatism of both 2004 AASHTO LRFD and ACI 318-05 increased as the compressive strength of concrete increased. The Vtest $/ n$ ratios were not applicable for the 
prestressed specimens with maximum amount of shear reinforcement since their failure was dominated by flexural compression.

The design of specimens with maximum amount of shear reinforcement in accordance to 2004 AASHTO LRFD (Eq. 2.5 in this report) resulted in an impractical spacing between stirrups, and therefore, could not be experimentally evaluated. 


\section{CHAPTER 5 SUMMARY, FINDINGS AND IMPLEMENTATION}

\subsection{Summary}

This report presents the results of a research study on the performance in shear of high-strength concrete beams, reinforced and prestressed, containing different amounts of shear reinforcement. The goal of the research program was to evaluate the behavior of beams with concrete compressive strengths up to 15000 psi containing the minimum amount of shear reinforcement specified by the 318-05 Code and the 2004 AASHTO LRFD Specifications, and the applicability of the upper limit on the shear strength in the same documents.

In Chapter 2 of this report an extensive review of applicable works was conducted. The results of this review assisted the researchers in the refinement of the experimental program presented in Chapter 3. The results of the experimental program are discussed in Chapter 4. This chapter also includes a comparison of the test and calculated capacities obtained with the procedures in the ACI 318-05 Code and the 2004 AASHTO LRFD Specifications. In Chapter 5, the salient findings are presented together with a proposed implementation.

\section{$5.2 \quad$ Findings}

The findings of the study are based on the review of applicable works in the literature and on the results of an experimental program of twenty specimens, sixteen reinforced and four prestressed, tested to failure. Only the two prestressed beams containing the largest amount of shear reinforcement failed in flexure. The rest of the specimens tested failed in shear. Eight of the reinforced concrete beams had no shear reinforcement. The main findings were:

\subsubsection{Strength}

- In the reinforced concrete beams without shear reinforcement and with lower percentage of longitudinal reinforcement $\left(\rho_{w}=1.32 \%\right)$, an increase in concrete compressive strength from 7000 to $10500 \mathrm{psi}$ enhanced the shear strength by 19\%. The same increase in compressive strength, resulted in a $2 \%$ increase in the shear capacity of companion beams with double the amount of longitudinal tension reinforcement $\left(\rho_{w}=2.62 \%\right)$. 
- As reported by previous researchers, the potential for overestimation of $V_{c}$ in beams with lower amounts of longitudinal reinforcement was observed. In all eight specimens without shear reinforcement, the ratio of test to calculated capacities in accordance to the 2004 AASHTO LRFD Specifications was greater than the ratio estimated using the ACI 318-05 Code. The lowest average ratio of 0.9 was calculated using $\mathrm{ACl} 318-05$ (Eq. 2.23 in this report and 11-5 in the $\mathrm{ACl} 318-05$ Code) in specimens with $\rho_{\mathrm{w}}=1.32 \%$. It must be noted that this reinforcement ratio, $\rho_{w}$, is estimated using the web width. If the width of the flexural compression flange of $12 \mathrm{in}$. was used instead, the flexural reinforcement ratio would be $0.66 \%$.

- The reinforced concrete specimens with minimum amount of shear reinforcement and $\rho_{w}=2.63 \%$ showed a $10 \%$ increase in shear capacity when the compressive strength of concrete was increased $9 \%$. The positive effect of increasing the uniaxial compressive strength of concrete was not observed in the specimens with minimum amount of shear reinforcement and $\rho_{w}=5.40 \%$. This was consistent with the behavior observed in the beams without shear reinforcement.

- In the reinforced concrete beams with concrete strength in the range from 13000 to $14500 \mathrm{psi}$, the current prescribed minimum amount of shear reinforcement resulted in an average ratio of test to calculated shear capacity of 1.2 and 1.4 for the 2004 AASHTO LRFD Specifications and the $\mathrm{ACl} 318-05$ Code, respectively. This finding supports the notion that the current prescribed minimum amounts of shear reinforcement in both documents provide sufficient reserve strength with respect to calculated diagonal tension capacity for concrete compressive strengths up to $15000 \mathrm{psi}$.

- The failure of the reinforced concrete specimens with intermediate amounts of shear reinforcement and the maximum amount of shear reinforcement in accordance with $\mathrm{ACl}$ 318-05 was not associated with a single inclined crack. Instead, failure occurred following crushing of concrete as numerous inclined cracks penetrated the compression flange. This observation indicates that, even though limited, there is room for redistribution of stresses when larger amounts of shear reinforcement are provided. The distortion of the web and the crack widths were reduced as the shear reinforcement was provided using larger size bars and smaller spacings.

- The increase in concrete compressive strength from 13000 to 15000 psi had minimal effect on the shear strength of the reinforced concrete beams containing the same amount of both longitudinal and shear reinforcement. 
- In the range of compressive strengths between 13000 and 15000 psi, reinforced concrete beams with intermediate amount of shear reinforcement and with the $\mathrm{ACl}$ 318-05 Code maximum amount of shear reinforcement had a ratio of test to calculated shear capacity in accordance with the 2004 AASHTO LRFD Specifications of 1.1 and 1.0, respectively. The ratio calculated for the same specimens using the $\mathrm{ACl} 318-05$ Code was 1.3 in members with intermediate amount and 1.2 for those reinforced with the $\mathrm{ACl}$ 318-05 Code maximum amount. The specimens reinforced with the maximum amount of shear reinforcement in accordance with the $\mathrm{ACl}$ 318-05 Code although failing in shear, exhibited yielding of both the stirrups and the longitudinal reinforcement and the load versus deflection plots developed a significant plateau prior to failure.

- Any effect on the shear strength of the reinforced concrete beams of either the compressive strength of concrete or the amount of longitudinal reinforcement diminished as the amount of transverse reinforcement increased. The maximum amount of shear reinforcement in accordance with the $\mathrm{ACl} 318-05$ Code proved to be a reasonable upper limit to prevent failures associated with the crushing of the web prior to the yielding of stirrups. Specimens 13.2-7.9-902 and 15.3-7.9-902, with the maximum amount of shear reinforcement in accordance with $\mathrm{ACl} 318-05$, failed at shear stresses above $11.5 \sqrt{f^{\prime}}$. The average test to calculated shear capacity ratio for these specimens was 1.0 with the 2004 AASHTO LRFD Specifications and 1.2 with the ACI 318-05 Code. It is important to note that the degree of underestimation of shear strength calculated using the 2004 AASHTO LRFD Specifications decreased as the amount of shear reinforcement increased. Furthermore, the upper limit on the shear strength in accordance with 2004 AASHTO LRFD can be up to three times the maximum specified in the ACI 318-05 Code.

- The presence of prestressing in beams with concrete compressive strength in the range from 13500 to $16500 \mathrm{psi}$, and reinforced with the minimum amount of shear reinforcement resulted in an average ratio of test to calculated shear capacity of 1.7 and 1.4 for the 2004 AASHTO LRFD Specifications and the ACI 318-05 Code, respectively. Thus indicating that the minimum amount of shear reinforcement prescribed in 2004 AASHTO LRFD is adequate in concrete compressive strengths up to $16500 \mathrm{psi}$. Note that the minimum amount of shear reinforcement provided corresponds to the spacing requirements in Section 5.8.2.7 of the 2004 AASHTO LRFD Specifications, and not to the minimum required in terms of shear strength.

\subsubsection{Average of Maximum Crack Width Measurements at Estimated Service Load Levels}

- In the reinforced concrete beams with minimum amount of shear reinforcement, the inclined crack width at estimated service load levels was around $0.02 \mathrm{in}$., which is slightly above the often accepted range of 0.013 to $0.016 \mathrm{in}$. for flexural cracks. Shortly before 
failure, crack widths up to $0.16 \mathrm{in}$. were measured. These crack widths led to large web distortions. Surface shear strains up to $0.022 \mathrm{in}$./in. were then measured close to failure.

- Crack widths at estimated service levels in the reinforced concrete beams with intermediate and maximum amount of shear reinforcement were around $20 \%$ of those observed in the specimens with minimum amount of shear reinforcement. The reduction in stirrup spacings positively decreased the main inclined crack width. Surface shear strains in these beams were also reduced by the presence of more closely spaced stirrups. The surface concrete shear strains were under $0.010 \mathrm{in}$./in. throughout the test of these specimens.

- The appearance of inclined cracking was significantly delayed by the presence of prestressing, and the inclination of diagonal cracks was slightly less. Crack width of the main inclined crack at estimated service levels was between 0.010 and $0.020 \mathrm{in}$. for the prestressed beams with minimum amount of shear reinforcement. Crack widths were observed to decrease as the concrete compressive strength increased. The presence of prestressing contributed to maintain the concrete shear strains at a lower level than that in the reinforced concrete specimens. The largest surface strains measured prior to the failure in the prestressed specimens were about half of those observed for the reinforced concrete beams with comparable amount of shear reinforcement.

\subsection{Proposed Implementation}

Current minimum amount of shear reinforcement together with spacing limits in the 2004 AASHTO LRFD Specifications provide adequate crack width control and reserve shear strength for reinforced concrete and prestressed concrete beams with concrete compressive strengths up to 16000 psi.

With respect to the maximum amount of shear reinforcement, and based on the results of the reinforced concrete specimens, an upper limit for the nominal shear strength of $12 \sqrt{f_{c}^{\prime}}$ in concretes with compressive strength up to 15000 psi was shown to be adequate to prevent web crushing failures. This limit is similar to that in the $\mathrm{ACl}$ 318-05 Code for reinforced concrete beams. The behavior of a prestressed concrete beam with large amounts of shear reinforcement at ultimate should be similar to that of a reinforced concrete beam since the precompression decreases as external loads increase and approach ultimate levels. Therefore, the finding of the reinforced concrete specimens can be extended to prestressed concrete members. 
For concrete compressive strengths up to $15000 \mathrm{psi}$, the current limit on the maximum shear strength in the 2004 AASHTO LRFD Specifications $\left(V_{n}=0.25 f^{\prime} b_{v} d_{v}+V_{p}\right)$ can be, in terms of average shear stress, up to twice the upper limit in the ACI 318-05 Code. It is also important to note that the findings of this study indicate that the 2004 AASHTO LRFD Specifications provide closer estimates of the actual shear strength of beams as their amount of shear reinforcement is increased. Therefore, it is recommended, for concrete strengths up to $15000 \mathrm{psi}$, and based on the findings of this study, that the upper limit of average shear strength be set at $12 \sqrt{f_{c}^{\prime}}$ for both reinforced concrete and prestressed concrete beams in the state of Indiana. This proposed limit on the shear strength, although below the limit in the 2004 AASHTO LRFD Specifications, should not effectively change the design of HSC flexural members because of the limitations on beam width and constructability issues related to the large amounts of shear reinforcement currently required to reach the upper limit of nominal shear strength.

\section{$5.4 \quad$ Future Work}

Future work is suggested to explore in detail the behavior of HSC in prestressed specimens with shear strength near the 2004 AASHTO LRFD upper limit. 


\section{REFERENCES}

AASHTO, Load and Resistance Factor Design Bridge Design Specifications, American Association of State Highway and Transportation Officials, Washington, DC, 2004, 632 pp.

ACI-ASCE Committee 326, Shear and Diagonal Tension, American Concrete Institute Journal, Proceedings, V. 59, No. 1, Jan. 1962, pp. 1-30; No. 2, Feb. 1962, pp. 277-334; and No. 3, Mar. 1962, pp. 352-396.

ACl-ASCE Committee 426, Shear Strength of Reinforced Concrete Members (ACl 426R-74), Proceedings, ASCE, V. 99, No. ST6, Jun. 1973, pp. 1148-1157.

ACl-ASCE Committee 426, Suggested Revisions to Shear Provisions for Building Codes, American Concrete Institute Journal, Proceedings, V. 75, No. 9, Sept. 1977, pp. 458-469.

ACl-ASCE Committee 445, Recent Approaches to Shear Design of Structural Concrete, American Society of Civil Engineers Journal of Structural Engineering, V. 124, No. 12, Dec. 1998, pp. 1375-1417.

$\mathrm{ACl}$ Committee 318, Building Code Requirements for Structural Concrete (ACl 318-05) and Commentary (ACI318R-05), American Concrete Institute, Farmington Hills, MI, 2005, 430 pp.

$\mathrm{ACl}$ Committee 363, State-of-the-Art Report on High-Strength Concrete (ACl363R-92), American Concrete Institute, Farmington Hills, MI, Reapproved 1997, 55 pp.

Ahmad, S.H., Khaloo, A.R., and Poveda, A., Shear Capacity of Reinforced High-Strength Concrete Beams, American Concrete Institute Journal, Proceedings, V. 83, No. 2, Mar.-Apr. 1986, pp. 297-305.

ASTM A 370-05, Standard Test Methods and Definitions for Mechanical Testing of Steel Products, American Society for Testing and Materials, West Conshohocken, PA, 2005, 47 pp.

ASTM A 615-05, Standard Specification for Deformed and Plain Carbon-Steel Bars for Concrete Reinforcement, American Society for Testing and Materials, West Conshohocken, PA, 2005, 6 pp.

ASTM C 39-04, Standard Test Method for Compressive Strength of Cylindrical Concrete Specimens, American Society for Testing and Materials, West Conshohocken, PA, 2004, 7 pp.

ASTM C 78-02, Standard Test Method for Flexural Strength of Concrete (Using Simple Beam with Third-Point Loading), American Society for Testing and Materials, West Conshohocken, PA, 2002, 3 pp.

ASTM C 143-05, Standard Test Method for Slump of Hydraulic-Cement Concrete, American Society for Testing and Materials, West Conshohocken, PA, 2005, 4 pp.

ASTM C 192-05, Standard Practice for Making and Curing Concrete Test Specimens in the Laboratory, American Society for Testing and Materials, West Conshohocken, PA, 2005, 8 pp.

ASTM C 231-04, Standard Test Method for Air Content of Freshly Mixed Concrete by the Pressure Method, American Society for Testing and Materials, West Conshohocken, PA, 2004, 9 pp.

ASTM C 469-02, Standard Test Method for Static Modulus of Elasticity and Poisson's Ratio of Concrete in Compression, American Society for Testing and Materials, West Conshohocken, PA, 2002, $4 \mathrm{pp}$.

ASTM C 496-04, Standard Test Method for Splitting Tensile Strength of Cylindrical Concrete Specimens, American Society for Testing and Materials, West Conshohocken, PA, 2004, 5 pp.

ASTM C 1231-00, Standard Practice for Use of Unbonded Caps in Determination of Compressive Strength of Hardened Concrete Cylinders, American Society for Testing and Materials, West Conshohocken, PA, 2000, 4 pp.

Burg, R.G., and Ost, B.W., Engineering Properties of Commercially Available High-Strength Concretes (Including Three-Year Data), Research and Development Bulletin RD104T, Portland Cement Association, Skokie, IL, 1994, 58 pp. 
Collins, M.P., Mitchell, D., Adebar, P., and Vecchio, F.J., A General Shear Design Method, American Concrete Institute Structural Journal, V. 93, No. 1, Jan.-Feb. 1996, pp. 36-45.

Collins, M.P., and Mitchell, D., Prestressed Concrete Structures, Prentice Hall, Englewood Cliffs, NJ, 1991, 766 pp.

Elzanaty, A.H., Nilson, A.H., and Slate, F.O., Shear-Critical High-Strength Concrete Beams (Research Report 85-1), Department of Structural Engineering, Cornell University, Ithaca, NY, Feb. 1985, 216 pp.

Elzanaty, A.H., Nilson, A.H., and Slate, F.O., Shear Capacity of Reinforced Concrete Beams Using High-Strength Concrete, American Concrete Institute Journal, V. 83, No. 2, Mar.-Apr. 1986, pp. 290296.

Farny, J.A., and Panarese, W.C., High-Strength Concrete, Engineering Bulletin EB114.01T, Portland Cement Association, Skokie, IL, 1994, 48 pp.

Jonsson, J.A., Durability and temperature related characteristics of high performance concrete, Ph.D. Thesis, Purdue University, West Lafayette, IN, 2002, pp.

Johnson, M.K., An Investigation of the Adequacy of the Minimum Shear Reinforcement Provision in High Strength Reinforced Concrete Beams, Master's Degree Thesis, Purdue University, West Lafayette, IN, Dec. 1987, 141 pp.

Johnson, M.K., and Ramirez, J.A., Minimum Shear Reinforcement in Beams with Higher Strength Concrete, American Concrete Institute Structural Journal, V. 86, No. 4, Jul.-Aug. 1989, pp. 376-382.

Kaufman, M.K., and Ramirez, J.A., Re-evaluation of the Ultimate Shear Behavior of High-Strength Concrete Prestressed I-Beams, American Concrete Institute Structural Journal, V. 85, No. 3, May-Jun. 1988, pp. 295-303.

Kong, P.Y.L., and Rangan, B.V., Studies on Shear Strength of High Performance Concrete Beams (Research Report No. 2/97), School of Civil Engineering, Curtin University of Technology, Perth, Western Australia, 1997, 163 pp.

Hognestad, E., A Study of Combined Bending and Axial Load in Reinforced Concrete Members, University of Illinois Engineering Experimental Station, Bulletin Series No.399, Nov. 1951, 128 pp.

Hognestad, E., What Do We Know About Diagonal Tension and Web Reinforcement in Concrete? A Historical Study, University of Illinois Engineering Experimental Station, Circular Series No. 64, V. 49, No. 50, Mar. 1952, 47 pp.

MacGregor, J.G. Reinforced Concrete Mechanics and Design, Prentice Hall, Upper Saddle River, NJ, 1997, 939 pp.

Malone, B.J., Shear Strength of Reinforced and Prestressed Concrete Beams with Lightweight Aggregate Concrete, Ph.D. Thesis, Purdue University, West Lafayette, IN, Dec. 1999, 946 pp.

Master Builders, Glenium 3030 NS Data Sheet, www.masterbuilders.com, 2002, 2 pp.

Mphonde, A.G., and Frantz, G.C., Shear Strength of High Strength Reinforced Concrete Beams (Report CE 84-157), Civil Engineering Department, University of Connecticut, Storrs, CT, Jun. 1984, 260 pp.

NSF-CSTACBM, Cementing the Future, National Science Foundation Center for Science and Technology of Advanced Cement-Based Materials, Northwestern University, Evanston, IL, 1992, page 8.

Ozcebe, G., Ersoy, U., and Tankut, T., Evaluation of Minimum Shear Reinforcement Requirements for Higher Strength Concrete, American Concrete Institute Structural Journal, V. 96, No. 3, May-Jun. 1999, pp. 361-368.

Park, R., and Paulay, T., Reinforced Concrete Structures, Wiley-Inter-Science, New York, NY, 1975, 769 pp.

Perenchio, W.F., An Evaluation of Some Factors Involved in Producing Very High-Strength Concrete, Research and Development Bulletin RD014T, Portland Cement Association, Skokie, IL, 1973. 
Pujol, S., Drift Capacity of Reinforced Concrete Columns Subjected to Displacement Reversals, Ph.D. Thesis, Purdue University, West Lafayette, IN, 2002, 309 pp.

Ramachandran, V.S., Concrete Admixtures Handbook: Properties, Science and Technology, Noyes Publications, Park Ridge, NJ, 1984,

Ramirez, J.A., Olek, J., Rolle, E., and Malone, B.J., Performance of Bridge Decks and Girders with Lightweight Aggregate Concrete (FHWA/IN/JTRP-98-17), Federal Highway Administration, Joint Transportation Research Program, Purdue University, West Lafayette, IN, May 1999, 616 pp.

Sarsam, K.F., and Al-Musawi, J.M.S., Shear Design of High- and Normal Strength Concrete Beams with Web Reinforcement, American Concrete Institute Structural Journal, V. 89, No. 6, Nov.-Dec. 1992, pp. 658-664. 